\title{
Selected Features of Bactrian Grammar
}

Dissertation zur Erlangung des philosophischen Doktorgrades an der Philosophischen

Fakultät der Georg-August-Universität Göttingen

Vorgelegt von

Saloumeh Gholami

Aus Teheran (Iran)

Göttingen 2009 


\section{Table of Contents}

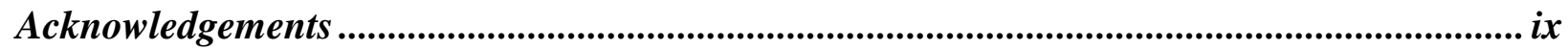

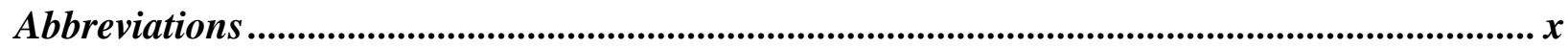

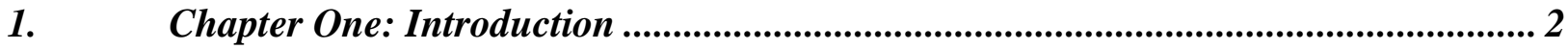

1.1 Bactria .................................................................................................................................................2

$1.2 \quad$ Bactrian language and script n..............................................................................................3

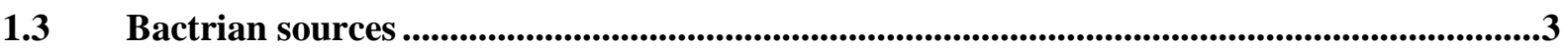

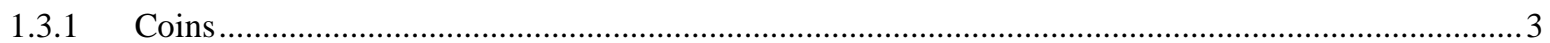

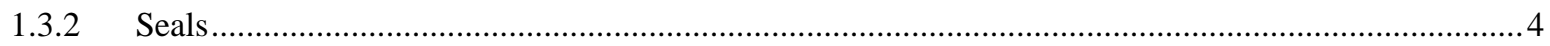

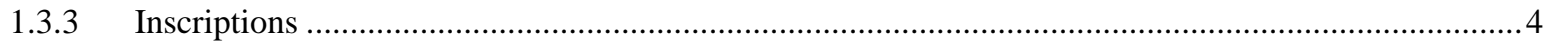

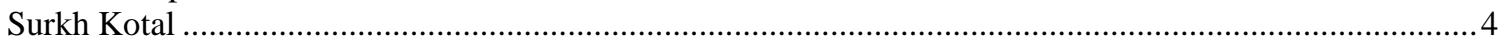

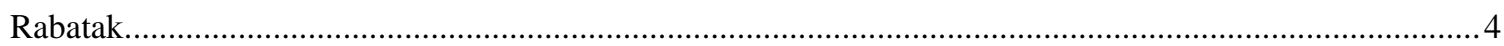

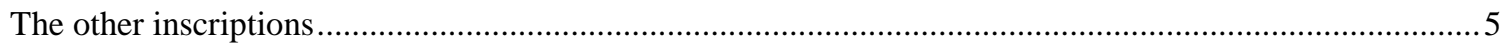

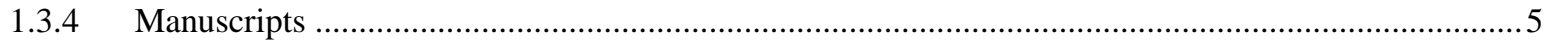

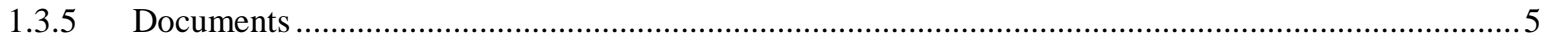

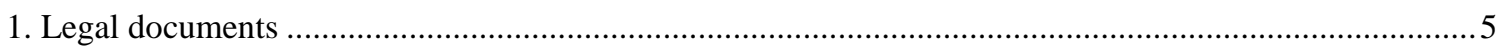

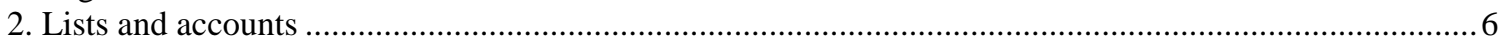

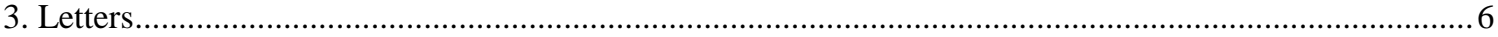

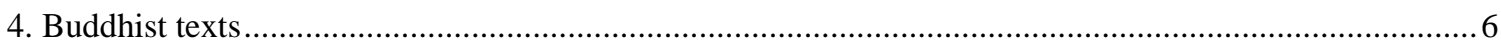

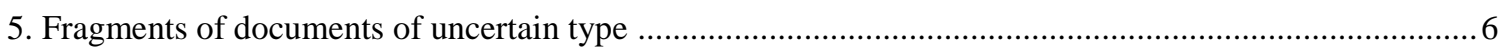

$1.4 \quad$ Aims and assumptions ........................................................................................................................6

2. Chapter Two: Historical phonology of Bactrian ….................................................... 8

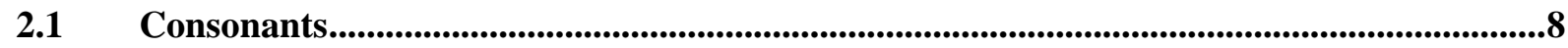

2.2 Simple Consonants .......................................................................................................................8

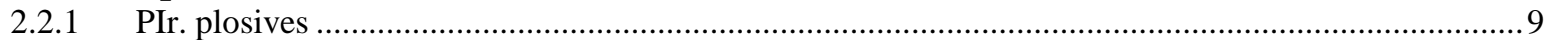

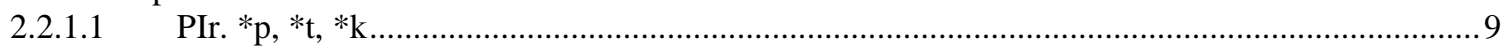

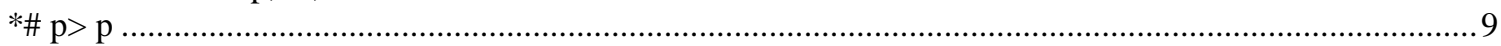

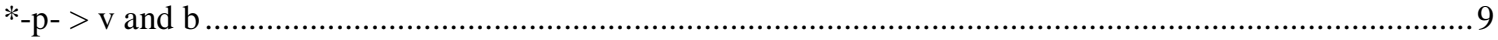

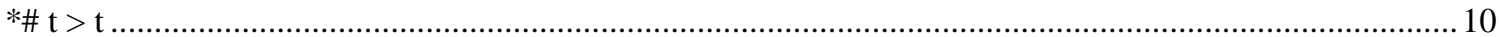

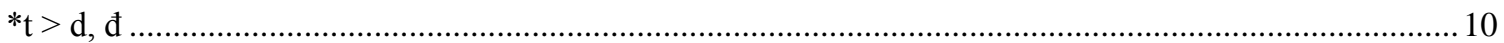

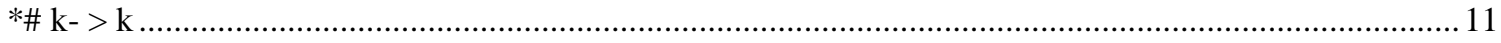

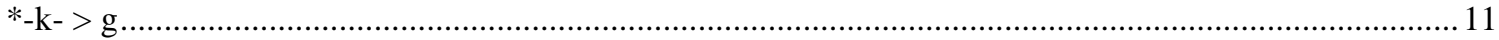

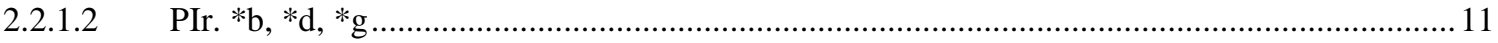

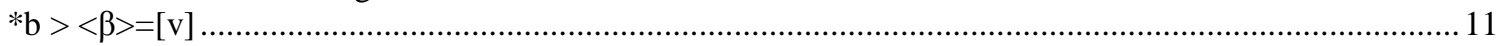

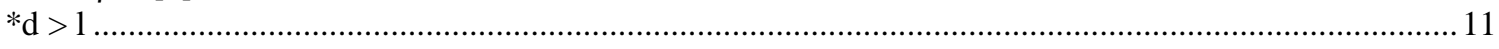

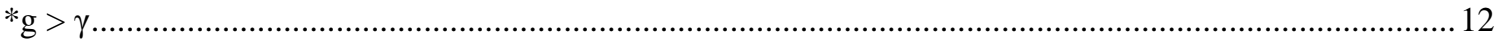

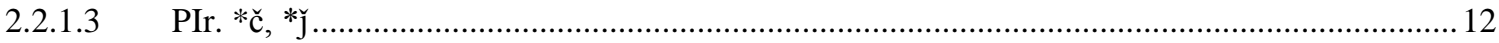

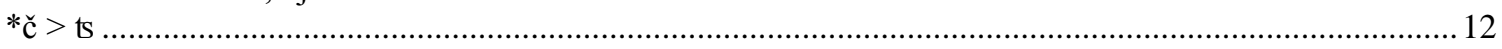

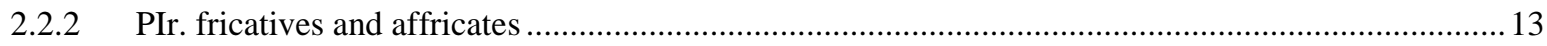

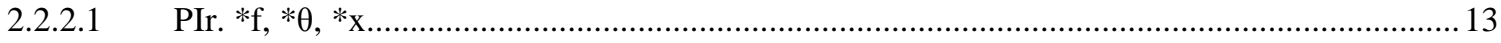

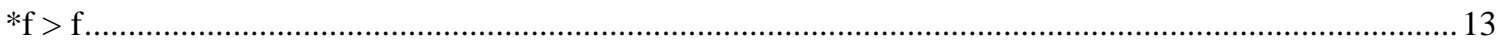

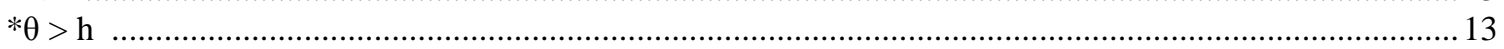

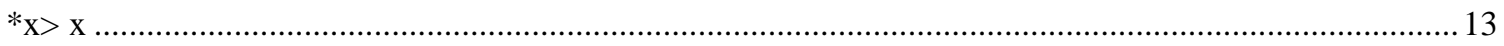

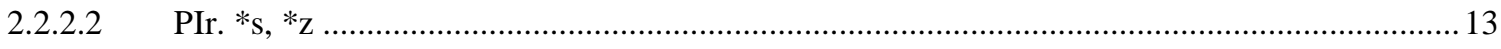

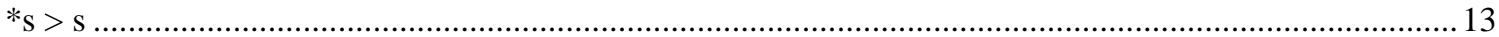

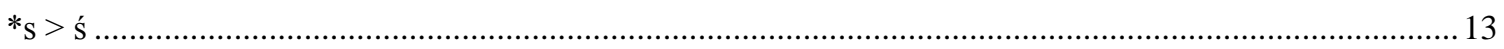

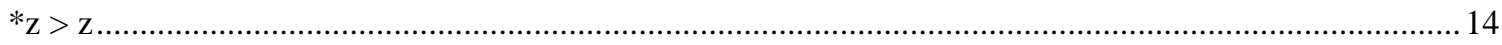

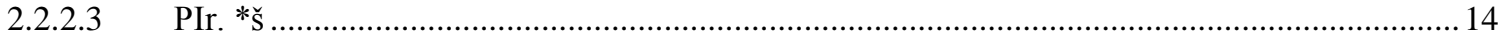

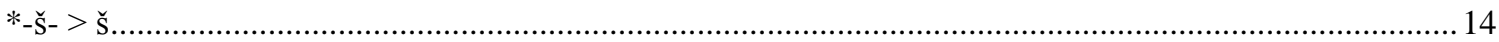

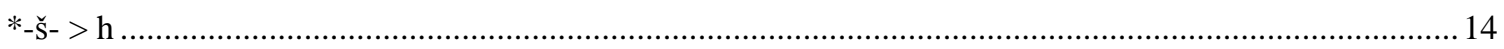

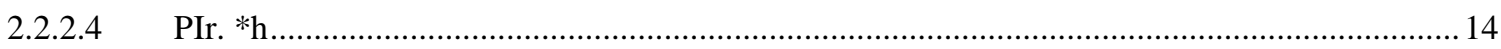

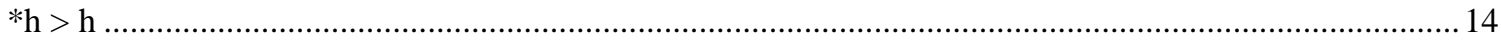




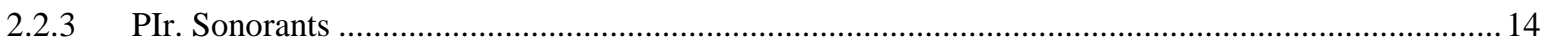

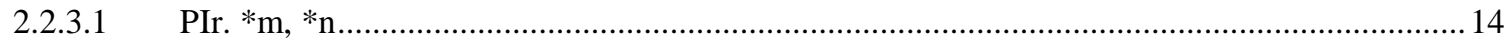

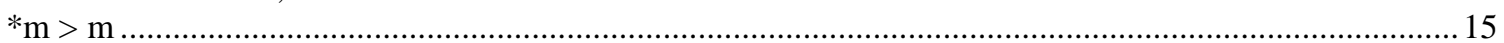

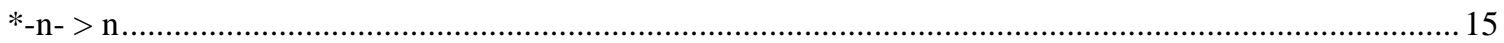

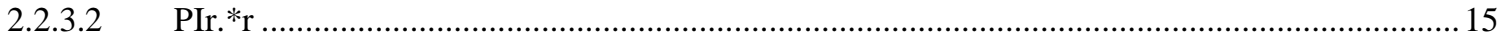

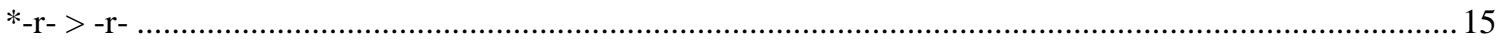

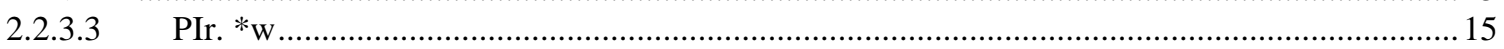

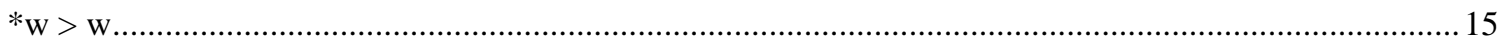

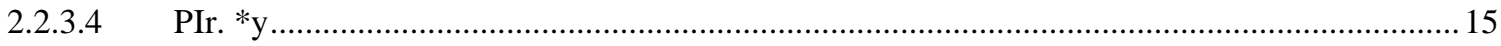

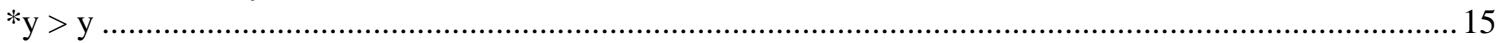

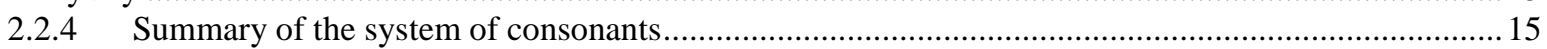

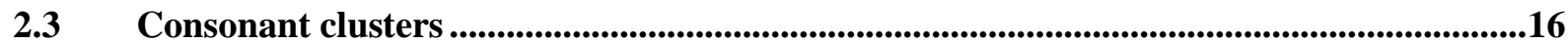

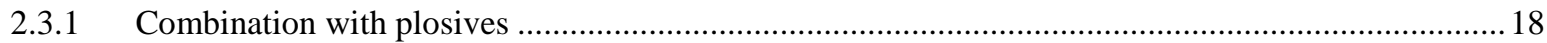

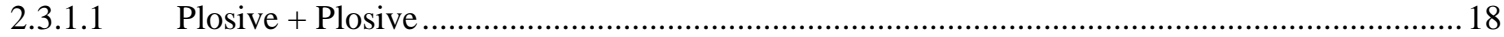

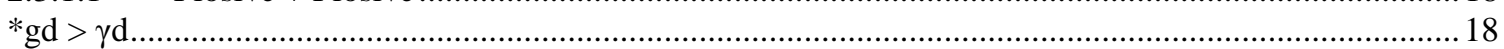

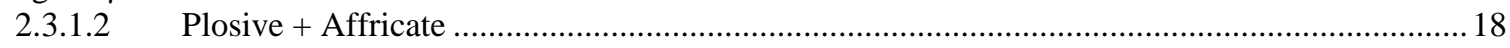

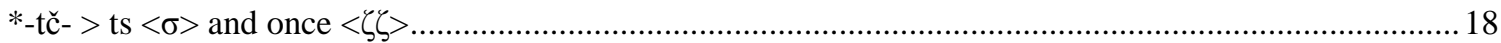

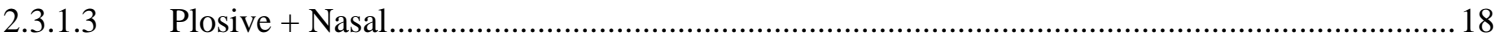

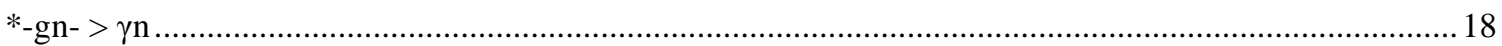

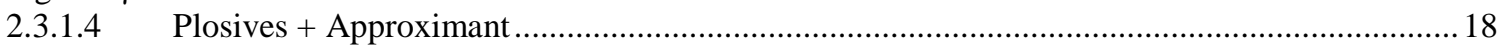

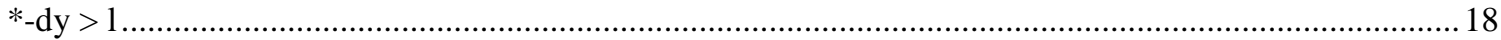

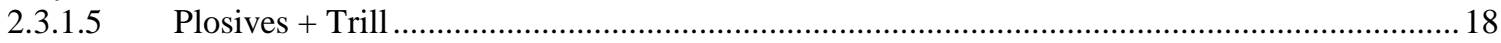

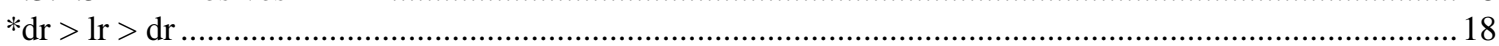

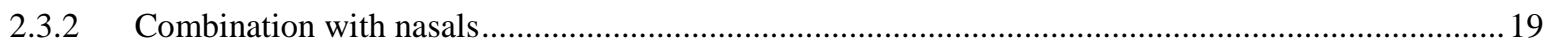

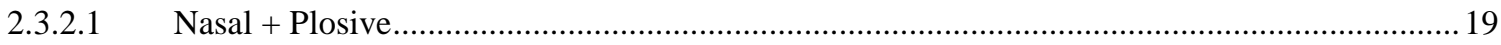

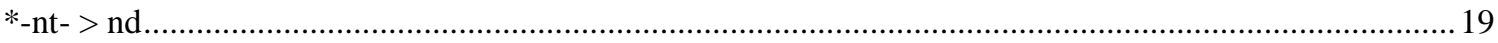

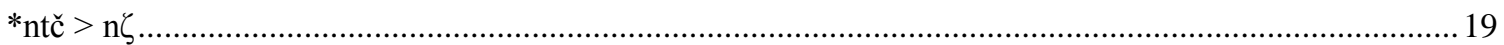

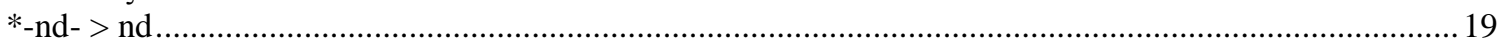

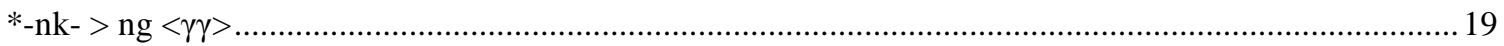

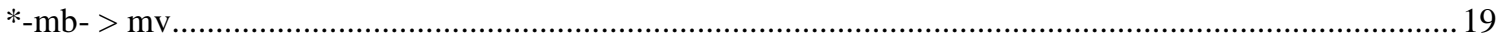

${ }_{*}$-mp- > mv

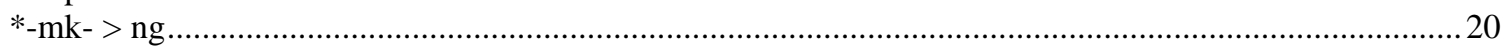

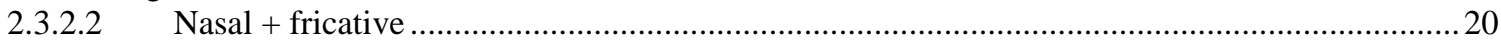

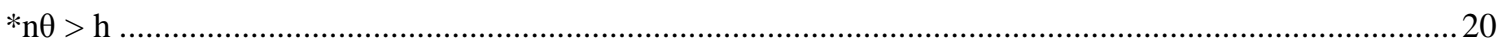

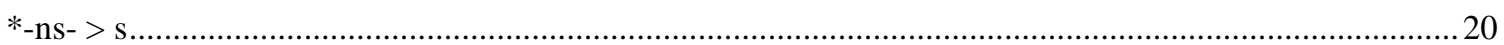

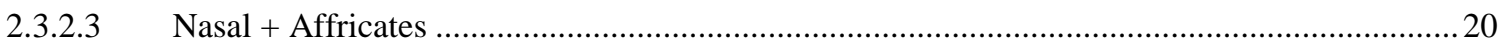

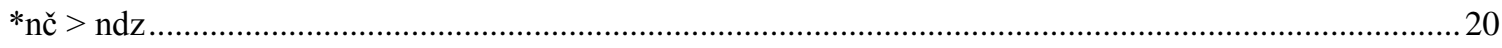

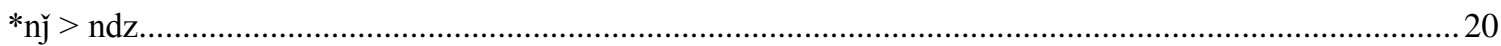

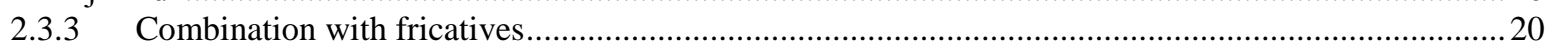

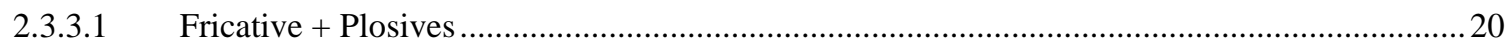

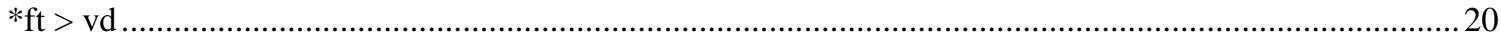

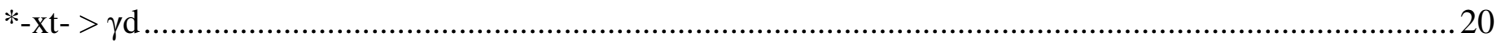

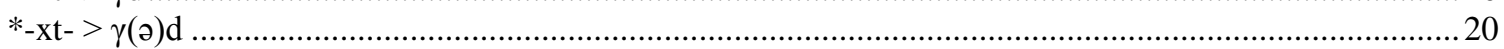

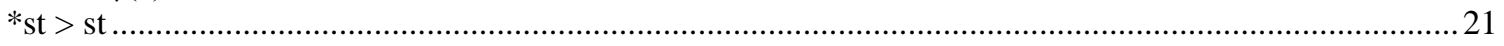

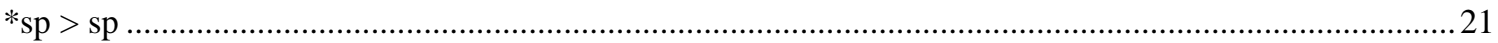

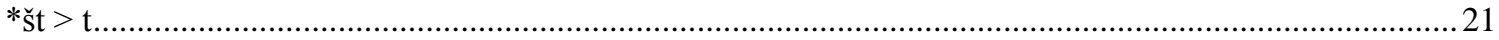

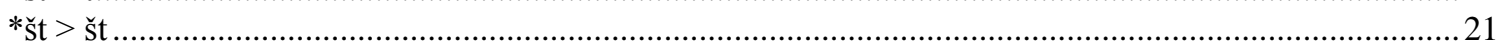

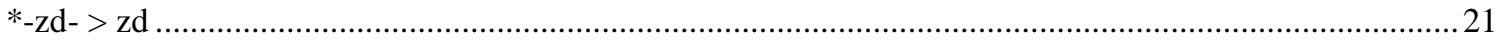

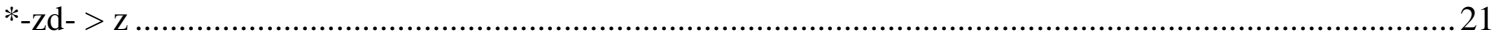

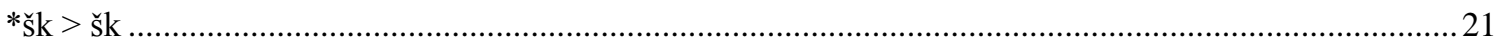

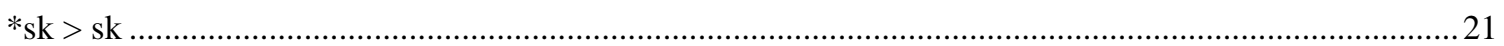

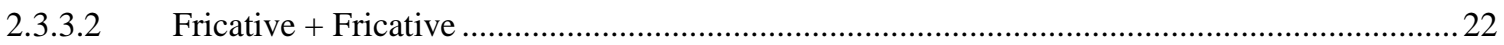

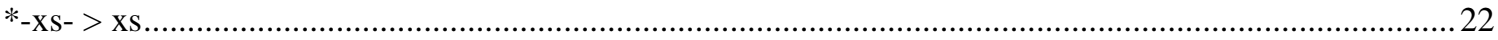

*\# f̊̆-> f .

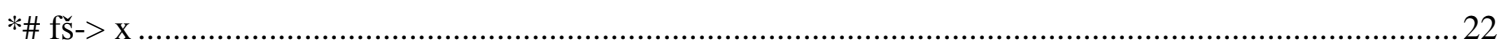

*-f̆́s

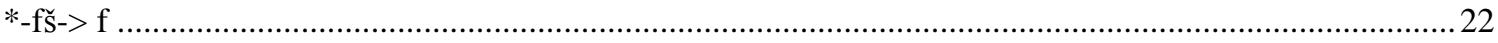

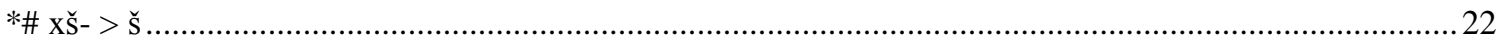

*\# $\mathrm{XS}-\mathrm{S}$

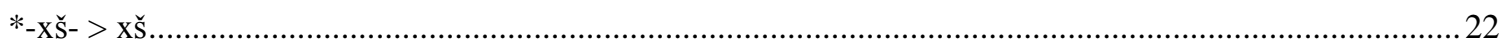

*-X̌́s 
$* \# x$ šn $>$ xn

$*$-xšt- $>\mathrm{xt}$

$*$-x ̌̌t- $>$ x

*-štk- > -šk-

$2.3 .3 .3 \quad$ Fricative + affricative

23

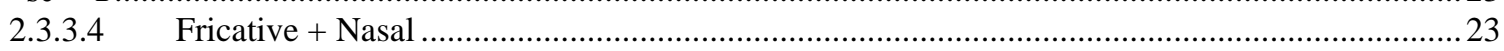

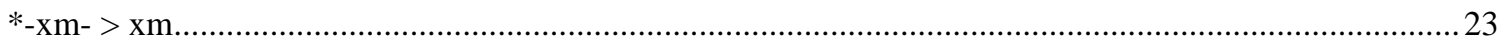

*

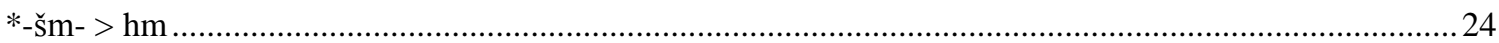

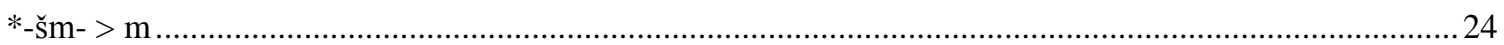

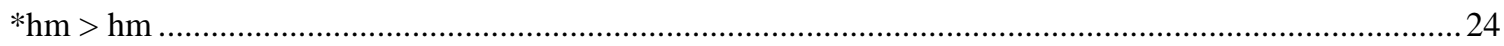

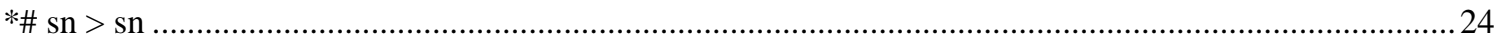

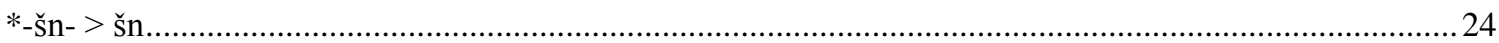

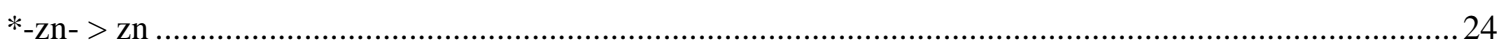

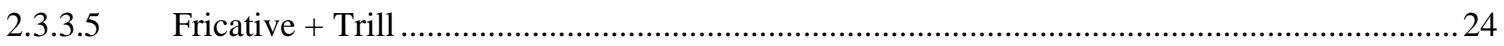

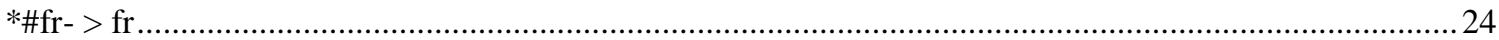

*\# fra- $>$ fr(ə)

$* \# \mathrm{sr}>\mathrm{s}$

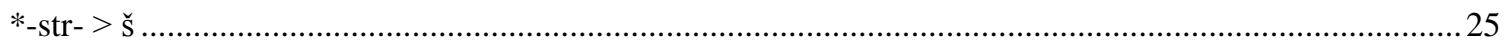

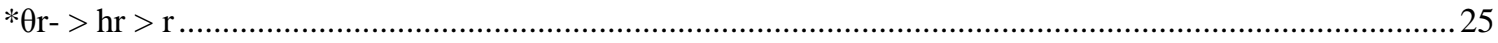

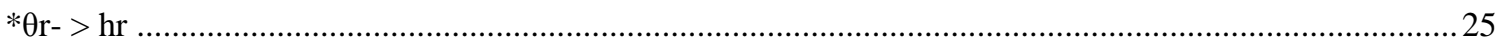

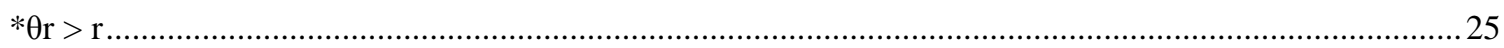

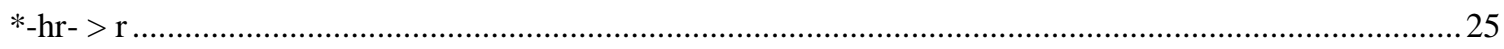

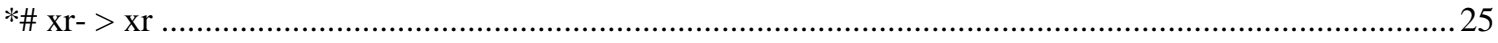

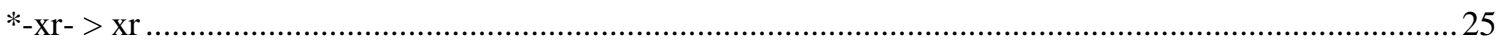

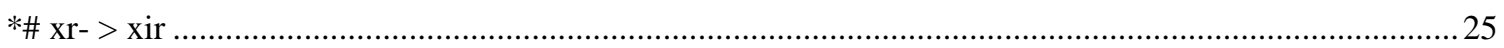

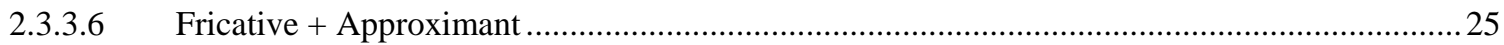

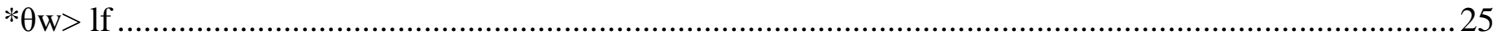

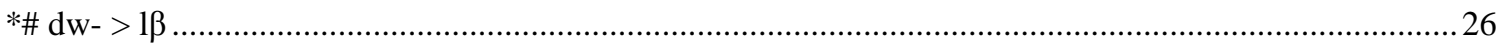

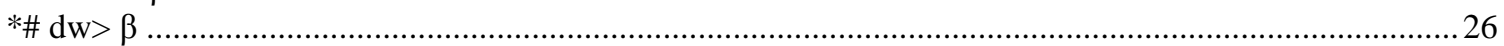

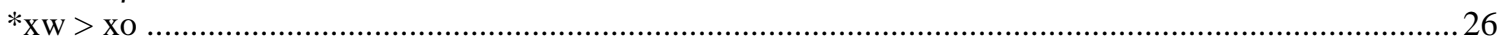

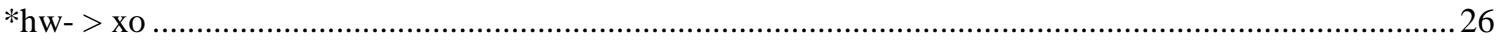

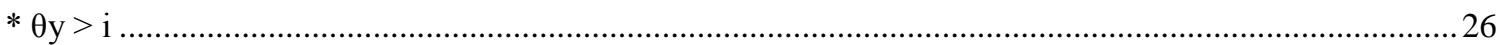

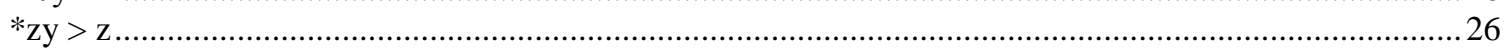

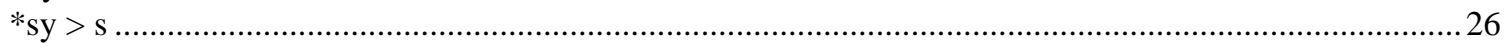

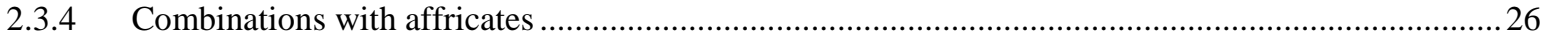

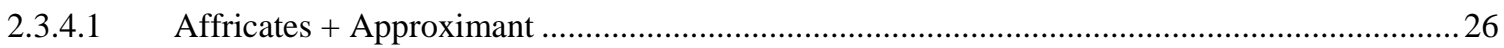

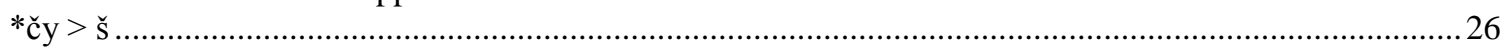

*č

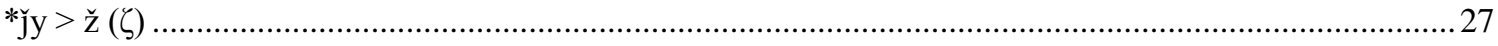

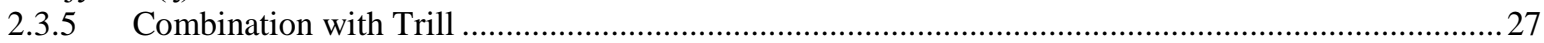

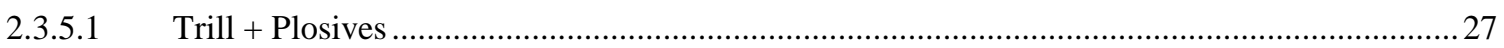

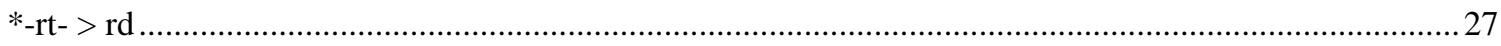

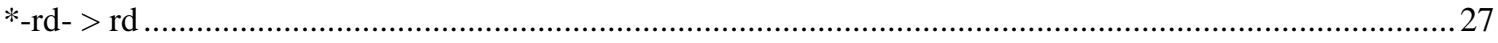

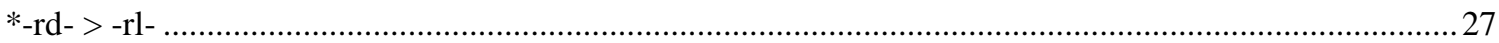

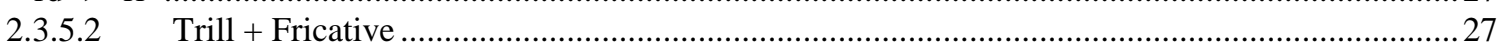

*-rš- $>$ s

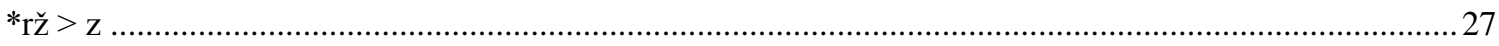

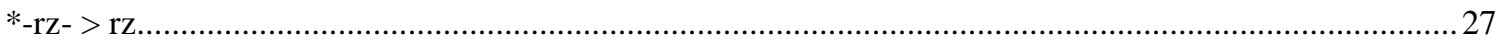

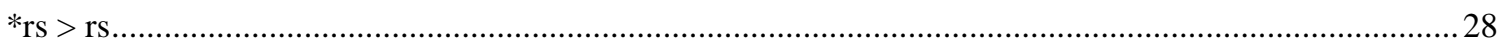

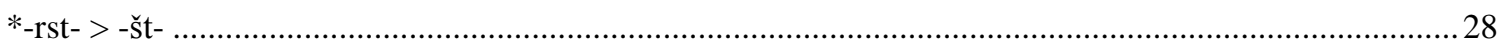

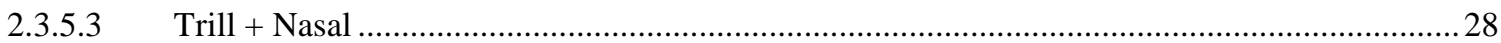

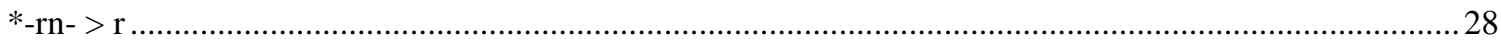

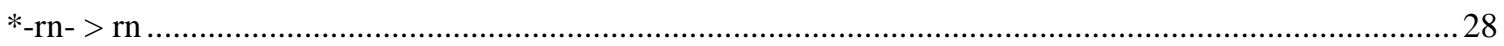

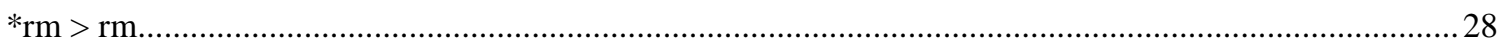

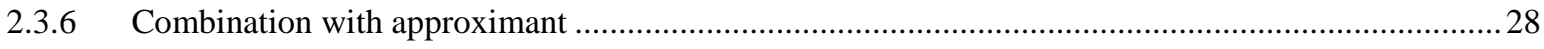

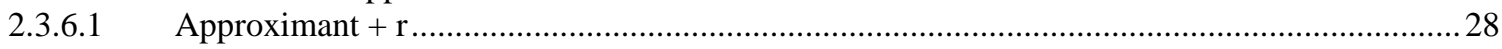

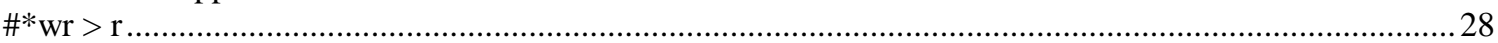

2.4 Phonological processes: Metathesis ...................................................................................28 


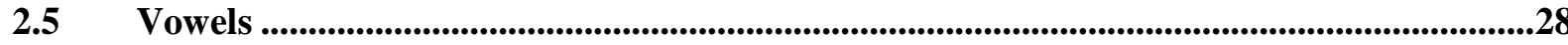

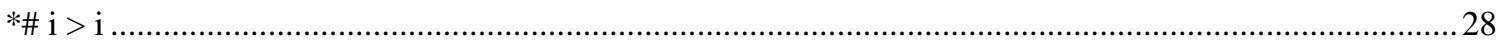

2.6 Simple vowels...............................................................................................................28

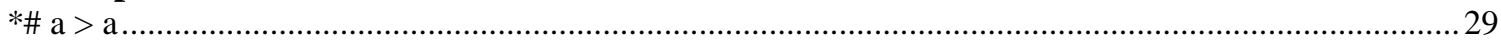

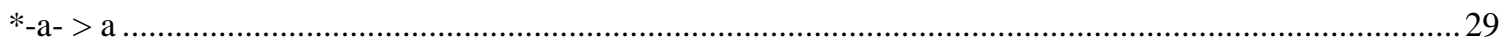

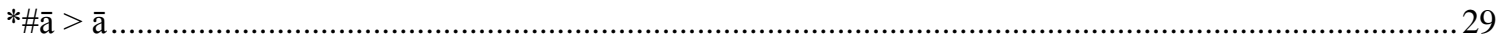

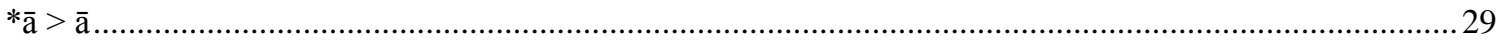

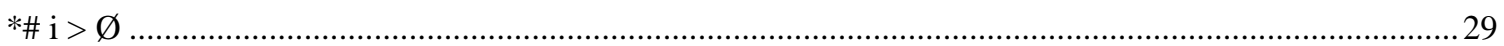

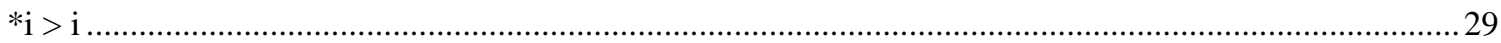

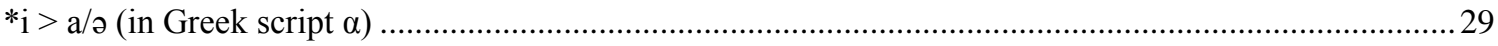

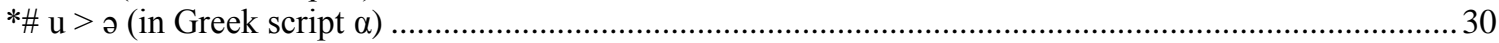

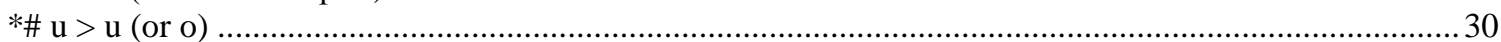

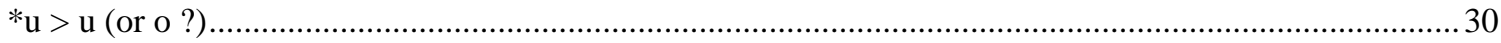

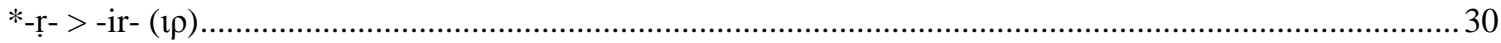

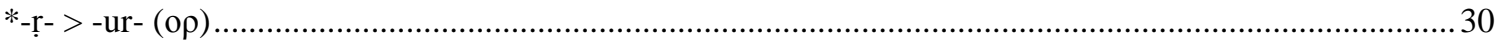

$2.7 \quad$ Loss of vowels ........................................................................................................................................

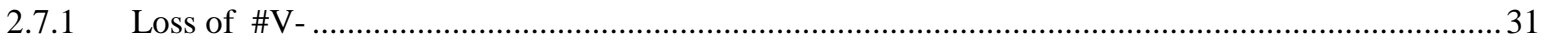

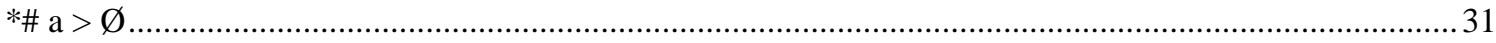

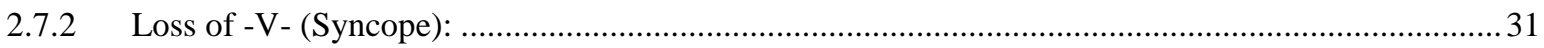

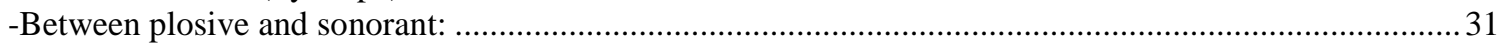

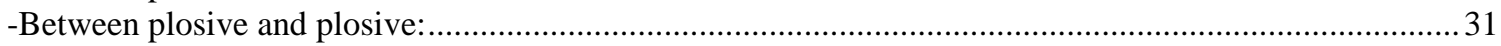

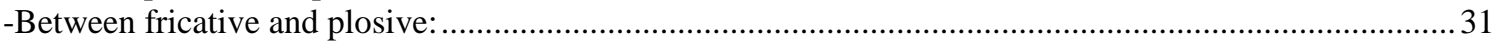

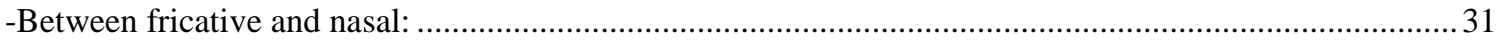

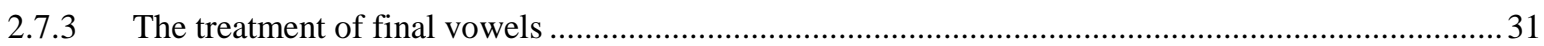

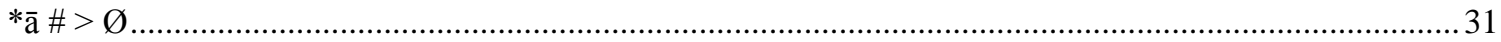

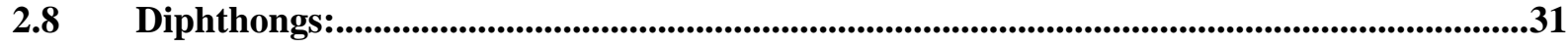

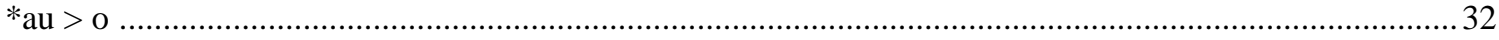

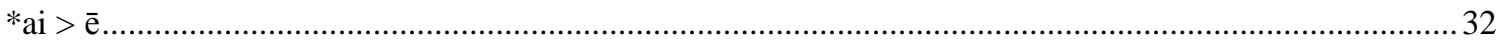

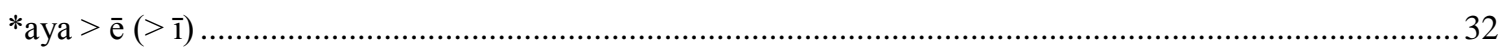

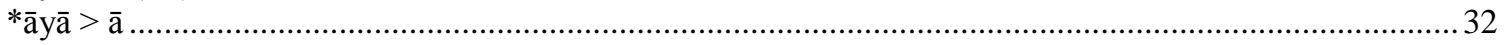

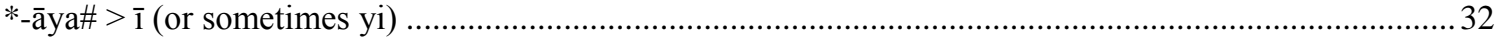

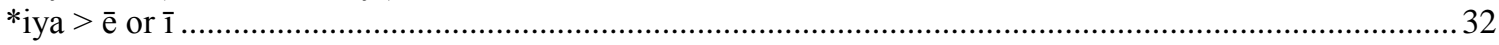

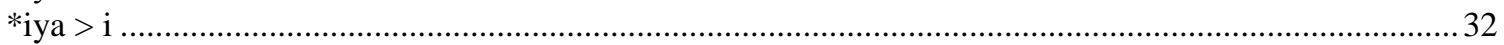

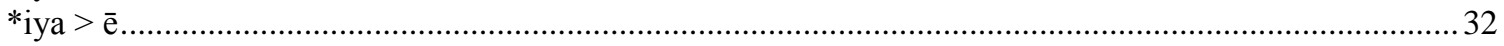

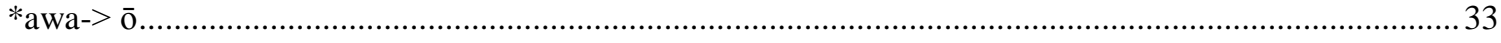

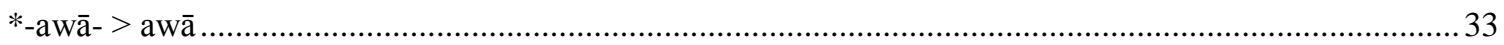

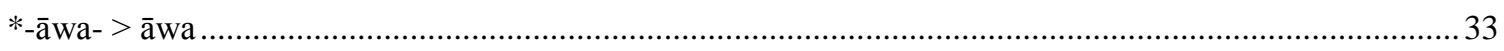

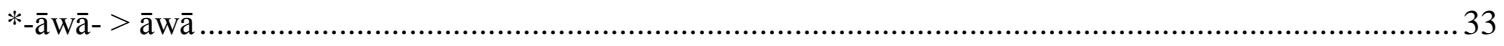

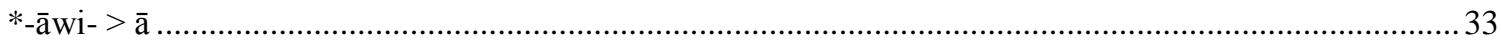

2.9 Combination of Vowel and Consonant ..............................................................................33

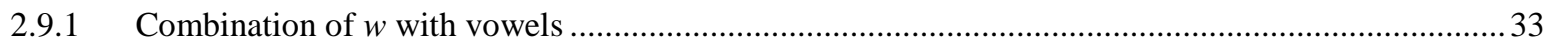

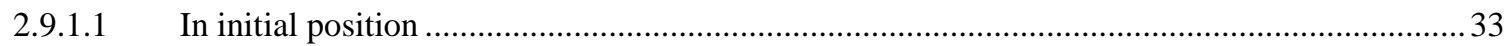

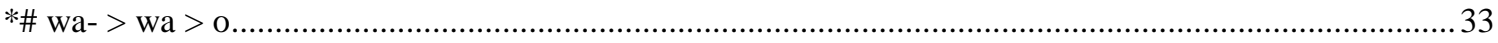

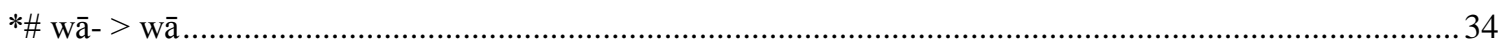

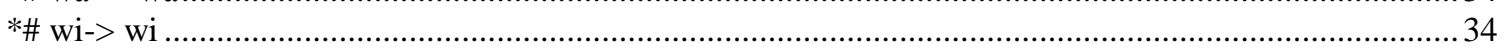

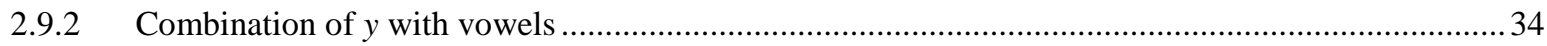

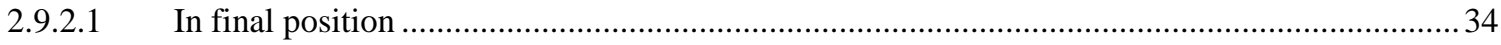

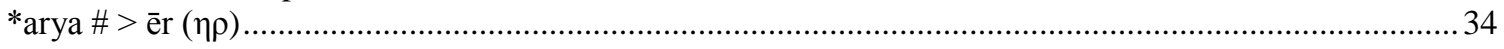

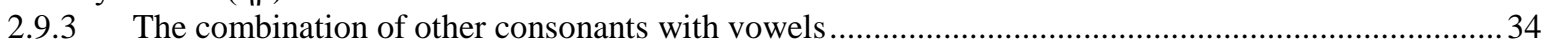

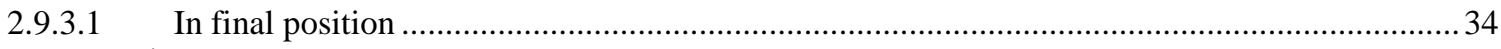

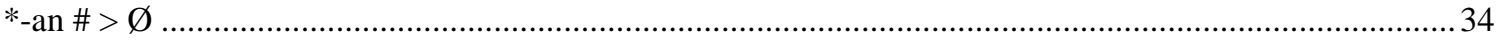

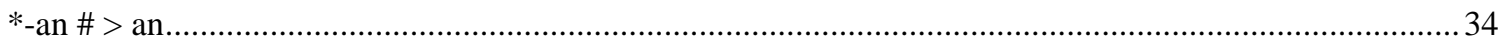

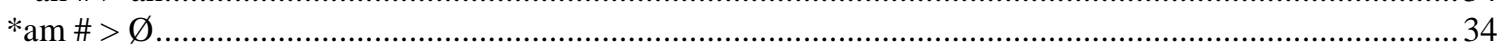

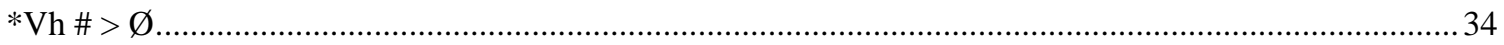

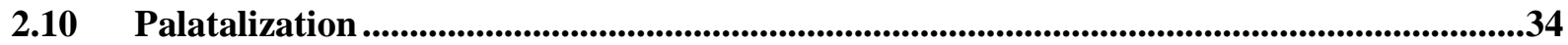

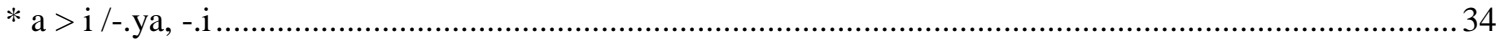

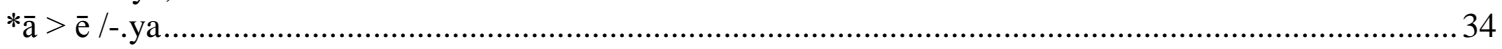

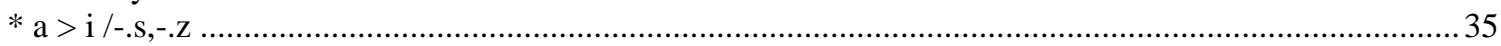




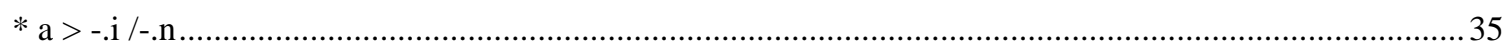

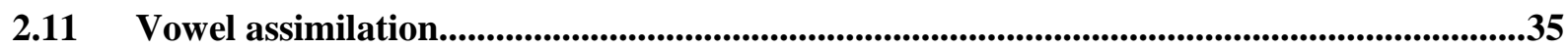

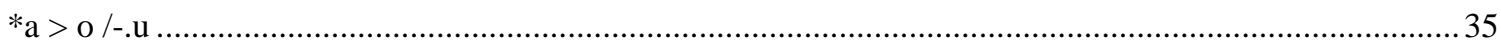

${ }_{\mathrm{i}}>\mathrm{p}$

2.12 Dissimilation .....................................................................................................................................35

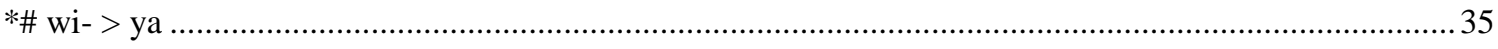

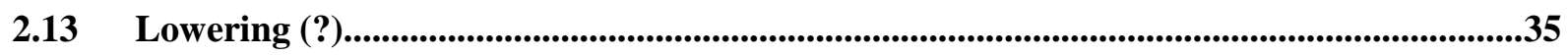

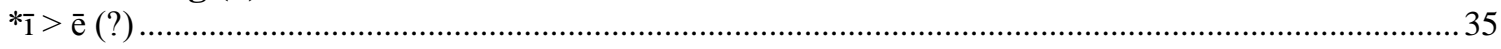

2.14 Reduced vowel (ə): ...........................................................................................................................35

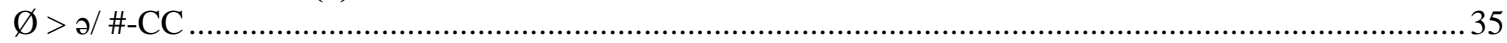

$* a, i$

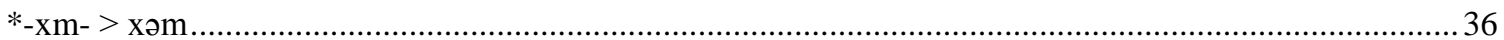

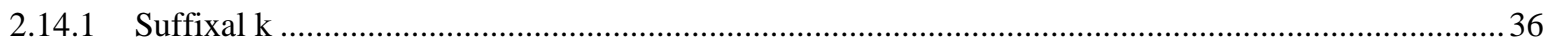

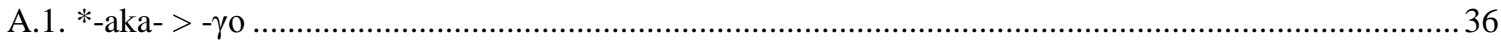

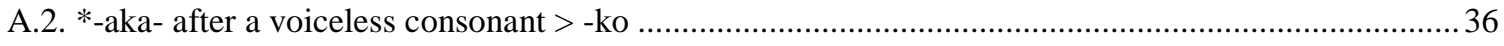

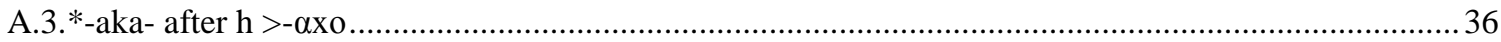

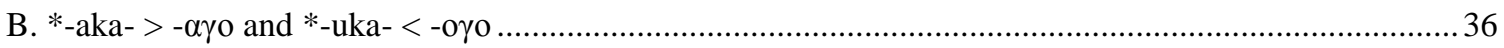

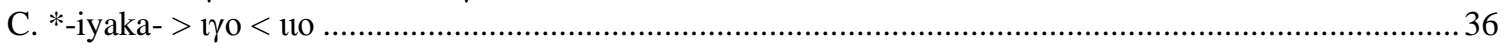

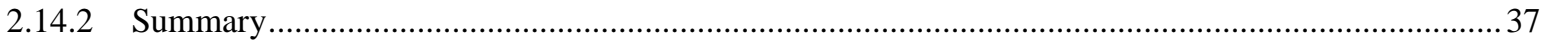

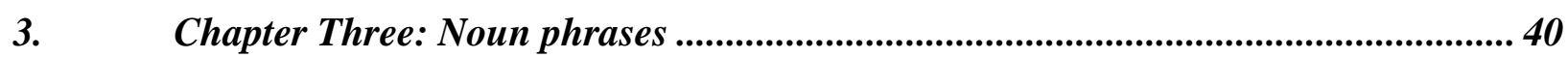

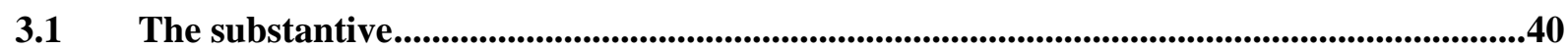

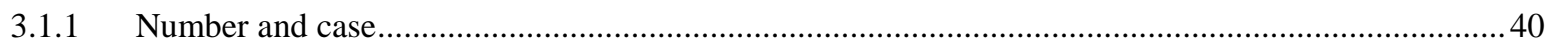

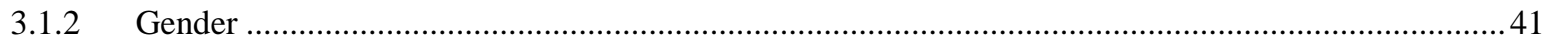

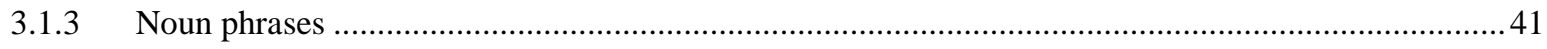

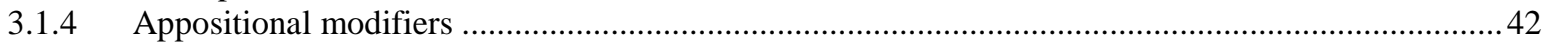

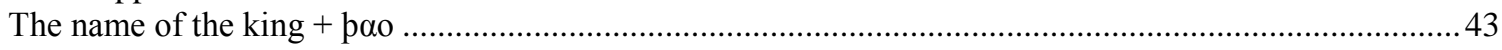

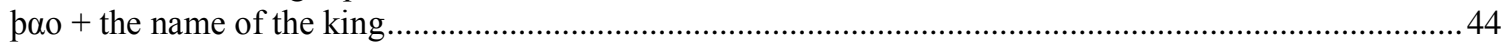

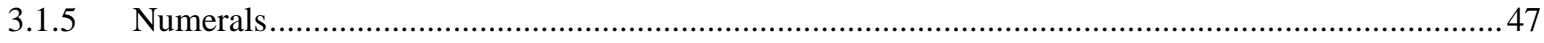

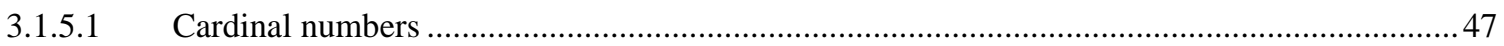

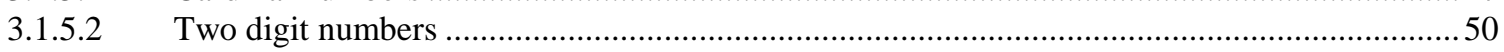

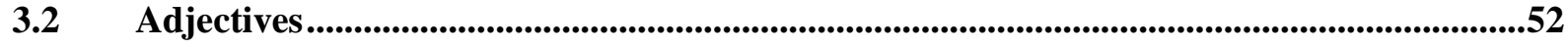

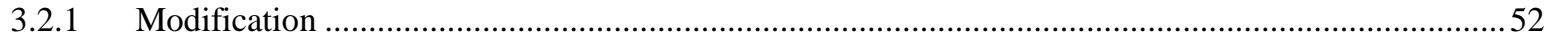

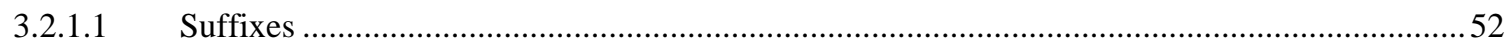

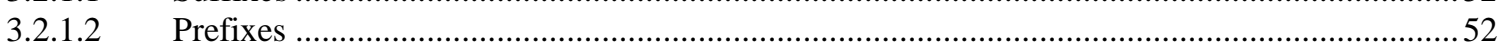

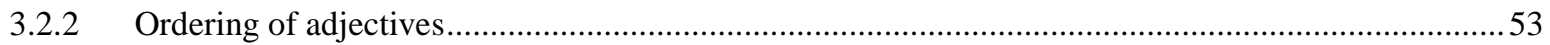

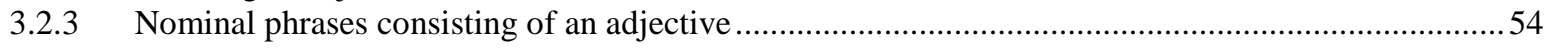

3.2.3.1 Adjectives may precede the noun they modify .........................................................5

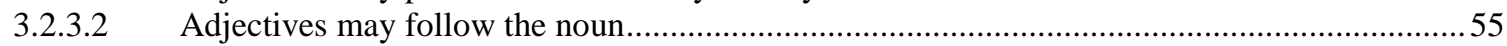

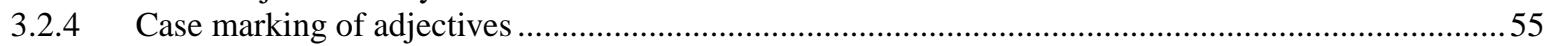

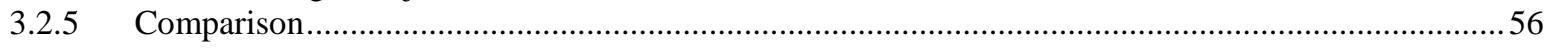

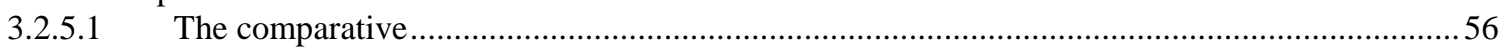

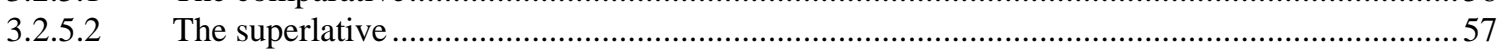

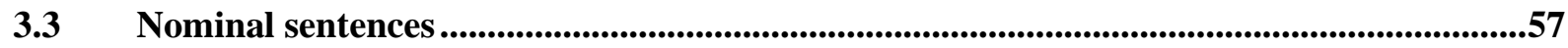

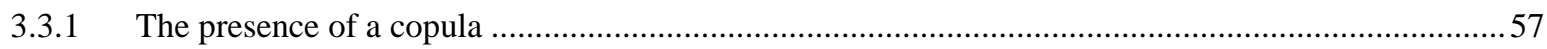

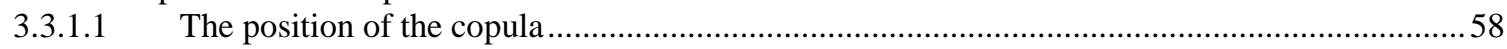

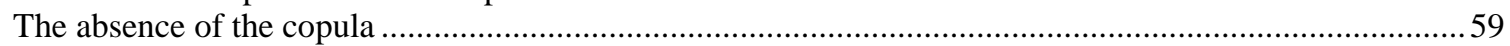

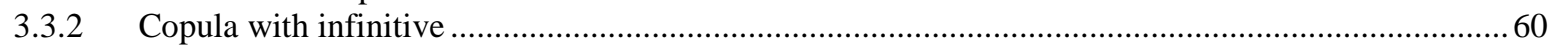

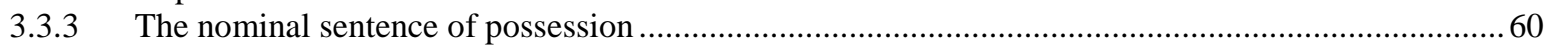

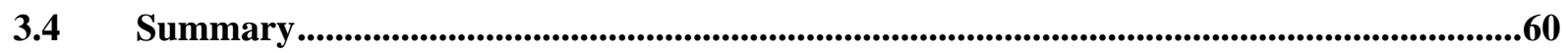

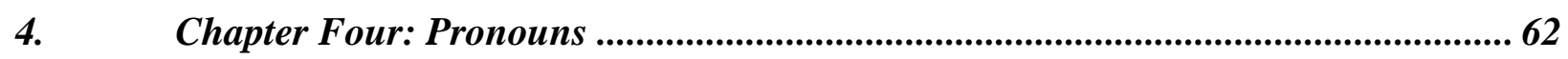

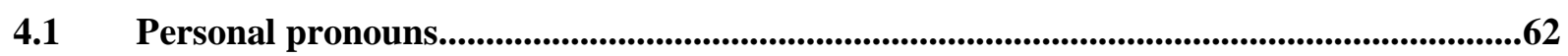

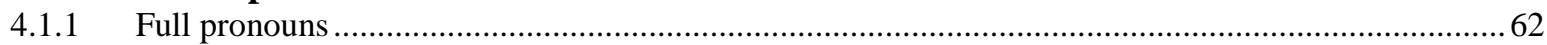

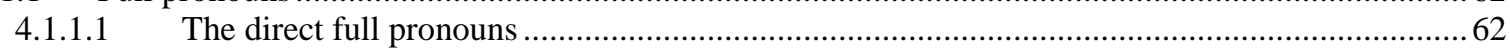

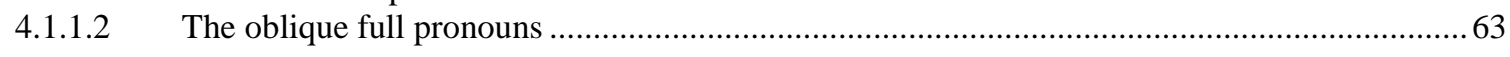




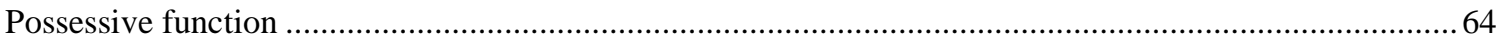

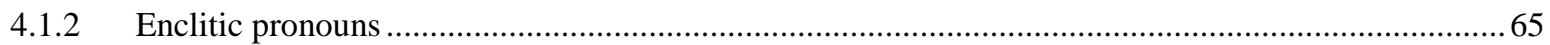

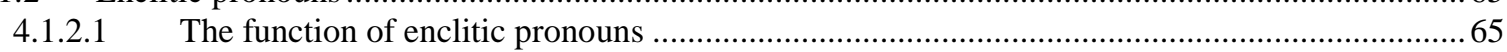

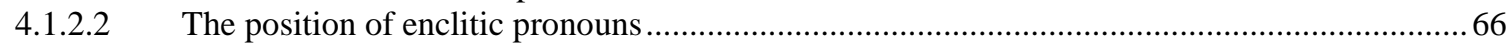

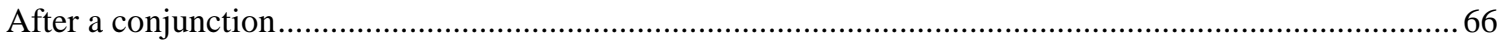

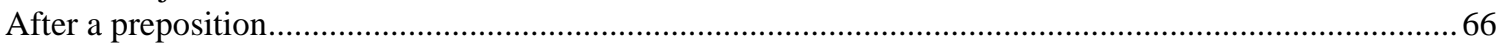

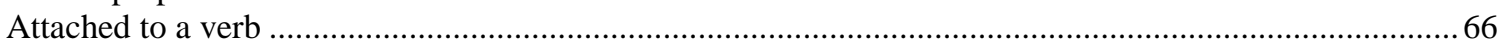

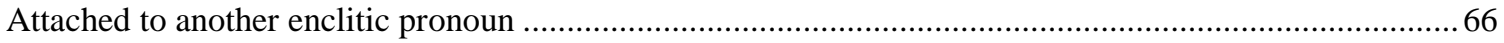

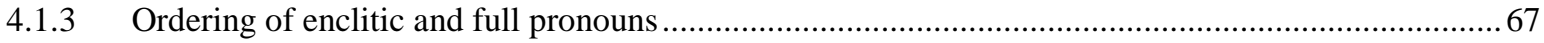

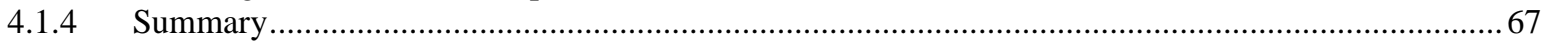

4.2 Demonstratives...........................................................................................................................68

4.3 Reflexive forms.....................................................................................................................................70

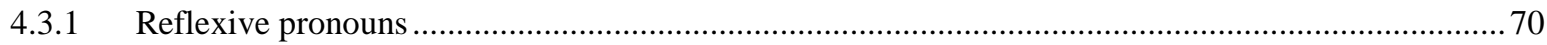

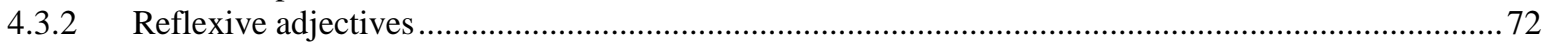

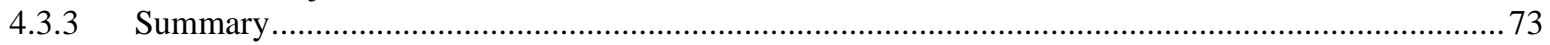

4.4 Indefinite Pronouns.........................................................................................................................73

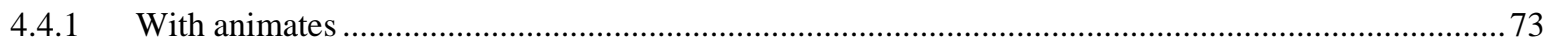

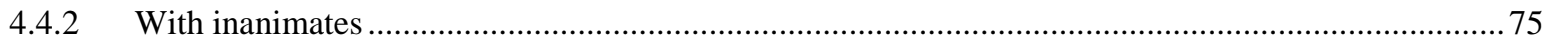

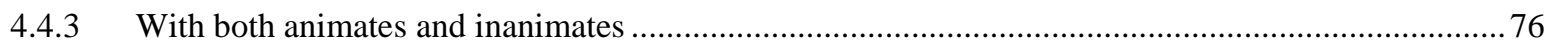

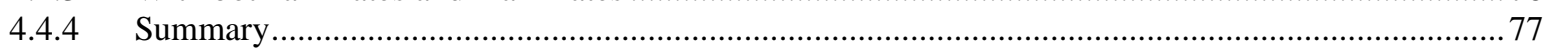

4.5 Possessive Pronouns..................................................................................................................78

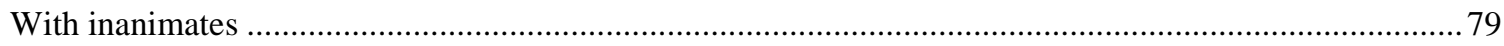

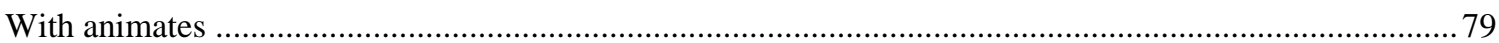

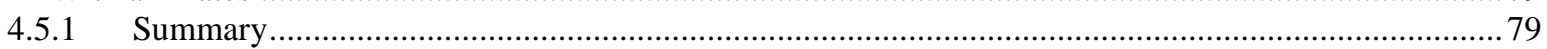

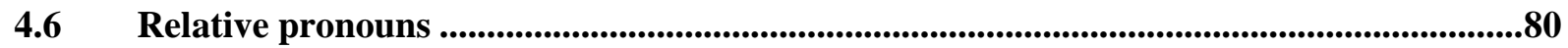

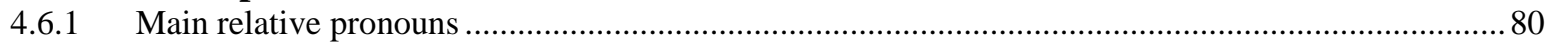

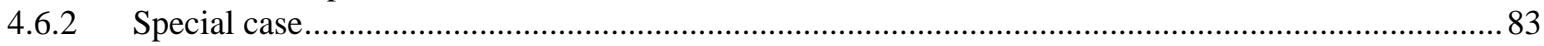

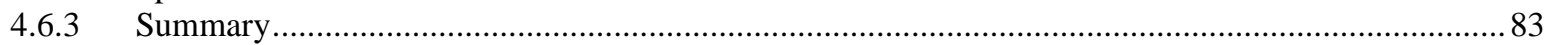

5. Chapter Five: Prepositions and postpositions........................................................... 85

5.1 The functions of prepositions and postpositions ....................................................................85

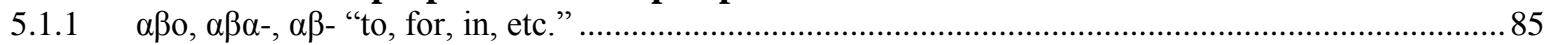

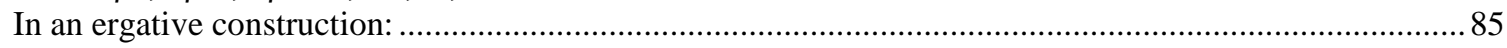

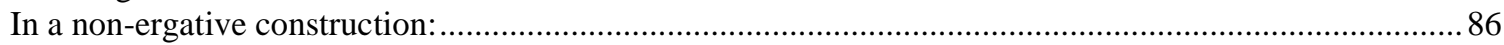

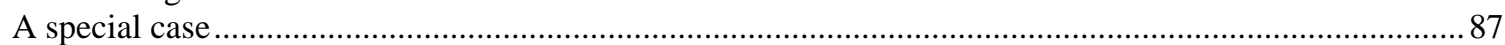

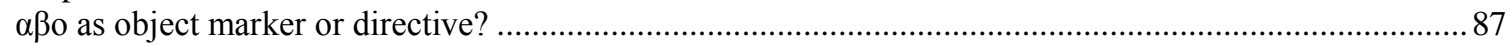

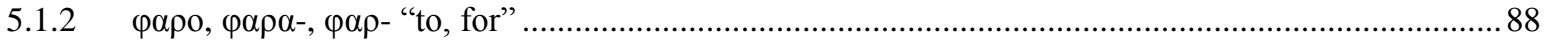

5.1.3 $\alpha \sigma 0$ "from, (out) of, by, against, concerning, according to, in respect of, as a result of, than, etc." ... 89

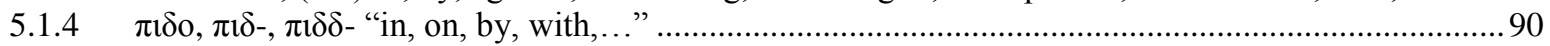

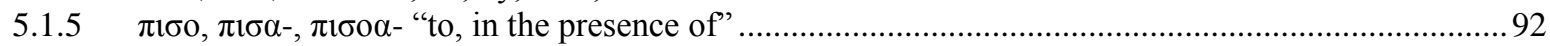

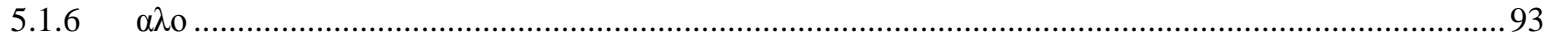

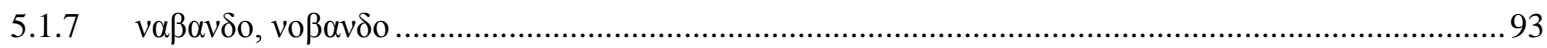

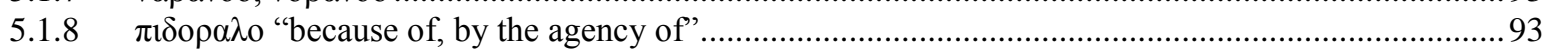

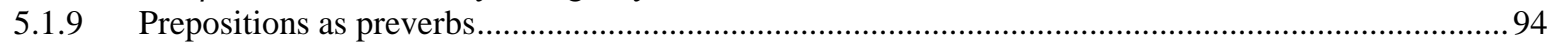

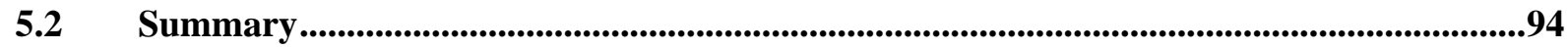

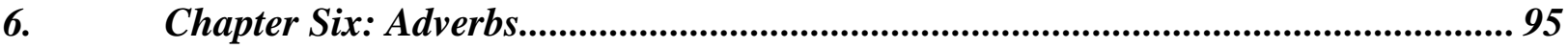

6.1 Formation of adverbs by suffixes.......................................................................................................95

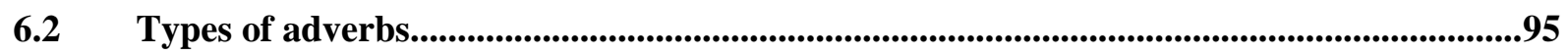

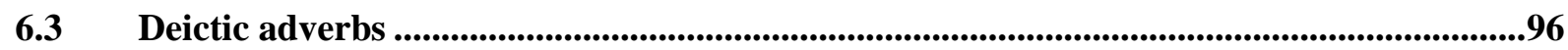

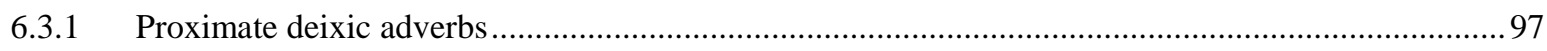

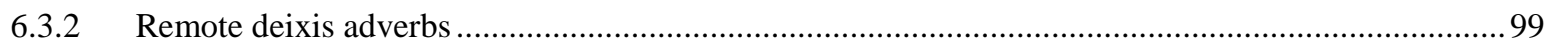

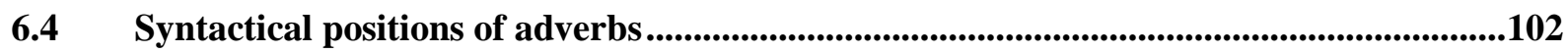

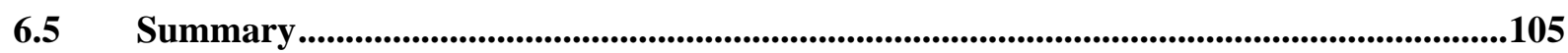


7.1 Coordinating conjunctions .....................................................................................................................107

7.1.1

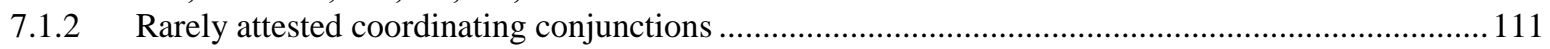

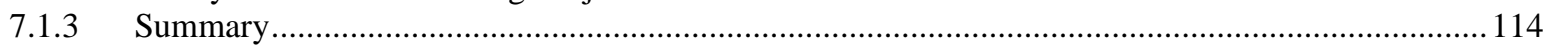

7.2 Correlative conjunctions .......................................................................................................114

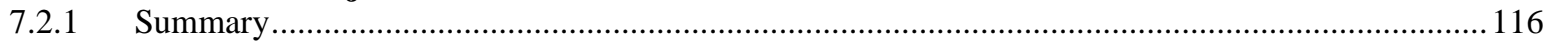

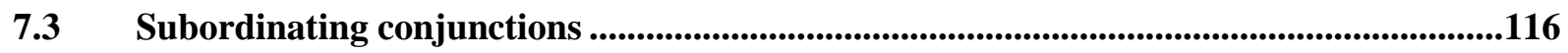

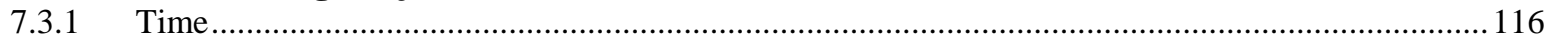

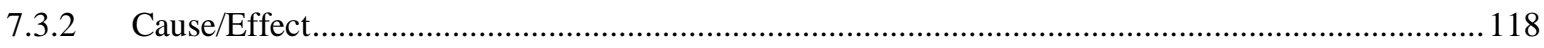

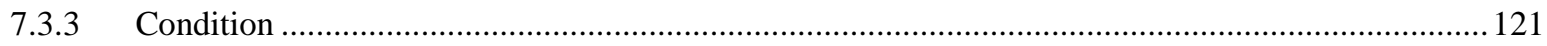

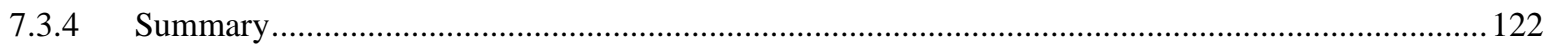

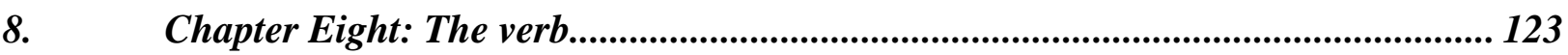

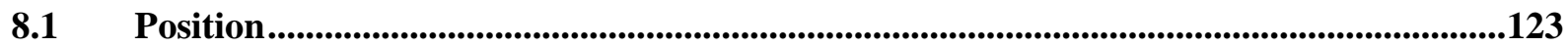

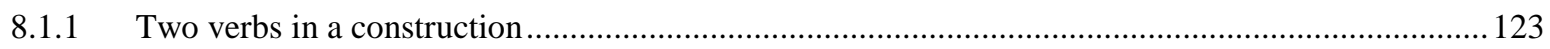

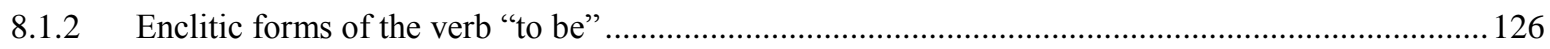

8.2 Agreement with subject .................................................................................................................127

8.3 Summary ............................................................................................................................130

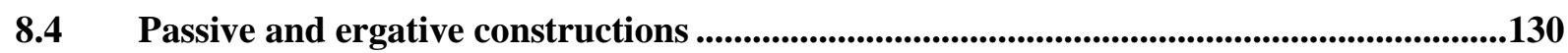

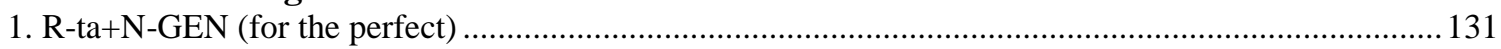

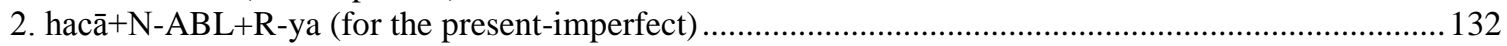

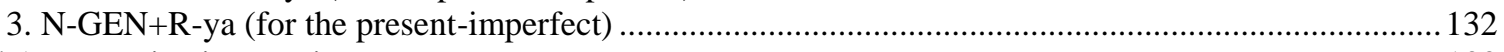

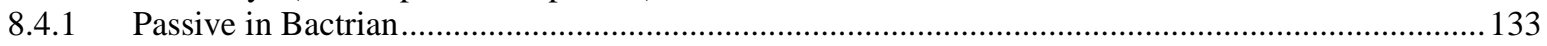

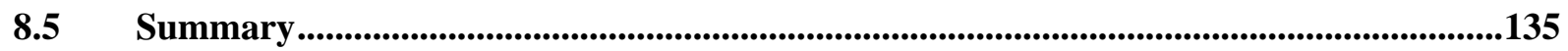

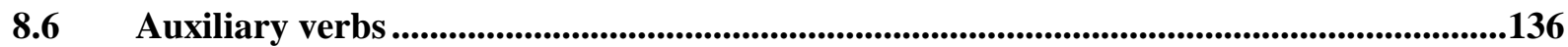

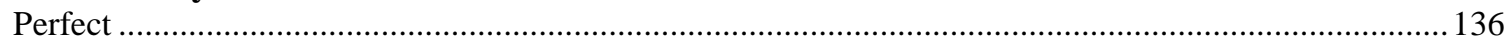

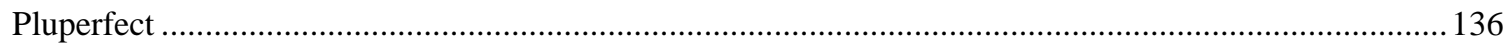

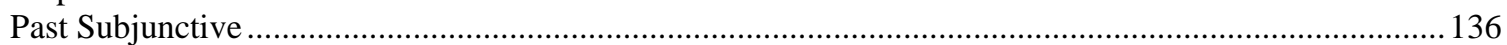

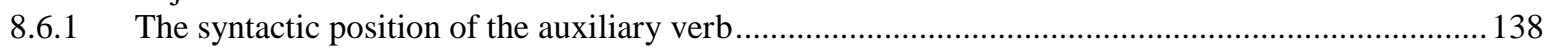

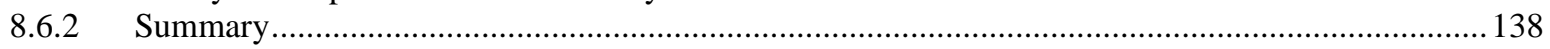

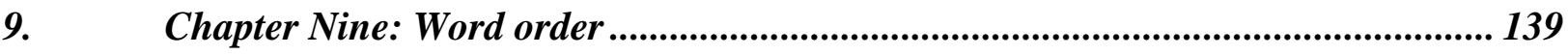

9.1 Intransitive verbs ..............................................................................................................139

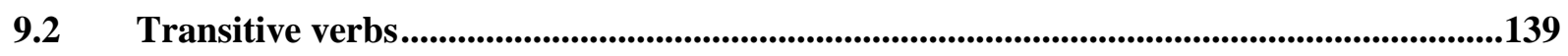

9.3 Double object constructions .........................................................................................................141

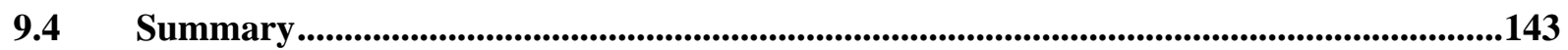

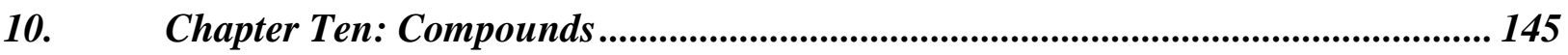

10.1 I. Bactrian compounds according to the grammatical feautures of elements....................145

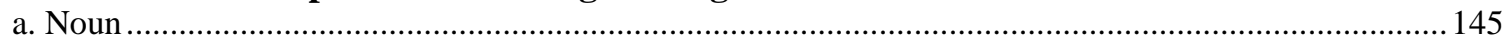

10.2 Classification of the two element compounds according to the syntactical connection of members to each other and their meaning relationship in a sentence ................................149

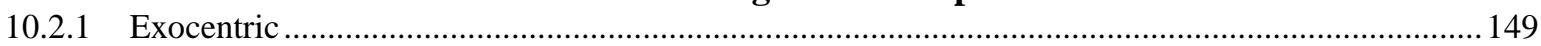

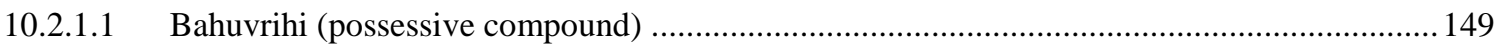

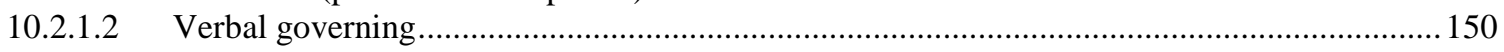

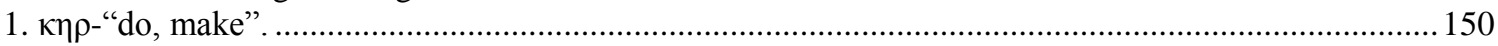

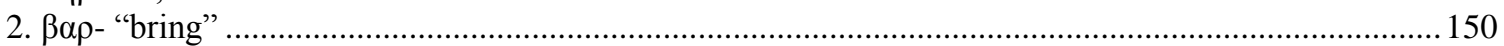

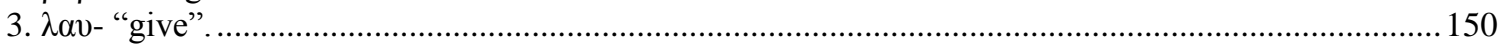

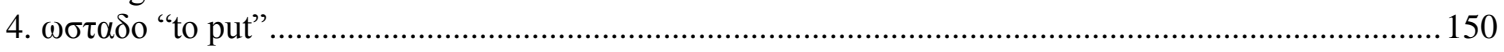

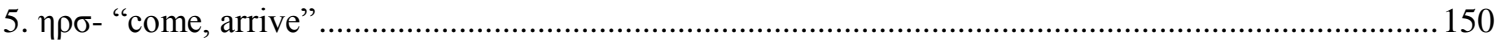

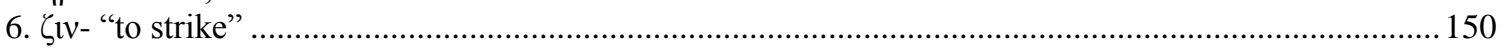

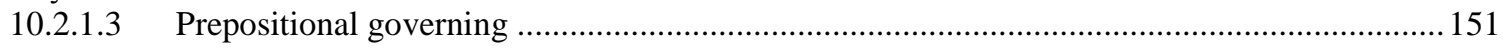




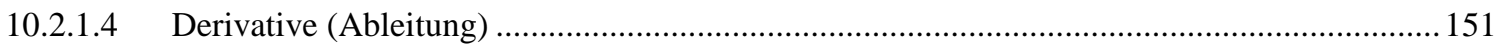

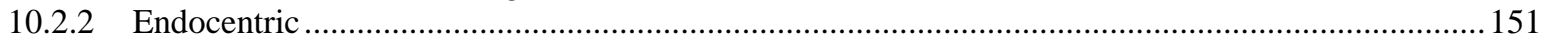

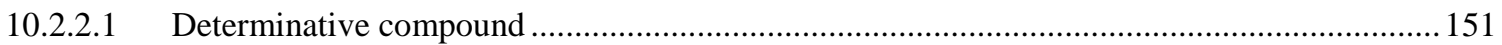

$\alpha$. Adjective (number)+ substantive or substantive+adjective ...................................................... 152

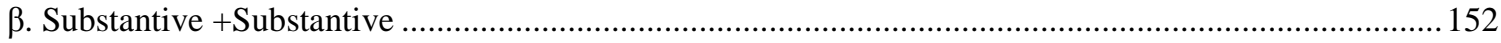

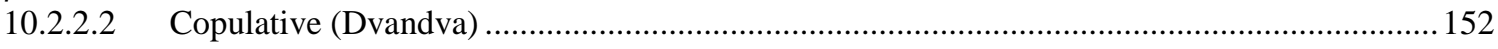

10.3 Tripartite compounds ...........................................................................................................152

10.4 Seam vowel.................................................................................................................................153

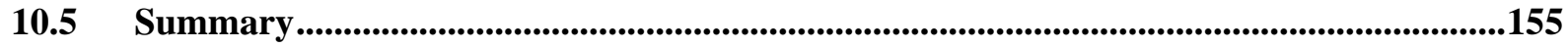

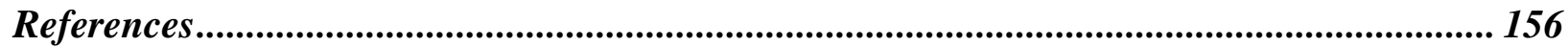




\section{ACKNOWLEDGEMENTS}

The first person who encouraged me to work on the Bactrian language was Dr. Hassan Rezai Baghbidi. He told me that only a few people in the world knew this language and that currently more experts in this field were needed. His encouragement was the main reason for my move to Germany and for writing my doctoral thesis on this language. He is the first person to whom I would like to express my gratitude.

I am also deeply indebted to Dr. Antje Wendtland at Göttingen University, who helped introduce me to the study of this language and to its sources and reference materials. She supported me throughout my study and read my thesis several times, always giving me very useful suggestions. Furthermore, I would particularly like to thank Professor Dr. Philip Kreyenbroek, who provided us with a very friendly atmosphere at our institute to work and study in. I really appreciate his encouragement and help.

I wish to express my appreciation as well to Dr. Agnes Korn, for her very insightful and useful comments on the chapters "historical phonology" and "compounds".

I would like to thank Denise Bailey for her unflagging support and help. She corrected and formatted this work several times with admirable patience.

Finally, I wish to express special gratitude to "The Soudavar Memorial Foundation" for the financial support that enabled the addition of the chapter "Phonology". This chapter was a part of the project "The position of Bactrian among the Indo-Iranian languages". 


\section{ABbreviations}

\begin{tabular}{|c|c|c|c|}
\hline A & Agent & OInd & Old Indian \\
\hline $\mathrm{ABL}$ & Ablative & $\mathrm{OM}$ & Object marker \\
\hline ADJ & Adjective & $\mathrm{OP}$ & Old Persian \\
\hline ADV & Adverb(ial) & OPT & Optative \\
\hline AR & Armenian & $\mathrm{p}$ & Person \\
\hline ART & Article & PA & Pronominal adjective \\
\hline AV & Avestan & PAR & Particle \\
\hline$B D \mathrm{I}$ & Sims-Williams 2000a & PASS & Passive \\
\hline$B D$ II & Sims-Williams 2007a & PF & Perfect \\
\hline COJ & Conjunction & PL & Plural \\
\hline $\mathrm{CP}$ & Enclitic pronoun & PLP & Pluperfect \\
\hline DB & Darius, Behistan document & PN & Personal name \\
\hline DEM & Demonstrative & POSA & Possessive adjective \\
\hline DIR & Direct & POSP & Possessive pronoun \\
\hline $\mathrm{EZ}$ & Ezafe & POST & Postposition \\
\hline $\mathrm{F}$ & Feminine & $\mathrm{pp}$ & Past participle \\
\hline FUP & Future participle & PRE & Preposition \\
\hline GEN & Genitive & $\mathrm{PROH}$ & Prohibitive \\
\hline INA & Indefinite adjective & PRON & Pronoun \\
\hline IND & Indicative & PRS & Present \\
\hline INDIR & Indirect & PST & Past \\
\hline INF & Infinitive & RA & Reflexive adjective \\
\hline INP & Indefinite pronoun & $\mathrm{RP}$ & Reflexive pronoun \\
\hline IMP & Imperative & RTP & Relative pronoun \\
\hline IMPF & Imperfect & RUS & Russian \\
\hline KHOT & Khotan Saka & $\mathrm{S}$ & Subject \\
\hline LAT & Latin & SBJV & Subjunctive \\
\hline M & Masculine & SG & Singular \\
\hline MP & Middle Persian & SPD & Second person demonstrative \\
\hline $\mathrm{N}$ & Noun & UFL & Uninflected \\
\hline $\mathrm{NE}$ & Neuter & $\mathrm{V}$ & Verb \\
\hline NEG & Negative & $\mathrm{XPa}$ & Xerxes, Persepolis document a \\
\hline NOM & Nominative & $1 \mathrm{~s} / 2 \mathrm{~s} / 3 \mathrm{~s}$ & First person \\
\hline NP & New Persian & & singular/second.../third \\
\hline $\mathrm{O}$ & Object & $1 \mathrm{p} / 2 \mathrm{p} / 3 \mathrm{p}$ & First person plural/second.../thir \\
\hline
\end{tabular}

OBL Oblique

The following table shows the Greek letters used for writing Bactrian (in bold) and their probable phonetic values in Bactrian.

\begin{tabular}{|c|c|c|c|c|c|c|c|}
\hline $\begin{array}{l}\boldsymbol{\alpha} \\
\mathrm{a}, \overline{\mathrm{a}}, \text { ə }\end{array}$ & $\begin{array}{l}\boldsymbol{\beta} \\
\mathrm{b}, \beta\end{array}$ & $\begin{array}{l}\gamma \\
\mathrm{g}, \gamma, \\
\gamma \gamma-\mathrm{pg}\end{array}$ & $\begin{array}{l}\boldsymbol{\delta} \\
\mathrm{d}\end{array}$ & $\begin{array}{l}\boldsymbol{\varepsilon} \\
\mathrm{e}, \\
\boldsymbol{\varepsilon l}-\overline{1}\end{array}$ & $\begin{array}{l}\zeta \\
\mathrm{z}, \check{z}, \mathrm{dz}\end{array}$ & $\begin{array}{l}\boldsymbol{\eta} \\
\bar{e}, \\
\text { final }-\boldsymbol{\eta} \mathbf{l o}-\overline{\mathrm{e}}\end{array}$ & \\
\hline $\begin{array}{l}\boldsymbol{\theta} \\
\theta\end{array}$ & $\begin{array}{l}\mathrm{l} \\
\mathrm{y}, \mathrm{i}, \overline{\mathrm{i}}\end{array}$ & $\begin{array}{l}\text { к } \\
\mathrm{k}\end{array}$ & $\begin{array}{l}\lambda \\
1\end{array}$ & $\begin{array}{l}\mu \\
\mathrm{m}\end{array}$ & $\begin{array}{l}v \\
\mathrm{n}\end{array}$ & $\begin{array}{l}\mathbf{0} \\
\mathrm{w}, \mathrm{u}, \overline{\mathrm{u}}, \mathrm{o}, \partial, \varnothing\end{array}$ & $\begin{array}{l}\pi \\
\mathrm{p}\end{array}$ \\
\hline $\begin{array}{l}\rho \\
\mathrm{r}\end{array}$ & $\begin{array}{l}\mathbf{p} \\
\text { š }\end{array}$ & $\begin{array}{l}\boldsymbol{\sigma} \\
\mathrm{s}, \mathrm{ts}, \mathrm{dz}\end{array}$ & $\begin{array}{l}\tau \\
\mathrm{t}\end{array}$ & $\begin{array}{l}\text { v } \\
h\end{array}$ & $\begin{array}{l}\varphi \\
\mathrm{f}\end{array}$ & $\begin{array}{l}\chi \\
x\end{array}$ & $\begin{array}{l}\omega \\
\bar{o}\end{array}$ \\
\hline
\end{tabular}

\footnotetext{
${ }^{1}$ Following Sims-Williams 1989: 233.
} 


\section{Chapter One: InTroduction}

\subsection{Bactria}

Bactria played an important role in the history of Central Asia. Originally, Bactria consisted of the plain between the Hindu Kush and the Āmū Daryā, with its string of agricultural oases dependent on water taken from the rivers of Balkh (Bactra), Tashkurgan, Kondūz, Sar-e Pol, and Šìīn Tagāō. ${ }^{2}$

The name Bactria is first mentioned in the list of Darius's conquests in the Behistan inscription and in a fragment of the work of Ctesias of Cnidos. ${ }^{3}$ According to historical sources, Bactra occupied a commanding position on the royal road to India, and the Bactrians also played an important role in the Persian army. For example, at Salamis they were under the great king's direct command. ${ }^{4}$

Alexander invaded Bactria, and Greek rulers maintained a rule informed by Hellenist culture for some 200 years after his death (323 B.C.). The Greek kings divided Bactria-Sogdiana into a number of satrapies, as this was a more manageable arrangement. This region was described as "Mother of cities" and as "Paradise on earth".

In the Avesta, Bactria is mentioned only in the list of countries in the first chapter of the Vendīdād and in the Pahlavi books in the Bundahišn and Šahrestānīhā $\bar{\imath} \bar{E} r \bar{a} n$.

In the Bundahišn, the Oxus, together with the Indus, is identified with the wehrōd, the "Good river", which forms the boundary of E Erānšahr and is conceptually linked with the Avestan Vayhvi Däitya , which is near the place where the first upholders of faith performed their sacrifices. $^{6}$

The Šahrestānīhā $\bar{\imath}$ Érān associates Bactria with the Kayanid prince Spandyād (Esfandīyār) and his victory in the holy war against Arjāsp. ${ }^{7}$

Soon after the middle of the second century B.C., Greek rule ended with invasions of nomads, notably the Yüeh-chih or Tokharoi from the North, who settled in Northern Afghanistan. ${ }^{8}$ The archaeological discoveries relating to this period point to a continuation of agricultural and urban development. ${ }^{9}$

Under the Kushans, Bactria lost its political importance, but it became a major commercial center on the Silk Road. In the Kushan period (68 B.C.-240 A.D.), people were able to travel there; among them were Indian monks who brought the religion of the Buddha to Bactria. ${ }^{10}$

\footnotetext{
${ }^{2}$ Leriche 1989: 339.

${ }^{3}$ Leriche 1989: 339 and Kent 1953: 117.

${ }^{4}$ Leriche 1989: 340.

${ }^{5}$ Tarn 1951: 113.

${ }^{6}$ Cf. Grenet 1989: 344.

${ }^{7}$ Grenet 1989: 344.

${ }^{8}$ Sims-Williams 1989c: 344.

${ }^{9}$ Leriche 1989: 341.

${ }^{10}$ Leriche 1989: 343.
} 


\subsection{Bactrian language and script}

Although Bactrian is geographically close to Eastern Iranian languages, from a linguistic point of view, it can be classified as an Eastern-Western Iranian language, because it possesses many characteristics of Western Iranian languages, particularly in the area of morphological and phonological features. Table 1 shows an overview of the Iranian languages:

Table 1. Overview of the Iranian languages

\begin{tabular}{|l|l|l|l|}
\hline Old Iranian & Old Persian, Avesta \\
\hline \multirow{2}{*}{ Middle Iranian } & Western & Western-Eastern & Eastern \\
\cline { 2 - 4 } & Middle Persian, Parthian & Bactrian & Sogdian, Khotanese, Chwaresmian \\
\hline New Iranian & Persian, Kurdish, Balochi, etc. & Pashto, Pamir languages, Ossetic, etc. \\
\hline
\end{tabular}

Some scholars have used other terms instead of Bactrian, such as "Greco-Bactrian", "Kushan", or "Kushano-Bactrian". The name "Eteo-Tocharian", proposed by A. Maricq, can hardly be justified. ${ }^{11}$

In Achaemenian times, in the fifth century B.C., correspondence between Iranians as well as between Iranians and non-Iranians was conducted in Aramaic. There is no reason to doubt that in Achaemenian times, Aramaic was also used in Bactria. In post-Achaemenian times, this probably led to Middle Bactrian being written with Aramaic ideograms in Aramaic script, as was the case with Middle Persian, Parthian, and Chorasmian. ${ }^{12}$

The practice of writing Bactrian in Greek script must have begun in the first century B.C., when literacy in Greek was still sufficiently widespread among the Bactrians. ${ }^{13}$ It seems that at first, the Kushans continued the traditional use of Greek. In the reign of Kanishka I (ca. 127-151 A.D.) ${ }^{14}$ Bactrian replaced Greek on the Kushan coins. After this period, Greek ceased to be used as an official language in Bactria. ${ }^{15}$

After the collapse of the Kushan empire, Bactrian continued to be used for at least six centuries, as is shown by the ninth century inscriptions from the Tochi valley in Pakistan and the remnants of Buddhist and Manichean manuscripts as far away as the Turfan oasis in western China. ${ }^{16}$

\subsection{Bactrian sources}

\subsubsection{Coins}

The coins of the first Bactrian kings give their names and titles in Greek. ${ }^{17}$ Kanishka's coins from the beginning of his reign were written in the Greek language and script, and depict Greek divinities. But later coins were written in the Bactrian language and a modified Greek script. ${ }^{18}$ With the eclipse of the Kushan dynasty, their lands west of the Indus fell into the hands of the Sasanians. In addition to coinage inscribed in Pahlavi and (occasionally) in Brāhmī, the Kušānšāhs issued coins with legends in cursive Greco-Bactrian script. ${ }^{19}$ The Bactrian coin-legends of

\footnotetext{
${ }^{11}$ Sims-Williams 1989c: 344, Henning 1960: 47 and Gershevitch 1979: 55.

${ }^{12}$ Gershevitch 1983: 1254.

${ }^{13}$ Gershevitch 1983: 1255.

${ }^{14}$ See Falk 2001: 121-136.

${ }^{15}$ Sims-Williams 1989c: 345.

${ }^{16}$ Sims-Williams 1997a.

${ }^{17}$ Sims-Williams 1989c: 345.

${ }^{18}$ See Bopearachchi 1991 and Humbach 1967a.

${ }^{19}$ Sims-Williams 1989c: 345
} 
the Hunnish ${ }^{20}$ period display a rich linguistic diversity, with loan titles from Indian, Turkish and Latin, as well as from Bactrian and Middle Persian. ${ }^{21}$

\subsubsection{Seals}

The number of Kushan seals bearing Bactrian inscriptions is small. Bactrian inscriptions on seals during the Kushano-Sasanian and subsequent periods were written in an extremely cursive variety of the Greek script. There is some difficulty in dividing Kushano-Sasanian seals from those of the preceding Kushan period (68 B.C.-240 A.D.). ${ }^{22}$ Many of the earlier Kushan seals can be distinguished because their Bactrian inscriptions are written in a less cursive form of the Greek alphabet. ${ }^{23}$ These seals are inscribed with names and titles of their owner ${ }^{24}$ in GrecoBactrian script.

\subsubsection{Inscriptions}

\section{Surkh Kotal ${ }^{25}$}

This inscription was carved in the second century A.D. into a large monolith in the ruins of the acropolis of Surkh Kotal in northern Afghanistan. ${ }^{26}$ It was discovered in May 1957 by the French Archaeological Delegation in Afghanistan. ${ }^{27}$ According to Henning, the purpose of this inscription was to record the construction work carried out by Nokonzoko. It was "the first substantial document of the Middle Iranian dialect of Bactria, which was previously only known from the coins..." 28 The text of the Surkh Kotal inscription was published first by André Maricq, who identified some important words and phrases including the name of Kanishka, and then by Henning, Gershevitch, Harmatta, and Livšic. The last version was published by Lazard, Grenet, and de la Lamberterie.

\section{Rabatak}

The stone bearing this inscription, together with fragments of a sculpture of a lion and agricultural elements, was found in March 1993 on a hill locally known as "the Kafirs' Castle", in a region called Rabatak, 25 miles north of Pul-i Khumri. ${ }^{29}$ The inscription relates to the rule of the Kushan emperor Kanishka and speaks of a sanctuary being built by Shafar, the local Kushan officer. This inscription was published for the first time by Cribb and Sims-Williams, ${ }^{30}$ and for the second time by Sims-Williams. ${ }^{31}$

This inscription provides an important list of gods, and according to Cribb, "it makes the role of the divine images on Kushan coins abundantly clear." 32 The Rabatak Inscription also shows

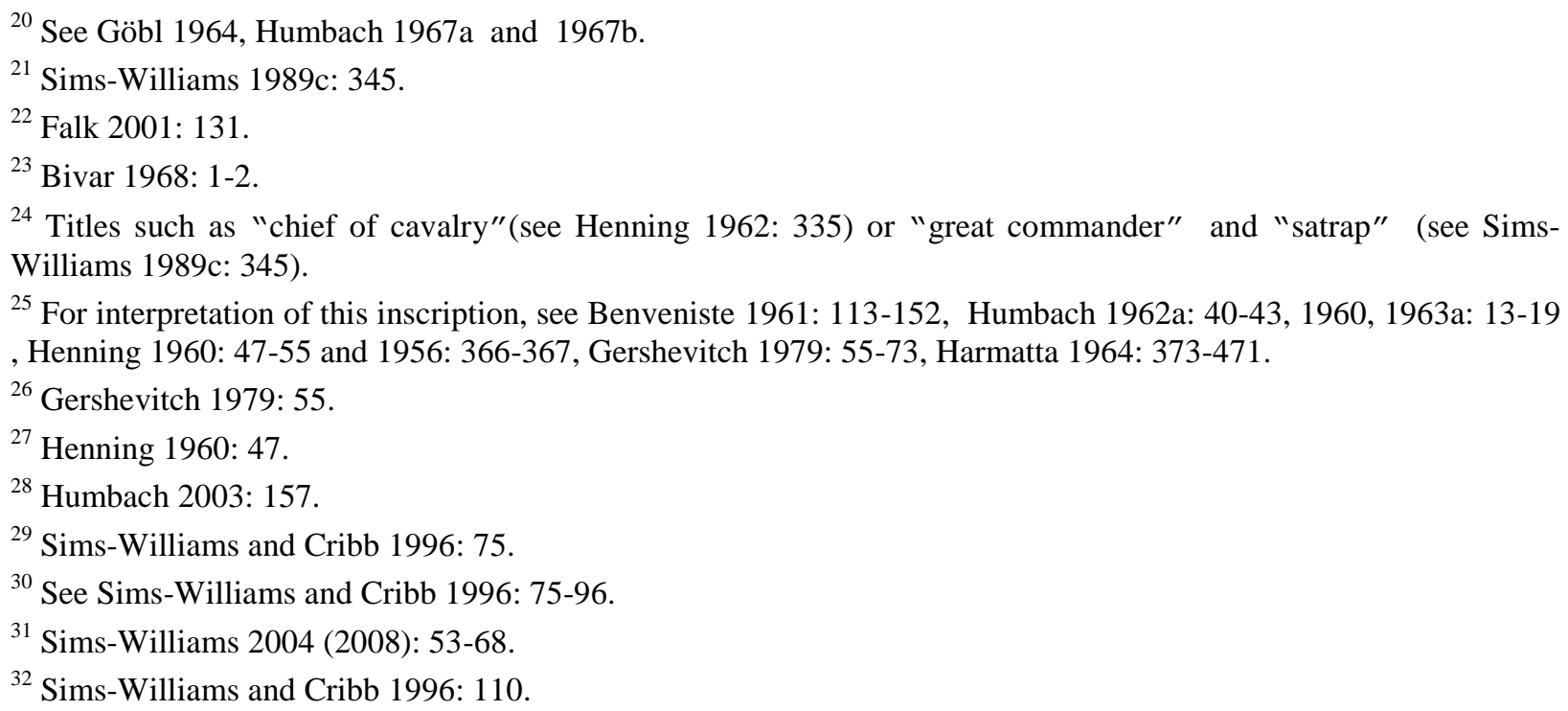


that Kanishka issued a Greek edict and then put it into Aryan and described some of the events of his first regal year. As Sims-Williams and Cribb note: "The most startling revelation is the identification of a new king, Vima Tak[to] (line 13), whose position among Kushan kings is clearly indicated." 33

\section{The other inscriptions}

The trilingual inscription of Dašt-e Nāvūr (in Bactrian, Kharoșțī and an undeciphered script $),{ }^{34}$ the inscription of Ayrtam, ${ }^{35}$ the inscription of Delbarjīn, ${ }^{3 \dot{6}}$ two inscriptions from Jaghatu, inscriptions from Uruzgan and the Tochi valley, and two very short rock inscriptions were also written in Bactrian. Several graffiti in cursive Bactrian script of the Kushano-Sasanian period have been found in the Buddhist cave-monastery of Kara-Tepe. ${ }^{37}$ Tang-i Safedak is another Bactrian inscription, which has been published by Lee and Sims-Williams. ${ }^{38}$

\subsubsection{Manuscripts}

Seven of eight known fragments in Greco-Bactrian script were found at Toyoq and one at Lou-lan. ${ }^{39}$ Certain words suggest that the Lou-lan manuscript may contain a Buddhist text. ${ }^{40}$

\subsubsection{Documents}

Our knowledge of the Bactrian language depends largely on a hundred documents in Bactrian cursive script, which appeared in the bazaar of Peshawar and on the international art market in recent years. Many of these are now in the collection of Dr. Nasser David Khalili in London. ${ }^{41}$ These documents were written on leather, cloth and even on wooden sticks. They span the whole period between Sasanian rule in the fourth century A.D. and Arab supremacy in the eighth century. ${ }^{42}$ Many of these documents are published by Sims-Williams (2000a and 2007a), and some of the other texts were published in separate articles in different magazines. ${ }^{43}$ The new Bactrian documents may be divided into five groups:

\section{Legal documents}

Twenty-six legal documents, including contracts and receipts dated from 342-781 A.D., and five documents of unknown date have been published. ${ }^{44}$ Most of the dated documents are legal contracts dealing with sales, leases, gifts, the manumission of a slave and the settlement of disputes. There is a marriage contract, which happens to be the earliest dated document in Bactrian. ${ }^{45}$

\footnotetext{
${ }^{33}$ Sims-Williams and Cribb 1996: 97.

${ }^{34}$ For this inscription, see Davary 1976, Sims-Williams and Cribb 1996: 95 (Appendix).

${ }^{35}$ It is dated early in the reign of Huvishka and resembles the almost contemporary Surkh Kotal monolith in vocabulary and phraseology (Sims-Williams 1989c: 346); for this inscription see Harmatta 1986: 131-146.

${ }^{36}$ These inscriptions include substantial fragments of a monumental inscription of the early Kushan period (SimsWilliams 1989c: 346).

${ }^{37}$ Sims-Williams 1989c: 346, and for Kara Tepe, see Humbach 1970: $43-50$ and Davary 1982: 40.

${ }^{38}$ Lee and Sims-Williams 2003: 159-174.

${ }^{39}$ For these manuscripts, see Humbach 1967a: 28-32.

${ }^{40}$ Sims-Williams 1989c: 346.

${ }^{41}$ For other possessors of the Bactrian documents, see Yoshida 2003: 156.

${ }^{42}$ Sims Williams 2002b: 12.

${ }^{43}$ For a list of these documents and magazines, see Yoshida 2003: 156.

${ }^{44}$ See Sims-Williams 2000a: 31-153.

${ }^{45}$ Sims-Williams 2002b: 12.
} 


\section{Lists and accounts}

Seven leather documents and 29 wooden slips or tallies have been published. ${ }^{46}$ These are generally undated, but one of them may present the date 379 A.D. ${ }^{47}$

\section{Letters}

Seventy letters are published in Bactrian Documents $\mathrm{II},{ }^{48}$ three of which show the dates of 430, 431, and 463 A.D. ${ }^{49}$

\section{Buddhist texts}

Only two Buddhist texts are published in Bactrian Documents II, which are undated. ${ }^{50}$ SimsWilliams published another Buddhist text belonging to the Schøyen. ${ }^{51}$

\section{Fragments of documents of uncertain type}

These three fragments of documents are published in Bactrian Documents II, ${ }^{52}$ which present only a few words. They are not complete documents, and many words are missing.

\subsection{Aims and assumptions}

In Section 1.3, I have presented a list of Bactrian sources and the names of people who have worked on this language. During recent years, many works have been published, especially articles. Many of these are corrections, reviews and notices of older studies. Most researchers have concentrated more on philology and etymology, and only a few grammatical points can be found in their works.

J. Harmatta gives some grammatical information in his articles such as "The great Bactrian inscription" (1964), "Minor Bactrian inscriptions" (1965) and "Late Bactrian inscriptions" (1969). For example, he discusses the function of conjunctions in the Surkh Kotal inscription.

G. Djelani Davary was the first person to write about the morphology of Bactrian. His dictionary of Bactrian includes a very short sketch of Bactrian morphology. ${ }^{53}$ This chapter consists of seven sections: Substantives, adjectives, pronouns, prepositions, conjunctions, preverbs, and verbal endings. In four pages, he introduces only a few examples of these categories and gives their etymologies.

In 1984, Gilbert Lazard, Franz Grenet and Charles de Lamberterie wrote "Notes bactriennes". This article is a new review of the Surkh Kotal inscription and includes a short section on nominal flection in Bactrian.

In 1985, Sims-Williams published "a note on Bactrian phonology"54 and, in_1989, the articles "Bactrian" in Compendium Linguarum Iranicarum and "Bactrian language" in Encyclopaedia Iranica III. In the last two articles, he describes some important grammatical

\footnotetext{
${ }^{46}$ See Sims-Williams 2000b: 10-12 and 2000a.

${ }^{47}$ See Sims-Williams 2002a: 226.

${ }^{48}$ See Sims-Williams 2007a: 53-167.

${ }^{49}$ See Sims-Williams 2002a: 226.

${ }^{50}$ See Sims-Williams 2007a: 174-177.

51 See Sims-Williams 2000, in Buddhist Manuscripts, ed. J. Braarvig, vol. 1, Oslo, pp. 275-77. In Internet: http://schoyencollection.com/greekdocscr.html.

${ }^{52}$ See Sims-Williams 2007a: 170-171.

${ }^{53}$ Davary 1982: 140-144.

${ }^{54}$ Sims-Williams 1985: 111-116.
} 
points of Bactrian. These articles provided the most detailed description of Bactrian and its morphology.

Sims-Williams has also published Bactrian Documents I (2000) and II (2007), which includes notes on the orthography and grammar of Bactrian. ${ }^{55}$ The glossary of these books also includes some grammatical points.

Other articles of Sims-Williams also contain information on Bactrian grammar.

In 2003, Tremblay investigated the function of the past participle with the copula in his article "La résurrection du Bactrien".

In the same year, Yoshida wrote a review of Sims-Williams' Bactrian Documents I and mentions some grammatical points. In "The great Surkh Kotal inscription", he reviewed the old readings and interpretations of this inscription and also briefly discussed several grammatical features.

The most recent works on Bactrian grammar are two articles by Sims-Williams, "Differential object marking in Bactrian", 56 and "Remarks on the phonology of the Manichaean Bactrian fragment (M 1224)"; 57 and three articles by Gholami on ergativity, ${ }^{58}$ demonstrative determiners and pronouns, ${ }^{59}$ and definite articles. ${ }^{60}$

As the above information shows, no study has been specifically devoted to Bactrian grammar and especially to its syntax. The only article on the subject of syntax was authored by Sims-Williams in 1973. In this short article, he analyses three examples of syntactic features of the Nokonzok inscription.

It was mainly for this reason that I decided to work on some important grammatical points in Bactrian. I selected a limited set of topics which were relatively unknown or which could show the unique character of this language. In this study, I aim to investigate various phonological, morphological, and syntactical features in Bactrian.

The text corpus used for this investigation is comprised of the texts edited by Sims-Williams as Bactrian Documents (henceforth abbreviated as $B D$ ) I (legal and economic documents) and $B D$ II (letters), the Rabatak inscription edited by Sims-Williams 2004 (2008), and the Kanishka inscription of Surkh Kotal (Lazard, Grenet and de Lamberterie 1984). The data for the linguistic investigation come from a selection of published articles, books and Internet sites. Details on these sources are provided in the footnotes and in the list of references.

This study includes the following parts: After Chapter One, that is, the introduction, in Chapter Two, "Historical phonology of Bactrian", I discuss the historical phonology of Bactrian, that is, the development of Old Iranian consonants and vowels in the Bactrian language.

In Chapter Three, I focus on noun phrases. The major aim of this chapter is to investigate the syntactical position of different kinds of nouns and their relationship in a sentence. The other topic to be addressed in this chapter is that of nominal sentences.

In Chapter Four, the different types of pronouns are discussed. The focus here is on their syntactical properties.

\footnotetext{
${ }^{55}$ Sims-Williams 2007a: 38-49.

${ }^{56}$ Sims-Williams 2011a: 23-38.

${ }^{57}$ Sims-Williams 2011b: 244-251

${ }^{58}$ Gholami 2009b: 132-141

${ }^{59}$ Gholami 2009a: 19-26

${ }^{60}$ Gholami 2011: 11-22.
} 
In Chapter Five, the function and syntactical position of prepositions and postpositions are discussed. In Chapter Six, adverbs are described in terms of their formation. I also focus on the proximate and remote deixis adverbs as well as their different syntactic positions.

The main aim of Chapter Seven is to introduce the various kinds of conjunctions and their functions in Bactrian.

In Chapter Eight, the previously unresearched aspects of the Bactrian verb are discussed. This chapter contains discussion of the syntactical position of the verb and its agreement with subject, and also of the passive and ergative constructions in Bactrian. The last part of this chapter treats the auxiliary verb.

In Chapter Nine, I examine word order in clauses with transitive or intransitive verbs, and also provide an investigation of double object constructions. Finally in Chapter Ten, I present a study of the different types of compounds in Bactrian. I describe first the grammatical features of compound elements, and then I describe their semantic relationship to each other.

\section{Chapter Two: Historical Phonology OF BACTRIAN ${ }^{61}$}

The purpose of this chapter is to update the research on the historical phonology of Bactrian according to the new findings of Bactrian materials, which were published 2000 and 2007 by Sims-Williams. He described Bactrian phonology in two articles, ${ }^{62}$ with his investigation based on the materials which had come to light up to that time. A question that arises here is whether the new findings will cause revision of the results of the older studies.

For this purpose, the development of the Proto Indo-Iranian phonemes ${ }^{63}$ to Bactrian will first be discussed in detail. As Bactrian is a transitional Iranian language, it will be also important to identify the Eastern and Western phonological characteristics in this language.

The study of phonology of Bactrian is faced with several problems. As this language is written in a variety of the Greek script, it is sometimes difficult to determine the exact characteristics of orthographic symbols, especially in the case of the long vowels and the consonants $\sigma$ and $\zeta$. In this respect, an unique Bactrian text in Manichean script could be very helpful. ${ }^{64}$ In many cases we observe more than one unexpected outcome of an Old Iranian consonant or vowel in Bactrian. This may introduce either a loanword or an archaism. It is not really clear whether we have more than one Bactrian dialect. Some material also show a different variety from what we regularly find.

The first part of this chapter focuses on simple consonants and then on consonant clusters. The second part focuses on the vowel system as well as the combination of vowels and consonants, and it also outlines the special phonological characteristics of Bactrian.

\subsection{Consonants}

\subsection{Simple Consonants}

In this section, the development of PIr. simple consonants in different positions is analysed.

\footnotetext{
${ }^{61}$ I would like to take this opportunity to express my special gratitude to Agnes Korn for her very helpful comments and suggestions on the present chapter.

${ }^{62}$ Cf. Sims-Williams 1989a and 1989b.

${ }^{63}$ The analysis is accompanied by an assessment of the etymology of the Bactrian forms mentioned in SimsWilliams's Lexicon in the glossary of $B D I I$.

${ }^{64}$ This fragment is published by Sims-Williams. See Sims-Williams 2009: 245-268, for the phonology of this fragment see Sims-Williams 2011: 244-251.
} 


\subsubsection{PIr. plosives}

\subsubsection{PIr. *p, *t, *k}

Table 2. Proto-Iranian plosives

\begin{tabular}{|c|c|c|c|c|}
\hline \multirow[t]{2}{*}{ PIr. } & \multicolumn{2}{|c|}{ Initial position } & \multicolumn{2}{|l|}{ Internal position } \\
\hline & Bac. script & Phonetic value & Bac. script & Phonetic value \\
\hline $\mathrm{p}$ & $\pi-$ & p- & $\begin{array}{l}-\beta-,-\beta \beta-\text { (only in } \\
\alpha \beta \beta o)\end{array}$ & $-\mathrm{v}-,-\mathrm{b}-$ \\
\hline $\mathrm{t}$ & $\tau-$ & t- & $-\delta-,-\delta \delta-$ & -d-, -d- \\
\hline $\mathrm{k}$ & $\kappa-$ & k- & $-\gamma-$ & $-\mathrm{g}-$ \\
\hline č & $\sigma-$ & ts- & $-\sigma-$ & -ts- \\
\hline $\mathrm{b}$ & $\beta-$ & $\mathrm{v}$ & $-\beta-$ & $-\mathrm{v-}$ \\
\hline d & $\lambda-$ & $1-$ & $-\lambda-$ & $-1-$ \\
\hline $\mathrm{g}$ & $\gamma-$ & & $-\gamma-$ & $-\gamma-$ \\
\hline j & $\zeta-$ & z-, dz- (?), ž- (?) & $-\zeta-$ & -z-, - - \\
\hline
\end{tabular}

The development of PIr. plosives is not uniform in Bactrian. In general, the word-initial plosives *\# p, *t, *k seem to have been preserved without any change. The inter-vocalic *-p-,

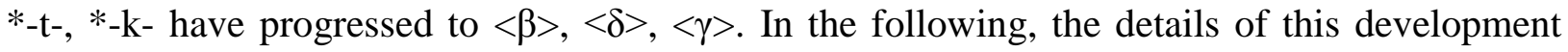
and some of the special characteristics are presented.

$* p$

PIr. *\#p is preserved in Bactrian:

$* \# p>p$

Examples: $\pi \alpha v \zeta_{0}$ "five" < *panča-, $\pi \alpha \rho \alpha \sigma \alpha \rho \lambda_{0}$ "last year" < *parā-sardV-, $\pi \alpha \lambda_{0}$ "family" <

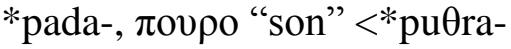

In general, the internal $*_{-} p$ - between two vowels is changed to $\langle\beta\rangle$ :

$*_{-} p->v$ and $b$

It is not clear exactly in which position the letter $\beta$ represents the sound $b$ and in which position it represents $v$. The Bactrian fragment in Manichean script has two different letters $b$ and $\beta$, representing the sounds $[\mathrm{b}]$ and $[\mathrm{v}]$, respectively. In this fragment, only three words possess $b$. These are b'gyg "65 "having a share" (also b'gy(g) ynd), bwt "Buddha" and źmbwd'ng "worldly, earthly". It seems that in Manichaen Bactrian, only $\beta$ is used, and it represents $v$, whereas $b$ can be seen only in loanwords. The Manichaen form (y)' $\beta$ "water" shows, at least at this stage of the language, that OIr. postvocalic *p developed to [v]. It is also important to know how Graeco-Bactrian $\langle\beta\rangle$ should be pronounced. The question is whether it always stands for [v], or whether in certain cases it stands for [b]. The double $-\beta \beta$ - in the Graeco-Bactrian form $\alpha \beta \beta o$ "water" $<* \bar{a}$ p- may represent $[\mathrm{b}]$, which distinguishes this word from the preposition $\alpha \beta o$ [av] "to". As $\delta \delta$ represents [d], and not fricative [đ], $-\beta \beta$ - may represent [b], and not fricative [v]. Unfortunately, there is no other example of the occurrence of $-\beta \beta-$.

In some compounds in which the second element begins with ${ }^{*} p,{ }^{*} p$ seems to be preserved,

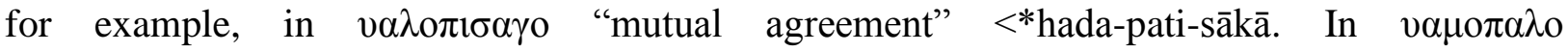
"accordingly"(?) <*hama-pada-, *p is preserved, but in another variant of this word, namely,

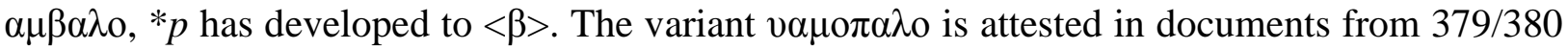
A.D., whereas $\alpha \mu \beta \alpha \lambda o$ occurs in documents from 417/418 A.D.. The question is whether the variant $v \alpha \mu \mathrm{o} \alpha \alpha \lambda_{\mathrm{o}}$ is older and whether ${ }^{*} \mathrm{p}$ is changed to $\langle\beta\rangle$, namely [v], in such a context in

\footnotetext{
${ }^{65}$ According to Sims-Williams "the writing with $b$ - and $g$ - for expected $\beta$ and $\gamma$ suggests a loanword from Western Iranian..., possibly from Parthian.” cf. Sims-Williams 2009: 258.
} 
later texts. Here, we look at other examples in order to find an answer to our question. In

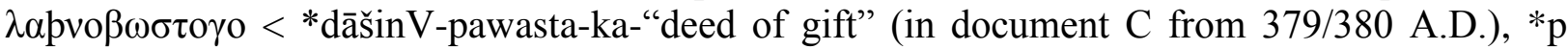
has developed to [v]. In $\lambda \alpha p v o \pi \alpha \lambda \alpha p v o \beta \omega \sigma \tau \imath \gamma_{0}<*$ dāšinV-pati-dāšin (in document $\mathrm{W}$ from 747 A.D.), the first $* \mathrm{p}$ is preserved. The document $\mathrm{W}$ represents the preservation of two varieties, namely, the preservation and changing of *p.

$* t$

$* \# t>t$

Initial $* t$ is preserved in Bactrian:

Examples: $\tau \alpha$ "then" $<*$ tā, $\tau \alpha \beta$ - "to impress" $<*$ tāpa-.

$*_{t}>d, d$

Post vocalic $* t$ has developed to $\langle\delta \delta\rangle$ and $\langle\delta\rangle$. The question is whether $\langle\delta \delta\rangle$ actually represents a double consonant or if it is here an attempt to distinguish [d] and $[\delta]$.

The letter $\delta$ is always doubled before palatal vowels $\langle\eta\rangle$ and $\langle 1\rangle$ in the later texts, ${ }^{66}$ for

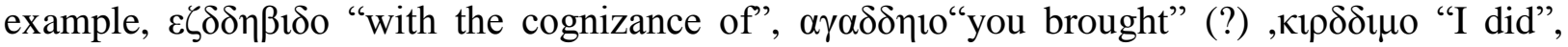
$\pi \_\delta \delta 1$ "in this". According to Sims-Williams, the writing $\delta \delta$ indicates [dd] resulting from the assimilation of [dy] from palatalized [d]. He mentions the sequence of forms $\tau \alpha \delta \eta 1 \alpha / \tau \alpha \delta \eta 10$ [tādē(i)] (Rabatak, Surkh Kotal, etc.) > $\tau \alpha \delta$ oını [tādyē(i)] (in unpublished documents, including two dated in the years 157 and 195=389 and 427 A.D.), $>\tau \alpha \delta \delta \eta 10$ [täddē(i)] (in documents from years $446-527=678-759$ A.D.). ${ }^{67}$ Regarding the above examples and information, we can conclude that $\langle\delta \delta>$ represents [d], and $\langle\delta>$ shows fricative [đ], which we expect in Eastern Middle Iranian Languages.

In the following examples, post vocalic $* \mathrm{t}$ has developed to $<\delta>$ namely [đ]:

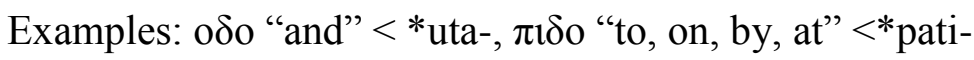

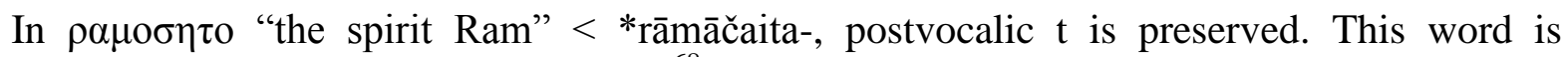
probably a loanword from Sogdian r'mcytk ${ }^{68}$.

In $\alpha \pi 1 \sigma o \delta \alpha \rho o<*$ pasča-tara-, *t has developed to [đ], but in another variant of this word, namely, $\alpha \pi \imath \sigma \tau \alpha \rho o$ is preserved. $\alpha \pi \imath \sigma \tau \alpha \rho o$ occurs two times, once in xp (uncertain date) and twice in Q (c. 671 A.D.). $\alpha \pi 1 \sigma o \delta \alpha \rho o$ is attested in documents cc, ci (c. 379/380 A:D.) and xe (uncertain date). It is difficult to believe that [d] is older than [t]. This is only one occurrence of $\alpha \pi \imath \tau \alpha \rho \rho$ in newer documents, and we can not conclude with certainty that it is an old variant. It is possible that both of these variants were known around 671 A.D., even though the variant with $[t]$ must be the older one.

The following examples with initial $\delta$ - seem to be native Bactrian words:

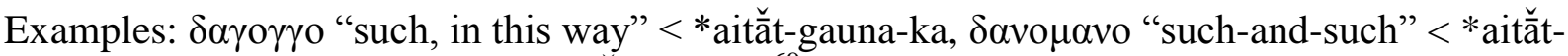

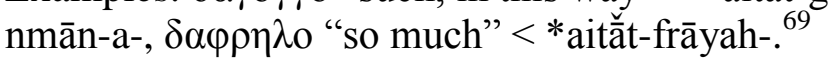

$* \boldsymbol{k}$

$*_{k}$ in initial position is preserved:

\footnotetext{
${ }^{66}$ Sims-Williams 2007a: 38

${ }^{67}$ Sims-Williams 1998a: 197

${ }^{68}$ Suggested to me by Sims-Williams.

${ }^{69}$ In these examples, *ai- has disappeared. The shortening or ultimate disappearance of Old Iranian long vowels or diphthongs in certain circumstances is one of the Eastern Middle Iranian charachteristics, for example, *aizma > Sogdian zm-, Chwaresmian (')zm. Cf. Sims-Williams 1989b: 168.
} 
*\# $k->k$

Examples: $\kappa \alpha \delta \alpha \mu$ o "whatever" < *katāma-, $\kappa \alpha \delta \gamma_{0}$ "house" < *kataka-, $\kappa \alpha \lambda \delta$ o "when, if" < *kadā $+-\delta o$

$*_{-}->g^{70}$

In the postvocalic position, $* k$ is changed to $\langle\gamma\rangle$. The question is whether $\langle\gamma\rangle$ represents $[\mathrm{g}]$ or $[\gamma]$, or both of them. In the Manichaen Bactrian fragment, there are separate letters for $[\mathrm{g}]$ or $[\gamma]$, but they are very similar. According to Sims-Williams, "Old Iranian postvocalic *k had developed only as far as the plosive [g], as exemplified by $\beta \mathrm{rg}$ and many other words with suffixal *-k-." ${ }^{, 71}$ Other examples of this development are $1 \omega \gamma \mathrm{\gamma}$ (Manich. ywg) "one, a, a certain"

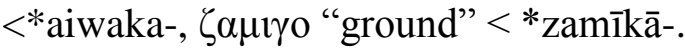

There are also some examples of the preservation of $* \mathrm{k}$ under special conditions. It seems that $* \mathrm{k}$ in the initial position of the second element in a compound could be preserved, and in this environment, it functions as an initial *k:

Examples: $v \alpha \kappa \alpha v \delta$ o "to dig" < *ni-kanta-, $\pi 1 \delta$ เ $\alpha \rho \delta$ o "retention" <*pati-karda-

\subsubsection{PIr. *b, *d, *g}

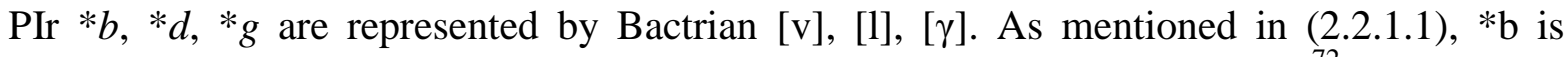
preserved only in loanwords and after nasals in the Manichaen Bactrian fragment. ${ }^{72}$

$* b\rangle\langle\beta\rangle=[v]$

Examples: $\alpha \beta \alpha \rho$ - "to bring" < *ābara-, $\alpha \sigma \beta \alpha \rho o$ "horseman" < *aspa-bāra-, $\beta \alpha \gamma_{0}$ "god" < *baga-

The $* d$ is changed to $l::^{73}$

$* d>l$

Examples: $\lambda \alpha \rho \zeta \mathrm{o}$ "subject to restrictions" $<*$ dărzV-, $\lambda \alpha v_{-}$"to give" $<*$ da $\theta \mathrm{a}-, \lambda 1 \sigma \tau \mathrm{o}$ "hand" $<$ *dasta-, $* \alpha \lambda \mathrm{o}, \alpha \lambda \alpha-$ "with" <* hada-, $\alpha \rho \lambda \mathrm{o}$ "side" <*arda-, $\kappa \alpha \rho \lambda-$ "to detain" <*karda-, $\mu \alpha \lambda \alpha \chi 0$ "locust" <*madaxa, $\mu$ o $\lambda_{0}$ "wine" $<*$ madu-

The PIr. ${ }^{*} \mathrm{~d}$ is only preserved in loanwords in the form of $\langle\delta\rangle$ and $\langle\delta \delta\rangle$, for example,

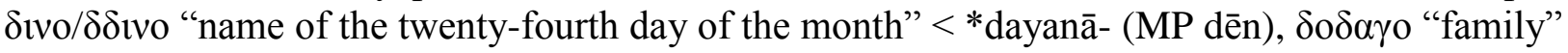
(MP dūdag), and in the form $\langle\Delta\rangle$ (in documents from the seventh and eighth centuries), for example, in $\Delta \rho \alpha \chi \mu \mathrm{o}^{74}$ "dirham" (Gk. $\left.\delta \rho \alpha \chi \mu \eta\right) .{ }^{75}$ The question is how $\delta, \delta \delta$ and $\Delta$ must be pronounced. According to Sims-Williams, in some cases, $\Delta$ seems to have the same function as $\delta \delta$. Possibly $\delta \delta$ and $\Delta$ indicate [d], and $\delta$ represents fricative [d] ${ }^{76}$ It is interesting to note that in some cases, all of these three variants are attested, for example, $\delta v \alpha \rho \rho / \delta \delta \imath v \alpha \rho o / \Delta v v \alpha \rho o$ "dinar". The issue to be addressed here then, is this: Why do we have three variants of "dinar" and what is the difference between them? As this form is a Greek loanword in Bactrian, we must look at the Greek language and the kind of $\langle\delta\rangle$. It seems that the plosive $d$ is changed to $d$ by the

\footnotetext{
${ }^{70}$ In the following examples, it is not clear whether the outcome is $g$ or $\gamma$ :

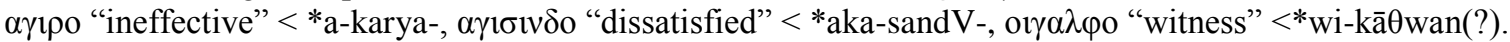
According to Tremblay 2003: $132-3$, the Bactrian form or $\gamma \alpha \lambda \varphi$ o is in origin an abstract *wi-kawya- $\theta$ wa- SimsWilliams 2007a: 246.

${ }^{71}$ Sims-Williams 2011: 246

${ }^{72}$ Cf. Sims-Williams 2011: 246

${ }^{73}$ According to Sims-Williams, $* d$ has developed via $* \delta$ to $l$ Sims-Williams 1989a: 233.

${ }^{74} \delta \delta \rho \alpha \chi \mu o$ is also attested.

${ }^{75}$ For the circumstances of $\Delta$, see Sims-Williams 2007a: 38-39.

${ }^{76}$ Sims-Williams 2007a: 39
} 
second century A.D. ${ }^{77}$ It means that a plosive is older than a fricative in a language like Greek. The first occurrence of $\delta$ ivapo (with a fricative d) appears by the fourth century in Bactrian

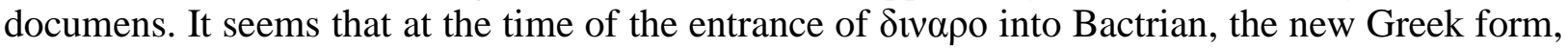
namely, with a fricative $\delta$, is accepted, and then within Bactrian, it developed to a plosive. We can observe that $\delta \delta$ iv $\alpha \rho$ (with a plosive d) occurs after 517 A.D., and $\Delta \delta$ iv $\alpha \rho o$ around 771 A.D.

$* g$ has developed to $\gamma$ :

$* g>\gamma^{78}$

Examples: $\alpha \gamma \alpha \delta$ o (past stem) "to come" < $* \bar{a}$-gata-, $\omega \gamma o \tau o$ (past stem) "to conceal”(?) (Manich.

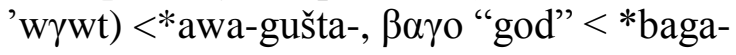

It must be added that $\langle\gamma \gamma\rangle$ represents [ng].

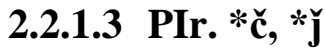

It seems that Bactrian, as other Eastern Middle Iranian languages, though with the exception of Sogdian, participates in the depalatalization of $* c ̌$ to $t s$ and $* j$ to $d z$.

$* \check{\mathbf{c}}$

*č is changed to $\langle\sigma\rangle$ in Bactrian. The Greek and Manichean script does not reflect the exact phonetic value of this consonant. We can only say that it is not a simple $s$, but it is not absolutely clear whether it is actually an affricate ts. It probably has two different phonological values, namely [ts] and [s]. When it derives from *č , it represents [ts] and if it derives from *s, it indicates [s]. The only exception is $\alpha \sigma 0$ "from", in Manichaen, 's. Even though this preposition derives from *hača, it is pronounced according to the Manichaen form as [as]. According to Sims-Williams, it was probably a proclitic and may attest a simplification of final [ts] to [s] in sandhi before certain consonants. ${ }^{79}$

$* \check{c}>t s$

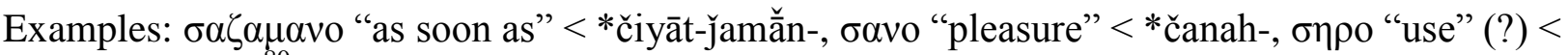
*čārya-, $(\alpha) \sigma \iota \delta o^{80 ~ " w h a t, ~ w h i c h " ~<* c ̌ i m ~}+-\delta o, \pi 1 \sigma o$ (Manichaen: pyc) "in the presence of". <*patīčā

The last example, namely, $\pi \iota \sigma o$, shows that [ts] may also occur after palatal vowels. ${ }^{81}$ *̌̃

According to Sims-Williams, the Manichaen script distinguishes between at least two, and perhaps three different sounds, namely, $\langle\mathrm{z}\rangle,\langle\mathrm{j}\rangle,{ }^{82}$ and $\langle\mathrm{j}\rangle,{ }^{83}$ which are all written with the letter $\langle\zeta\rangle$ in the Graeco-Bactrian script. It is impotant to know which of these would be the outcome of $*_{\mathrm{j}}$. In the Manichaen fragment, we have two outcomes, namely, $<\mathrm{j}>$ and $<\mathrm{j}>$ for $*_{\mathrm{j}}$, as shown in the following examples:

Examples: jynn'g "body" < j̄inā-kā-/jayanā-kā-, 'wjyd "to kill” <*awa-ǰata-

\footnotetext{
${ }^{77}$ Browning 1983: 26-27

${ }^{78}$ It is not clear where this letter represents $g$ and in which position it is used for $\gamma$. In the Manichaean fragment, it is also difficult to recognize these very similar letters, cf. Sims-Williams 2011: 244.

${ }^{79}$ Sims-Williams 2011: 247

${ }^{80}$ According to Sims-Williams, (ə) tsid, Sims-Williams 2011: 247.

${ }^{81}$ This is also mentioned by Sims-Williams 2011: 247

${ }^{82}$ Sims-Williams transliterated this sound as $z^{\prime}$ in Sims-Williams 2009.

${ }^{83}$ For further discussion on these three sounds, see Sims-Williams 2011: 247-249.
} 
It is not clear whether it is really a difference between $<\mathrm{j}>$ and $<\mathrm{j}\rangle$. According to SimsWilliams, $<\mathrm{j}>$ represents [dz] (and [dz]?), and $<\mathrm{j}>$ may show [3] (and [dz]?).

\subsubsection{PIr. fricatives and affricates}

\subsubsection{PIr. *f, * $\boldsymbol{\theta}, *_{\mathbf{x}}$}

Table 3. Proto-Iranian fricatives and affricates

\begin{tabular}{|l|l|l|}
\hline \multirow{2}{*}{ PIr. } & \multicolumn{2}{|l|}{ Both initial and internal position } \\
\cline { 2 - 3 } & Bac. script & Phonetic value \\
\hline $\mathrm{f}$ & $\varphi$ & $\mathrm{f}$ \\
\hline$\theta$ & $\mathrm{v}$ & $\mathrm{h}$ \\
\hline $\mathrm{x}$ & $\chi$ & $\mathrm{x}$ \\
\hline $\mathrm{s}$ & $\sigma$ & $\mathrm{s}$, ś (after a palatal vowel) \\
\hline $\mathrm{z}$ & $\zeta$ & $\mathrm{z}$ \\
\hline$\breve{\mathrm{s}}$ & $\mathrm{b}$ & $\breve{s}$ \\
\hline $\mathrm{h}$ & $\mathrm{v}$ & $\mathrm{h}$ \\
\hline
\end{tabular}

PIr. ${ }^{*} f$ and $* x$ are preserved in Bactrian, and $* \theta$ has developed to $h$ :

$$
*_{f}>f
$$

Examples: $\varphi \alpha \rho \delta \alpha \rho$ " "more" <*faru-tara-, $\varphi \alpha \rho$ o "glory" <*farnah-, $\pi \alpha \delta o \varphi \rho \alpha \sigma o$ "punishment" <

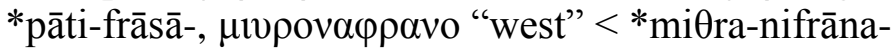

$* \theta>h^{84}$

Examples: v $\alpha \gamma \gamma o$ "load" < * $\theta$ anga-, $\alpha v \alpha v \alpha \gamma \delta o$ "without deduction" (?) <*an-ā- $\theta$ axta- ${ }^{85}$

In one instance, $\theta$ is preserved in $1 \theta \alpha o$ "thus" $<* i \theta \bar{a}$. This word could be a loanword or it may be an archaism.

$* x>x$

Examples: $\chi \alpha \lambda$ - "to prick" <*xada-, $\chi \alpha v o$ "house" <*xānā-, $\chi \alpha \rho o$ "donkey" <*xara-, $\alpha \chi \alpha \sigma_{-}$" "to

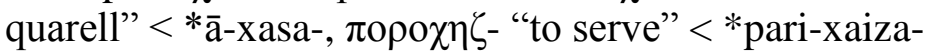

\subsubsection{PIr. * ${ }_{\mathrm{s}},{ }^{*} \mathrm{Z}$}

$*_{\mathbf{S}}$

As mentioned above, $\sigma$ has different phonological values, for example, it may represent [ts], when it derives from Old Iranian *č. Another function of $\sigma$ can be a development of $*$ s. In Manichean script, there are two different forms as the output of *s, that is, $\mathrm{s}$ and ś. $*_{S}>s$

Examples: $\sigma \alpha \beta$ o $\lambda_{0}$ "jar" < *sapauda-, $\sigma \alpha \gamma \delta$ o "level" < *sātaka-, $\sigma \alpha \delta o$ "hundred" < *sata-,

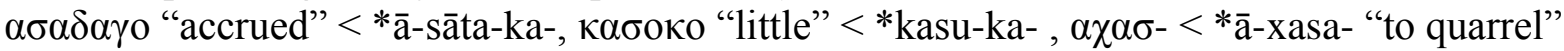
$*_{S}>\dot{s}$

According to Sims-Williams, we find ś after a palatal vowel , e.g., hßyśznng "of many

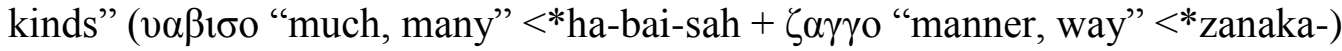

\footnotetext{
${ }^{84}$ The development of $* \theta$ to $h$ in Bactrian, is also mentioned by Wendtland 2009:176-177.

${ }^{85}$ In one instance, $\theta$ is changed to $x$ in the consonant cluster in $\zeta \alpha \chi \mu$ o "wound" $<*_{\text {ja }}(\mathrm{n}) \theta \mathrm{ma}(\mathrm{n})-$. This word may be a loanword.
} 
$*_{\mathbf{Z}}$

Without any doubt, we can claim that $*$ z has developed only to z: $*_{z}>z$

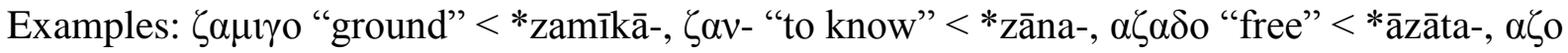
"I" <*azam

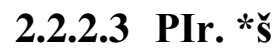

It seems that there are two different outcomes for $* \check{s}$ in Bactrian, namely, $\check{s}$ and $h$ :

$*_{-} \check{S}->\check{S}$

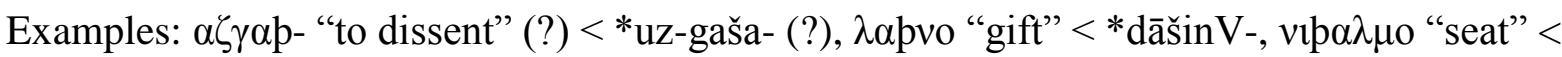
*ni-šadman-, $\pi \alpha \chi$ puo "relation by marriage" < pagVšaka-, $\varphi \rho \imath \eta p$ "to seduce" (?) <*fraxrāšaya-, $\chi \alpha$ pıro "clothing" < *xāša-ka-

$*_{-\check{S}-}>h$

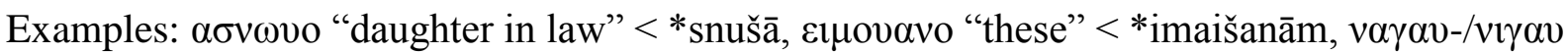
"to hear" < *ni-gauša-, vovapto "to settle" <*ni-šăšta-

\subsubsection{PIr. *h}

Generally $* h$ is preserved in both initial and internal position:

$* h>h$

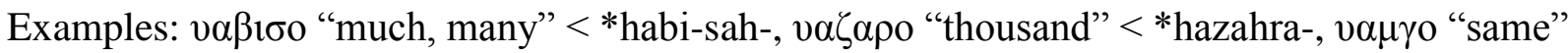

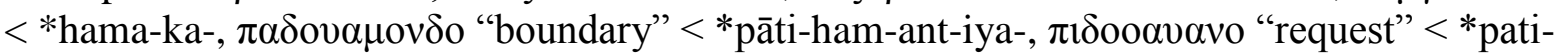
wahana-

It seems that $* h$ could have disappeared in some cases. In the case of the word "month", we observe both developments, that is, it can be preserved, such as in $\mu \alpha v o$ "month" < māhV-, or it can disappear, as in $\mu \alpha_{0}$ "month" < māhV-. A word-initial *h is lost very often, for example, $* \alpha \lambda o, \alpha \lambda \alpha-$ "with" <*hada-, $\alpha \lambda \omega \gamma \delta$ o "fully privileged" $<*$ hada-uxta- "possessing (the right of) speech", $\alpha \gamma \gamma \alpha \rho \gamma_{0}$ "property" < *ham-kāraka-, $\alpha \gamma \gamma \iota \tau$ "to receive" < *ham-kašta-, $\alpha \mu \beta \alpha \gamma \delta$ o "to give away" < *ham-baxta-

There are also other examples of the omission of h. It seems that *h can have disappeared before a long vowel:

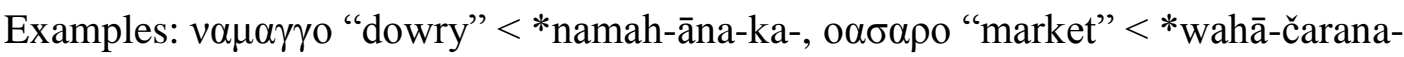

\subsubsection{PIr. Sonorants}

Table 4. Proto Iranian Sonorants

\begin{tabular}{|l|l|l|}
\hline \multirow{2}{*}{ PIr. } & \multicolumn{2}{|l|}{ Both initial and internal position } \\
\cline { 2 - 3 } & Bac. script & Phonetic value \\
\hline $\mathrm{m}$ & $\mu$ & $\mathrm{m}$ \\
\hline $\mathrm{n}$ & $\mathrm{v}$ & $\mathrm{n}$ \\
\hline $\mathrm{r}$ & $\rho$ & $\mathrm{r}$ \\
\hline $\mathrm{w}$ & $\mathrm{o}$ & $\mathrm{W}$ \\
\hline $\mathrm{y}$ & $\mathrm{l}$ & $\mathrm{y}$ \\
\hline
\end{tabular}

\subsubsection{PIr. *m, *n}

The Olr. nasals are preserved in Bactrian. 
$*_{m}>m$

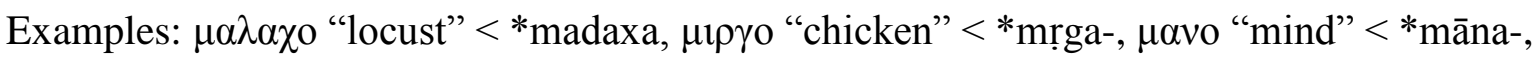

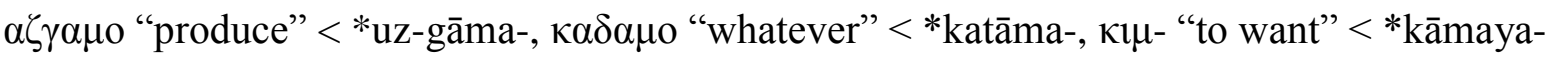
$*_{-} n->n$

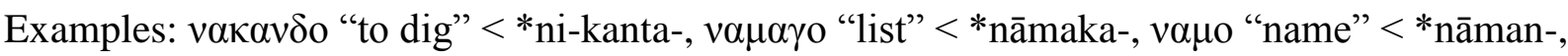

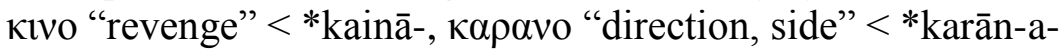

\subsubsection{PIr.*r}

$*_{r}$ is preserved in Bactrian:

$*_{-} r->-r-$

Examples: $\rho \alpha$ o "plain" < *rāgā-, $\rho \alpha \zeta-$ "to call" < *rāza-, $\rho \omega \sigma o$ "day" < *raučah-, $\alpha \beta \alpha \rho-$ "to bring" <*ā-bara-, $\alpha v \delta \alpha \rho o$ "other" $<*$ antara-, $\alpha \sigma \beta \alpha \rho o$ "horseman" $<*$ aspa-bāra-

\subsubsection{PIr. * ${ }^{*}$}

Bactrian preserves the ${ }^{*} \mathrm{w}$ in both initial and internal positions:

$*_{w}>w$

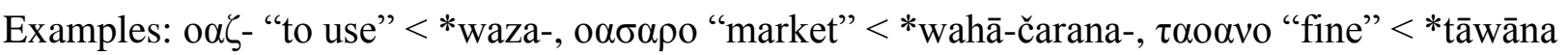

\subsubsection{PIr. *y}

$* \mathbf{y}$

$*^{*} \mathrm{y}$ is consistently preserved in Bactrian:

$* y>y$

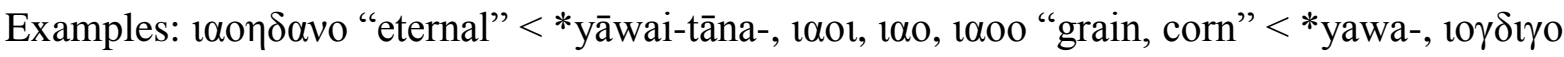
"pair" < *yuxta-ka-, tovo "apprentice" <*yuwan-a- or yūn-a-

\subsubsection{Summary of the system of consonants}

According to the above discussion and examples, we can summarize the consonant system in Bactrian as follows:

Table 5. The basic consonantal system

\begin{tabular}{|c|c|c|c|c|c|c|}
\hline & & $\begin{array}{l}\text { bilabial/ } \\
\text { labiodental }\end{array}$ & dental & alveolar & palatal & $\begin{array}{l}\text { velar/ } \\
\text { glottal }\end{array}$ \\
\hline \multirow[t]{2}{*}{ plosive/affricate } & voiceless & $\mathrm{p}$ & $\mathrm{t}$ & ts & č & $\mathrm{k}$ \\
\hline & voiced & $\mathrm{b}$ & d & $\mathrm{dz}$ & ј & $\mathrm{g}$ \\
\hline \multirow[t]{2}{*}{ fricative } & voiceless & $\mathrm{f}$ & $\theta$ & $\mathrm{s}$ & š & $\mathrm{x}$ \\
\hline & voiced & $\beta$ & $\delta$ & $\mathrm{z}$ & Ž & $\gamma$ \\
\hline nasal & & $\mathrm{m}$ & & $\mathrm{n}$ & & $\eta$ \\
\hline glide & & w & 1 & $\mathrm{r}$ & $\mathrm{y}$ & $\mathrm{h}$ \\
\hline
\end{tabular}




\subsection{Consonant clusters}

Table 6. Consonant clusters

\begin{tabular}{|c|c|c|c|}
\hline PIr. & Bac. script & Phonetic value & Details in Chapter \\
\hline \multicolumn{4}{|c|}{ Plosive + Plosive } \\
\hline gd & $\gamma \delta$ & $\gamma \mathrm{d}$ & 2.3 .1 .1 \\
\hline \multicolumn{4}{|c|}{ Plosive + Africate } \\
\hline tč & $\sigma$ and once $\zeta \zeta$ & ts & 2.3 .1 .2 \\
\hline \multicolumn{4}{|c|}{ Plosive + Nasal } \\
\hline gn & $\gamma \nu$ & $\gamma \mathrm{n}$ & 2.3.1.3 \\
\hline \multicolumn{4}{|c|}{ Plosive + Approximant } \\
\hline dy & $\lambda$ & 1 & 2.3 .1 .4 \\
\hline \multicolumn{4}{|c|}{ Plosive + Trill } \\
\hline $\mathrm{dr}$ & $\lambda \rho, \delta \rho$ & $\mathrm{lr}, \mathrm{dr}$ & 2.3 .1 .5 \\
\hline \multicolumn{4}{|c|}{ Nasal + Plosive } \\
\hline nt & $v \delta$ & nd & 2.3.2.1 \\
\hline ntč & $\mathrm{n} \zeta$ & $\mathrm{nz}(?)$ & 2.3.2.1 \\
\hline nd & $v \delta$ & nd & 2.3.2.1 \\
\hline $\mathrm{nk}$ & $\gamma \gamma$ & $\eta \mathrm{g}$ & 2.3.2.1 \\
\hline $\mathrm{mb}$ & $\mu \beta$ & $\mathrm{mv}$ & 2.3.2.1 \\
\hline $\mathrm{mk}$ & $\gamma \gamma$ & $\eta \mathrm{g}$ & 2.3.2.1 \\
\hline \multicolumn{4}{|c|}{ Nasal + fricative } \\
\hline $\mathrm{n} \theta$ & $\mathrm{v}$ & $\mathrm{h}$ & 2.3 .2 .2 \\
\hline $\mathrm{ns}$ & $\sigma$ & $\mathrm{s}(?)$ & 2.3.2.2 \\
\hline \multicolumn{4}{|c|}{ Nasal + Africates } \\
\hline$\overline{n c ̌}$ & $v \zeta$ & $\mathrm{ndz}$ & 2.3.2.3 \\
\hline nŭ & $v \zeta$ & $\mathrm{ndz}$ & 2.3.2.3 \\
\hline
\end{tabular}


Continuation of Table 6. Consonant clusters

\begin{tabular}{|c|c|c|c|}
\hline PIr. & Bac. script & Phonetic value & Details in Chapter \\
\hline \multicolumn{4}{|c|}{ Fricative + Plosives } \\
\hline $\mathrm{ft}$ & $\beta \delta$ & $\mathrm{vd}$ & 2.3 .3 .1 \\
\hline $\mathrm{xt}$ & $\gamma \delta$ & $\gamma \mathrm{d}$ & 2.3.3.1 \\
\hline st & $\sigma \tau$ & st & 2.3.3.1 \\
\hline $\mathrm{sp}$ & $\sigma \pi$ & $\mathrm{sp}$ & 2.3.3.1 \\
\hline št & $\mathrm{p} \tau, \tau$ & št, t & 2.3.3.1 \\
\hline $\mathrm{zd}$ & $\zeta \delta, \zeta$ & $\mathrm{zd}, \mathrm{z}$ & 2.3.3.1 \\
\hline šk & рк & šk & 2.3.3.1 \\
\hline sk & $\sigma \kappa$ & sk & 2.3.3.1 \\
\hline \multicolumn{4}{|c|}{ Fricative + Fricative } \\
\hline $\mathrm{xs}$ & $\chi \sigma$ & $\mathrm{xs}$ & 2.3 .3 .2 \\
\hline$\#$ \#乩 & $\varphi, \chi$ & $f, x$ & 2.3.3.2 \\
\hline -f̌s- & $\varphi p, \varphi$ & $\tilde{\mathrm{fs}}, \mathrm{f}$ & 2.3.3.2 \\
\hline$\#$ \#x̌s & $\mathrm{p}, \chi$ & $\check{\mathrm{s}}, \mathrm{x}$ & 2.3.3.2 \\
\hline -X̌s- & $\chi \mathrm{p}, \chi$ & x̌s, $\mathrm{X}$ & 2.3.3.2 \\
\hline$\# x$ šn & $\chi v$ & $\mathrm{xn}$ & 2.3.3.2 \\
\hline xšt & $\chi \tau, \chi p$ & $\mathrm{xt}, \mathrm{xš}$ & 2.3.3.2 \\
\hline štk & $\mathrm{p \kappa}$ & šk & 2.3.3.2 \\
\hline \multicolumn{4}{|c|}{ Fricative + Africative } \\
\hline sč & $\sigma$ & is & 2.3 .3 .3 \\
\hline \multicolumn{4}{|c|}{ Fricative + Nasal } \\
\hline $\mathrm{xm}$ & $\chi \mu$ & $\mathrm{xm}$ & 2.3 .3 .4 \\
\hline šm & $v \mu, \mu$ & $\mathrm{hm}, \mathrm{m}$ & 2.3.3.4 \\
\hline $\mathrm{hm}$ & $v \mu$ & $\mathrm{hm}$ & 2.3.3.4 \\
\hline sn & $\sigma \nu$ & $\mathrm{sn}$ & 2.3.3.4 \\
\hline šn & pv & šn & 2.3.3.4 \\
\hline zn & $\zeta v$ & $\mathrm{zn}$ & 2.3.3.4 \\
\hline \multicolumn{4}{|c|}{ Fricative + Trill } \\
\hline fr & $\varphi \rho$ & fr & 2.3 .3 .5 \\
\hline fra & $\varphi \rho о$ & $\operatorname{fr}(\partial)$ & 2.3.3.5 \\
\hline \#sr & $\mathrm{p}$ & $\breve{s}$ & 2.3.3.5 \\
\hline -str- & $\mathrm{p}$ & $\breve{s}$ & 2.3.3.5 \\
\hline$\theta \mathrm{r}$ & $v \rho, \rho$ & $\mathrm{hr}, \mathrm{r}$ & 2.3.3.5 \\
\hline $\mathrm{hr}$ & $\rho$ & $\mathrm{r}$ & 2.3.3.5 \\
\hline $\mathrm{xr}$ & $\chi \rho$ & $\mathrm{xr}$ & 2.3.3.5 \\
\hline \multicolumn{4}{|c|}{ Fricative + Approximant } \\
\hline$\theta \mathrm{w}$ & $\lambda \varphi$ & lf & 2.3.3.6 \\
\hline$\#$ dw & $\lambda \beta, \beta$ & $1 \beta, \beta$ & 2.3.3.6 \\
\hline $\mathrm{xw}$ & $\chi_{0}$ & хо & 2.3.3.6 \\
\hline hw & $\chi 0$ & xo & 2.3.3.6 \\
\hline$\theta \mathrm{y}$ & 1 & $\mathrm{i}$ & 2.3.3.6 \\
\hline zy & $\zeta$ & $\mathrm{z}$ & 2.3.3.6 \\
\hline sy\# & $\sigma$ & s & 2.3.3.6 \\
\hline \multicolumn{4}{|c|}{ Africates + Approximant } \\
\hline čy & $\mathrm{p}, \sigma$ & $\breve{s}, \mathrm{~s}$ & 2.3 .4 .1 \\
\hline јуy & $\zeta$ & $\check{z}(?)$ & 2.3.4.1 \\
\hline
\end{tabular}


Continuation of Table 6. Consonant clusters

\begin{tabular}{|c|c|c|c|}
\hline PIr. & Bac. script & Phonetic value & Details in Chapter \\
\hline \multicolumn{4}{|c|}{ Trill + Plosives } \\
\hline $\mathrm{rt}$ & $\rho \delta$ & $\mathrm{rd}$ & 2.3 .5 .1 \\
\hline $\mathrm{rd}$ & $\rho \delta$, once $\rho \lambda$ & $\mathrm{rd}$, once $\mathrm{rl}$ & 2.3.5.1 \\
\hline \multicolumn{4}{|c|}{ Trill + Fricative } \\
\hline rš & $\mathrm{p}$ & $\check{s}$ & 2.3 .5 .2 \\
\hline rž & $\zeta$ & $\mathrm{z}$ & 2.3.5.2 \\
\hline $\mathrm{rz}$ & $\rho \zeta$ & $\mathrm{rz}$ & 2.3.5.2 \\
\hline rs & $\rho \sigma$ & rs & 2.3.5.2 \\
\hline rst & $\mathrm{p} \tau$ & št & 2.3.5.2 \\
\hline \multicolumn{4}{|c|}{ Trill + Nasal } \\
\hline $\mathrm{rn}$ & $\rho$ & $\mathrm{r}$ & 2.3 .5 .3 \\
\hline $\mathrm{rm}$ & $\rho \mu$ & $\mathrm{rm}$ & 2.3 .5 .3 \\
\hline \multicolumn{4}{|c|}{ Approximant $+\mathrm{r}$} \\
\hline wr & $\rho$ & $\mathrm{r}$ & 2.3 .6 .1 \\
\hline
\end{tabular}

\subsubsection{Combination with plosives}

Some typical cases of the development of consonant clusters are listed here:

\subsubsection{Plosive + Plosive}

*gd

$* g d>\gamma d$

Example: $\lambda$ o $\gamma \delta$ o "daughter" $<*$ dugdā

\subsubsection{Plosive + Affricate}

*-ť̌-

$\left.*_{\text {-t } t \check{c}-}\right\rangle$ ts $\langle\sigma\rangle$ and once $\langle\zeta \zeta\rangle$

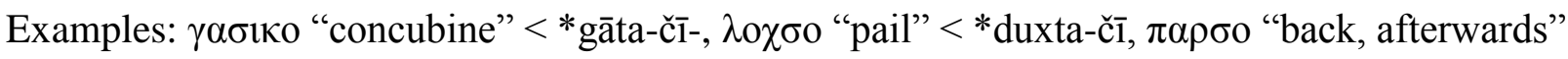

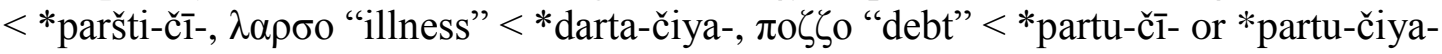

\subsubsection{Plosive + Nasal}

*-gn-

$*_{-} g n->\gamma n$

Example: oryvo "famine" <*waignā-

\subsubsection{Plosives + Approximant}

*-dy-

$*_{-} d y>l$

Example: $\mu \imath \lambda \alpha v_{0}$ "middle" <*madyāna(ka)-

\subsubsection{Plosives + Trill}

$* \mathbf{d r}$

$* d r>l r>d r$

Old Iranian $* \mathrm{dr}$ had developed to $\langle\lambda \rho\rangle=[\mathrm{lr}],\langle\delta \delta \rho\rangle=[\mathrm{dr}]$ and $\langle\delta \rho\rangle=$ [dr]. It seems that [lr] is older than $[\mathrm{dr}]$ and $[\mathrm{dr}]$. A good example showing this development is the word $\lambda \rho \circ \gamma_{0} / \delta \delta \rho \circ \gamma_{0}<$ 
*druwa-ka- "in good health". $\lambda \rho o \gamma o$ occurs very often in old texts between 359 and 472 A.D., whereas $\delta \delta \rho 0 \gamma o$ is attested in a document from 700 A.D. (document T). ${ }^{86}$ Another example is $\lambda \rho \omega \gamma o / \delta \delta \rho \omega \gamma o$ "falsehood" $<*$ drauga-. $\lambda \rho \omega \gamma o$ is attested in document cg (379/380 A.D.), whereas the form $\delta \delta \rho \omega \gamma o$ occurs between the seventh and eighth centuries. ${ }^{87} \mathrm{We}$ can find the same development for internal $* \mathrm{dr}$ as initial $* \mathrm{dr}$. $\mu \alpha \lambda \rho \mathrm{\rho}$ as the name of a city and district is used in document $\mathrm{J}$ (about 517 A.D.) and $\mu \alpha \delta \delta \rho o$ in document $\mathrm{U}$ (about 712 A.D.). It must be added that both $\langle\delta \delta \rho\rangle$ and $\langle\Delta \rho\rangle$ in $\delta \rho \alpha \chi \mu \mathrm{o} / \Delta \rho \alpha \chi \mu$ o are used between the seventh and eighth centuries.

\subsubsection{Combination with nasals}

\subsubsection{Nasal + Plosive}

*-nt-

*-nt- >nd

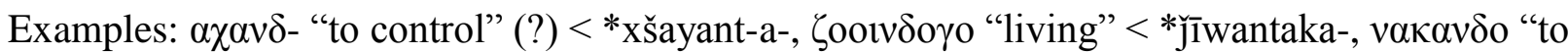
dig" <*ni-kanta-, o $\alpha \rho \sigma o \chi o \alpha v \delta o ~ " w o n d e r f u l " ~<*$ warčahwant-

*nť̌

$*_{n t c ̌}>n \zeta$

Example: $\varphi \imath v \zeta o$ "lady" <* fšuyant-ī-čĩ

PIr. *nd is preserved as such:

*-nd-

*-nd- > nd

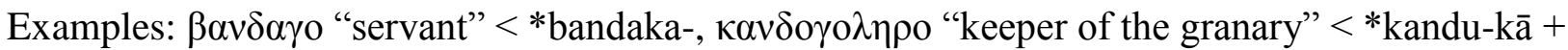
$\lambda \eta \rho о, \gamma \alpha \nu \delta$ o o "wheat" < *ganduma-, $\nu \alpha \beta \alpha \nu \delta$ o "beside" < *ni-band V, vo $\beta \alpha v \delta \alpha v o$ "established custom" (?) < *ni-band-anā-, $\pi \eta \sigma ı v \delta$ - "to approve" <*pati-sandaya-, $\sigma \mathfrak{l v \delta} \delta$ " to wish" <

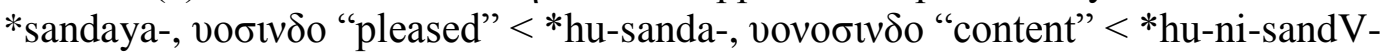

*-nk-

$*_{-} n k->n g\langle\gamma \gamma\rangle$

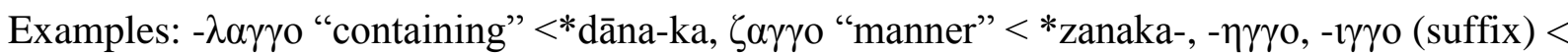

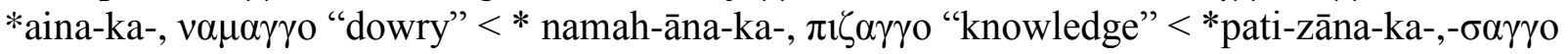
(suffix) $<*$ čāna-ka-

*-mb-

$*_{-} m b->m v$

$\alpha \mu \beta \alpha \gamma \delta$ o "to give away" < *ham-baxta-, $\sigma \tau \alpha \mu \beta o$ "to injury" < *stambV-

*-mp-

$*_{-} m p->m v$

Example: $\alpha \mu \beta \alpha \rho o$ "store" < *ham-pārV-

${ }^{86} \delta \delta \rho \circ \gamma o$ is also attested in another document $(\mathrm{jh})$. The time of this document is not clear, but according to SimsWilliams, jc-ji are all shown to be late by the doubling of $\delta$ before palatal vowels and the use of the letter transliterated $\Delta$. Cf. Sims-Williams 2007a: 26.

${ }^{87}$ This form occurs in documents $\mathrm{W}, \mathrm{Q}, \mathrm{T}, \mathrm{U}$, and $\mathrm{X}$. 
*-mk-

*-mk- >ng

Examples: $\alpha \gamma \gamma \alpha \rho \gamma_{0}$ "property" < *ham-kāraka-, $\pi 1 \delta \alpha \gamma \gamma \eta \rho-$ "to agree" < *pati-ham-kāraya-, $\alpha \gamma \gamma ı$ เ (past stem) "to receive" $<*$ ham-kašta-

\subsubsection{Nasal + fricative}

$*_{\mathbf{n} \theta}$

$*_{n} \theta>h$

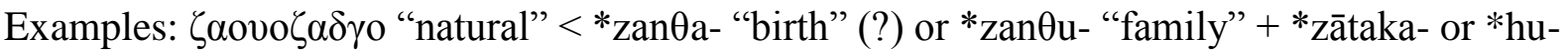

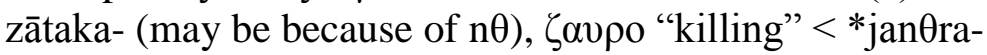

*-ns-

$*_{-} n s^{-}>s$

Example: $v \alpha \beta 1 \sigma-$ "to write" $<*$ ni-pinsa-

\subsubsection{Nasal + Affricates}

*nč

After a nasal č is changed to z:

$*_{n} \check{c}>n d z$

Examples: $\pi \alpha v \zeta \alpha \sigma o$ "fifty" < *pančāsat-, $\pi \alpha v \zeta o$ "five" < *panča-,

*ny̆

$*_{n j}>n d z$

Examples: $\rho \alpha v \zeta_{\mathrm{o}}$ "quickly" < *ranǰyah-, $\alpha \lambda \varphi \alpha v \zeta$ - "to acquire" $<* \theta$ wanj̄a-

\subsubsection{Combination with fricatives}

\subsubsection{Fricative + Plosives}

$* f t{ }^{88}$ is developed to $v d$ in Bactrian:

$* f t>v d$

Examples: $\gamma \alpha \beta \delta \delta$ 1 $\gamma_{0}$ "exerting oneself" < * gaf-ta-ka-, $\tau \alpha \beta \delta$ o (past stem to $\tau \alpha \beta$ - "impress") < *tafta-, $\pi 1 \delta$ o $\rho \circ \beta \delta$ o "received" < *pati-gṛfta-

$* x^{89}$

$*_{-} x t->\gamma d$

Examples: $\alpha \lambda \omega \gamma \delta$ o "fully privileged" $<*$ hada-uxta- "possessing (the right of) speech", $\alpha \mu \beta \alpha \gamma \delta o$ (past stem)"to give away" < *ham-baxta-, $\alpha v \alpha v \alpha \gamma \delta$ o "without deduction" (?) <*an-ā- $\theta$ axta-

$*_{-x t-}>\gamma(\partial) d$

Examples: $\alpha \beta \alpha v \alpha \gamma \alpha \delta$ o "to charge" < *apa- $\theta$ axta "deducted", ol $\sigma \alpha \gamma \alpha \delta$ o "accounted" (?) < *wisaxta-, $\sigma \alpha \gamma \alpha \delta$ o (?) (past stem to $\sigma \alpha \chi \sigma-$ ) "to be assessed" < saxta-

There is one example in which *xt is preserved. This word is probably a loanword from MMP/Pth. sxt: $\sigma \alpha \chi \tau \tau$ "elapsed" $<*$ saxta-

\footnotetext{
${ }^{88}$ Fort the development of $* f t$ in Pamir languages, see Wendtland 2009: 176.

${ }^{89}$ See also Wendtland 2009: 175.
} 
$* \mathbf{s t}$

$*_{s t}$ is always preserved:

$*_{s t}>s t$

Examples: $\sigma \tau$ $\tau \gamma_{0}$ "great" <*stūraka-, $\sigma \tau \alpha \mu \beta$ o "to injury" <*stambV-, $\alpha \sigma \tau$ o "be present" < *asti-, $\alpha \beta \alpha \sigma \tau \alpha v_{0}$ "support" <*upa-stāna-, $\beta \alpha \sigma \tau$ " "to bind" $<*$ basta-.

*sp

The initial and internal $* \mathrm{sp}$ is preserved in Bactrian:

$*_{s p}>s p$

Examples: $\sigma \pi \alpha \delta$ o $\alpha \gamma \gamma_{0}$ "on bended knee" < *spāta-zānu-ka, $\sigma \pi \alpha \lambda \iota \gamma_{0}$ "jar" <*spādaka-, $\sigma \pi \alpha \sigma o$

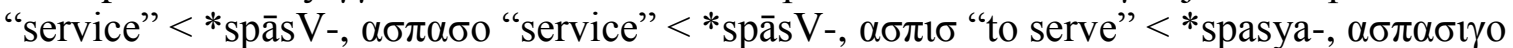

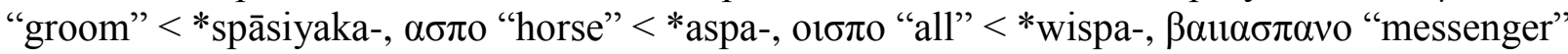
$<*$ dwayaspāna-

Only once $s p$ is changed to $s v$ in a loanword:

$\alpha \sigma \beta \alpha \rho 0^{\prime}$ "horseman" < *aspa-bāra-. This word might have been borrowed from MP aswār, MMP 'sw'r.

$*$ št

$*_{s} t>t$

Examples: $\alpha \tau \alpha 0$ "eight" < *aštā, vıนı "to send" < *ni-štāya-

$*_{\breve{s} t}>\check{s} t$

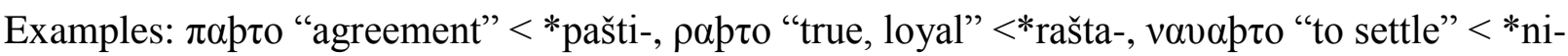
šāšta-

$* \mathbf{z d}$

$*_{\mathrm{zd}}$ seems to have two outcomes. It is possible that $d$ will be shown to disappear in new material:

$*_{-z d-}>z d$

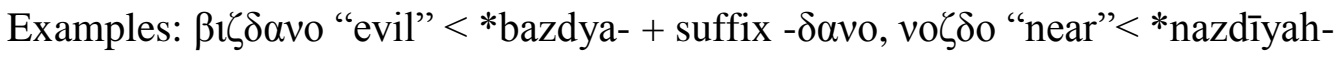

$*_{-} z d->z$

Examples: $\beta 1 \zeta \alpha \gamma_{0}$ "evil" $"$ < $<$ bazdya-kā-

*šk

$*_{s} k>\check{s} k$

Example: $\alpha$ pк $\alpha \rho-$ "to follow" <* škara-

*sk

$*_{s k}>s k$

Examples: $\alpha \sigma \kappa \alpha \delta \alpha \rho o$ "more" <*uskād+suffix $-\delta \alpha \rho o, \alpha \sigma \kappa \alpha v_{0}$ "note" <*us-kānV

${ }^{90}$ This is the only attested example of the development of $* z d$ to $z$. 


\subsubsection{Fricative + Fricative}

$* \mathbf{X S}$

$*_{-} x s^{-}>x S$

Example: $\sigma \alpha \chi \sigma-$ "to be assessed" $<*$ saxsa-

*f̌̆

It seems that in Bactrian, we have more than one outcome for the consonant cluster $* \tilde{\mathrm{fs}}$ :

$* \# f \check{s}->f$

Example: $\varphi \imath v \zeta o$ "lady" < *fšuyant-1-1-čì

*\# frs-> $x$

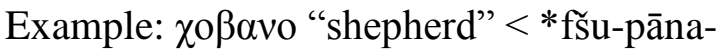

$*_{-} \check{S}->f \check{S}$

Example: кафpo "shoe" < *kafs̃i-

$*_{-} f \check{s}->f$

Example: $\pi 1 \delta$ o $\alpha \rho \rho^{\prime}$ "honour" < *pati-fšarV-

The following table shows the frequency of different developments of $* f \tilde{s}$ in Bactrian:

Table 7. Development of PIr. *fš

\begin{tabular}{|c|c|}
\hline phonological change & $\begin{array}{l}\text { number of examples in } \\
\text { our corpora }\end{array}$ \\
\hline *\#f̌s̆-> f & 1 \\
\hline$* \#$ frs̆-> x & 1 \\
\hline 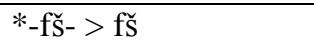 & 1 \\
\hline 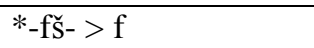 & 1 \\
\hline
\end{tabular}

*x̌

In the case of this consonant cluster, we observe two different outcomes in both initial and internal position, which may reflect a dialectal difference (?):

$* \# x \check{s}->\check{s}$

Example: pu "to be able" < *xšāya- ${ }^{91}$

$* \# x \check{s}->x$

Examples: $\chi \alpha \beta \rho \omega \sigma o$ "(by) night and (by) day" < *xšapā- + $\rho \omega \sigma o, \chi \alpha \rho o$ "ruler" < xšāâriya-, $(\alpha) \chi \alpha v \delta$ - "to control" < *xšayant-a-

$*_{-} x \check{s}->x \check{S}$

Example: $\pi \alpha \delta \alpha \chi$ pavo "having authority" < *pāti-xšāna-

*-x̌̌- > $x$

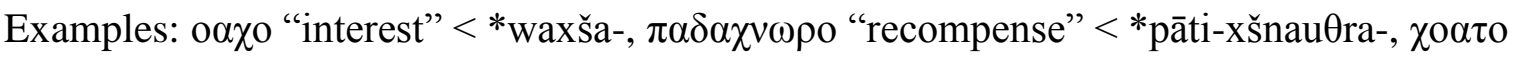
"sixty" < *xšwašti-

91 There are also other examples of the development of $* x \check{s}$ to $\check{s}$, but these words are probably Middle Persian

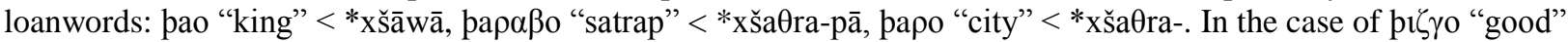
$<*$ xšija-ka-, the etymology is unclear. For that reason, the best example of this development in Bactrian is the word pu, which is mentioned above. 
In the following table, the frequency is shown of different developments of *xš in our Bactrian corpora:

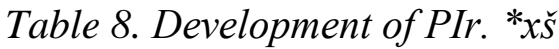

\begin{tabular}{|c|c|}
\hline phonological change & number of examples \\
\hline 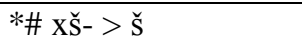 & 4 \\
\hline$* \# \mathrm{x} \check{\mathrm{S}}->\mathrm{x}$ & 3 \\
\hline$*_{\text {-X } \mathrm{XS}-}>\mathrm{X} \check{\mathrm{S}}$ & 2 \\
\hline$*$-X̌S- > X & 2 \\
\hline
\end{tabular}

*xšn

$* \# x \check{s} n>x n$

Example: $(\alpha) \chi v \omega \rho o$ "satisfaction" < *xšnau $\theta$ ra-

*xšt

The consonant cluster *xšt has two different outcomes, which may show a dialectal difference:

$*-x \check{s} t->x t$

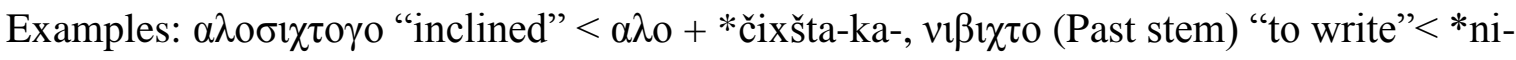
pixšta-

$*_{-} x \check{s} t->x \check{s}$

Example: $\lambda \alpha \chi$ p $\alpha \tau \alpha v i \gamma o$ "place of cremation" $<* \lambda \alpha \chi$ p $\alpha \tau \alpha v o(<*$ daxštana $)+$ suffix $-\imath$ o

*štk

$*_{-\check{s} t k-}>-\check{s} k-$

Example: vapкo "pupil" < *hāwišta-ka-

\subsubsection{Fricative + affricative}

*š

$*_{s c \breve{c}}>t s$

Example: $\pi 1 \sigma 0$ "before, in the presence of" < *pasča

As Greek $\sigma$ is used both for $t s$ and $s$ in Bactrian, the question is whether $\sigma$ represents [ts] or $[\mathrm{s}]$ in the above-mentioned context. It seems that $* s c ̌$ developed to $t s$ in Bactrian. $\pi 1 \sigma 0$ is attested in the Manichaen fragment in the form of pyc [pits].

\subsubsection{Fricative + Nasal}

$* \mathbf{x m}$

$*_{-} x m_{-}>x m$

Examples: $\lambda \alpha \chi \mu 1 \gamma_{0}$ "place of burial" $<*$ daxma-ka-, $\tau$ o $\chi \mu \alpha v_{0}$ "seed" $<* \operatorname{tauxman-a-,} \tau \alpha \chi \mu o$ "stream" < *taxman-

*šm

* šm could be changed to $h m$ and $m$ : 
$*_{s ̌ m}>h m>m$

$*_{-} \check{s} m->h m$

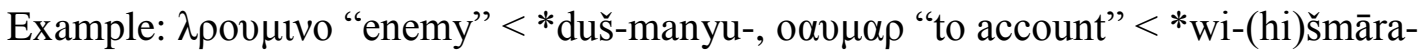

*-šm- > $m$

Example: $\pi \alpha \mu \alpha v o$ "wool" $<*$ pašman-

*hm

$* h m>h m$

Example: $\alpha v \mu \alpha \rho o$ "account" <*ā-hmāra-

*sn (non-Persian)

$* \# s n>s n$

Example: $\alpha \sigma v \omega v 0$ "daughter in law" $<*^{*}$ snušă $\bar{a}^{92}$

*šn

*-šn- $>\check{s} n$

Example: $\beta \alpha \mu$ opvo "queen" <*bāmušn-

$*_{\mathbf{z n}}$

$*_{-} z n->z n$

Example: $\gamma \alpha \zeta$ vo "treasury" < *gazna-

\subsubsection{Fricative + Trill}

$* \mathbf{f r}$

*\#fr- > fr

Example: $\varphi \rho ı \alpha \chi o \delta \alpha \rho o$ "more" <*frāyah-aka- + suffix - $\delta \alpha \rho o, \varphi \rho ı 0 ~ " d e a r "<*$ friya-

In the word-internal position, * $f r$ is also preserved:

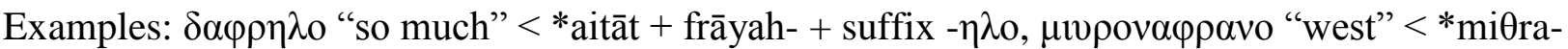
nifrāna-, $\pi \alpha \delta$ $\varphi \rho \alpha \sigma o$ "punishment" $<*$ pāti-frāsa-

*fra-

*\# fra- $>$ fr $(\partial)$

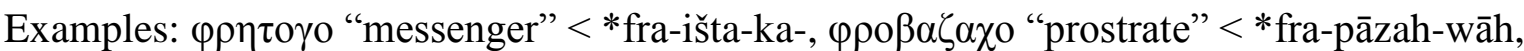

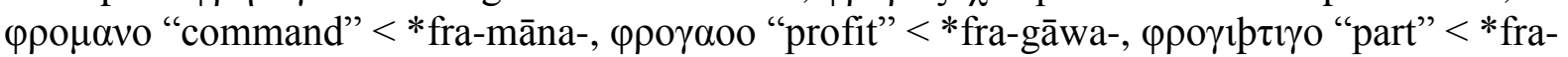
kṛsta-ka-, $\varphi \rho о \mu \alpha v \zeta_{0}$ "commanding" < *fra-mānaka-, $\varphi \rho \mu_{\alpha} \alpha v_{0}$ "command" < *fra-māna-,

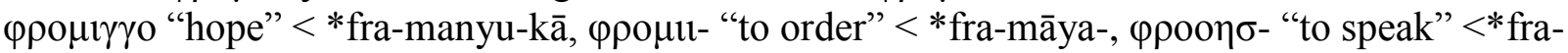
wāčaya-

$*_{\text {sr }}$

As in other Eastern Iranian languages *sr is changed to š in Bactrian:

$* \# s r>\check{s}$

Example: povo "fingernail" < *srū(-kā)

${ }^{92}$ This word is discussed in Korn 2005: 128. 
*str

$*_{-s t r-}>\check{s}$

Example: oopo "hay" <*wāstra-

$* \theta \mathbf{r}$

The development of the $* \theta$ r- could be introduced as in the following:

$* \theta r->h r>r$

$* \theta r->h r$

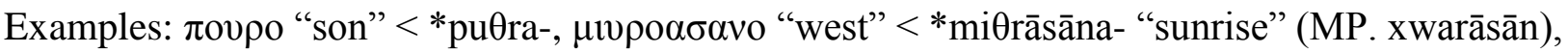

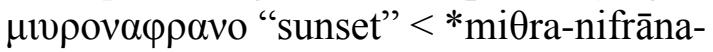

$* \theta r>r$

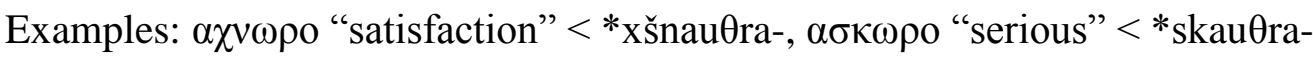

$* \mathbf{h r}$

*-hr- > $r$

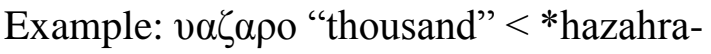

*xr

Bactrian preserves *xr:

*\# $x r->x r$

Example: axpıvo "purchase" < *xray-anā-

*-xr- > $x r^{93}$

Example: olxpıvo "hire" <*wi-xray-anā-

*\# $x r->x i r^{94}$

Example: $\chi \imath \uparrow \gamma_{0}$ "purchase" $<*$ xraya-ka-

In both of following examples, we find metathesis:

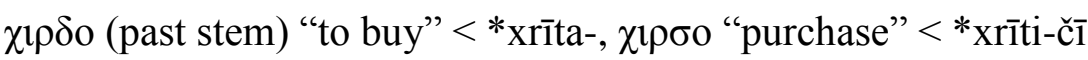

\subsubsection{Fricative + Approximant}

$* \theta \mathbf{w}$

PIr. $* \theta \mathrm{w}$ is developed to $l f$ in Bactrian:

$* \theta w>$ lf

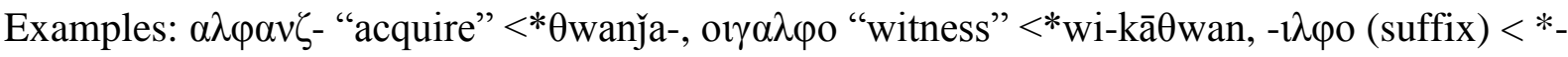
iya- $\theta$ wa- (Pth. îf(t), MP îh)

$* \mathbf{d w}$

The occurrence of $l$ in $\alpha \lambda \beta \alpha \rho$ proves that this is an original Bactrian word, and on these grounds, we can observe an original Bactrian development of PIr. * $d w$ in this word.

It can therefore be concluded that the development of $* \# d w$ must be $l \beta$ in Bactrian:

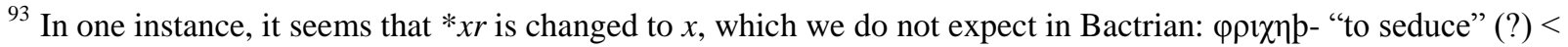
fra-xrāšaya-

${ }^{94}$ It is possible that 1 represents an omicron here.
} 
$* \# d w->l \beta$

Example: $\alpha \lambda \beta \alpha \rho o$ "court" $<*$ dwar-a

There are two other examples in the extant materials which show the change of $* d w$ to $\beta$.

As this development is not expected in Bactrian, these words could be regarded as either loanwords or representatives of another dialect of Bactrian:

$* \# d w>\beta$

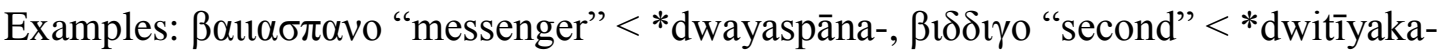

*xw

$* x w$ is generally changed to $x o$ :

*xw $>x o$

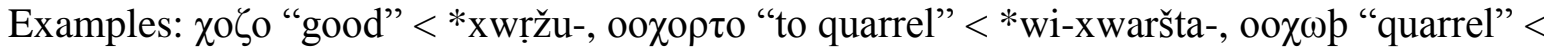
*wi-xwarša-

*hw

As *xw, *hw is changed also to xo:

$* h w->x o$

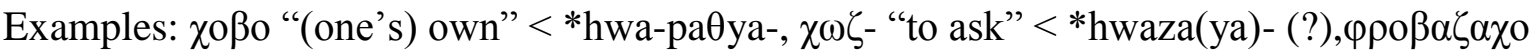
"prostrate" <*fra-pāzah-wāh

$* \boldsymbol{\theta y}$

$* \theta y>i$

It seems that* $\theta$ is omitted in the following examples:

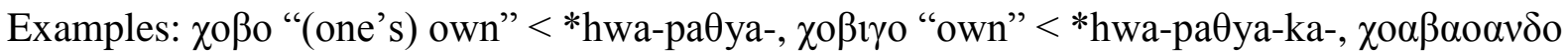
"owner" <*hwapa $\theta$ yāwant-

$*^{*} \mathbf{y}$

$*_{z y}>z$

Examples: $\rho \zeta_{-}$(passive to $\rho \alpha \zeta_{-}$) "be named" < *āzya-, oı $\alpha \alpha \delta$ o "injury" < *wi-zyanta*sy

$*_{s y}>s$

Example: $\sigma \pi 1 \sigma-$ "to serve" $<*$ spasya-

\subsubsection{Combinations with affricates}

\subsubsection{Affricates + Approximant}

$* \check{\mathbf{c y}}$

$* \check{c} y>\check{s}$

Examples: p$\alpha o-$ "to go" < * čyawa-, p $\alpha \delta$ o "satisfied" < *čyāta-, $\alpha \beta \alpha$ po "back, in return"< *apāčyā

$*_{c} y->s^{\prime}(\sigma)$

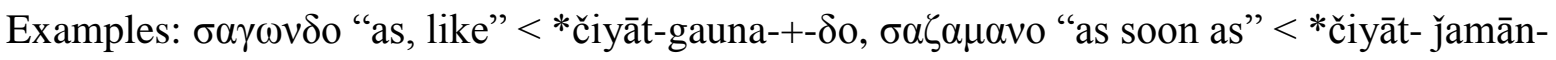


*jy

$* \check{y} y>\check{z}(\zeta)$

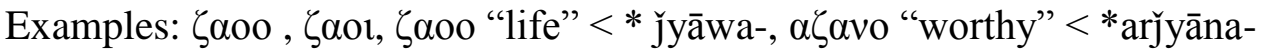

\subsubsection{Combination with Trill}

\subsubsection{Trill + Plosives}

$* \mathbf{r t}$

PIr. *rt is changed to $r d$ - in Bactrian:

$*_{-r t-}>r d$

Examples: $\beta w r d$ past stem "to bear, bring" $(\beta o \rho \delta o)<*$ brta-, $\mu \alpha \rho \delta \alpha v o$ "valiant" < *martāna-, $\mu \alpha \rho \delta$ o "man" <*martiya-,

*rd

PIr. *rd is preserved in Bactrian:

*-rd- > $r d$

Examples: prdyjg or prdyźg "orchard" < *pari-daiza-ka-, $\pi 1 \delta$ oк $\alpha \delta$ o "retention" < *pati-karda-,

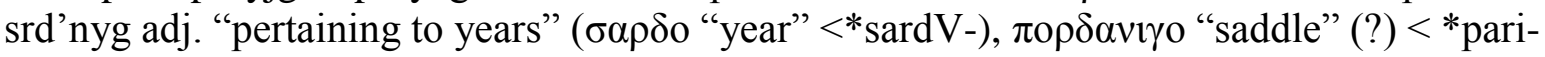
dāna- + suffix 1 o

In the case of $\pi \alpha \delta \alpha \rho \lambda \gamma_{0} / \pi \alpha \delta \alpha \rho \delta \delta$ iro "opposing side" < *pāti-arda-ka-, we observe two different developments, namely, [rd] and [rl]. $\pi \alpha \delta \alpha \rho \lambda o \gamma_{0}$ is used both in old documents such as A, C, F (between 332-472 A.D.), and also in the later documents, for example, in J, L, U (between 517-712 A.D. ), whereas the variant with [rd] is attested only in later documents S, V and W (692-747 A.D.). Regarding this example, we can conclude that [rd] is a newer development. But the older form, namely, [rl], is also preserved along with [rd] in later Bactrian.

$*$-rd- > -rl-

Examples: $\gamma \varphi \lambda \lambda$ - "to call" < *grda, $\pi \alpha \delta \alpha \rho \lambda \gamma_{0}$ o "opposite party"<*pati "against"+*arda "side"

\subsubsection{Trill + Fricative}

*řs

$*-r \check{s}->\check{S}$

Example: oo $\chi \omega p$ "quarrel” <*wi-xwarša-

*rž

$*_{r z ̌}>z$

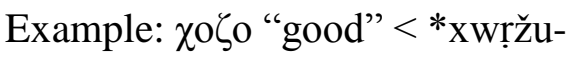

*rz

PIr. * rz is preserved in Bactrian:

$*_{-} r z_{-}>r z$

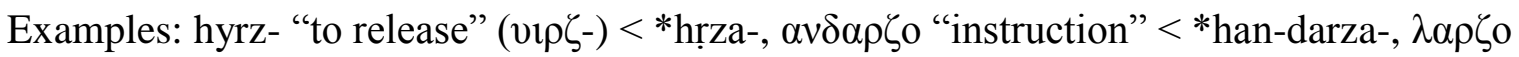

"subject to restrictions" $<$ dārzV-, o $\alpha \rho \zeta_{0}$ "farming" < *warza- 
*rs

$* r s>r s$

Example: $\pi \circ \rho \sigma-$ "to ask" < *prsa-

*rst

$*_{-} r s t->-\check{s} t-$

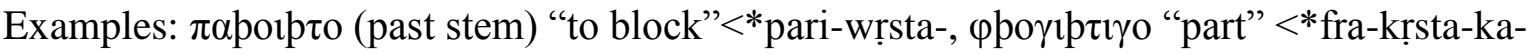

\subsubsection{Trill + Nasal}

*rn

$*_{-} r n->r$

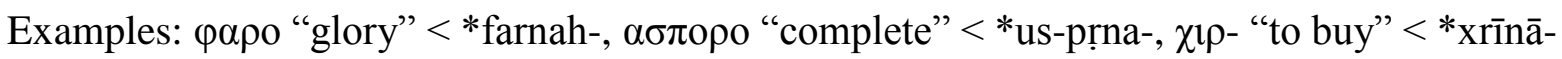
$*_{-r n-}>r n$

Examples: oo $\alpha$ vo a place name $<*$ Warnu-

*rm

$* r m>r m$

Examples: $\alpha \rho \mu \alpha v-$ "to be present" <*arma- "still"+*āh-/āsta- "to sit, remain"

\subsubsection{Combination with approximant}

\subsubsection{Approximant $+r$}

$*_{w r}$

$\# * w r>r$

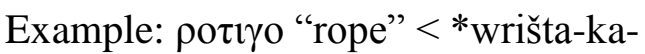

\subsection{Phonological processes: Metathesis}

In the following, some examples of metathesis are given:

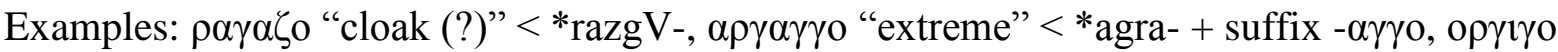

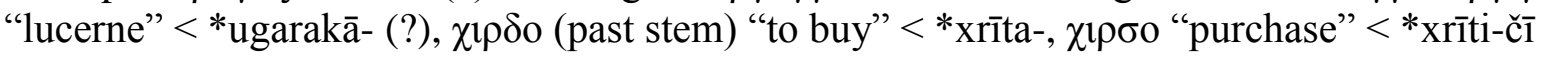

\subsection{Vowels}

$* \# i>i$

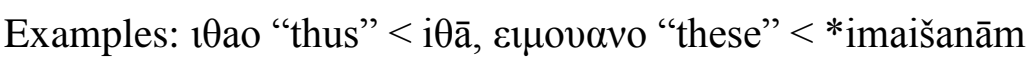

\subsection{Simple vowels}

The following table represents the vowel system in Bactrian: ${ }^{95}$

${ }^{95}$ Cf. Sims-Williams 1989a: 233. 
Table 9. Bactrian vowel system

\begin{tabular}{|l|l|}
\hline$\alpha$ & $\mathrm{a}, \overline{\mathrm{a}}$, initial ə- \\
\hline$\varepsilon$ & $\mathrm{e}$ \\
\hline$\eta$ & $\overline{\mathrm{e}}$ \\
\hline $\mathrm{c}$ & $\mathrm{i}, \overline{\mathrm{i}}$ \\
\hline $\mathrm{o}$ & $\mathrm{u}, \overline{\mathrm{u}}, \mathrm{o}, \partial, \varnothing$ \\
\hline$\omega$ & $\overline{\mathrm{o}}$ \\
\hline
\end{tabular}

The Greek alphabet of Bactrian does not distinguish a, i, and $u$ from $\bar{a}, \overline{1}$, and $\bar{u}$. The letter $\eta$ is used to represent the long vowel $\overline{\mathrm{e}}$, while the letter $\omega$ represents the long vowel $\overline{0}$. In the case of $o$, it is not easy to identify its exact phonetic value. According to Sims-Williams, all these vowels are attested in both initial and internal positions. Three of them (o, e and $\bar{u}$ ) occur less often. Vocalic $r$ is lost and results in ar, ir, ur, according to the phonetic context. ${ }^{96}$

In this section we attempt to show the details of development of PIr. vowels in Bactrian and its characteristics.

*a

Generally $* a$ is preserved in both internal and initial positions:

$* \# a>a$

Examples: $\alpha \sigma \pi$ o "horse" < *aspa-, $\alpha \beta 0 \imath \alpha \sigma-$ "to remember" < *abi-yāsa-, $\alpha \delta o \rho \imath \gamma \delta o$ (probably past stem) "to deny" <*ati-rixta-

$*_{-} a->a$

Examples: $\rho \alpha v \zeta_{0}$ "quickly" < *ranǰyah-, $\alpha v \delta \alpha \rho \zeta_{0}$ "instruction" < *han-darza-, $\sigma \tau \alpha \mu \beta$ o "to injury" < *stambV-

$* \bar{a}$

*ā is preserved generally in both initial and internal positions:

$* \# \bar{a}>\bar{a}$

Example: $\alpha \beta \beta$ o (Manich. $y$ ' $\beta$ ) “water" <*āpa-

$* \bar{a}>\bar{a}^{97}$

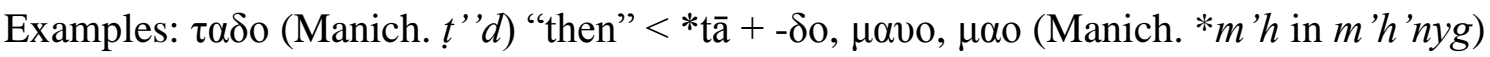
"month" <*māhV-

$* \mathbf{i}$

$* \# i>\emptyset$

Examples: $\mu \alpha \lambda_{0}$ "here" $<*$ imada-, $\mu \alpha \rho o$ "here" $<*$ ima $\theta$ ra-, $\mu$ o "the, this" $<*_{\text {ima- }}$

$*_{i}>i$

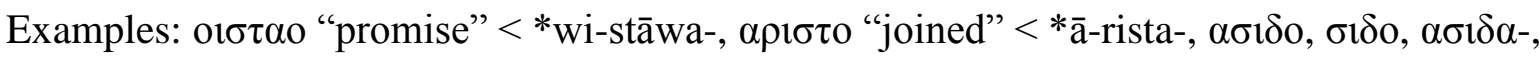
$\alpha \sigma 1 \delta$ - "what, which" $<*$ čim $+-\delta o$

$*_{i}>$ a/a (in Greek script $\alpha$ )

It seems that $*_{i}$ in the prefix $*_{\text {ni }}$ is changed to $ə:$

${ }^{96}$ Cf. Sims-Williams 2011: 234.

${ }^{97}$ It must be added that in composites, a free form of the word is sometimes used. For example in $\pi \alpha \rho \underline{\rho} \beta \alpha \rho-$ "to bring forth" $<*$ parā-bara- , we observe $\pi \alpha \rho o$, not $\pi \alpha \rho \alpha$. 


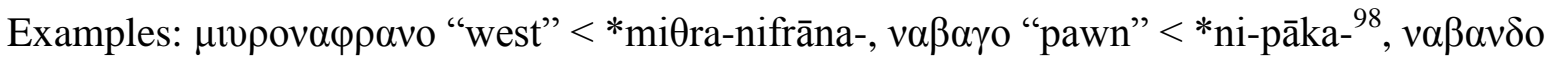
"beside" < *ni-band V, v $\alpha \beta 1 \sigma-$ "to write" <*ni-pinsa-

\section{$* \mathbf{u}$}

*\# $u>$ o (in Greek script $\alpha$ )

In all the next examples, following the omission of $\mathrm{u}$ in the initial position, we have the \#CC- environment, which then is changed to əCC:

Examples: $\alpha \zeta \gamma \alpha$ p- "to dissent" (?) < *uz-gaša- (?), $\alpha \zeta \gamma \alpha \mu$ o "produce" < *uz-gāma-, $\alpha \zeta \beta \alpha \rho-$ "to bring forth" <*uz-bara-, $\alpha \sigma \pi$ о $о$ "complete" < *us-prna-, $\alpha \sigma \kappa \alpha v_{0}$ "note" < *us-kānV-,

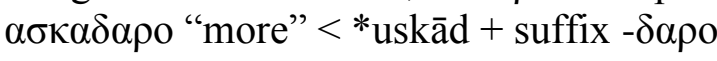

In the following example, we observe its occurrence in another environment, that is, \#CV: $\alpha \beta \alpha \sigma \tau \alpha v_{0}$ "support" < *upa-stāna-

$* \# u>u($ or $o)$

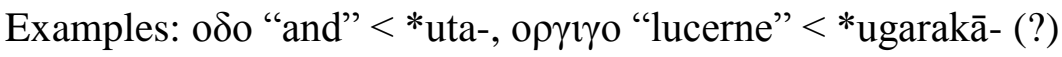

$* u>u($ or $o$ ?)

It is not clear whether $o$ represents $o$ or $u$ in Bactrian. In this case, an investigation of the Bactrian loanwords in other languages could be very helpful. In the following, examples of the development of $* u$ are listed:

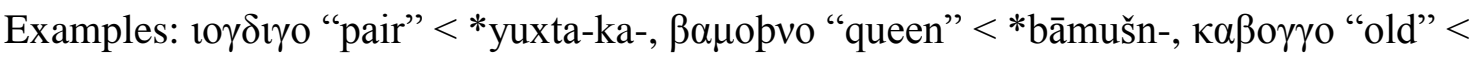
*kapuna-ka-, кабоко "little" < *kasu-ka-, кобо "dog" < *kuta-/kutī$* \mathbf{r}^{99}$

In the case of $* r$, we can observe the same development in Bactrian as in Parthian and Persian. In all these languages, in the natural and palatal context, the outcome will be $i r$ :

$*_{-}-{ }_{-}>-i r-(\imath \rho)$

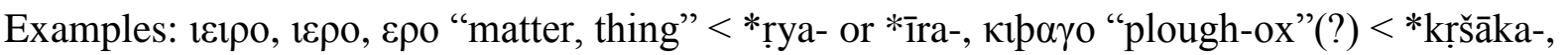

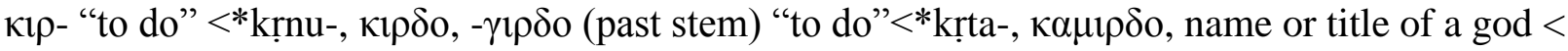

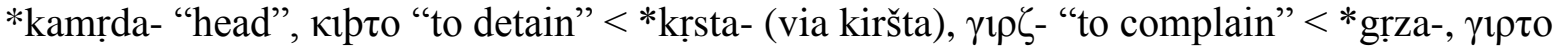
(past stem) "to complain" < *gṛšta-, $\gamma \iota \lambda$ - "to call" < * gṛda, $\lambda \rho \imath \gamma \delta$ o (past stem) "to have" < *dṛxta- (via lirgdo), $\lambda \iota \rho \delta$ o (past stem of unknown meaning) < *dṛta-, $\lambda \iota \tau \tau \eta \gamma \iota \delta$ o "estate" <

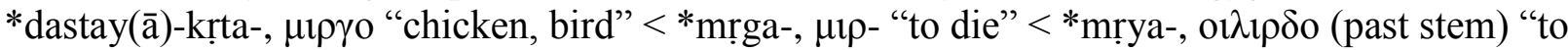

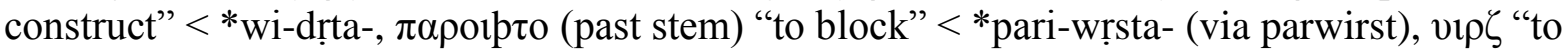

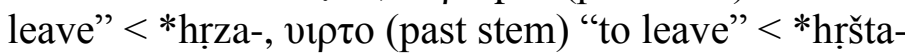

Generally PIr. * $r$ has the outcome as Bactrian $u r$ in the environment of a labial:

$*_{-} r_{-}^{-}>-u r-(o \rho)$

Examples: $\alpha \beta$ o $\rho \delta$ (past stem) "to bring" <*abi- ṛta-, $\alpha \beta o \rho \alpha \delta \alpha v_{0}$ "repayment" < *āprtana-,

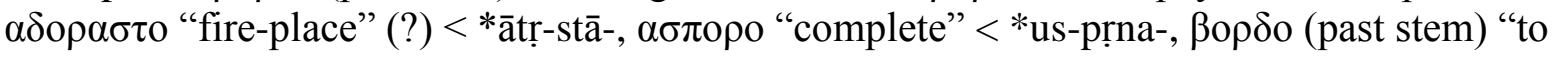

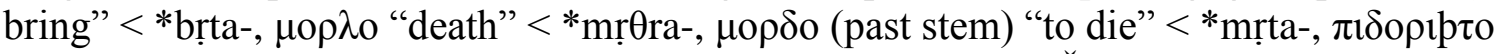

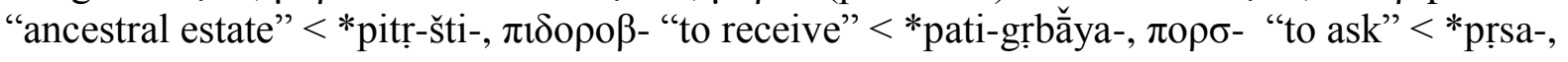

\footnotetext{
${ }^{98} \mathrm{PIr}$. * $n i$ - is often changed to $n a$ - in the first position in Bactrian, but there are also some exceptions in which PIr.

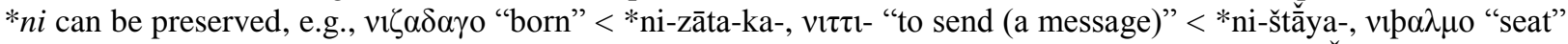

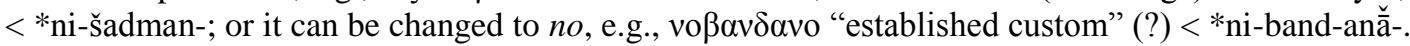

${ }^{99}$ We can find the same development of PIr.* $r$ in Balochi, see Korn 2005: 143-148. For the development of * $r$ in other Iranian languages and also in Bactrian, see Korn 2011:4-8.
} 


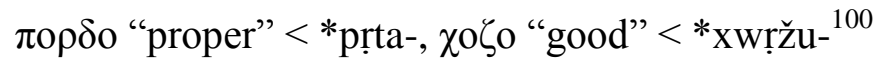

\subsection{Loss of vowels}

\subsubsection{Loss of \#V-}

$* \# a>\varnothing$

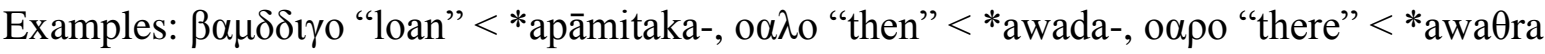

\subsubsection{Loss of -V- (Syncope):}

Syncope can occur in various environments, as in the following:

-Between plosive and sonorant:

Examples: oı $\delta \rho$ "so long" <*witarā(d)-, $\pi \_\delta \rho \rho \gamma \alpha v o$ "paternal relatives" < *pitarakāna-,

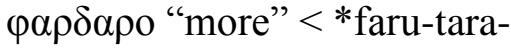

-Between plosive and plosive:

Example: $\alpha \delta \beta \eta \gamma o$ "disrespect" < *ati-baya-ka-

-Between fricative and plosive:

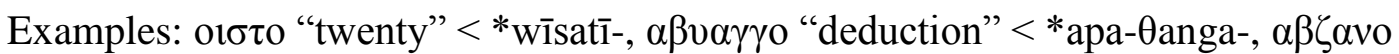

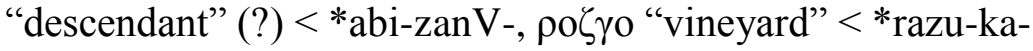

-Between fricative and nasal:

Example: $\lambda \alpha$ pvo "gift" $<*$ dāšin $V-$

In the following example, we can observe the relative chronology of changes. The question arises of whether the syncobe happened before the development of $d$ to $l$ :

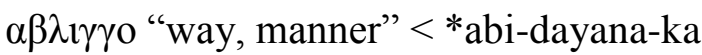

\subsubsection{The treatment of final vowels}

In new Bactrian materials, the PIr. vowels are generally lost. But there are some remnants of them in the old Bactrian texts, for example, in some words such as $\lambda_{1} \zeta \alpha / \lambda_{1} \zeta \mathrm{o}$ "citadel" $<*$ dizā-, $\imath \theta \alpha / \imath \theta 0$ "thus", $\beta \alpha \gamma \varepsilon / \beta \alpha \gamma o$ "gods", $\tau \alpha \delta \mathrm{l} / \tau \alpha \delta$ o "then".

As a general rule, $* \bar{a}$ is lost in the final position:

$* \bar{a} \#>\varnothing$

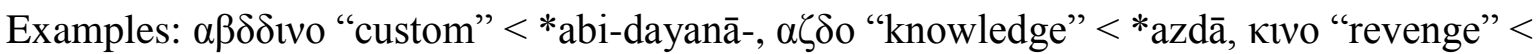

*kainā-, $\mu \alpha \delta$ o "mother" < *mātā

In the following examples, we observe an unexpected development:

Examples: $\alpha \tau \alpha \mathrm{o}$ "eight" <*aštā, $\imath \theta \alpha \mathrm{o}$ "thus" $<* i \theta \bar{a}, \tau \alpha$ "then" $<*$ tā

In the first case, it is not clear why *ā ie preserved. The second example $\imath \theta \alpha o$ represents an achaism by preserving both $\theta$ and $\bar{a}$. In the case of $\tau \alpha$, we cannot expect another development, as it is a one syllable word.

\subsection{Diphthongs:}

In the following section, the most common diphthongs in Bactrian are presented:

\footnotetext{
${ }^{100}$ According to our above results, the etymology suggested by Tremblay in $\beta \alpha \rho \tau$ “to be necessary"(?) <*ā-pršst-
} Tremblay 2003: 131 is problematic. 
$* a u>o^{101}$

Examples: $\delta \rho \omega \gamma о \mu \imath \gamma_{0}$ "false" <*draug-mā or drug-mā + $\gamma_{0}$ (Pth. drwgmyg), $\gamma \omega v \zeta_{0}$ "bag" <

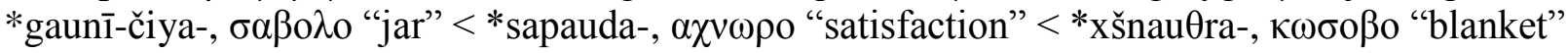
$<*$ kaučapa-

$* a i>\bar{e}$

Examples: $\beta \eta о \alpha \rho o$ "ten thousand" $<*$ baiwara-, $1 \alpha o \eta \delta \alpha v_{0}$ "eternal" $<*$ yāwai-tāna-, $\kappa \eta \delta o$

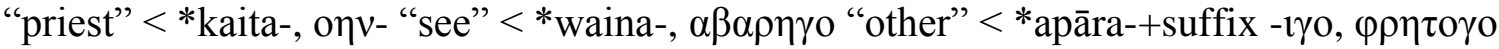
"messenger" $<*$ fra-išta-ka-

There are two examples in which it appears that *ai has been changed to i rather than to ê. It seems that $\overline{\mathrm{e}}$ must be the older form, and that it is changed to $\mathrm{i}$ in new materials. In the following examples, either these forms are loanwords from probably Persian, or they are new versions of the old forms: kıvo "revenge" < *kainā-, o $\gamma v 0$ "famine" <*waignā-

In some cases, as in the following example, both new and old forms are attested in the extant

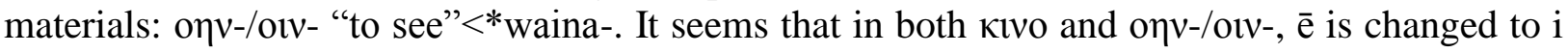
before a nasal, but in oryvo, the same environment is not observed.

*aya $>\bar{e}(>\bar{\imath})$

Examples: $\alpha \beta \alpha \chi \rho \eta \gamma_{0}$ "fee" < apa-xraya-ka-, $\alpha$ $\propto \eta \zeta v o$ name of a month < *ahura-yazniya-, o $\chi \rho \eta \gamma \alpha v o$ "hire" <*wi-xraya-+suffix - $\gamma \alpha v o$

It seems that *aya is changed to $\bar{l}$ before a nasal. In all the following examples, it occurs before $n$ :

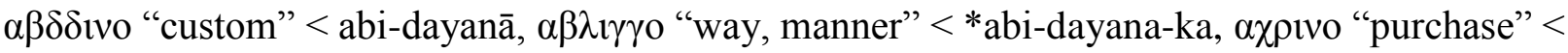
*xray-anā

It seems that * āyā in the internal position can be changed to â:

$* \bar{a} y \bar{a}>\bar{a}$

Example: бayo "shade, shadow" <*sāyā-kā-

$*_{-}$aya\# > $\bar{\imath}$ (or sometimes yi)

It seems that in all verbal forms, āya in a word-final position is changed to $\overline{1}$ or $y i$.

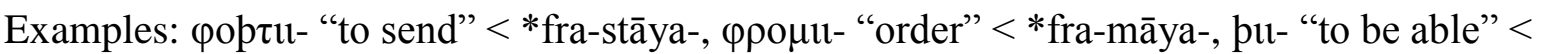

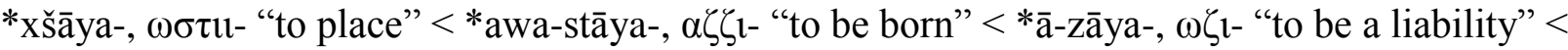
*awa-zāya-

*iya $>\bar{e}$ or $\bar{l}$

*iya $>i$

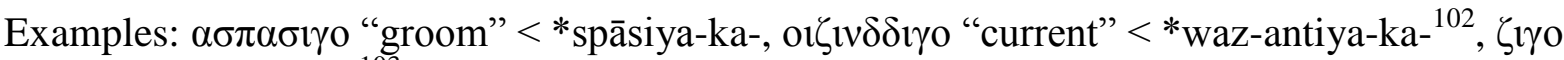
"damage" <* ziyakā- ${ }^{103}$

*iya $>\bar{e}$

Example: $\mu \alpha \rho \eta \gamma \mathrm{o}$ "servant" <*mar(i)yaka-

*iyā is preserved in all the following examples, which in reality are Persian loanwords:

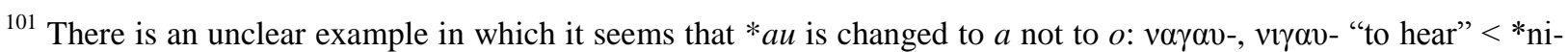
gauša-.

${ }^{102}$ In both of these examples, *-iyaka- is changed to -1 o.

${ }^{103}$ According to Sims-Williams, *z(i)yakā- Sims-Williams 2007a: 212. In my opinion, it must be *ziyakā-. 


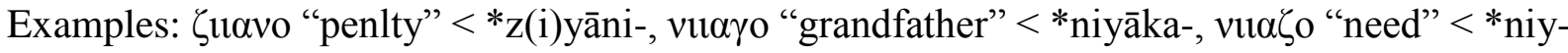
āza-

In the following example, it seems that *iyā is changed to $\bar{a}$. This word is probably a Persian loanword in Bactrian:

$\pi \eta \delta \alpha \gamma_{0}$ "revealed" <*patiyāka-

*awa-> $\bar{O}$

*awa is changed to $\overline{0}$ :

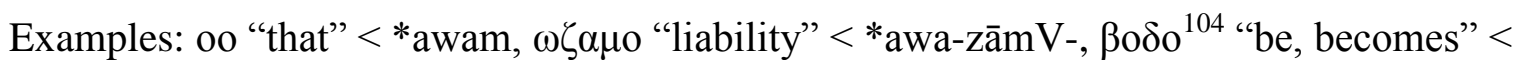

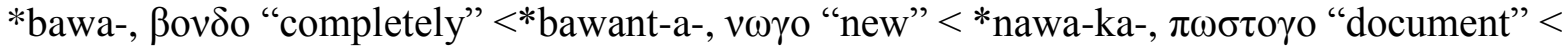
*pawasta-ka-

In the final position, *awa is changed to $a w$ :

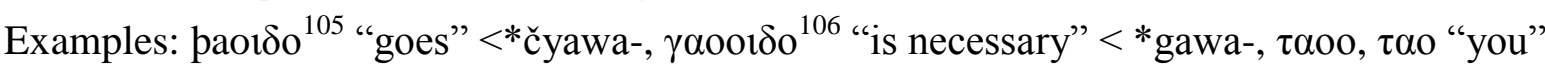
$<*$ tawa

*-awā- > awā

It seems that Bactrian preserves *awā:

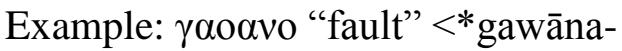

*-āwa- and *-āwā- are also preserved in Bactrian:

*-āwa- > $\bar{a} w a$

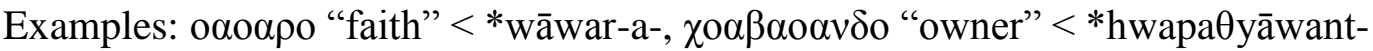

$*_{-} \bar{a} w \bar{a}->\bar{a} w \bar{a}$

Example: $\tau$ oo $\alpha v_{0}$ "fine" < *tāwāna

It seems that in the following example, $* \bar{a} w i$ is changed to $\bar{o}$ :

Example: vwı "channel" < *nāwiyā $\bar{a}^{107}$

In the following example, āwi is changed to $\bar{a}$ :

$*_{-} \bar{a} w i->\bar{a}$

Example: vapко “pupil” < *hāwišta-ka-

\subsection{Combination of Vowel and Consonant}

\subsubsection{Combination of $w$ with vowels}

\subsubsection{In initial position}

$* \mathbf{w}+\mathbf{a}$

$* \# w a->w a>o$

In these examples *\#wa is preserved:

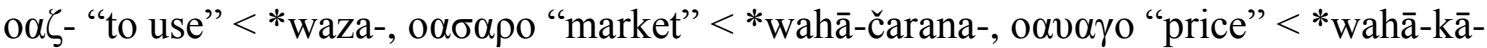

\footnotetext{
104 This form is third person present.

105 This form is third person present.

106 This form is third person present.

${ }^{107}$ For this word in Iranian languages, see Widmer 2007: 215-228.
} 
In both of these examples, wa is changed to o:

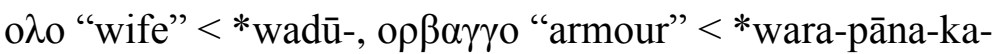

$* \# \mathbf{w}+\overline{\mathbf{a}}$

$* \# w \bar{a}->w \bar{a}$

Examples: o $\alpha \delta o$ "wind" < *wāta-, o $\alpha$ o $\rho$ o "faith" < *wāwar-a-, o opo "hay" < *wāstra-

$* \# \mathbf{w}+\mathbf{i}$

$* \# w i->w i$

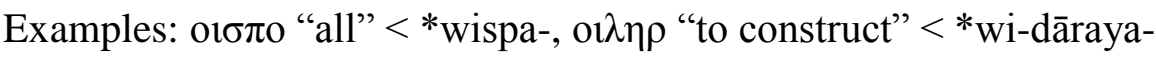

\subsubsection{Combination of $y$ with vowels}

\subsubsection{In final position}

*arya \# $>\bar{e} r(\eta \rho)$

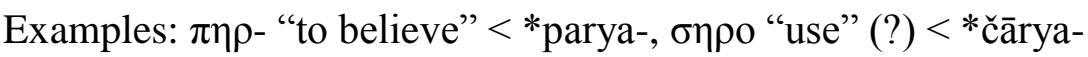

\subsubsection{The combination of other consonants with vowels}

\subsubsection{In final position}

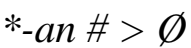

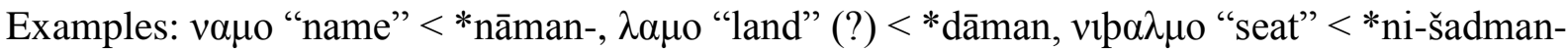
*an \# > an

Example: $\pi \alpha \mu \alpha v o$ "wool” $<*$ pašman-

$* a m \#>\varnothing$

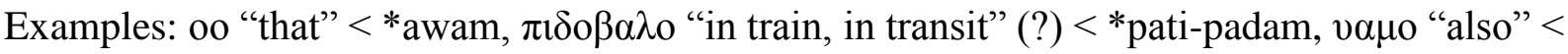
*hamam-

$* V h \#>\varnothing$

*h after a vowel in final position is lost in Iranian languages including in Bactrian.

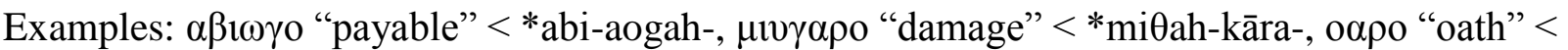
*warah-, $\mu 1 \sigma 0$ "even, more" <*masyah-, oı $\sigma \lambda \mathrm{\gamma} \gamma \delta \mathrm{o}$ "princess" < *wisah duxtā

\subsection{Palatalization}

There are two kinds of palatalization of vowels in Bactrian:

$a$ to $i$ and $\bar{a}$ to $\bar{e}$ before $-y a$ and $-i$

$* a>i /-. y a,-. i$

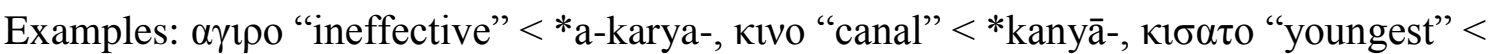
*kasišta-

$* \bar{a}>\bar{e} /-. y a$

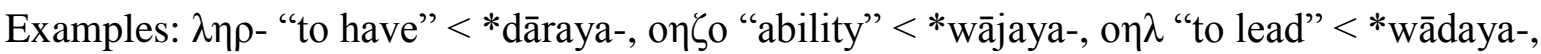

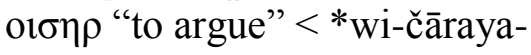

$a$ to $i$ before $s$ and $z$ 
$* a>i /$-.s, -. $z$

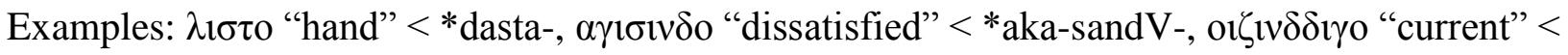

*waz-antiya-ka-

$a$ to $i$ before nasals:

$* a>-. i /-. n$

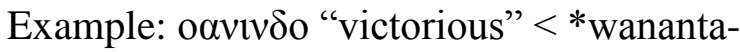

\subsection{Vowel assimilation}

In some cases, the quality of a vowel can be assimilated to that of a neighbouring vowel:

$* a>o /-. u$

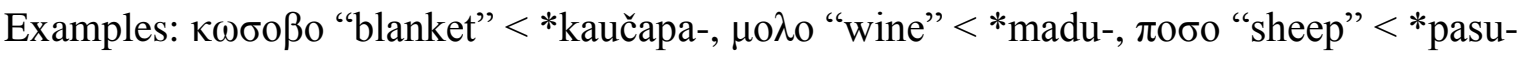

In the following example, we observe assimilation of voicing:

$* i>\partial$

In all the following examples, it seems that $i$ is changed to $\partial$, which occurs in the form $o$ in Greek script:

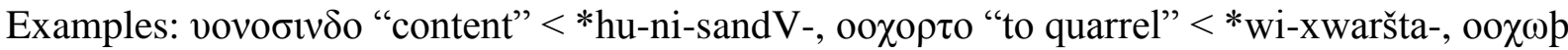
"quarrel" < *wi-xwarša-

\subsection{Dissimilation}

In the following example we can observe a process of dissimilation:

*\# wi- > ya

Example: 1 oo $\rho \circ$ "terms, conditions" < *wi-wāra-

\subsection{Lowering (?)}

The following example is an unclear case; it may be a Middle Persian loanword or it may be an archaism. This word is attested only once in the document X, which is a new text. It is not yet clear whether $\eta$ is pronounced as $i$.

$*_{\bar{l}}>\bar{e}(?)$

Example: $v \alpha \beta \eta \gamma_{0}$ "text, writing" $<*$ dipīka-

\subsection{Reduced vowel (ə):}

The reduced vowel $ə$ (in script $\alpha$ or $o$ ) occurs very often in initial position, especially before a consonant cluster:

$\emptyset>$ a/\#-CC

The different examples of this development are shown in the following table: 
Table 10. Examples of initial vowel

\begin{tabular}{|c|c|c|}
\hline PIr. & Bactrian & Examples \\
\hline *\# šk- & $\partial s^{2} k$ & $\alpha$ pк $\alpha \rho-$ "to follow" < *škara- \\
\hline *\#sp- & $\partial s p$ & $\begin{array}{l}\alpha \sigma \pi \alpha \sigma o \text { "service" < *spāsV-, } \alpha \sigma \pi \iota \sigma \text { "to serve" < *spasya-, } \alpha \sigma \pi \alpha \sigma \iota \gamma o \text { "groom" < } \\
\text { *spāsiyaka- }\end{array}$ \\
\hline *\# sn- & $\partial s n$ & $\alpha \sigma v \omega v o$ "daughter in law" <*snušā \\
\hline$* \# x \check{s}-$ & $\partial x$ & $\alpha \chi \alpha \nu \delta$ - "to control" < *xšayant-a-, $\alpha \chi v \omega \rho o$ "satisfaction" < *xšnau $\theta$ ra- \\
\hline$* \# x r-$ & $\partial x r$ & axpıvo "purchase" < *xray-ană- \\
\hline$* \# x w-$ & $\partial x w$ & 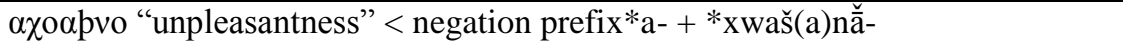 \\
\hline$\# * \theta w-$ & alf & $\alpha \lambda \varphi \alpha v \zeta$ - "acquire" $<* \theta$ wanja- \\
\hline$* \# d w-$ & alß & $\alpha \lambda \beta \alpha \rho \rho^{\prime}$ "court" <*dwar-a- \\
\hline
\end{tabular}

$* a, i>\partial$

Examples: $\varphi \rho о \beta \alpha \zeta \alpha \chi \alpha_{0} 108$ "prostrate" < *fra-pāzah-wāh, $\varphi \rho \mu_{\alpha} \alpha v_{0}$ "command" < *fra-māna,

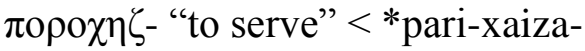

In the following examples, omicron occurs in a consonant cluster:

*-xm- > xam

Example: $\tau$ o $\alpha \mu \eta ı$ "relationship" < *tauxma-yă̄- (?)

\subsubsection{Suffixal $k$}

I describe the suffixal $* k$ in three different categories: A, B, and C. In the first group (A), we observe the following developments:

A.1. *-aka- > - $\gamma o$

Examples: $\alpha \gamma \alpha \lambda \gamma_{0}$ "wish" <*ā-gādaka-, $\alpha \gamma \gamma \alpha \rho \gamma_{0}$ "property" < *ham-kāraka-, $\beta \alpha \rho \gamma_{0}$ "animal for riding" <*bāraka-, $\kappa \alpha \delta$ o "house" <*kataka-

A.2. *-aka- after a voiceless consonant > -ko

Example: vapкo "pupil" < *hāwišta-ka-

A.3. *aka-after $h>-\alpha x 0^{109}$

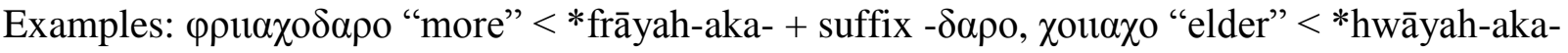

In the second group (B), we observe the following development:

B. *-aka- > - $\alpha \gamma o$ and $*_{-} u k a-<-o \gamma o$

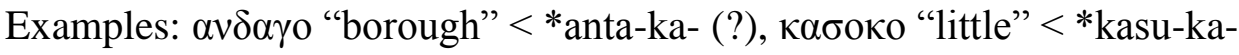

In the group, $\mathrm{C}$, the following development is observed:

C. *-iyaka- > $\imath \gamma o<\imath l o$

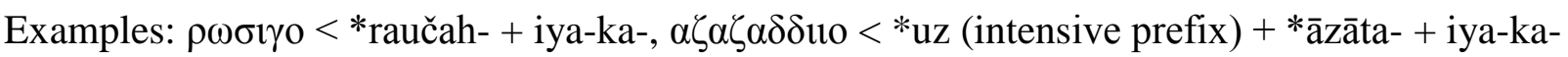
$\rho .^{110}$

According to Sims-Williams, the development of *(i)yaka- to - $\eta$ \%o seems to occur only after

108 According to Sims-Williams, o in unstressed syllables, for example, in the preverbs $\varphi \rho 0-$ and $\pi \circ \rho \circ$, often represents the reduced vowel a cf. Sims-Williams 1989a: 234.

${ }^{109}$ This development is mentioned by Sims-Williams in Sims-Williams and Tucker 2005: 594.

${ }^{110}$ Sims-Williams 2007a: 217. 
According to the Manichean document, it is clear that *-āna-ka- is changed to - 'ng (Greek script $-\alpha \gamma \gamma o$ ). This suffix is used to derive adjectives mostly from nouns and pronouns.

Examples: lyn'ng "Glory of the Religion", $m l$ 'm'ng "this-worldly, mundane"111

Another example, which proves the development of suffixal $* k$ to $g$, is $-\eta \gamma \gamma o,-i \gamma \gamma o$ (Manich.-yng) <*-aina-ka-, e.g., pwnyng "consisting of merits". 112

\subsubsection{Summary}

In the case of its historical phonology, Bactrian shares some similarities with other Eastern Iranian languages. For example, the conservative feature of Eastern Iranian languages, retention of the sound $\theta$, can be observed in the Bactrian word $1 \theta \alpha$ o "thus, also". The voicing of the fricative in the Old Iranian clusters $* f t$ and $* x t$ is also attested in Bactrian. In general, $* b, d, g$ develop into fricatives in both initial and internal positions, as in other Eastern Middle Iranian languages.

In Bactrian, we have an additional development of $* d$ to $l$ via $\delta$ in both initial and internal positions. This development can also be found in some Modern Eastern Iranian languages, such as Pashto, Munji, and Yidgha. According to the Manichaen fragment and other materials, we can conclude that there is a phonemic distinction between voiced plosives and voiced fricatives in Bactrian. $\beta \beta$ probably represented in a special period [b], whereas $\beta$ was used for [v]. It seems that intervocalic $* b$ is changed to [v], as in many Middle and Modern Eastern languages. In new texts, it seems that $\beta$ represents both [b] and [v]. In the same way, it seems that $<\delta \delta>$ represents [d], and that $\langle\delta>$ shows fricative [đ]. $\gamma$ may represent both $[\mathrm{g}]$ and $[\gamma]$. [g] would be a development of $* k$ and $[\gamma]$ can be a development of $* g$. It is not clear where intervocalic $* p$ has developed to $[\mathrm{b}]$ or $[\mathrm{v}]$. Generally sonorants, affricates, and fricatives are preserved with the exception of $\theta, \check{c}$, and $\check{J}$. * $\theta$ has developed to $h$ in Bactrian. The only exception is $1 \theta \alpha o$ "also", which may show an archaism. Among the modern Eastern Iranian languages, Pashto, Munji, and Yidgha also do not preserve $* \theta$. But the outcome is not as in Bactrian. $* \check{c}$ is depalatalized and probably results in $t$. It is not clear exactly what the outcome of ${ }^{*} y$ is, whether it is [dz], [d] or [3]. * $s$ after $a$ palatal vowel is changed to $s ́$.

In the case of consonant clusters, the Eastern Iranian languages are treated variously. Some characteristics of Bactrian cannot be observed in other Middle Iranian languages, for example the preservation of $* f r$ and $* r d$ and the development of $* r t$ to $r d$. These phonological features are attested in few New Eastern languages. The retention of * $f r$ is found in Yaghnobi. In Ossetic and Wakhi, we find the preservation of $* r d$. The change of $* r t$ to $r d$ is attested in Yaghnobi and Wakhi. In the following table, some of phonological developments in Bactrian are selected and compared to developments in other Middle and New Iranian languages. According to the following table, we can conclude that Bactrian is more connected with Choresmian and Sogdian than with Saka. Among the New Eastern languages, it is closer to Wakhi and Iškāšmīi-Sanglīčī and further from the Shughni group and Parāčì:

\footnotetext{
${ }^{111}$ Sims-Williams 2009: 263.

112 Sims-Williams 2009: 264.
} 
Table 11 Comparable phonological developments in Middle and New Eastern Iranian languages

\begin{tabular}{|c|c|c|}
\hline \multirow[t]{2}{*}{ Bactrian } & \multicolumn{2}{|c|}{ The same development in other Eastern languages } \\
\hline & Middle Eastern languages & New Eastern Languages \\
\hline$* b>v$ & Sogdian, Choresmain, Khotanese & $\begin{array}{l}\text { Yaghnobi, Wakhi, Yazghulami, Shughni group, } \\
\text { Iškāšmī-Sanglīčì, Yidgha, Munǰ̄i, Pashto }\end{array}$ \\
\hline$* \mathrm{~d}>1$ & - & Yidgha, Munj̄̄i, Pashto \\
\hline$* \mathrm{~g}>\gamma$ & Sogdian, Choresmain, Khotanese & $\begin{array}{l}\text { Ossetic, Yaghnobi, Wakhi, Yazghulami, Iškāšmī̄- } \\
\text { Sanglīčì, Yidgha, Munǰ̄i, Pashto }\end{array}$ \\
\hline$*_{-p}->v$ and $b$ & $\begin{array}{l}>\text { b in Choresmian, > w in } \\
\text { Khotanese }\end{array}$ & Ossetic (b > v) \\
\hline$*_{-\mathrm{t}-}>\mathrm{d}, \mathrm{d}$ & - & Iškāšmī-Sanglīčī \\
\hline$*-\mathrm{k}->\mathrm{g}$ & $\begin{array}{l}\text { Sogdian, Choresmain, Khotanese (g } \\
>\gamma)\end{array}$ & Ossetic, Yazghulami, Iškāšmī-Sanglīčī, Pashto, Parāč̄̄ \\
\hline$* f>f$ & Sogdian, Choresmian & $\begin{array}{l}\text { Yaghnobi, Wakhi, Yazghulami, Shughni group, } \\
\text { Iškāšmī-Sanglīčìi, Yidgha, Munj̄î, Parāčì, Ōrmuṝi }\end{array}$ \\
\hline$*_{-} \theta->\mathrm{h}$ & Khotanese (?) & - \\
\hline$* x>x$ & Sogdian, Choresmian & $\begin{array}{l}\text { Ossetic, Yaghnobi, Wakhi, Yazghulami, Shughni } \\
\text { group š(x), Iškāšmīi-Sanglīčî, Yidgha, Munj̄î, Parāčī (> } \\
\text { kh), Ōrmuṛi }\end{array}$ \\
\hline *čc- > ts & Choresmian, Khotanese & $\begin{array}{l}\text { Ossetic, Wakhi (both č and Łs), Yazghulami, Shughni } \\
\text { group š(x), Iškāššmī-Sanglīčī, Pashto, Ōrmuṛī }\end{array}$ \\
\hline$*_{-}$-č- $>$ts & Choresmian & Wakhi, Iškāšmī-Sanglīčñ \\
\hline$*_{-} \check{\mathrm{s}}_{-}>$-š- & Sogdian & Yaghnobi, Wakhi \\
\hline$* \mathrm{ft}>\mathrm{vd}$ & Sogdian, Choresmian, Khotanese & $\begin{array}{l}\text { Ossetic, Wakhi (both vd and b), Yazghulami, Shughni } \\
\text { group š(x), Iškāšmī-Sanglīčî, Yidgha, Munj̄̄i, Pashto } \\
\text { (wd) }\end{array}$ \\
\hline$* x t>\gamma d$ & Sogdian, Choresmian & Ossetic, Wakhi, Yazghulami, Yidgha, Munǰ̄ \\
\hline$*_{\text {-fr- }}>$-fr- & - & Yaghnobi \\
\hline$* \theta \mathrm{r}->\mathrm{hr} / \mathrm{r}$ & Choresmisn $(>\check{\mathrm{s}} / \mathrm{hr})$ & Iškāšmī-Sanglīčīi (> r) \\
\hline$*_{-}-\theta \mathrm{r}->\mathrm{hr} / \mathrm{r}$ & Khotanese (> r) & $\begin{array}{l}\text { Iškāšmī-Sanglīčì, Yidgha, Munǰ̄i, Pashto (in all these } \\
\text { languages > r) }\end{array}$ \\
\hline$* \mathrm{rt}>\mathrm{rd}$ & - & Yaghnobi, Wakhi \\
\hline $\begin{array}{l}* \mathrm{rd}>\mathrm{rd} \text {, once } \\
\mathrm{rl}\end{array}$ & - & Ossetic, Wakhi \\
\hline$*_{\mathrm{rs}}>\mathrm{rs}$ & Sogdian & Ossetic, Yaghnobi, Wakhi, Yidgha, Munǰ̄̄ \\
\hline$* \mathrm{rz}>\mathrm{rz}$ & Sogdian, Khotanese & Wakhi, Yidgha, Munǰ̄i, Parāč̄̃ \\
\hline \multicolumn{3}{|l|}{$*$ ršt $>$} \\
\hline$*$ št $>$ št, t & $\begin{array}{l}\text { Sogdian (> št), Choresmian (> š), } \\
\text { Khotanese (șț) }\end{array}$ & 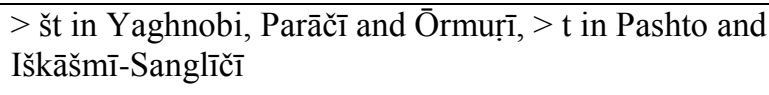 \\
\hline$*_{\mathrm{sr}}>\check{\mathrm{s}}$ & $\begin{array}{l}\text { Sogdian, Choresmian, Khotanese (> } \\
\text { s) }\end{array}$ & 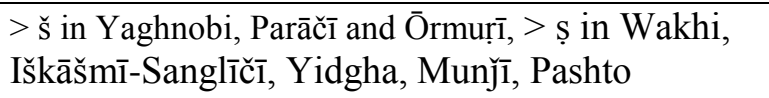 \\
\hline$*$ str & & \\
\hline
\end{tabular}

In the case of vowels (except for $a$ and $\bar{a}$ ), the Greek alphabet helps us more than the Manichaen script. $\alpha$ is used for $a, \bar{a}$ and initial ə-. In this case, Manichaen script is more informative than Greek, as it distinguishes between short $a$ and long $\bar{a}$. 
The letter $\varepsilon$ represents $e$ and $\eta$ shows $\bar{e}$. The letter 1 may represent both $i$ and $\bar{l}$. The Greek letter $\omega$ represents $\bar{o}$, but the phonetic range of the phoneme $o$ is extremely wide. It may show $u$, $\bar{u}, o$, , , or $\emptyset$.

In Bactrian, we find the other common Middle Iranian processes of contraction, syncope, monophthongization and palatalization, as well as assimilation and dissimilation. The internal Old Iranian short vowels $a, i, u$ generally preserve their identities in Bactrian. The initial $* i$ - can disappear. The initial $* u$ - can be preserved or changed to $ə$. The internal $* i$ in prefixes, for example, in $* n i$, has developed probably also to ə. The treatment of $*_{r}$ is complex in Eastern languages such as Sogdian, Choresmian, and Khotanese. In this case, we can observe the same development in Bactrian as in Parthian and Persian. In all these languages, in the natural and palatal context, the outcome will be ir and in the environment of a labial $u r$.

A vowel in the initial position and $* \bar{a}$ in the final position can be lost. Generally, the final an, $a m$, and $* h$ after a vowel can also be omitted.

Syncope can occur in various environments, for example, between plosive and sonorant, between plosive and plosive, between fricative and plosive, and between fricative and nasal.

As we know, one of the characteristics of Eastern Midddle Iranian languages is a tendency to shorten or lose Old Iranian long vowels in certain circumstances. The most common examples of monophthongization in Bactrian are *au $>0$, *ai $>\bar{e}, *$ aya $>\bar{e}(>\overline{1}), \bar{a} y \bar{a}>\bar{a}, *$-āya $>\overline{1}, *$ iya $>$ $\overline{\mathrm{e}} / \overline{1}, *_{\text {iya }}>\mathrm{i}, *_{\text {iya }}<\overline{\mathrm{e}}, *_{\text {awa- }}>\overline{\mathrm{o}}$ and $*_{-} \mathrm{a} w \mathrm{i}->\overline{\mathrm{a}}$. In this case, it seems that Bactrian is closer to Sogdian than to other Eastern Middle Iranian languages.

The development of $* a$ to $i$ before $y a, i, s, z$, and $n$ and the development of $* \bar{a}$ to $\bar{e}$ before $y a$ are the most common examples of vowel palatalization in Bactrian.

As examples of vowel assimilation, we can mention here the development of $* a>$ to $o$ before $u$ and $* i$ to $\partial$.

*wi- can be dissimilated to $y a$. The development of $* \bar{l}$ to $\bar{e}(?)$ is probably an example of lowering in Bactrian.

It seems that in Bactrian there is a reduced vowel (ə), which may occur in different positions, for example, in the initial position before a consonant cluster. It is the most common occurrence of that in Bactrian. $* a$ and $* i$ can develop to $ə$. The reduced vowel may also occur in a consonant cluster, for example, in ${ }^{*} \mathrm{xm}>\mathrm{x} ə \mathrm{~m}$.

In the case of suffixal *-aka-, we can observe three different developments. It can be changed to $-\gamma_{0}$, and after a voiceless consonant, it can develop to $-k o$ or after $h$ to $-\alpha x o$. Suffixal

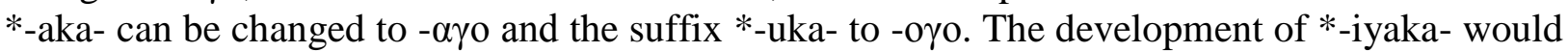
be 1 o or t1o in Bactrian. 


\section{CHAPTER THREE: NOUN PHRASES}

This chapter begins with an overview of the substantive, the nominal system, and the definition of the substantive. It also introduces noun phrases in Bactrian. Here, the discussion centers on the features of head and dependent nouns.

\subsection{The substantive}

\subsubsection{Number and case}

Sims-Williams points out that "The Bactrian of the Kushan period displays a system of two numbers and two cases". ${ }^{113}$ It can be added that a difference can be perceived between this system in material from the inscriptions and the economic and legal documents, letters, and Buddhist texts. ${ }^{114}$

The following table shows the case endings most commonly found in the researched texts:

Table 12. Case morphology in Inscriptions (Kushan period)

\begin{tabular}{|l|l|l|}
\hline & SG & PL \\
\hline DIR & $-o$ & $-\varepsilon$ \\
\hline OBL & -1 or $-\varepsilon$ & $-\alpha v_{0}$ \\
\hline
\end{tabular}

The distinction between direct and oblique case with singular number can still be seen in the inscriptions, "only in traditional expressions", ${ }^{115}$ such as pal "king", poope "city" and the names of kings. In the documents, however, there is no remnant of the oblique ending. In only one instance, a form with a morphological ending that could be explained as oblique seems to have been preserved beside the direct: $1 \alpha 0$ beside $1 \alpha 0$ "grain". Both forms are used, however, as direct. ${ }^{116}$ In the inscriptions, plural nouns are found both in the direct and in the oblique case. For example, $\beta \alpha \gamma \varepsilon$ "gods" is used as a direct case, plural noun. There are also oblique singulars

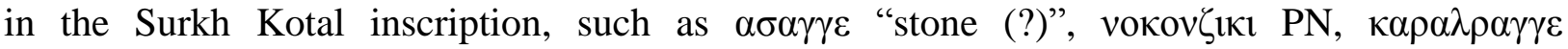

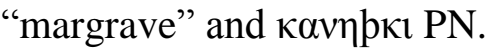

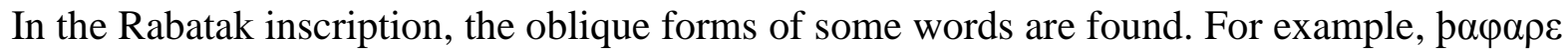

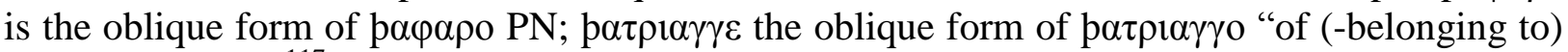

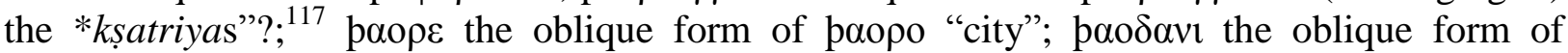

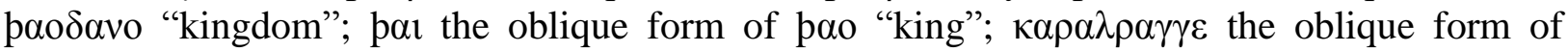

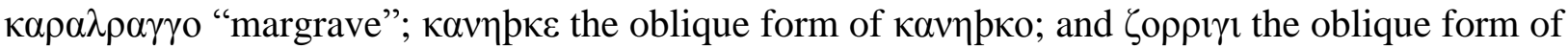

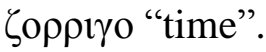

In the economic texts, legal documents, letters, and Buddhist texts, plural nouns are found almost exclusively in the oblique. In this instance, the morpheme - $\alpha$ vo indicates the plural. The plural oblique case has been generalized.

The examples of case distinction in Bactrian are extremely rare, and we can therefore conclude that a real case distinction is no longer found in nouns.

\footnotetext{
${ }^{113}$ Sims-Williams 2007a: 40.

${ }^{114}$ It must be added here that only two Buddhist texts are published in Bactrian Documents II by Sims-Williams.

115 Humbach 2003: 160.

${ }^{116}$ Sims-Williams 1997b: 7.

${ }^{117}$ Sims-Williams 2004 (2008): 60.
} 
From the above information, we can conclude that two changes have taken place in the nominal system of Bactrian, as in other Middle Iranian languages: ${ }^{118}$

1- Generalization of the plural oblique ending - $\alpha$ vo.

2- The loss of the singular oblique, generalization of the direct case.

The next table shows case distinctions in Bactrian after the above changes:

Table 13. Case endings in new Bactrian material

\begin{tabular}{|l|l|l|}
\hline & SG & PL \\
\hline DIR/OBL & -0 & $-\alpha v o$ \\
\hline
\end{tabular}

\subsubsection{Gender}

According to Sims-Williams, in Bactrian, "feminine stems are no longer distinguishable from masculines". ${ }^{119}$ But he refers to a few remnants of the original feminine ending $-\alpha$ in older texts, such as the Rabatak and Surkh Kotal inscriptions. For example, the $\alpha$-ending of some nouns and adjectives, such as $\lambda_{1 \zeta} \alpha / \lambda i \zeta_{0}$ "citadel" <*dizā-, ${ }^{120} \alpha \gamma 1 \tau \alpha$ "the whole(?)", $\alpha \mu \gamma \alpha$ "same,

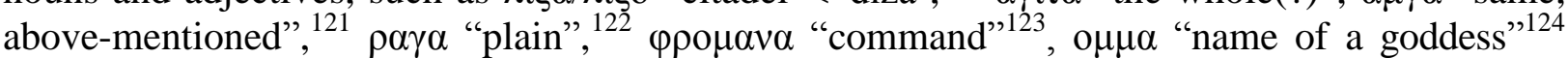
and $v a v \alpha$ "name of a goddess" 125 distinguishes them from masculine forms.

Similarly, the articles 1 and $\mu$ o have the feminine forms $1 \alpha$ and $\mu \alpha$, but these are not used consistently. The feminin $1 \alpha$ is also attested in $1 \alpha \mu \alpha \rho \gamma_{0}$ "meadow"126 and $1 \alpha \rho \omega \sigma 0$ "day". ${ }^{127}$

The feminine article $\mu \alpha$ is consistently used with the feminine noun $\lambda_{\imath} \zeta_{0}$ "citadel" $<*$ dizā-, ap. didā in the Surkh Kotal inscription. ${ }^{128}$

(Surkh Kotal 1)

\begin{tabular}{|c|c|c|c|c|c|c|}
\hline$\varepsilon 1 \delta o$ & $\mu \alpha$ & $\lambda i \zeta_{0}$ & $\mu \mathrm{o}$ & 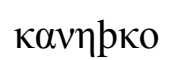 & o $\alpha v i v \delta o$ & $\beta \alpha \gamma о \lambda \alpha \gamma \gamma о$ \\
\hline DEM & ART & fortress & ART & Kaniška & victor & sanctuary \\
\hline
\end{tabular}

There are some suffixes such as $-\sigma 0,-v \zeta_{0},-\gamma_{0}$ and $-\gamma \gamma \mathrm{o}$ in Bactrian, forming feminine adjectives from names of persons and places, for example: $\tau$ o $о \sigma \alpha \alpha \nu \zeta_{0}$ "Turkish", $\alpha \sigma \kappa ı \sigma \alpha \gamma \gamma_{0}$ "of

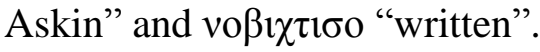

\subsubsection{Noun phrases}

In Bactrian, the noun phrase is generally head-final, and most modifiers occur before the head noun:

\footnotetext{
${ }^{118}$ Haig mentions these two changes for Western Middle Iranian languages; see Haig 2008: 137.

${ }^{119}$ Sims-Williams 2007a: 40.

${ }^{120}$ Sims-Williams 2007a: 40.

${ }^{121}$ Sims-Williams 2004 (2008): 64.

${ }^{122}$ Sims-Williams 2004 (2008): 63.

${ }^{123}$ Sims-Williams and Cribb 1996: 81.

${ }^{124}$ Sims-Williams and Cribb 1996: 79.

${ }^{125}$ Sims-Williams and Cribb 1996: 78.

${ }^{126}$ Sims-Williams 2007a: 231.

${ }^{127}$ Sims-Williams 2007a: 261.

${ }^{128}$ See Surkh Kotal 1, 2, 3, 6, 11, 13, 16, 19.

${ }^{129}$ Cf. Lazard, Grenet and de Lamberterie 1984: 227.
} 


\section{(F3)}

(2) $\alpha \beta o$

PRE

\section{$\kappa \alpha \delta \alpha \gamma о \beta เ \delta 0$ \\ governor}

"in the court of governor"

(dd 4)

(3)

$\begin{array}{ll}\boldsymbol{\sigma \alpha \gamma o} & \pi 0 \rho 0 \\ \mathrm{PN} & \text { son } \\ \text { "son of Sag"131 }\end{array}$

(bg 10)

(4)

$\begin{array}{ll}\text { loxpooip } \lambda_{0} & \boldsymbol{\alpha \beta} \boldsymbol{\beta} \boldsymbol{\alpha} \boldsymbol{\alpha} \boldsymbol{\mu} \boldsymbol{\mu} \\ \text { Yukhsh-wirl } & \text { stream } \\ \text { "stream of Yukhsh-wirl"133 }\end{array}$

(eh 4)

(5)

\begin{tabular}{|c|c|c|}
\hline$\tau о \chi о \alpha \rho \circ \sigma \tau \alpha \nu \circ$ & odo & $\gamma \alpha \rho \sigma \imath \gamma о \sigma \tau \alpha \nu o$ \\
\hline Tukharistan & and & Gharchistan \\
\hline
\end{tabular}

The construction in which the dependent noun follows the head noun is much less common:

(C 3)

(6)

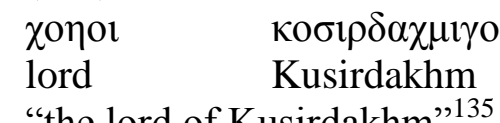

"the lord of Kusirdakhm"135

(F 1-2)

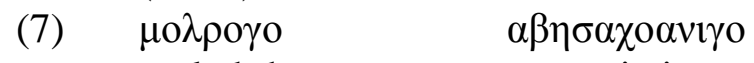

sealed-document renunciation

"sealed-document of renunciation" 136

In some Iranian languages, such as Middle and New Persian, the dependent noun may follow the head noun with a connecting ezafe particle. ${ }^{137}$ In Bactrian, the ezafe may link the different elements, for example, a noun, a name, or one or more adjectives to a head noun. There are also cases in which no ezafe particle is used. ${ }^{138}$

\subsubsection{Appositional modifiers}

As in other languages, sometimes two nouns are placed side by side, and one defines or modifies the other. In Bactrian, the same syntax that is used to express such a relationship as possession can also be used for expressing apposition. That is, apposition could include the particle 1 , which is usually employed for the ezafe construction. The appositive element can be a short or long combination of words. The following elements can be used as appositional modifiers in the Bactrian language:

\footnotetext{
${ }^{130}$ Sims-Williams 2000a: 45.

${ }^{131}$ Sims-Williams 2007a: 105.

${ }^{132}$ According to Sims-Williams, the name of a place, including a meadow and stream see Sims-Williams 2007a: 218.

${ }^{133}$ Sims-Williams 2007a: 65.

${ }^{134}$ Sims-Williams 2007a: 123.

${ }^{135}$ Sims-Williams 2000a: 39.

${ }^{136}$ Sims-Williams 2000a: 45.

${ }^{137}$ Heston 1976: 19.

${ }^{138}$ For more details on the ezafe in Bactrian, see Gholami 2011: 17.
} 
A) Titles, patronymics and family names can appear with or without the ezafe particle in Bactrian.

In the following example, the first name and family name appear with an ezafe particle. This construction is very rare in the extant material:

With Particle i:

(xd 6)

$\begin{array}{lll}v \alpha \tau \text { o } & 1 & \boldsymbol{\chi \alpha \rho \alpha \gamma \alpha \boldsymbol { \alpha }} \\ \text { Nat } & \text { ezafe } & \text { family name/patronymic "Kharagan" } \\ \text { "Nat Kharagan" } & \end{array}$

The first and family name can also appear without an ezafe particle. This construction is much more common. For example:

(cf 1$)$

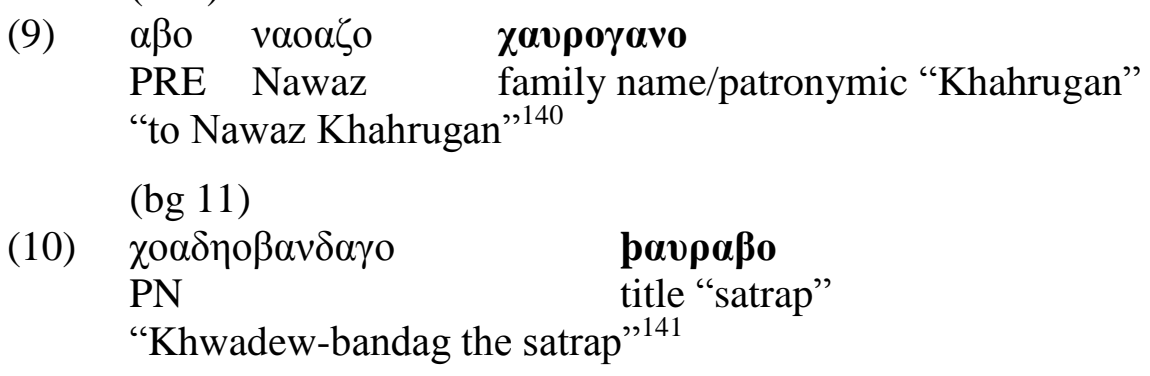

In the case of the recipient of letters and names of witnesses, both the last and first name are used, and there is usually no ezafe particle between them. When the first person mentions his name, he occasionally introduces himself with his first name and the name of his father, for example, Lad-guzg the son of Yol-guzg.

In constructions with the name of a king and the word pao "king" in apposition, the name of the king occurs more often before the word pao.(see Table 14) than after it. In light of the results in the following table, we can conclude that Bactrian seems to have the same structure as in Middle Persian.

Table 14. Nominal phrases consisting of the name of king in Rabatak inscription

\begin{tabular}{|l|l|}
\hline structure & number of examples \\
\hline the name of king + p $\alpha \mathrm{o}$ & 5 \\
\hline p $\alpha \mathrm{o}+$ the name of king & 1 \\
\hline
\end{tabular}

It must be added that this construction is attested only in inscriptions. In the Rabatak inscription, there are five examples of occurrence of bao after the name of the king, while there is only one example of the other type:

The name of the king + pao

(Rabatak 14)

\begin{tabular}{|c|}
\hline 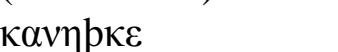 \\
\hline $\begin{array}{l}\text { Kanishka.OBL } \\
\text { "king Kanishka",142 }\end{array}$ \\
\hline
\end{tabular}

\footnotetext{
${ }^{139}$ Sims-Williams 2007a: 145.

${ }^{140}$ Sims-Williams 2007a: 79.

${ }^{141}$ Sims-Williams 2007a: 65.

${ }^{142}$ Sims-Williams 2004 (2008): 56.
} 
pao + the name of the king

(Rabatak 7)

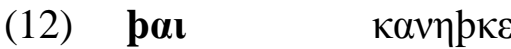

king.OBL Kanishka.OBL

"king Kanishka""143

In Surkh Kotal. there is only one example of such a construction and the name of a king, i.e., the name Kanishka occurs after pao:

(Surkh Kotal 1)

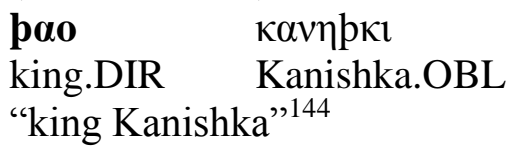

In the case of names of gods, the word $\beta \alpha \gamma_{0}$ "god" generally occurs before the name of the god:

$\left(\mathrm{O} 3^{\prime}\right)$

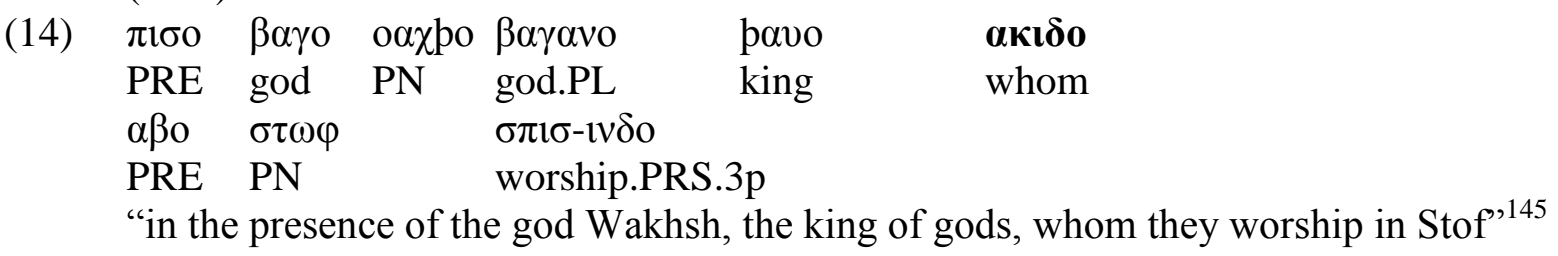

In document $\mathrm{T}$ (from 700/701 A.D.), there are many examples of the occurrence of $\beta \alpha \gamma o$ after the name of the god. This document belongs to the new texts and probably may show a development in the syntax of Bactrian during this period:

(T 12-13)

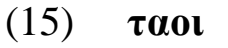

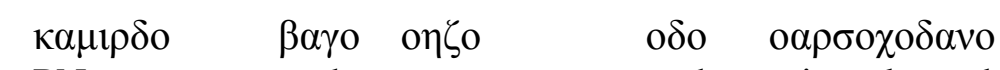
you.OBL. PN god power and miraculous ability

"The power and miraculous ability of you, the god Kamird" 146

B) Names of places

The names of places occur as the second member of a phrase. For example:

(bg 11)

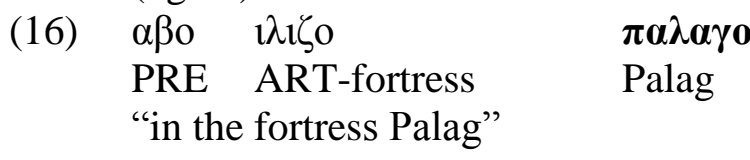

C) Names of days and months

There are some differences between the use of the month names in old and new texts. The names of the days always occur after $\rho \omega \sigma 0$ "day", both in old and new texts. The following example is from a text of the year 247 of the Bactrian era. The name of the day occurs after $\omega \sigma 0$ "day":

\footnotetext{
${ }^{143}$ Sims-Williams 2004 (2008): 56.

${ }^{144}$ Lazard, Grenet and de Lamberterie 1984: 226.

${ }^{145}$ Sims-Williams 2000a: 81.

${ }^{146}$ Sims-Williams 2000a: 101.
} 
(F 1)

(17) $\quad \rho \omega \sigma 0 \quad \omega \rho 0 \mu о \zeta \delta 0$

day Ormuzd

"the day Ormuzd"147

In the new texts, as the following example from the year 470 of the Bactrian era shows, the name of the day also occurs after $\rho \omega \sigma 0$ "day":

(S 1)

(18) $\rho \omega \sigma 0$

plpto

day Risht

"the day Risht"148

The only exception is found in the document $\mathrm{A}$, from the year 110, in which the name of the day appears before $\rho \omega \sigma 0$ "day". From my point of view, the change of word order is probably influenced by the use of "elapsed": ${ }^{149}$

(A 1)

(19) $\sigma \alpha \chi \tau 0$

$\boldsymbol{\alpha} \boldsymbol{\beta} \boldsymbol{\alpha \mu \boldsymbol { \mu } \chi 0 \mathrm { ovo }} \quad \rho \omega \sigma 0$

elapsed Abmukhwin day

"the elapsed day Abmukhwin"150

In the case of the month names, in the Bactrian era 195-527 (Documents D-X), ${ }^{151}$ the name of the month occurs after $\mu \alpha v o$ or $\mu \alpha \mathrm{o}$ "month".

The following example is from the year 247 in the Bactrian era:

(F 1)

(20)

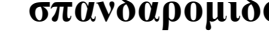

month Spandarmid

"the month Spandarmid"152

The next example is from the year 507 in the Bactrian era:

(V 1)

(21) $\mu$ avo

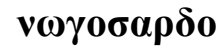

month New-year

"the month New-year"153

In the three old documents A, B, and C (110-157), the name of the month occurs before $\mu \alpha v o$ or $\mu \alpha_{0}$ "month". According to Sims-Williams, the placement "of the word $\mu \alpha_{0}$ "month" after the name of the month seems to be an archaic feature": ${ }^{154}$

(A 1)

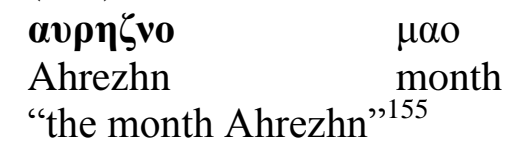

${ }^{147}$ Sims-Williams 2000a: 45.

${ }^{148}$ Sims-Williams 2000a: 95.

${ }^{149}$ For the use of $\sigma \alpha \chi \tau 0$ "elapsed" with a day-name, see Sims-Williams 1998b: 150-151.

${ }^{150}$ According to Sims-Williams, "the day Abmukhwin, having elapsed"; Sims-Williams 2000a: 33.

${ }^{151}$ In the document $\mathrm{Y}$, the month is not mentioned.

${ }^{152}$ Sims-Williams 2000a: 45.

${ }^{153}$ Sims-Williams 2000a: 115.

${ }^{154}$ Sims-Williams 1998b: 150

${ }^{155}$ Sims-Williams 2000a: 33. 
(C 1)

(23) $\begin{array}{ll}\boldsymbol{\delta} \boldsymbol{\rho} \eta \boldsymbol{\mu} \boldsymbol{\alpha} \mathbf{\tau} \boldsymbol{\alpha} \boldsymbol{\alpha v o} & \mu \alpha \mathrm{o} \\ \text { Drematigan } & \text { month } \\ \text { "the month Drematigan"156 }\end{array}$

\section{Apposition with particle $\mathrm{t}$ :}

In many Iranian languges, such as Middle Persian, Kurdish, Gilaki, and New Persian, the particle " $\mathrm{i}$ " is used in genitive/possessive constructions. In Bactrian, in some cases, it has the same function. This particle can also be used for expressing apposition, as in the following examples:

(al 18)

(24) $\varphi \alpha \rho о$

for $\quad \mathrm{PN} \quad \mathrm{EZ}$ lord

"for Wirishtmish the lord"157

(G 2-3)

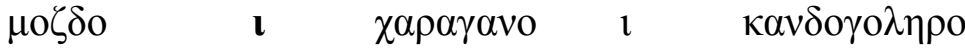

Muzd EZ Kharagan EZ keeper of the granary

"Muzd Kharagan, the keeper of the granary"158

(H 3)

(26) $\mu \alpha v o$

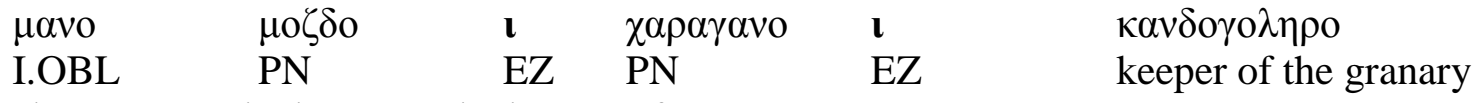

"by me, Muzd Kharagan, the keeper of granary"

(ba 4)

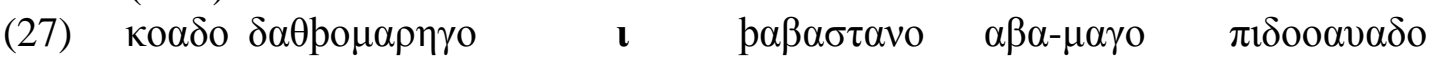

that PN EZ eunuch PRE-I.CP appeal.PST.3s

"that Dathsh-mareg the eunuch has appealed to me". ${ }^{159}$

(ck 1)

$\begin{array}{lllll}\alpha \beta o & v \alpha o \alpha \zeta o & 1 & \varphi \rho u o & \beta \rho \alpha \delta o \\ \text { to } & \text { PN } & \text { EZ } & \text { dear } & \text { brother }\end{array}$

"to Nawaz, (my) dear brother"

According to the above mentioned examples, word order in apposition constructions is: $P N \boldsymbol{\imath}$ Title. The following example is clearly an exception, because the particle $\mathbf{\imath}$ occurs before the name of a god, i.e., oxxpo:

(L 2)

(29) Bayo l oxхpo

god EZ Wakhsh

"the god Wakhsh"160

\section{Apposition containing a group of words}

The appositional phrase can be a noun phrase containing a group of words, as shown in the following example:

\footnotetext{
156 Sims-Williams 2000a: 39.

${ }^{157}$ Sims-Williams 2000a: 163.

158 Sims-Williams 2000a: 49.

${ }^{159}$ Sims-Williams 2007a: 53.

${ }^{160}$ Sims-Williams 2000a: 65.
} 
(ea 1-2)

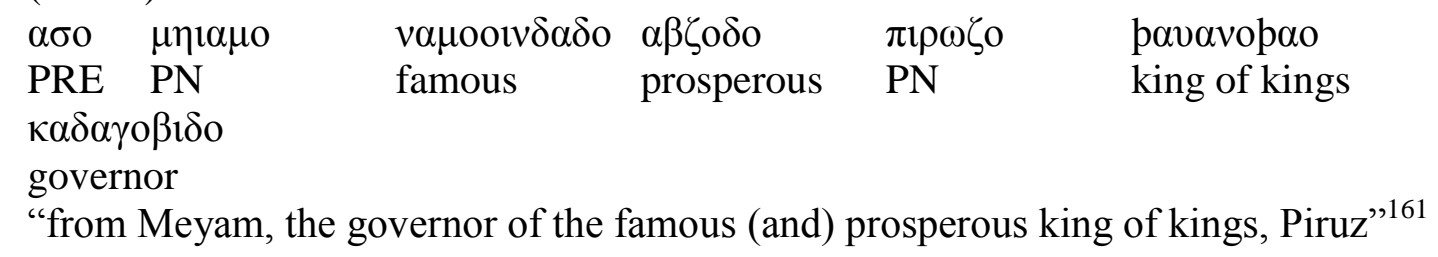

In this case, the adjectives v $\alpha \mu$ oo $v \delta \alpha \delta$ o "famous" and $\alpha \beta \zeta$ o $\delta$ o "prosperous" modify the

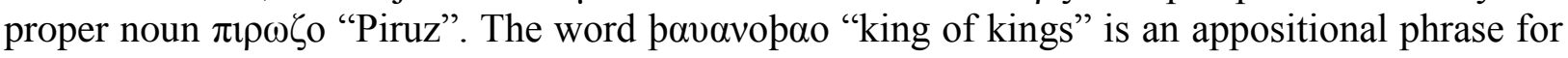
$\pi \iota \omega \zeta o$ "Piruz". The phrase $v \alpha \mu$ oo $v \delta \alpha \delta o ~ \alpha \beta \zeta o \delta o ~ \pi \imath \rho \omega \zeta o ~ p \alpha v \alpha v o p \alpha o$ is a dependent noun for $\kappa \alpha \delta \alpha \gamma o \beta 1 \delta$ o "governor", which is the head noun, and these two phrases are an appositional phrase for the proper name $\mu \eta \iota \mu$.

\section{Summary}

According to the above information and examples, it can be concluded that in appositional constructions, the names of persons, places, gods, days, and months generally occur after the nouns themselves. There is an exception in the case of the names of kings. In the Rabatak inscription, pao occurs more frequently after the name of the king, which we do not expect in Bactrian. As in Middle Persian and Pathian, e.g., frēdōn šāh, wištāsp šāh, zarwān šāh, tūrānšāh the names of the kings occur before the words for king. We can interpret this syntactical feature as a Middle Persian or Parthian influence on Bactrian. In the case of the name of gods, we can find the common syntactical pattern, which is expected in Bactrian. The only exception is document $\mathrm{T}$, in which the name of the god occurs very often before the word $\beta \alpha \gamma o$ "god". It may show a development in the late Bactrian language.

\subsubsection{Numerals}

In this chapter, I first analyse the position of the number in a noun phrase. In Bactrian, numerals can be expressed in a variety of ways: by ciphers, words, by both ciphers as well as words, or partially by words and partially by ciphers. The question arises here of whether or not there is a connection between the position of the number and the type of expression of the numeral (i.e., as a word or as alphabet letter). As a second focus in this chapter, I investigate the relationship between numbers (as a modifier) and nouns to show whether the noun tends to occur more frequently in the singular or plural. It also is a question whether a number may appear in the plural, that is, with plural marking or as plural lexical item.

\subsubsection{Cardinal numbers}

As the cardinal numbers are expressed in English by the figures 1 to 10, so in a similar way are Bactrian's numerals also expressed very frequently as figures (such as numerals 1 to 10, 20, $30,40,50,60,70,80,90,100,200,300,400,500$, and 1000). In Bactrian Greek, letters of the alphabet are used to introduce these types of numerals in figures (e.g., $\alpha$ instead of 1 , and $\beta$ instead of 2). There are also some examples of alphabetical numbers.

The following table shows the occurrences of numbers when written alphabetically in BD I and II:

${ }^{161}$ Sims-Williams 2007a: 109. 
Table 15. The occurrences of alphabetical numbers in BD I and II

\begin{tabular}{|c|c|c|}
\hline numbers in alphabet & translation & $\begin{array}{l}\text { the total of occurrences in } \\
\text { BD I and II }\end{array}$ \\
\hline $1 \omega \gamma o$ & one & 21 \\
\hline$\lambda \mathrm{ol}, \lambda \mathrm{oo}, \lambda \mathrm{oo}$ & two & 7 \\
\hline боф & four & 4 \\
\hline$\pi \alpha v \zeta o$ & five & 2 \\
\hline$\alpha \tau \alpha o$ & eight & 1 \\
\hline$\lambda \alpha \sigma o$ & ten & 6 \\
\hline 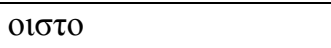 & twenty & 4 \\
\hline$\pi \alpha \nu \zeta \alpha \sigma o$ & fifty & 3 \\
\hline$\chi 0 \alpha \tau 0$ & sixty & 1 \\
\hline$\sigma \alpha \delta o$ & hundred & 10 \\
\hline$\pi \alpha \nu \zeta \circ \sigma \alpha \delta$ o & five hundered & 1 \\
\hline
\end{tabular}

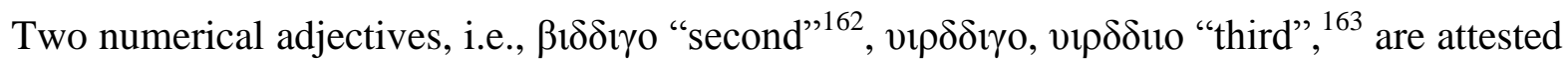
in BD I and II.

There are two main groups. Each group has three subtypes based on the position and the kind of numeral. In the first main group, the number occurs before the noun. In the second main group, the number appears after the noun. For each main group, there are three variations. Table 16 shows these variations:

Table 16. The relationship between numbers and nouns

\begin{tabular}{|l|l|l|l|}
\hline \multicolumn{2}{|l|}{ Types } & first position & second position \\
\hline I & 1 & number (alphabetically) & noun (ex.31) \\
\cline { 2 - 4 } & 2 & number (in figures) & noun (ex.32) \\
\cline { 2 - 4 } & 3 & $\begin{array}{l}\text { number (both alphabetically and in } \\
\text { figure) }\end{array}$ & noun (ex.33) \\
\cline { 2 - 4 } & 4 & $\begin{array}{l}\text { Number (partly alphabetically and } \\
\text { partly in figure) }\end{array}$ & noun (ex. 34) \\
\hline II & 1 & noun & number (alphabetically) (ex.35) \\
\cline { 2 - 4 } & 2 & noun & $\begin{array}{l}\text { number (both alphabetically and in } \\
\text { figure) (ex.37) }\end{array}$ \\
\cline { 2 - 4 } & 3 & noun & number (in figure) (ex. 36) \\
\hline
\end{tabular}

In the following examples, the numeral is written alphabetically and occurs before the noun:

(K 8)

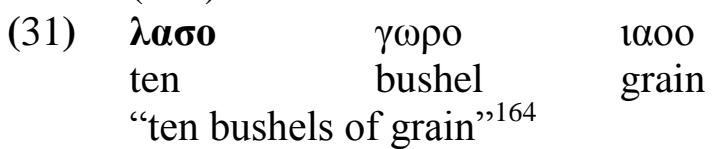
noun:

In the following example, the numeral occurs as a figure, and it is positioned before the

\footnotetext{
162 Sims-Williams 2007a: 203.

${ }^{163}$ Sims-Williams 2007a: 272.

${ }^{164}$ Sims-Williams 2000a: 63.
} 
(Jf 8-9)

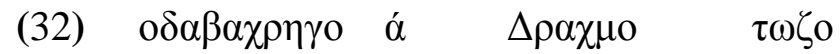
and-fee 1 dirham pay.IMP,2s

"and pay one dirham (as) a fee" 165

In example (33), the numeral is written both alphabetically and as a figure, with both types appearing before the noun:

(df 8)

(33) $\lambda \alpha \sigma o$ í $\quad \beta \rho \alpha \kappa o \pi \alpha \mu \alpha v o$

ten 10 ? wool

"10... of wool" "166

In the following example, the numeral 100 is written as a figure, whereas the numeral eight is written alphabetically:

(H 7-8)

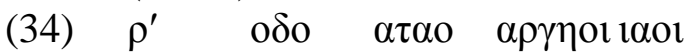

100 and eight peck grain

"one hundred and eight pecks of grain"167

In example (35), the numeral is written alphabetically and is positioned after the substantive:

(aj 9)

(35) $\delta$ iv $\alpha \rho o \lambda \alpha \sigma o$

dinar ten

"ten dinar"168

In the following example, the numeral 3 occurs as a figure and it is positioned after the substantive:

(M 3)

(36) $\delta \delta \rho \alpha \chi \mu о ~ \kappa o \alpha \delta \alpha \gamma о \quad \gamma^{\prime}$

dirham kawad 3

"the three dirhams of (king) Kawad" 169

In example (37), the numeral is written as both as a figure and an alphabet letter, with both forms positioned after the substantive:

(C 20')

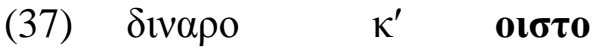

dinar $20 \quad$ twenty

"twenty dinars"170

Another interesting aspect relating to this topic of numerals is the discovery of the most common type in the extant material. To this end, I have chosen to investigate the relationship of numerals and the word Sivapo "dinar", which is often attested in use with numbers in the Bactrian texts. Table 17 shows the results of this investigation:

\footnotetext{
${ }^{165}$ Sims-Williams 2007a: 133.

${ }^{166}$ Sims-Williams 2007a: 107.

${ }^{167}$ Sims-Williams 2000a: 49.

${ }^{168}$ Sims-Williams 2000a: 161.

${ }^{169}$ Sims-Williams 2000a: 73.

${ }^{170}$ Sims-Williams 2000a: 41.
} 
Table 17. The relationship between numbers and $\delta$ iv $\alpha \rho$

\begin{tabular}{|c|c|c|c|c|}
\hline \multicolumn{2}{|c|}{ types } & first position & second position & sum \\
\hline \multirow[t]{3}{*}{$\mathrm{I}$} & 1 & number (alphabetically) & Siv $\alpha \rho o$ & 1 \\
\hline & 2 & number (in figures) & $\delta ı v \alpha \rho o$ & 6 \\
\hline & 3 & $\begin{array}{l}\text { number (both alphabetically and in } \\
\text { figure) }\end{array}$ & 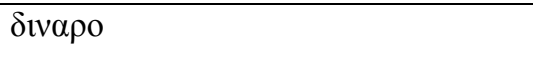 & 2 \\
\hline \multirow[t]{3}{*}{ II } & 1 & 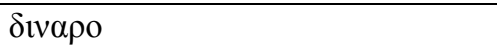 & number (alphabetically) & 1 \\
\hline & 2 & Sivapo & number (as a figure) & 18 \\
\hline & 3 & Sivapo & $\begin{array}{l}\text { number (both alphabetically and as a } \\
\text { figure) }\end{array}$ & 1 \\
\hline
\end{tabular}

Sum: the number of examples of each type in our corpora

According to Table 17, the numbers appear more often as figures than as alphabetically.The most common variety is II.2, i.e., noun-number (in figures). This shows when the number is expressed by ciphers, it tends to occur after the substantive.

The use of both alphabetical numbers and numbers in figures can also be found in other Middle Iranian languages, e.g., Middle Persian. It must be added that there are some differences too, however. For example, types I.3, II.3 are not attested in Middle Persian. ${ }^{171}$

\subsubsection{Two digit numbers}

In the case of two digit numbers, the number based on ten occurs first:

(K 8-9)

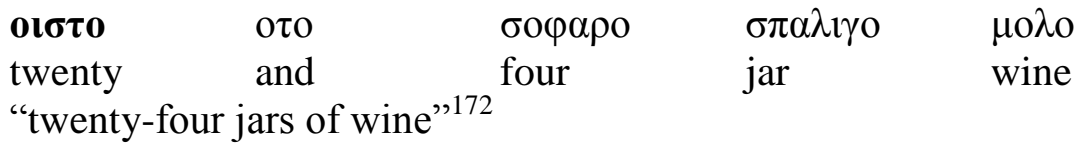

In the Surkh Kotal inscription, we find another system for two digit numbers. In this example, the decimal appears in the second position. It seems to be an archaic form:

(Surkh Kotal 5)

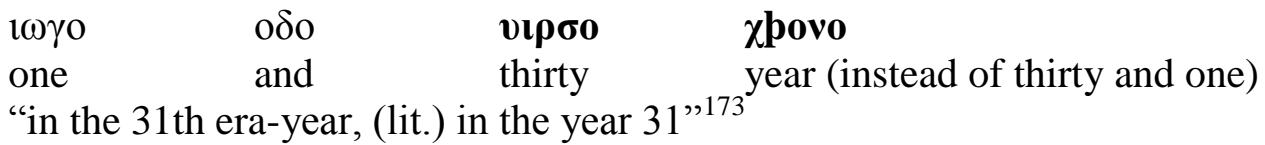

\section{Plural or no plural ending}

In Bactrian, a noun qualified by a cardinal number does not take usually the plural ending

-avo, but instead, it occurs in the singular. For example:

(K 8)

$(40)$

$\begin{array}{lcl}\lambda \alpha \sigma 0 & \gamma \omega \rho 0 & \mathbf{1 \alpha o 0} \\ \text { ten } & \text { bushel } & \text { grain } \\ \text { "ten bushels of grain", } & \end{array}$

\footnotetext{
${ }^{171}$ For the system of numerals in Middle Persian, see West 1978: 334-337 and Brunner 1977: 45-51.

${ }^{172}$ Sims-Williams 2000a: 63.

${ }^{173}$ Lazard, Grenet and de Lamberterie 1984: 226.

${ }^{174}$ Sims-Williams 2000a: 63.
} 


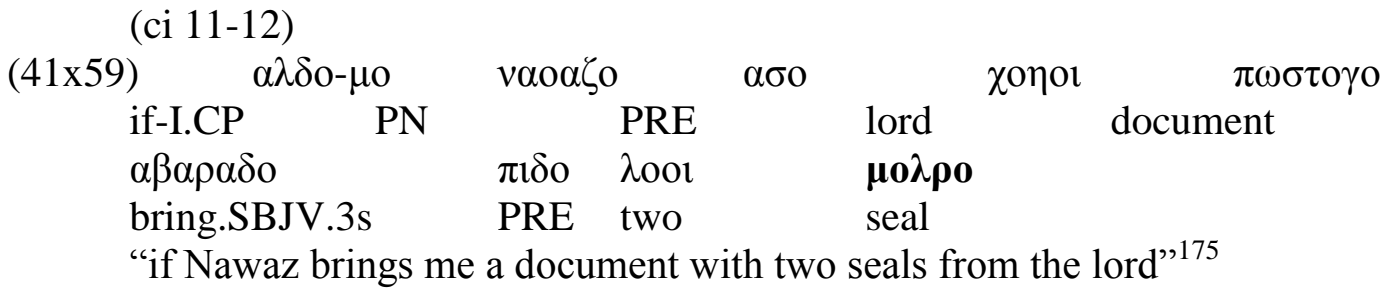

Only once in the document ef does the substantive occur in the plural:

(ef 17)

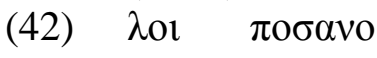

two sheep

"the two sheep",176

The word $\pi 0 \sigma 0$ "sheep" occurs very often in the singular form in the Bactrian materials. In Middle Persian and Parthian, unlike Bactrian, the modified substantive may occur in both singular and plural forms.

Also in Middle Persian and Parthian, the cardinal numbers tend to appear in the singular, though in some cases they are also pluralized. ${ }^{177}$ In Bactrian, there are no examples of plural numerals.

The singular head noun with a numeral can be used with a plural dependent noun:

(A35)

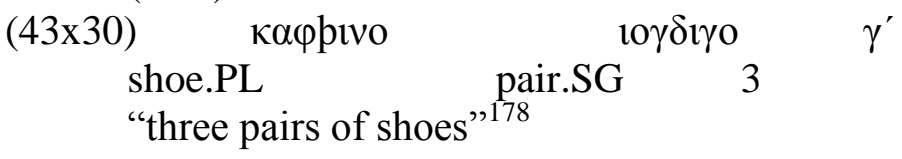

\section{Ordinal numbers}

Clear examples of ordinal numbers have not been attested in Bactrian so far. There is only a case in which an interpretation of an ordinal number is suspected. According to Sims-Williams, "if the reading $\alpha \rho \eta \mu \sigma \sigma o$ is correct, this may be analysed as * $\alpha \rho \eta \mu \sigma o$ "third" (a formation similar to $\varphi о \rho \delta \alpha \mu \sigma 0$ "(at) first"... plus enclitic - $\sigma 0$ "also"). ${ }^{179}$

(Rabatak 20)

$\begin{array}{llll}\alpha \beta \mathrm{r} & \mathrm{l} & \boldsymbol{\alpha \rho \eta \mu \sigma \sigma o} & \chi \text { povo } \\ & \text { PRE } & \text { ART third } & \text { year }\end{array}$

"in the third year" 180

The other word for "third", i.e., vip $\delta \delta \gamma_{0}$, is used five times in the extant Bactrian material:

(eg 5-6)

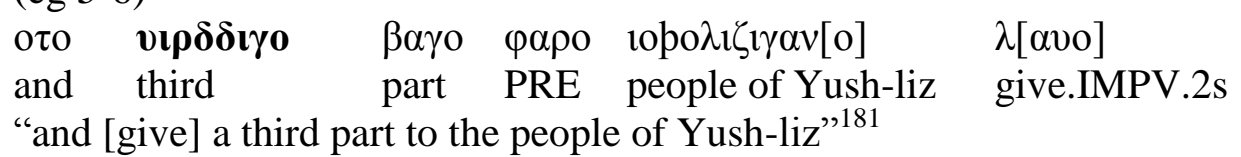

\footnotetext{
${ }^{175}$ Sims-Williams 2007a: 85.

${ }^{176}$ Sims-Williams 2007a: 119.

${ }^{177}$ For examples of plural numerals in Middle Persian, see Brunner 1977: 47, and in Parthian, e.g., pnj'n rwšn'n, see Sundermann 1973: 51, lines 942 and 1206; or hft'n, see Durkhin-Meisterernst 2004: 176.

${ }^{178}$ Sims-Williams 2000a: 35.

${ }^{179}$ Sims-Williams 2004 (2008): 66.

${ }^{180}$ Sims-Williams 2004 (2008): 57.
} 
It seems that there is no difference between $\alpha \rho \eta \mu \sigma \sigma o$ and $v \imath \rho \delta \delta \gamma_{0}$ in the extant material.

\subsection{Adjectives}

\subsubsection{Modification}

\subsubsection{Suffixes}

In Bactrian, adjectives may possess especial elements. Various prefixes and suffixes are used to form adjectives from nouns. In this chapter, first, adjectival prefixes and suffixes are listed. They can help us distinguish adjectives from other word classes. The first group of suffixes are those forming only adjectives:

$-\eta \gamma \gamma o,-\imath \gamma \gamma o$ forming adjectives from nouns, especially those nouns denoting substances, ${ }^{182}$ e.g., $\lambda \alpha \rho \sigma \gamma \gamma \gamma_{0}$ "ill".

$-\sigma \alpha \gamma \gamma o$ (f.), $-\sigma \alpha v \zeta_{0}$ forming adjectives from words referring to persons or places, ${ }^{183}$ e.g., $\alpha \sigma \kappa ı \sigma \alpha \gamma \gamma_{0}$ "belonging to (the place) Askin" 184

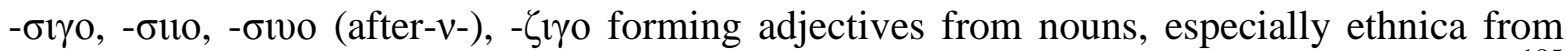

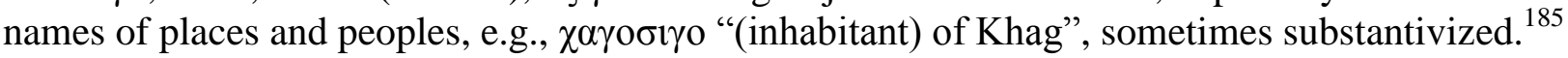

- $\alpha \gamma \gamma \mathrm{o}$ forming adjectives, mostly from nouns and pronouns referring to persons or places, ${ }^{186}$ e.g., $\beta \alpha \gamma \alpha \gamma \gamma \mathrm{\gamma}$ "godly".

$-\alpha v_{0},-\gamma \alpha v_{0},-\kappa \alpha v_{0}$ forming adjectives (often substantivized), especially from proper names, ${ }^{187}$ e.g. $\kappa \alpha \delta \alpha \gamma \alpha v o$ "of Kadag".

$-\delta \alpha \rho \rho,-\tau \alpha \rho \circ,-\alpha \tau \alpha \rho \circ$ forming comparatives from adjectives, adverbs and nouns, ${ }^{188}$ e.g., $\kappa \alpha \mu \beta$ о $\alpha \rho \rho_{0}$ "less".

The second group of these suffixes may form adjectives as well as adverbs:

$-1 \gamma 0,-\eta \gamma o,-110,-10,-100$, also abbreviated -1 forming adjectives (sometimes substantivized) and adverbs from nouns or adverbs. Without noticeable difference in the meaning, it is added to adjectives, e.g., $\alpha \beta \alpha v \delta \alpha \rho o v i \gamma_{0}$ "interior".

$-\gamma \omega \gamma \gamma \mathrm{o},-\gamma \mathrm{\gamma} \gamma \mathrm{\gamma},-\mathrm{o} \gamma \gamma_{\mathrm{o}}$ forming adjectives and adverbs expressing likeness from nouns, pronouns and numerals, ${ }^{189}$ e.g., $\alpha \sigma v \omega v o \gamma \omega \gamma \gamma \mathrm{\gamma}$ "like a daughter-in-law".

$-\eta \lambda \mathrm{o},-1 \lambda \mathrm{o}$ forming adverbs and adjectives, especially adverbs of place and adjectives of appurtenance. Often added to adverbs and inflected forms of pronouns without appreciable change of meaning, ${ }^{190}$ e.g., $\alpha \mu \beta \eta \rho \sigma \sigma \gamma \eta \lambda \mathrm{o}$ "(inhabitant) of Amber”.

\subsubsection{Prefixes}

There are four prefixes in Bactrian usually forming adjectives from nouns. The following prefixes help us to distinguish adjectives from other types of words:

\footnotetext{
${ }^{181}$ Sims-Williams 2007a: 121.

${ }^{182}$ Sims-Williams 2007a: 213.

${ }^{183}$ Sims-Williams 2007a: 261.

${ }^{184}$ Sims-Williams 2007a: 195.

${ }^{185}$ Sims-Williams 2007a: 263.

${ }^{186}$ Sims-Williams 2007a: 187.

${ }^{187}$ Sims-Williams 2007a: 193.

${ }^{188}$ Sims-Williams 2007a: 208.

${ }^{189}$ Sims-Williams 2007a: 207.

${ }^{190}$ Sims-Williams 2007a: 213-214.
} 
I. $\alpha v \alpha-, v \alpha-$ are the privative prefix "without", ${ }^{191}$ e.g., $\alpha v \alpha v \alpha \gamma \delta$ o "without restriction".

II. $\alpha \beta \eta-, \alpha \beta \eta \alpha-, \alpha \beta \eta 10-, \alpha \beta \eta 0^{-}, \alpha \beta \eta v o-, \alpha \beta v \eta-, \beta \eta-, \beta \eta \gamma 0^{-}, \beta \eta v o-$ are also the privative prefix "without"192, e.g., $\alpha \beta \eta 10 \alpha \beta \varphi \alpha \gamma \gamma o$ "without deduction".

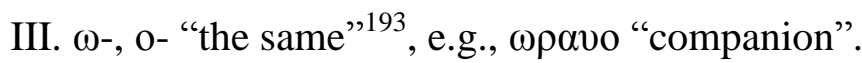

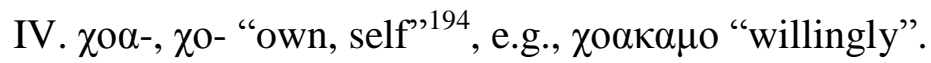

\subsubsection{Ordering of adjectives}

In some languages, "adjectives seem to be ordered according to semantic criteria" ${ }^{195}$ and special kinds of adjectives occur first. According to Hetzron:

the general cross-linguistic tendency is that adjectives that usually appear closest to the noun are those denoting purpose or destination. In pronominal position, for instance, these are preceded by adjectives denoting composition, origin, colour, physical defect, shape and finally, age. ${ }^{196}$

It must be added that the ordering of adjectives may be different from language to language. Valois mentions the following groups for the ordering of adjectives: ${ }^{197}$

$\begin{array}{lllll}\text { I. A-N Languages (English) } & \text { Evaluating } & \text { Size } & \text { Colour } & \text { N } \\ \text { II. N-A Languages (Persian) } & \text { N } & \text { Colour } & \text { Size } & \text { Evaluating } \\ \text { III. A-N-A Languages (Italian) } & \text { Evaluating } & \text { Size } & \text { N } & \text { Colour }\end{array}$

In Bactrian, there are both types I and II. Examples of constructions with more than one adjective are rare in Bactrian, and for this reason, the study of the ordering of adjectives is difficult and complex. At first, we look at the extant examples and then move on to discuss the ordering factors.

In both of the following examples, we have an A-N construction. The adjectives are of the same class, i.e., "(human propensity)", ${ }^{198}$ and therefore, their order must be interchangeable: ${ }^{199}$

(ea 1)

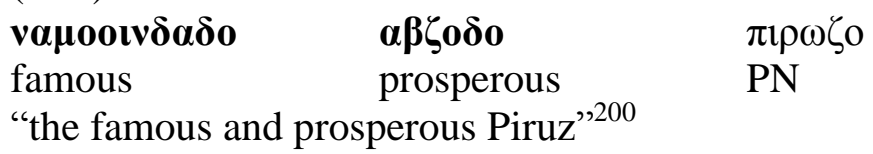

(jh 1-2)

\begin{tabular}{|c|c|c|c|}
\hline 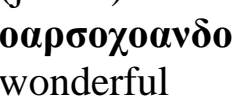 & $\begin{array}{l}\lambda \boldsymbol{\alpha} \delta \boldsymbol{\delta} \alpha \gamma \boldsymbol{\alpha} \lambda \gamma \mathbf{0} \\
\text { granter of favours }\end{array}$ & $\begin{array}{l}\text { vovapyo } \\
\text { renowned }\end{array}$ & $\begin{array}{l}\beta \alpha \gamma \alpha v o \\
\text { god.PL }\end{array}$ \\
\hline
\end{tabular}

${ }^{191}$ Sims-Williams 2007a: 191.

192 Sims-Williams 2007a: 182.

193 Sims-Williams 2007a: 281.

${ }^{194}$ Sims-Williams 2007a: 278.

${ }^{195}$ Valois 2006: 62.

${ }^{196}$ Valois 2006: 62-63.

197 Valois 2006: 63.

${ }^{198}$ Valois 2006: 64.

${ }^{199}$ For this theory, see Valois 2006: 63.

${ }^{200}$ Sims-Williams 2007a: 109.

${ }^{201}$ Sims-Williams 2007a: 137. 
In the following examples, we have an $\mathrm{N}-\mathrm{A}$ construction, and the different classes of adjectives are used together:

$$
\text { (V 10-11) }
$$

\begin{tabular}{|c|c|c|c|c|c|}
\hline$\pi \mathrm{l} \delta \mathrm{o}$ & & & $\sigma \iota \mu \imath \gamma \gamma$ & & $\omega \delta \alpha \gamma o$ \\
\hline PRE & & & silver & & district \\
\hline $0 \iota \zeta \mathrm{lv} \delta \delta \mathrm{l} \gamma \mathrm{o}$ & $\sigma \alpha \delta \mathrm{o}$ & $\rho^{\prime}$ & 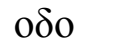 & $\pi \alpha \nu \zeta \alpha \sigma o$ & \\
\hline current & hundred & 100 & and & fifty & \\
\hline
\end{tabular}

We can show the above construction as follows:

\begin{tabular}{|l|l|l|l|l|l|l|}
\hline PRE & N & A 1 & A 2 & A 3 & A 4 & Number \\
\hline & & Arab & silver & good & $\begin{array}{l}\text { locally } \\
\text { current }\end{array}$ & \\
\hline & & proper & proper & quality & proper & \\
\hline
\end{tabular}

As we saw above, four adjectives occur between noun and number, and these are from different categories of adjectives. All of these adjectives modify the noun "dirhams". The adjective of origin $\tau \alpha \zeta \alpha v o$ "Arab" occurs first in the line of adjectives.

In the following example, the two adjectives occur before the noun; therefore we have an A$\mathrm{N}$ construction. The adjective $\tau$ o $о \sigma \alpha \alpha v \zeta_{0}$ "Turkish", of the same category, appears second in the line of adjectives. Both adjectives of origin occur nearest to the substantive in examples (48) and (49):

$$
\text { (T 20) }
$$

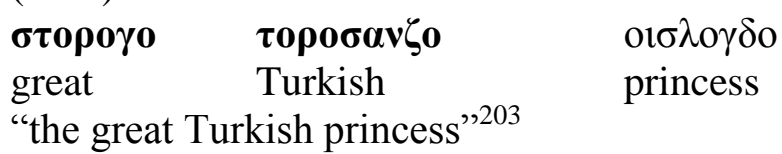

In Bactrian, according to the extant examples, it seems that there are some rules for the ordering of adjectives. For example, the adjective of origin appears closest to the substantive, but a conclusive statement about this order is impossible, since supporting evidence is limited to only a few constructions with more than one adjective.

\subsubsection{Nominal phrases consisting of an adjective}

As mentioned, in some languages, adjectives occur before the noun, such as in English. In other languages, adjectives appear after the noun, such as in Persian. Bactrian belongs to the latter group of languages. There are various positions of adjectives within noun phrases, to be described here.

\subsubsection{Adjectives may precede the noun they modify}

For example:

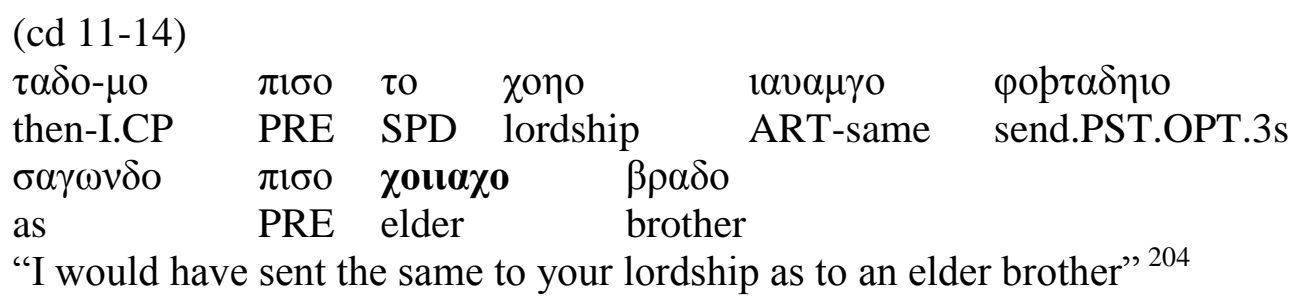

\footnotetext{
${ }^{202}$ Sims-Williams 2000a: 117.

${ }^{203}$ Sims-Williams 2000a: 103.
} 
In the following example, the adjective does not occur close to the substantive; and there are other words between the adjective and the substantive:

(Q 20-21)

\begin{tabular}{|c|c|c|c|}
\hline$\alpha \sigma \alpha \mu \alpha \chi 0$ & $\pi 1 \delta o o \alpha \sigma \mathrm{lv} \delta \alpha v o$ & $\chi 0 \lambda 1 \sigma \tau 0$ & $\alpha \beta \eta \pi \alpha \rho \circ \delta \omega \gamma 0$ \\
\hline RE-we.CP & declarant.PL. & personally & non-refundable \\
\hline$x \beta \alpha v \delta \alpha \rho \rho v i \gamma c$ & $\beta \eta v i \gamma o$ & $\zeta ı \alpha v o$ & 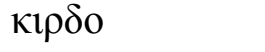 \\
\hline inside & outside & penalty & do.INF \\
\hline
\end{tabular}

"to fix a non-refundable penalty of (property) inside (or) outside the house, (payable) by us, the declarants personally" 205

\subsubsection{Adjectives may follow the noun}

(cc 12-14)

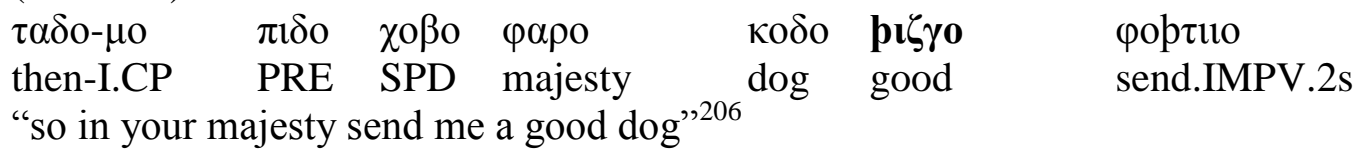

$$
\text { (J 9-10) }
$$

$\begin{array}{llllll}\alpha \sigma 1 \delta \text { o- } \mu \eta v 0 & \alpha \sigma \tau o & \mu \alpha \lambda \eta \lambda \mathrm{o} & \alpha \beta \mathrm{o} & \mu \alpha \lambda \rho \mathrm{c} & \alpha \gamma \gamma \alpha \rho \gamma \mathrm{o} \\ \text { but-we.CP } & \text { be.PRS.3s } & \text { here } & \text { PRE } & \text { PN } & \text { property }\end{array}$

$\pi \alpha \rho \operatorname{\alpha \beta } \beta$ เуо

disposable

"But we have a disposable property here in Malr.",207

The first type is more frequent in Bactrian. It seems that in the majority of examples, there may be a semantic difference between the A-N and N-A constructions. The N-A construction

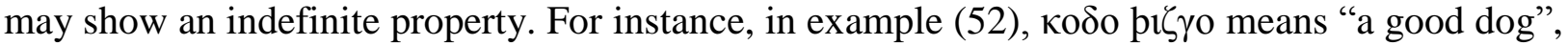
and in example (53), $\alpha \gamma \gamma \alpha \rho \gamma_{0} \pi \alpha \rho o 1 \alpha \beta$ r $\gamma_{0}$ has a meaning of "a disposable property", which seems to be indefinite. Another reason for using the N-A construction may be an emphasis on the adjective.

\subsubsection{Case marking of adjectives}

We can say that adjectives are sometimes inflected only for number in Bactrian texts. Gender and case inflection is absent, but there are a few exceptions. In general, adjectives modifying plural nouns have a plural ending. This characteristic can be seen in examples from both old and new documents:

(J 3)

(54) $\pi \imath \sigma 0$

$\mu \alpha v \delta \alpha \rho o v \alpha v i \sigma o$

ART-other.PL-ADV

PRE

"also in the presence of the other freemen (and) witnesses"208

(S 22-23)

\begin{tabular}{|c|c|}
\hline$\alpha \sigma o$ & 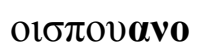 \\
\hline PRE & all.PL \\
\hline
\end{tabular}

\footnotetext{
${ }^{204}$ Sims-Williams 2007a: 75.

205 Sims-Williams 2000a: 91.

${ }^{206}$ Sims-Williams 2007a: 73.

${ }^{207}$ Sims-Williams 2000a: 55, 57.

208 Sims-Williams 2000a: 55.

${ }^{209}$ Sims-Williams 2000a: 95, 97.
} 
(Rabatak 2)

\begin{tabular}{|c|c|c|}
\hline$\alpha \sigma o$ & 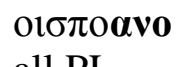 & $\mu \mathrm{l}$ \\
\hline PRE & all.PL & ART.PL \\
\hline
\end{tabular}

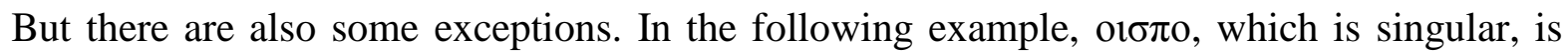
used with a plural noun. Neither of the adjectives are inflected:

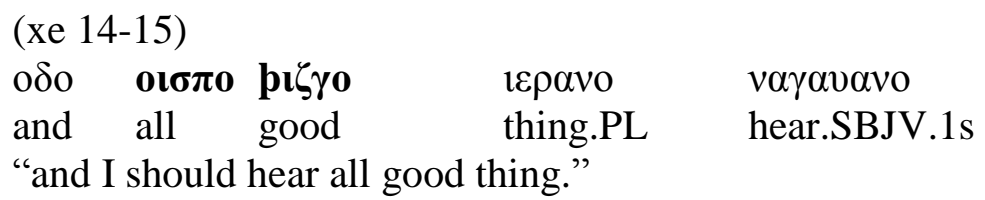

In the following case, the adjective ppuo is singular, whereas the noun is plural. Such an adjective is not inflected in the extant Bactrian texts:

(cj 1)

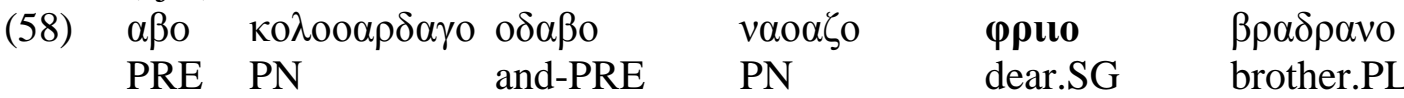

"to Kulu-ardag and to Nawaz,(my) dear brothers". 211

In the following example, a plural adjective is used with the singular substantive $\alpha \zeta \alpha \delta$ oк $\alpha \rho o$ "freeman":

(Q 8)

$\begin{array}{lll}\pi 1 \sigma 0 & \boldsymbol{\mu \alpha v \delta \alpha \rho o v \alpha v ı \sigma o} & \alpha \zeta \alpha \delta \text { oк } \alpha \rho 0 \\ \text { PRE } & \text { ART-other.PL-ADV } & \text { freeman }\end{array}$

"also in the presence of the other freemen" 212

The plural form of $\alpha \zeta \alpha \delta$ ок $\alpha \rho$ is attested in the extant Bactrian material. In the following example, a singular adjective is used with the plural noun:

(X 3)

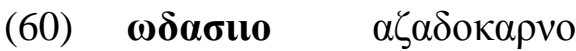

local freeman.PL

"local freemen" 213

\subsubsection{Comparison}

\subsubsection{The comparative}

The suffixes - $\delta \alpha \rho o,-\tau \alpha \rho o$ and - $\alpha \tau \alpha \rho o$ form comparatives from adjectives, for example, $\alpha v \delta \alpha \rho \circ \zeta \alpha \gamma \gamma о \delta \alpha \rho \circ$ ADV. "otherwise" $<\alpha v \delta \alpha \rho \circ \zeta \alpha \gamma \gamma o$ "of another kind" $+-\delta \alpha \rho{ }^{214}$ The suffix

\footnotetext{
${ }^{210}$ Sims-Williams 2004 (2008): 55.

${ }^{211}$ Sims-Williams 2007a: 87.

212 Sims-Williams 2000a: 89.

${ }^{213}$ Sims-Williams 2000a: 137.

${ }^{214}$ Sims-Williams 2007a: 192.
} 
$-\delta \alpha \rho o$ is also attested in the adverb $\alpha \sigma \kappa \alpha \delta \alpha \rho$. According to Sims-Williams, $\alpha \sigma \pi$ o $\delta \alpha \rho o^{215}$ "mule" $<1 \alpha \sigma \pi 0+-\delta \alpha \rho o$, OInd. aśva-tará, is also a comparative from $\alpha \sigma \pi \mathrm{o}$. But the suffix -tará can also be described as ““"die Annäherung an den Begriff de[s] grundw[o]rt[es]” AiGr II 2,603”,216

\subsubsection{The superlative}

Only one example of the superlative form is attested in extant material. This example is $\boldsymbol{\beta} \boldsymbol{\alpha} \boldsymbol{\alpha} \boldsymbol{\alpha v o \delta} \boldsymbol{\alpha} \mu \mathbf{0}$ "most divine", which is the superlative form of $\boldsymbol{\beta} \boldsymbol{\alpha} \boldsymbol{\alpha} \boldsymbol{\alpha} \mathbf{v}$ :

(jh 3-4)

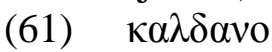

$\alpha \beta o \quad \tau o$

when-PAR PRE SPD olv $\alpha \mathrm{VO}^{217}$

see.SBJV.1s

"when I myself might see your most divine healthy"218

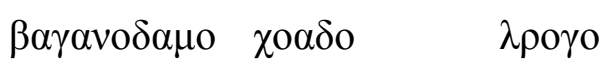

most divine RP health

\subsection{Nominal sentences}

\subsubsection{The presence of a copula}

A simple sentence in Bactrian may be placed in one of two general categories, as a nominal or verbal sentence. In this chapter, we will focus on nominal sentences.

The predicate is a constant element in nominal sentences. The following table shows the present indicative forms of the verb "to be" in Bactrian.

Table 18. Copula, present indicative

\begin{tabular}{|c|c|c|c|}
\hline & full form & enclitic form & full form, NEG \\
\hline $1 \mathrm{~s}$ & & $\begin{array}{l}-\eta \mu \mathrm{o} \\
-\imath \mu \mathrm{o}(\text { in late Bactrian) } \\
219\end{array}$ & \\
\hline $2 \mathrm{~s}$ & & $-\eta 10$ & \\
\hline $3 \mathrm{~s}$ & $\alpha \sigma \tau o$ & $-1 \sigma \tau 0$ & 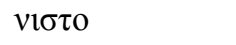 \\
\hline $1 \mathrm{p}$ & & $-\alpha \mu \mathrm{o}$ & $v \alpha \mu \mathrm{o}$ \\
\hline $2 \mathrm{p}$ & & $-\eta \delta o$ (only as suxiliary) ${ }^{220}$ & \\
\hline $3 p$ & $\alpha \sigma \tau \imath v \delta o$ & $-1 v \delta o$ & vivסo \\
\hline
\end{tabular}

The present optative and subjunctive forms of the verb "to be" are attested in the Bactrian texts $^{221}$. They are tabulated in the following table:

\footnotetext{
${ }^{215}$ Khot. khaḍara<*xara-tara Mayrhofer 1992: 140, NP. astar "mule".

${ }^{216}$ Mayrhofer 1992: 140.

${ }^{217}$ Sims-Williams 2007a: 137.

${ }^{218}$ Sims-Williams 2007a: 137.

${ }^{219}$ Sims-Williams 2007a: 42.

${ }^{220}$ Sims-Williams 2007a: 42.

${ }^{221}$ See Sims-Williams 2007a: 197-198 under $\boldsymbol{\alpha \sigma \tau \tau \text { . }}$
} 
Table 19. Copula, optative

\begin{tabular}{|l|l|l|l|}
\hline & full form & enclitic form & NEG \\
\hline $1 \mathrm{~s}$ & & & \\
\hline $2 \mathrm{~s}$ & & $-\eta 10(?)^{222}$ & \\
\hline $3 \mathrm{~s}$ & $\alpha \sigma \tau \eta 10, \alpha \sigma \tau 10$ & $-\eta 10,-\alpha 10(?)^{223}$ & \\
\hline $1 \mathrm{p}$ & & & \\
\hline $2 \mathrm{p}$ & & & \\
\hline $3 \mathrm{p}$ & & $-1 v \delta \eta 10(\text { only as auxiliary) })^{224}$ & \\
\hline
\end{tabular}

Table 20. Copula, subjunctive

\begin{tabular}{|l|l|l|l|}
\hline & full form & enclitic form & full form, NEG \\
\hline $1 \mathrm{~s}$ & & $-\alpha v o$ & \\
\hline $2 \mathrm{~s}$ & & & \\
\hline $3 \mathrm{~s}$ & $\alpha \sigma \tau \alpha \delta \mathrm{o}$ & $\begin{array}{l}-\alpha \delta \mathrm{o},-\delta o \text { (the latter only as } \\
\text { auxiliary) }\end{array}$ & $v \alpha \delta \mathrm{o}$ \\
\hline $1 \mathrm{p}$ & & & \\
\hline $2 \mathrm{p}$ & & & \\
\hline $3 \mathrm{p}$ & & & \\
\hline
\end{tabular}

The following table shows the past forms of the verb "to be":

Table 21. Copula, PST

\begin{tabular}{|c|c|c|}
\hline & Past "to be" & NEG \\
\hline $1 \mathrm{~s}$ & & \\
\hline$\frac{15}{2 s}$ & & \\
\hline $3 \mathrm{~s}$ & $\alpha \sigma \tau \alpha \delta o, \sigma \tau \alpha \delta \mathrm{o}$ & 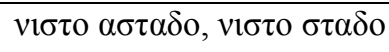 \\
\hline $1 \mathrm{p}$ & $\sigma \tau \alpha \delta \delta \mu \rho, \alpha \sigma \tau \alpha \delta \alpha \mu \mathrm{o}$ & \\
\hline \multicolumn{3}{|l|}{$2 p$} \\
\hline $3 p$ & $\begin{array}{l}\sigma \tau \alpha \delta i v \delta o, \sigma \tau \alpha \delta \delta 1 v \delta o, \\
\alpha \sigma \tau \alpha \delta \delta เ v \delta o\end{array}$ & \\
\hline
\end{tabular}

$\sigma \tau \alpha \delta \eta 10, \alpha \sigma \tau \alpha \delta \eta 10$ PST.OPT.3s and - $\alpha v \eta 10$ Pf.OPT.3s (?) are the only forms of past optative attested. The past subjunctive of the verb "to be" is not attested in extant texts.

\subsubsection{The position of the copula}

In the following example, there are two adjectives connected without a conjunction. The copula is added as an enclitic to the second adjective:

(C 21)

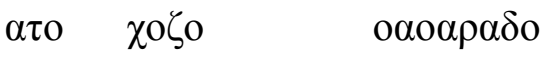

$$
\begin{aligned}
& \text { that good valid-be.SBJV.3sg }
\end{aligned}
$$

"that it might be good and valid" 226

\footnotetext{
${ }^{222}$ See Sims-Williams 2007a: 42.

${ }^{223}$ See Sims-Williams 2007a: 42.

${ }^{224}$ See Sims-Williams 2007a: 42.

${ }^{225}$ See Sims-Williams 2007a: 42.

${ }^{226}$ Sims-Williams 2000a: 41.
} 
In the following examples, negative and prohibitive particles are not added to the copula, but added directly to the adjective:

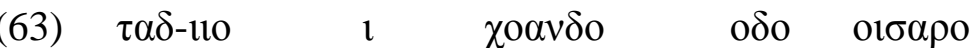

then-he.CP ART claim and argument

voo $\alpha(\mathrm{o} \alpha) \rho \alpha \delta o$

NEG.PAR.-valid-be.SBJV.3s

"then his claim and argument shall be invalid"227

(C 17-18)

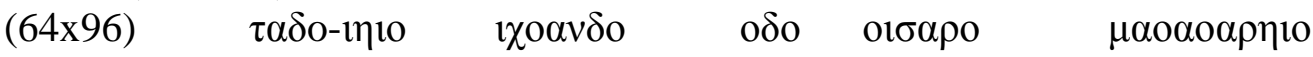

then-he.CP ART-claim and argument PROH.PAR.-valid-be.OPT.3s

"then his claim and argument shall not be valid"228

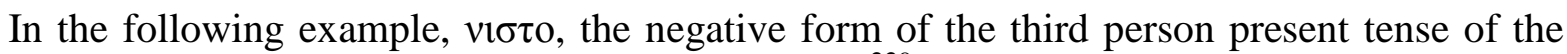
verb "to be", is used instead of the negative particle $v \alpha:{ }^{229}$

(W 7-8)

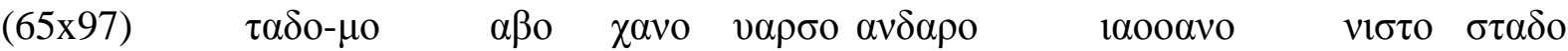

then-I..CP PRE house just other means NEG.be.PST.3s

"and I had no other means in (my) house" 230

The absence of the copula

In Bactrian, the copula can be omitted in different situations. In the following examples, it does not occur in the subordinate clause:

(W 14-15)

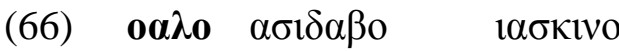

there which-PRE PN

"there, which (is) in Askin"

(T 6-7)

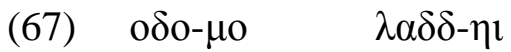

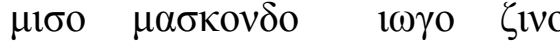

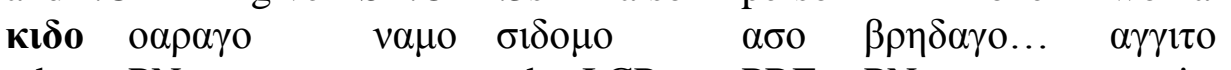

whose PN name who-I.CP PRE PN receive.PST.3s

"and also there was given by me, a person, a woman whose name (is) Warag who was received by me from the bredag" 231

The copula can also be omitted in a relationship of apposition:

(V 12-13)

(68) $\alpha \sigma o \quad \mu 1 \rho o \sigma \alpha v o \quad \kappa i v o . .$.

PRE east canal

"to the east (is) a ditch"232

\footnotetext{
${ }^{227}$ Sims-Williams 2000a: 151.

${ }^{228}$ Sims-Williams 2000a: 41.

${ }^{229}$ See also Sims-Williams 2007a: 47, 2.2.6.

${ }^{230}$ Sims-Williams 2000a: 127.

${ }^{231}$ Sims-Williams 2000a: 99.

${ }^{232}$ Sims-Williams 2000a: 117.
} 
(aa 18-19)

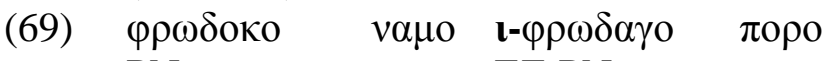

PN name EZ-PN son

"(whose) name (is) Froduk, the son of Frodag",233

In the following example, the demonstrative is used in a copular function. (see 4.2)

(E 4'-5')

(70) $\tau \alpha \delta$ o $\varepsilon 10 \quad \tau \alpha o 1 \quad \sigma i p \gamma o$

then DEM you.OBL proof

"so this (is) your proof",234

\subsubsection{Copula with infinitive}

A copula verb may occur with an infinitive. In the following example, the copula verb "to be" is attached directly to an infinitive:

(bc 7-8)

(71) $\tau \alpha \delta o-\mu o$

then-I.CP

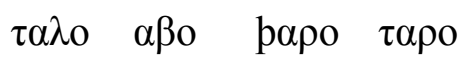

thus PRE city thither

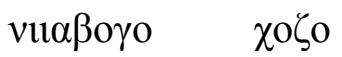

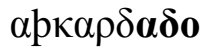

follow.INF-be.SBJV.3s

"so it would be very fitting for me to follow (him) thither to the city."235

\subsubsection{The nominal sentence of possession}

There are two different possibilities to indicate possession in Bactrian: either the verb $\chi 0 \alpha \rho-$ "to have" or the copula is used. Indication of possession with the use of the copula is much more common than the use of the verb $\chi 0 \alpha \rho-$, however. For example:

$\begin{array}{llllll}\tau \alpha \delta o-\mu o & \alpha \beta o & \kappa \alpha \delta \gamma o & \alpha v \delta \alpha \rho o & \sigma \alpha \gamma 1 \sigma o & \tau \alpha o r \\ \text { then-I.CP } & \text { PRE } & \text { house } & \text { other } & \text { any } & \text { assets }\end{array}$

$v i \sigma \tau \mathrm{O}$

NEG.be.PRS. 3s

"and I have no other assets in the house",236

Very rarely the verb $\chi 0 \alpha \rho$ - "to have" indicates possession, as the next example shows:

(A 26)

(73) $\tau \alpha \delta \alpha v o$

$$
\pi 1 \delta \text { o } \quad \chi 0 \beta о \quad \chi о \alpha \rho \eta 10
$$

then-PAR PRE own have.OPT.3s

"then she may have (him) for her own" 237

A clear difference between the two types of indication of possession is not found in the extant Bactrian material.

\subsection{Summary}

In this chapter, we have seen some properties of case morphology and nominal phrases. First, we can conclude that there is really no case distinction between direct and oblique. Only a

\footnotetext{
${ }^{233}$ Sims-Williams 2000a: 149.

${ }^{234}$ Sims-Williams 2000a: 43.

235 Sims-Williams 2007a: 57.

${ }^{236}$ Sims-Williams 2000a: 55

${ }^{237}$ Sims-Williams 2000a: 35.
} 
few words in the old texts, such as the inscriptions, have preserved their old oblique endings. In the new texts, the endings -o for the singular and - $\alpha$ vo for the plural have been generalized.

Second, there are only a few words with the feminine ending $-\alpha$ in old texts. On this limited basis, therefore, we cannot argue that one can distinguish feminine stems from masculine in Bactrian.

In this chapter, I have also described the properties of nominal phrases, such as descriptive adjectives, appositional modifiers, the relationship between head noun and dependent noun and numerical substantives. Furthermore, this chapter has focused on the syntactical properties of the described elements. It has also been shown that the positions of adjectives, head nouns and dependent nouns or numerals are very flexible and interchangeable in Bactrian.

Finally, I have reviewed nominal sentences with the presence, absence, and position of the copula. The different functions of the copula have been presented as well. 


\section{Chapter Four: Pronouns}

The purpose of this chapter is, in the first place, to show the function of pronouns in Bactrian. I first present the common types of pronouns and their case system. Thereafter I will focus on each set of pronouns and examine their specific properties. Several items relating to the pronouns are investigated, including full and enclitic forms of pronouns, direct and oblique case forms and their functions, the syntactic position of pronouns and their ordering. However, due to the limited amount of texts, some of the above mentioned items cannot be satisfactorily examined.

\subsection{Personal pronouns}

There are two kinds of personal pronouns in Bactrian: full and enclitic pronouns. As in other Iranian languages, an enclitic pronoun is in the oblique case. The full pronouns may occur in direct or oblique case in the singular. There is no distinction between direct and oblique in plural. As in many Iranian languages for third person full pronouns, demonstratives are used. Full and enclitic personal pronouns have different functions in the texts. The direct full pronoun can be used as the subject of a transitive verb in the present, as the object of a transitive verb in the past, as the subject of an intransitive verb in all tenses and as the subject of a copula. Both full and enclitic oblique pronouns can express the role of the subject of a transitive verb in the past, the object of a transitive verb in the present, show possessive relations with nouns and express a recipient/indirect object. The personal pronouns occur in different syntactic positions. For example, the oblique form of a personal pronoun can appear before or after a nominal phrase. It can appear after prepositions, after conjunctions, or in rare cases, it can be attached to another enclitic pronoun or to a verb.

\subsubsection{Full pronouns}

As mentioned above, personal pronouns only distinguish a direct and oblique form in the singular. For the third person, demonstrative pronouns are used (see 3.2). The next table shows the most common forms of personal pronouns found in the researched documents.

Table 22. Personal pronouns

\begin{tabular}{|c|c|c|}
\hline Person & direct & oblique \\
\hline $1 \mathrm{~s}$ & $\alpha \zeta_{0}$ & $\mu \alpha v o$ \\
\hline $2 s$ & 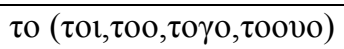 & $\tau \alpha o(\tau \alpha o 1, \tau \alpha o o)$ \\
\hline $1 \mathrm{p}$ & \multicolumn{2}{|c|}{$\alpha \mu \alpha \chi 0, \mu \alpha \chi_{0}$ (in old texts), $1 \alpha \mu \alpha \chi 0$ (only in possessive function) $)^{238}$} \\
\hline $2 \mathrm{p}$ & \multicolumn{2}{|l|}{$\tau \omega \mu \alpha \chi 0, \tau о \mu \alpha \chi 0, \tau \alpha \mu \alpha \chi 0$} \\
\hline
\end{tabular}

\subsubsection{The direct full pronouns}

The full personal pronouns have different functions. In this section, I will concentrate on the direct function of full pronouns.

A full pronoun can function as the subject of transitive verbs in the present tense:

${ }^{238}$ Sims-Williams 2007a: 216. 
(A 12-13)

(74) $\quad \imath \theta \alpha v \alpha \tau \alpha v_{0}$

so that

$\lambda \eta \rho \eta 10$ treat.PRS.OPT.1s

$\zeta$ ivo

vo $\beta \imath \tau \tau i \sigma o$

described

woman

"so that, I, Bag-farn, may treat the woman described herein",239

It can also be used in the role of the object of transitive verbs in the past tense (ergative construction):

(F 7-8)

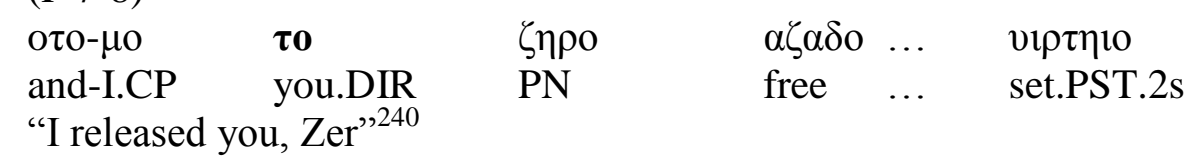

It can occur as the subject of intransitive verbs in all tenses:

(O 16)

(76) $\mathrm{k} \alpha \lambda \delta \mathrm{o}$

$\alpha \chi \alpha \sigma \alpha v o$

if dispute.PRS.SBJV.1s I.DIR

"If I should quarrel, I, Yobig myself ..."241

$\begin{array}{lll}\boldsymbol{\alpha} \zeta \mathbf{o} & 1 \omega \beta 1 \gamma o & \chi 0 \alpha \delta o \\ \text { I.DIR } & \text { PN } & \text { RP }\end{array}$

In the following example, it is used as the subject of a copula verb:

(bh 7)

\begin{tabular}{|c|c|}
\hline$\alpha \zeta o$ & $\mu \alpha \rho o$ \\
\hline I.DIR & here \\
\hline
\end{tabular}

"And I am healthy here.",242

The form $\alpha \zeta o$ is a full pronoun, not an enclitic pronoun, but once it is directly attached to a conjunction, it becomes like an enclitic pronoun:

(eh 6)

(78) $\tau \alpha \delta \alpha \zeta_{0}$

$\lambda \rho \gamma_{0}$

then-I.DIR health

$\alpha \gamma \alpha \delta \mu \mathrm{o}$

"Then I arrived in good health." 243

\subsubsection{The oblique full pronouns}

The oblique personal pronouns have different functions in the extant texts. In the following examples, these functions are presented:

The ergative construction shows the agent in the oblique case, when the agent is a pronoun. It is only in the inscriptions that the oblique form of a substantive is attested:

(ba 9)

(79) $\mu \alpha v 0$

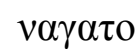

I.OBL hear.PST.3s

"I have heard" "244

\footnotetext{
${ }^{239}$ Sims-Williams 2000a: 33.

${ }^{240}$ Cf. Sims-Williams 2000a: 45.

${ }^{241}$ Sims-Williams 2007b: 10.

${ }^{242}$ Sims-Williams 2007a: 67.

${ }^{243}$ Cf. Sims-Williams 2007a: 123.

${ }^{244}$ Sims-Williams 2007a: 53.
} 
It may be used as a recipient/indirect object, such as in the following example:

(cf 8-9)

(80) $\tau \alpha \delta o \quad \mu \alpha v o \quad \alpha \sigma \pi o \delta \alpha \rho o \quad \lambda \alpha v o$

then I.OBL. mule give.IMP.2s

"Then give me a mule" 245

With a preposition, an enclitic pronoun usually occurs. In the following example, we expect $\alpha \sigma \alpha \varphi \alpha \gamma o$, but a full pronoun in oblique case, i.e., $\tau \omega \mu \alpha \chi 0$ is used after the preposition $\alpha \sigma o$ :

(L 28' -29 ')

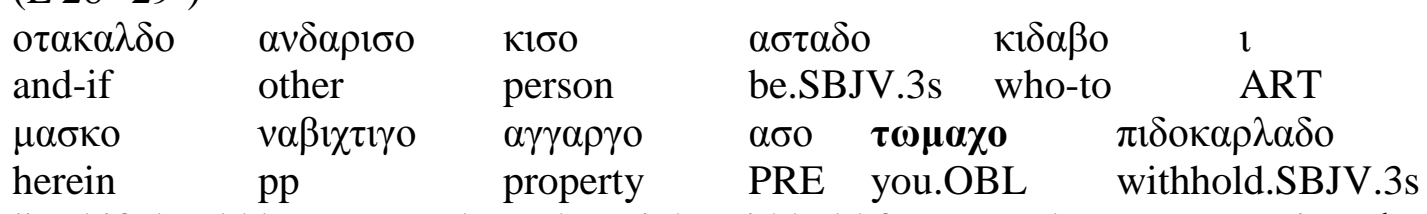

"and if should be anyone else, who might withhold from you the property written herein"

\section{Possessive function}

An oblique full personal pronoun is used occasionally with a noun to indicate possession. In this case, it functions as a possessive adjective and generally occurs before the substantive:

(cl 3-4)

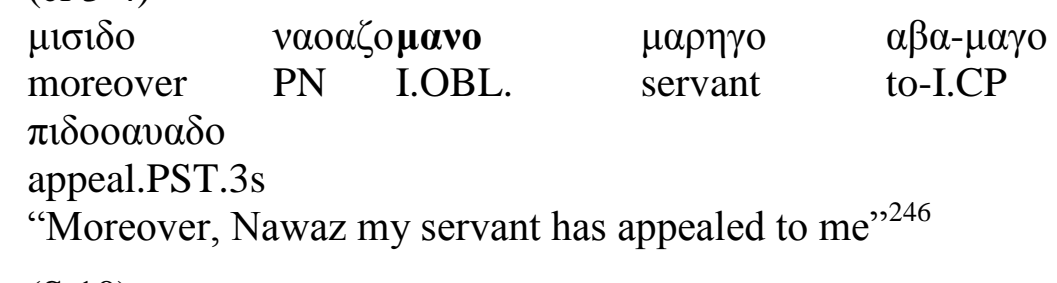

(S 10)

\begin{tabular}{|c|c|c|c|c|c|}
\hline $\begin{array}{l}\tau \alpha \delta o \\
\text { then }\end{array}$ & $\begin{array}{l}\boldsymbol{\mu} \boldsymbol{\alpha \chi 0} \\
\text { we.UFL }\end{array}$ & 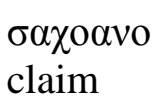 & $\begin{array}{l}\mu \alpha \tau o \\
\text { give up.PST.3s }\end{array}$ & $\begin{array}{l}\text { odo } \\
\text { and }\end{array}$ & $\begin{array}{l}\boldsymbol{\mu \alpha \chi 0} \\
\text { we.UFL }\end{array}$ \\
\hline $1 \alpha \chi \alpha \sigma$ & & $\eta 10$ & & & \\
\hline disput & & de.PST.O & & & \\
\hline
\end{tabular}

In the following example, it appears before $\kappa \alpha \mu \iota \delta о ~ \beta \alpha \gamma_{0}$ " the god Kamird ", which is in

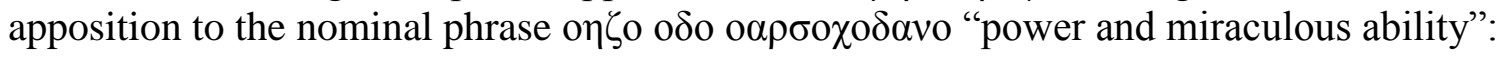

(T 12-13)

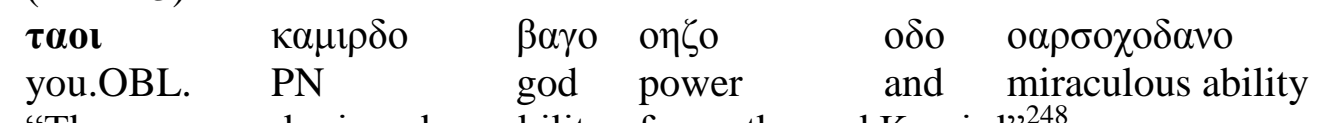

"The power and miraculous ability of you, the god Kamird"248

In the following example, a demonstrative and a personal pronoun are used. The demonstrative appears before the nominal phrase, whereas the personal pronoun occurs after it, which happens very rarely in Bactrian:

$\begin{array}{lll}\varepsilon \mu \mathrm{o} & \pi \omega \sigma \tau t u o & \boldsymbol{\mu \alpha v o} \\ \text { DEM } & \text { contract } & \text { I.OBL } \\ \text { "this contract of mine" } & \end{array}$

\footnotetext{
${ }^{245}$ Sims-Williams 2007a: 79.

${ }^{246}$ Sims-Williams 2007a: 89.

247 Sims-Williams 2000a: 95.

${ }^{248}$ Sims-Williams 2000a: 101.
} 


\subsubsection{Enclitic pronouns}

As in other Iranian languages, the case of the enclitic pronouns is exclusively oblique. There are two forms for the first and second singular enclitic pronouns in Bactrian. The suffixed forms, 1s - $\mu \alpha \gamma_{0}$ (<encl.acc./abl. *-mā/-mad+ particle ${ }^{*} \mathrm{k}^{250}$ ) and $2 \mathrm{~s}-\varphi \alpha \gamma o\left(<\right.$ encl.acc./abl. ${ }^{*} \theta \mathrm{wa} /-$ $\theta \mathrm{wad}+$ particle $* \mathrm{ka}^{251}$ ), are used only with prepositions, as can be seen in the next table below (??). Members of the second group are also attached to other kinds of words:

Table 23. Enclitic pronouns

\begin{tabular}{|c|c|}
\hline $1 \mathrm{~s}$ & $\begin{array}{l}-\mu \mathrm{o} \\
-\mu \alpha \gamma o \text { with PRE }\end{array}$ \\
\hline $2 s$ & $\begin{array}{l}-\delta \eta 10,-\tau \eta 10,{ }^{*}-\delta o \\
\text {-фауо with PRE }\end{array}$ \\
\hline $3 \mathrm{~s}$ & $-\eta 10,-1 \eta 10,-110,-\eta о,-11-,-110,-1-$ \\
\hline $1 \mathrm{p}$ & $-\mu \eta v o$ \\
\hline $2 \mathrm{p}$ & $-\delta \eta v o$ \\
\hline $3 p$ & $-\eta v o,-1 \eta v o,-1 v o$ \\
\hline
\end{tabular}

\subsubsection{The function of enclitic pronouns}

An enclitic pronoun has the following functions in the extant Bactrian material.

It may be used as the subject of transitive verbs in the past:

(L 21-22)

\begin{tabular}{|c|c|c|c|c|}
\hline 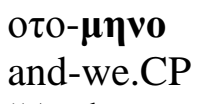 & $\begin{array}{l}\alpha \gamma \gamma ı \tau \iota v \delta o \\
\text { receive.PST.3p }\end{array}$ & ART & $\begin{array}{l}\text { odvayo } \\
\text { price }\end{array}$ & 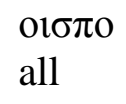 \\
\hline
\end{tabular}

The object of transitive verbs in the present may also be expressed as the form of an enclitic pronoun.

In the following examples, a preposition governs the enclitic pronoun:

(F 12-13)

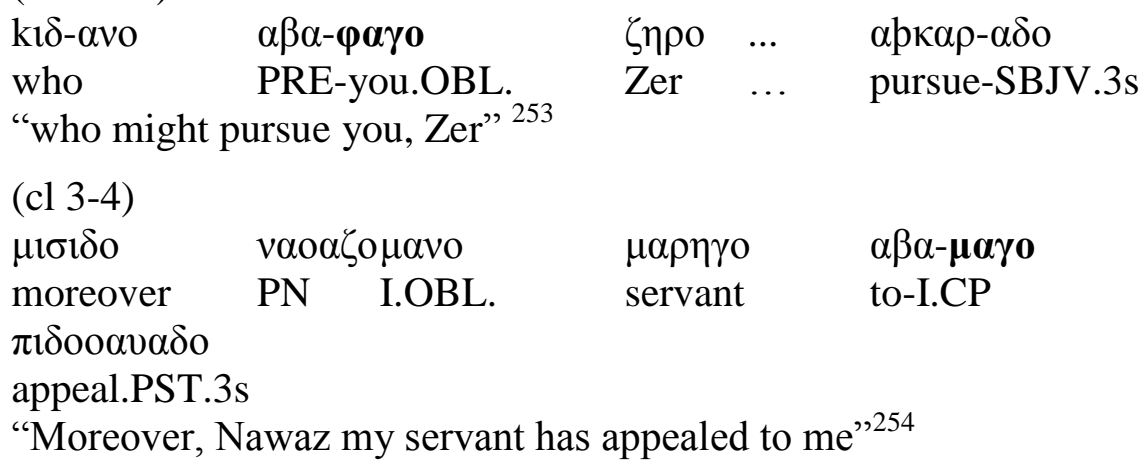

Like a full pronoun, an enclitic pronoun may be used to indicate possession. In this case, it functions as a possessive adjective:

\footnotetext{
${ }^{249}$ Sims-Williams 2000a: 103.

${ }^{250}$ Sims-Williams 2007a: 229.

${ }^{251}$ Sims-Williams 2007a: 273.

252 Sims-Williams 2000a: 67.

253 Sims-Williams 2000a: 46.

${ }^{254}$ Sims-Williams 2007a: 89.
} 
(C 7)

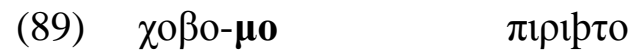

RA-I.OBL. inheritance
"my own inheritance" 255

An enclitic pronoun may to be used as a recipient/ indirect object. In the following example, an enclitic pronoun is attached directly to a verb:

(Y 6-7)

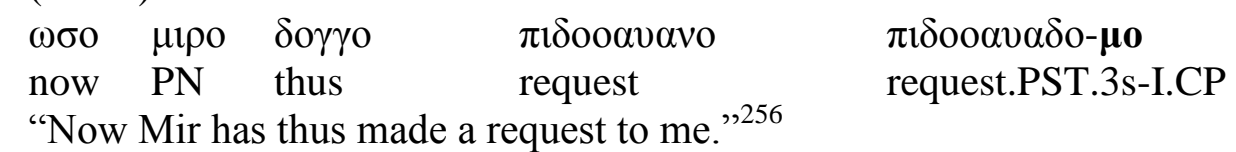

\subsubsection{The position of enclitic pronouns}

After a conjunction

An enclitic pronoun may be attached to the conjunction:

(J 8)

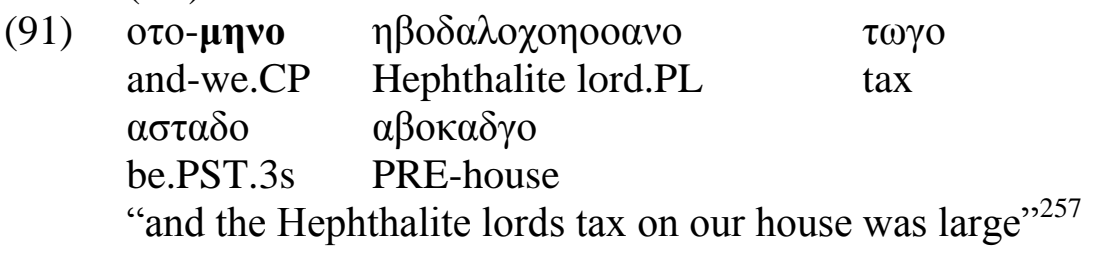

(R 10-11)

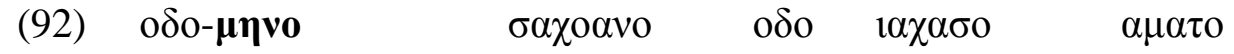
and-we.CP claim and disputegive up.PST.3s

"and our claim and dispute was given up",258

This type (conjunction with an enclitic) is more common than the other type (conjunction with a full pronoun) in Bactrian.

After a preposition

The oblique full pronoun can be attached directly to a preposition:

$\begin{array}{llllll}\text { (93) } \sigma 1 \delta 0 & \tau \text { o } & \chi 0 \eta о 1 & \alpha \sigma \alpha-\mu \alpha \gamma o & \text { p } \alpha \delta o & \beta o o \eta 10 \\ \text { that } & \text { SPD } & \text { lordship } & \text { PRE-I.OBL. } & \text { pleased } & \text { be.OPT.3s? }\end{array}$

"that your lordship may be pleased with me",259

Attached to a verb

Examples of the personal pronoun attached to a verb are rarely found in the Bactrian material (see example 90).

\section{Attached to another enclitic pronoun}

In the following example, an enclitic pronoun is attached to another enclitic pronoun already attached to a conjunction. The first enclitic personal pronoun expresses the subject of a transitive past verb, and the second personal pronoun expresses the object of the sentence:

\footnotetext{
${ }^{255}$ Sims-Williams 2000a: 39.

${ }^{256}$ Sims-Williams 2000a: 145.

${ }^{257}$ Sims-Williams 2000a: 55.

${ }^{258}$ Sims-Williams 2000a: 93.

${ }^{259}$ Sims-Williams 2007a: 97.
} 
(jh 12-13)

(94) $\tau \alpha \delta o-\mu-\eta \iota$

then-I.CP-he.CP

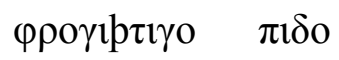

$\tau \alpha o o \alpha v o \quad \tau \alpha \rho o$

$\varphi \circ \bar{\tau} \alpha \delta$ o

contribution PRE fine thither

send.PST.3s

"I have sent it thither (to you as) his contribution in respect of the fine"260

In view of the function of personal pronouns, a few differences can be observed between the full pronouns and enclitic pronouns. After a conjunction and a preposition both the enclitic and full pronouns may occur, but the first form is found much more often.

\subsubsection{Ordering of enclitic and full pronouns}

Examples of a sentence with more than one personal pronoun are rare in the extant Bactrian material. In example (95), the full pronoun occurs first, while the enclitic pronoun, which is attached to a preposition, appears after it. It must be added here that very often, other words may stand between them. In example (75), an enclitic pronoun, which functions to express the subject, is attached directly to the conjunction, while the direct full pronoun, which expresses object, occurs after it. In example (94), two enclitic pronouns are attached to a conjunction. The first is the subject and the second a possessive adjective. When a sentence contains a full pronoun and a pronoun which is governed by a preposition, it seems that the full pronoun must occur first:

\begin{tabular}{|c|c|c|c|c|c|c|c|}
\hline$\mu 1 \sigma \mathrm{l} \delta \mathrm{o}$ & \multicolumn{2}{|l|}{ 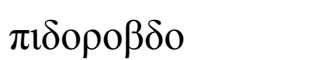 } & $\mu \alpha v o$ & $\mu о \zeta \delta o$ & 1 & $\chi \alpha \rho \alpha \gamma \alpha v o$ & $\ldots$ \\
\hline now & \multicolumn{2}{|c|}{ receive.PST.3s } & I.OBL & PN & EZ & PN & $\ldots$ \\
\hline$\alpha \sigma 0-\varphi \alpha \gamma 0$ & $\omega \rho о \mu о \zeta \delta o$ & 1 & $\beta о \rho v 1 к \alpha v o$ & & & & \\
\hline PRE-you.CP & PN & EZ & PN & & & & \\
\hline
\end{tabular}

\subsubsection{Summary}

There are two kinds of personal pronouns in Bactrian: full and enclitic pronouns. As in other Iranian languages, an enclitic pronoun is in the oblique case. The full pronouns may occur in direct or oblique case in the singular. There is no distinction between direct and oblique in the plural. As in many Iranian languages, for third person full pronouns, demonstratives are used. Full and enclitic personal pronouns have different functions in the texts. The direct full pronoun can be used as the subject of a transitive verb in the present, as the object of a transitive verb in the past, as the subject of an intransitive verb in all tenses and as the subject of a copula. Both full and enclitic oblique pronouns can express the role of the subject of a transitive verb in the past, the object of a transitive verb in the present, show possessive relations with nouns and express a recipient/indirect object. The personal pronouns occur in different syntactic positions. For example, the oblique form of a personal pronoun can appear before or after a nominal phrase. In this context, it very often plays the role of a possessive pronoun. It can suffixed to a preposition, a conjunction, or in rare cases, it can be attached to another enclitic pronoun or to a verb. 


\subsection{Demonstratives}

In my article on "demonstratives and determiners in Bactrian" (2009a), I discussed the different types of demonstratives and their function. ${ }^{261}$ Here in this chapter, I would like to concentrate on the function of demonstratives and other pronouns as a copula.

The conversion of pronominals to copula forms and the use of pronouns as copula forms is already pointed out and discussed by Li and Thompson (1977) and Korn (2011). Korn shows that pronouns can be used as the copula and the copula as pronouns in some Iranian languages. ${ }^{262}$ Her article also argues that some Iranian pronominal clitics might derive from copula or verbal ending forms. ${ }^{23}$ In this chapter, we discuss the conversion of pronouns to copula in Bactrian, if it exists. We also show whether pronouns are derived from the copula and verbal ending forms in Bactrian.

Copula sentences are common in Bactrian, as in other Iranian languages (see 3.3).

But in some cases, the copula can be omitted. These examples might prove that the copula is optional in Bactrian (see 3.3.1). It is a question here whether in such sentences without the copula, the pronouns are used in a copular function.

In discussing this topic, we first concentrate on clitic pronouns and demonstratives in Bactrian.

In some Iranian languages, for example, New Persian, the singular pronominal clitics can be traced back to the OIr. genitive/dative clitics. In certain other Iranian languages, for example, from the Western group, there is a group of clitics which might derive from copula forms or verbal endings. ${ }^{264}$ In Bactrian, enclitics have not derived from copula or verbal ending forms, but rather from OIr. genitive/dative enclitics:

$1 \mathrm{~s} .-\mu \mathrm{o}<*$ mai

$2 \mathrm{~s} .-\delta \eta 10,-\tau \eta 10,{ }^{265} *_{-} \delta \mathrm{o}<*$ tai

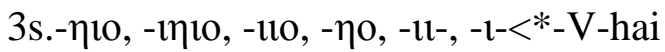

The plural clitic forms are a secondary formation from singular forms:

1p.- $\mu \eta v o$ "formed from - $\mu$ o on the analogy of - $\delta \eta v o,-\eta v o ", 266$

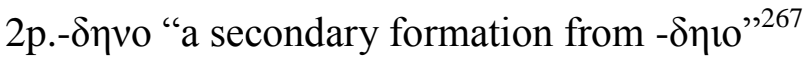

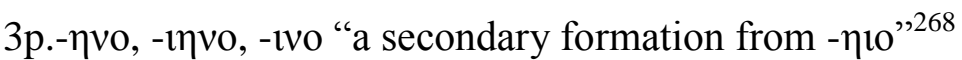

To judge from the limited material available, we conclude that enclitic personal pronouns are not used in the copular function. ${ }^{269}$ But the question of this development must also be asked of the demonstratives.

In the glossary of the Bactrian Documents II, we find the following words classified as demonstratives:

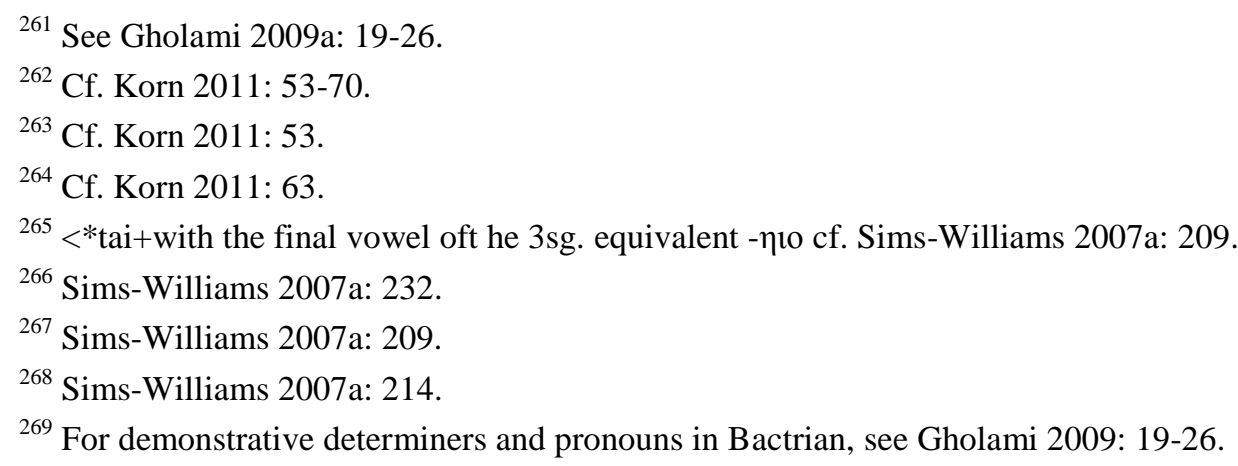


1. $\varepsilon 10,1 \varepsilon 10,-110,-1 \gamma o,-1$, older form $\varepsilon 110, \varepsilon 10$ (in the Surkh Kotal inscription) <*ayam

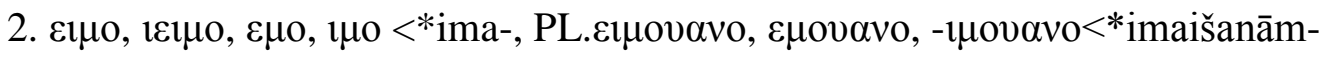

3. $\varepsilon 1 \delta o, \varepsilon \delta o,-1 \delta o<* a i t a-, P L . \varepsilon \delta o v \alpha v o,-1 \delta o v \alpha v o<*$ aitaišanām

4. oo<*awam

5. $\mu$ o, $\mu-<*$ ima-

The first three demonstratives are the most common forms in Bactrian. In the following table, the demonstratives, copula forms, and verbal endings are listed.

Table 24. Demonstratives, copula forms, and verbal endings

\begin{tabular}{|c|c|c|c|c|}
\hline Demonstratives & PIr. & \multicolumn{2}{|c|}{ Copula forms } & Verbal endings \\
\hline$\varepsilon \Perp \rho, \imath \varepsilon 1 \mu \mathrm{o}, \varepsilon \mu \mathrm{o}, 1 \mu \mathrm{o}$ & $<*$ ima- & $1 \mathrm{~s}$ & $-\eta \mu \mathrm{o},-1 \mu \mathrm{o}$ & $-\eta \mu \mathrm{o},-\imath \mathrm{o}_{0}$ \\
\hline$\varepsilon 10,1 \varepsilon 10,-110,-1 \gamma \mathrm{o},-1$, older form $\varepsilon 110, \varepsilon 10$ & $<*$ ayam- & $2 \mathrm{~s}$ & $-\eta 10$ & $-\eta 10$ \\
\hline$\varepsilon 1 \delta \mathrm{o}, \varepsilon \delta \mathrm{o},-1 \delta \mathrm{o}$ & $<*$ aita- & $3 \mathrm{~s}$ & $-1 \sigma \tau 0$ & $-1 \delta 0,-\delta 0$ \\
\hline
\end{tabular}

According to Table 24 above, we can conclude that in Bactrian copula forms and verbal endings are likely to derive from demonstrative pronouns. In the case of $\varepsilon 1 \delta o$, there is no derivation from *aita, but the enclitic form $-1 \sigma \tau \mathrm{o}$ is used as a copular form. The $3 \mathrm{~s}$. verbal endings are derived from demonstratives.

In some languages such as Sogdian, demonstratives show a deixis (or personal) distinction. ${ }^{270}$ In Bactrian such a distinction is not observed. ${ }^{271}$

The other question arises here is whether the demonstrative could be used in the copular function. For answering this question, some examples are given and analysed in the following section.

In some constructions, both the copula and the demonstrative are used:

(X 31)

(96)

$$
\pi \omega \sigma \tau \text { r } \quad \chi 0 \zeta_{0} \quad \ldots \quad \beta 00 \alpha \delta o
$$

and-DEM contract good be.OPT.3s

"And may this contract be good.",272

(V 12-13)

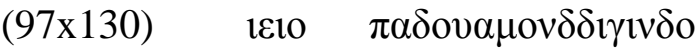

DEM boundary-be.PRS.3p

"these are the boundaries" 273

But in some cases, there is no copula and the demonstrative may play the role of a copula:

(E 4'-5')

$\begin{array}{llll}\tau \alpha \delta \text { o } & \varepsilon 10 & \tau \alpha 01 & \sigma i p \gamma o \\ \text { then } & \text { DEM } & \text { you.OBL } & \text { proof }\end{array}$

"so this (is) your proof",274

In above $\varepsilon 10$ seems to be used as a copula. According to Korn, "most of the pronominal copula forms are only used in the $3 \mathrm{rd}$ person, and in the present tense." ${ }^{275}$ In Bactrian, as far as

\footnotetext{
${ }^{270}$ See Wendtland 2006: 241-259 and Wendtland 2004: 17-39.

${ }^{271}$ Cf. Gholami 2009: 19-26.

${ }^{272}$ Sims-Williams 2000a: 143.

${ }^{273}$ Sims-Williams 2000a: 117

${ }^{274}$ Sims-Williams 2000a: 43.
} 
we can tell from the material available, the pronominal copula forms can be also used for second person. In the preceding example, it seems that the use of $\varepsilon 10$ has a connection with $\tau \alpha o 1$ "you", although in Bactrian, these three demonstratives do not show more of a deixis distinction.

If the statements suggested above are correct, we can conclude that demonstratives are also used in a copular function in Bactrian.

\subsection{Reflexive forms}

\subsubsection{Reflexive pronouns}

There is more than one reflexive pronoun in Bactrian:

(i) $\chi 0 \alpha \delta 0$

The form $\chi \mathbf{0 \alpha \delta 0}$ is the most common reflexive pronoun in Bactrian. It occurs frequently in the role of a reflexive pronoun, but not as a reflexive adjective. It is preceded by the noun or pronoun to which it refers. In the following examples, it occurs after a noun and pronoun, which expresses the subject of the sentence:

(ab 11)

\begin{tabular}{|c|c|}
\hline$\alpha \zeta o$ & oךpo $\lambda \alpha \delta$ o \\
\hline
\end{tabular}

"Whether I, Wesh-lad myself"276

(ba 14)

(100) $\tau \alpha \delta o \quad \alpha \zeta o$

then I.DIR RP

"then I myself shall order",277

$\varphi \rho \mu_{11 \alpha v o}$

order.SBJV.1s

The reflexive pronoun may occur directly after its antecedent or some distance from it. In the following example, the verbal ending indicates the person and number of the subject. The reflexive pronoun appears after the object of the sentence, though it does not refer to that object:

(bb 4)

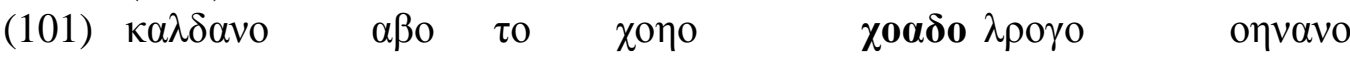

when-PAR PRE SPD lordship RP healthy see.SBJV.1s

"When I myself might see your lordship healthy"278

In the following example, the reflexive pronoun occurs after the verb. The verbal ending indicates the person and number of the reflexive pronoun:

(jf 13-14)

(102) $\mu 1 \sigma เ \delta o$ moreover as PRE health remain.PRS or OPT.2p RP

"Moreover in as much as you (PL.) yourself remain in (good) health" 279

The reflexive pronoun $\chi 0 \alpha \delta$ o is very often used to refer to the first person singular pronoun (examples (99)-(101)). It may also used to refer to second person plural (example (102)), third person singular (example (103)) and first person plural pronouns (example (104)):

\footnotetext{
${ }^{275}$ Korn 2011: 60.

${ }^{276}$ Sims-Williams 2007a: 151.

277 Sims-Williams 2007a: 53.

${ }^{278}$ Sims-Williams 2007a: 55.

${ }^{279}$ Sims-Williams 2007a: 133.
} 
(ea 10-11)

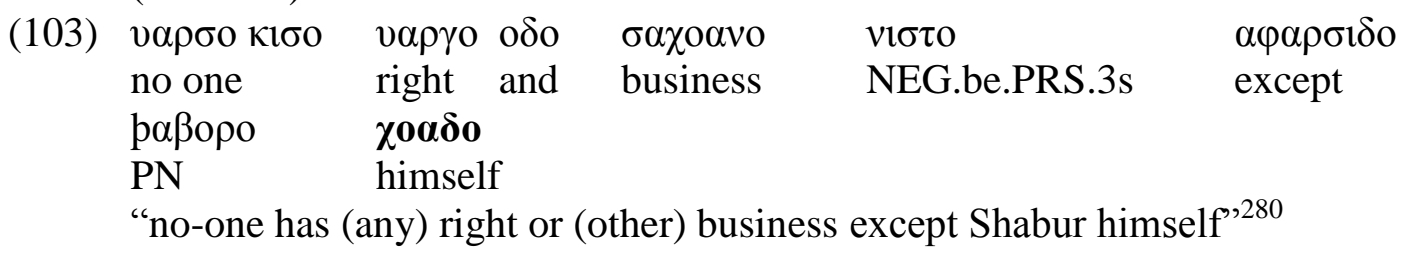
(A 23-24)

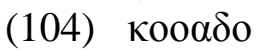

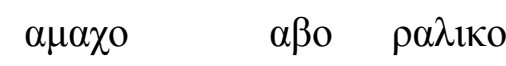

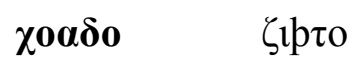
RP request.PST.3s

that we.UFL PRE PN

"that we ourselves have requested Ralik",281

Other words as prepositions or adverbs may be directly attached to $\chi 0 \alpha \delta$ o, e.g., $\chi 0 \alpha \delta \alpha \lambda \mathrm{o}$ ( $\chi 0 \alpha \delta 0+\alpha \lambda \mathrm{o}$ "with") and $\chi 0 \alpha \delta \alpha \sigma o$ ( $\chi 0 \alpha \delta \mathrm{o}+\alpha \sigma o$ "from"), $\chi 0 \alpha \delta 1 \sigma o(\chi 0 \alpha \delta \mathrm{o}+1 \sigma 0$ "also"):
(ji 7-9)

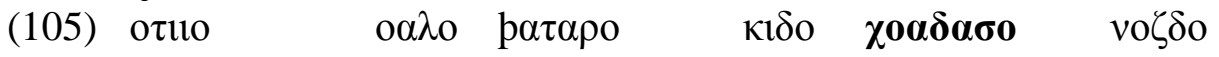
and-he.CP then more happy who RP-PRE nearby

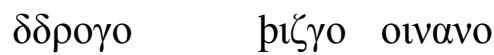
healthy well see.SBJV.1s
"And then [it would be] more happy for him who might see (you) himself from nearby, healthy (and) well",282

\section{(ii) $\chi 0 \beta о \sigma \alpha \rho о$}

The form $\chi 0 \beta о \sigma \alpha \rho o^{283}$ (older $\chi 0 \beta 1 \sigma \alpha \rho o$ in the Rabatak inscription ${ }^{284}$ ) is used two times in our corpora. It functions as a reflexive pronoun. In the following example, it refers to a second person plural antecedent. The verbal ending indicates the number and person of its antecedent:

(bc 12-13)
(106)

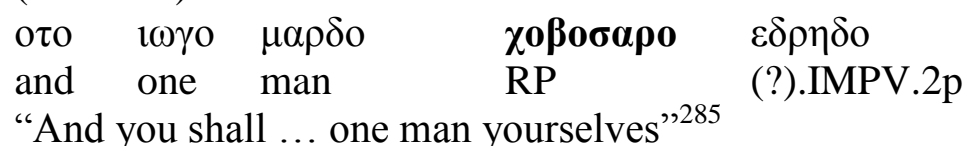

In the following example, it is used to refer to a third person singular antecedent:

(Rabatak 13-14)

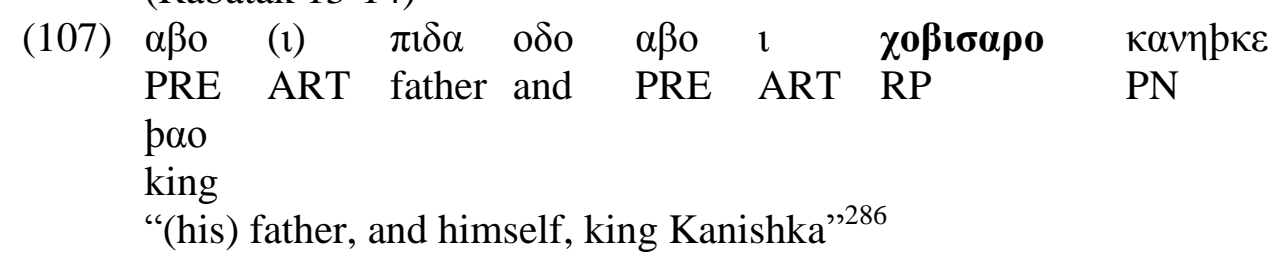

\footnotetext{
${ }^{280}$ Sims-Williams 2007a: 109.

${ }^{281}$ Sims-Williams 2000: 35.

${ }^{282}$ Sims-Williams 2007a: 139.

${ }^{283}$ We can compare this word with „xpasar in Pashto“ Sims-Williams 2007a: 279 <*xpəl-sar “self” Morgenstierne 2003: 96, according to Bellew khpul “self, own”, khpul.sar “obstinate, self-opinionated” Bellew 1867: 63.

${ }^{284}$ Sims-Williams 2007a: 279.

${ }^{285}$ Sims-Williams 2007a: 57.

${ }^{286}$ Sims-Williams 2004 (2008): 57.
} 


\subsubsection{Reflexive adjectives}

\section{(i) $\chi 0 \beta 0$}

The form $\chi 0 \beta 0$ very often plays the role of a reflexive possessive adjective. It can also be used as a noun or rarely as a pronoun. The reflexive possessive adjective usually occurs before the noun to which it refers:

(I $\left.5^{\prime}\right)$

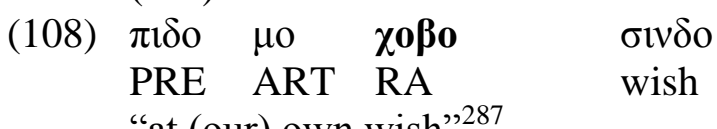

"at (our) own wish" 287

In some cases, it is more common to use a reflexive adjective instead of a possessive adjective, i.e., $\chi о \beta о ~ \kappa \alpha \delta \gamma o$ instead of $\tau \omega \mu \alpha \chi о ~ \kappa \alpha \delta \gamma о$ :

(ca 7-8)

(109) $\tau \alpha \sigma ı \imath \eta v o(\tau \alpha-+\alpha \sigma ı \delta o+-\delta \eta v o) \alpha \sigma o$ then-whatever-you.CP.2p PRE RA house horsemen be.SBJV.3s

"Whatever horsemen you may have (available) from your house" 288

Only in the following example does it play the role of a reflexive pronoun, like $\chi 0 \alpha \delta o$ :

(W 28'-29')

\begin{tabular}{|c|c|c|c|c|}
\hline $\begin{array}{l}\text { o } \delta \alpha \lambda \mathrm{o} \\
\text { and-or }\end{array}$ & $\begin{array}{l}\mu \alpha \chi 0 \\
\text { we.UFL }\end{array}$ & $\begin{array}{l}\chi \mathbf{0} \boldsymbol{\beta} \mathbf{0} \\
\mathrm{RP}\end{array}$ & $\begin{array}{l}\pi i \delta o o \alpha \sigma i v \delta \delta \imath \gamma \alpha v o \\
\text { declarant.PL }\end{array}$ & $\begin{array}{l}\alpha \chi \alpha \sigma \alpha \mu \mathrm{o} \\
\text { dispute.SBJV.1p }\end{array}$ \\
\hline
\end{tabular}

In the following example, $\chi 0 \beta 0$ is used as a noun:

(dd 5-6)

(111) $\quad 1-\mu \alpha v o$ $\chi \circ \beta 0$

ART-I.OBL property

"my property" 290

It can be observed that other words, such as an enclitic pronoun, are often attached to $\chi 0 \beta 0$ :

(V 8)

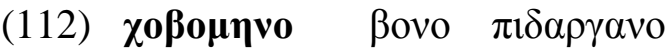

RA-we.CP land ancestral

"our own ancestral estate" 291

\section{(ii) $\chi 0 \beta เ \gamma o$}

The distinction between $\chi_{0} \beta o$ and $\chi_{0} \beta 1 \gamma_{0}$ is not clear. Both may function as reflexive possessive adjectives. As the suffix - 1 o may form adjectives and adverbs, it must function as an adjective, not as a noun. We can compare this word with wēbē(h), (wxybyhh) in Parthian. According to Sundermann, it functions predominantly as an adjective in the meaning of "own" and it is also rarely used as a substantive. ${ }^{292}$

\footnotetext{
${ }^{287}$ Sims-Williams 2000a: 51.

${ }^{288}$ Sims-Williams 2007a: 69.

${ }^{289}$ Sims-Williams 2000a: 133.

${ }^{290}$ Sims-Williams 2007a: 105.

${ }^{291}$ Sims-Williams 2000a: 115

${ }^{292}$ See Sundermann 1989a: 132.
} 
$\chi 0 \beta 1$ yo is used only six times in the texts in BD I and II. This word can be used with a possessive pronoun. In this case, the word $\chi 0 \beta$ r o occurs between the possessive pronoun and noun:

(113) o o o

\begin{tabular}{|c|c|c|}
\hline vavo & $\mu \alpha v \alpha \gamma \gamma о$ & 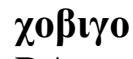 \\
\hline and & POSA & RA \\
\hline
\end{tabular}

"and nor my own (household) family"293

$\chi 0 \beta$ үyo may be also used independently, as in the following, where it is repeated and used with the meaning of "all our own":

(N 30-31)

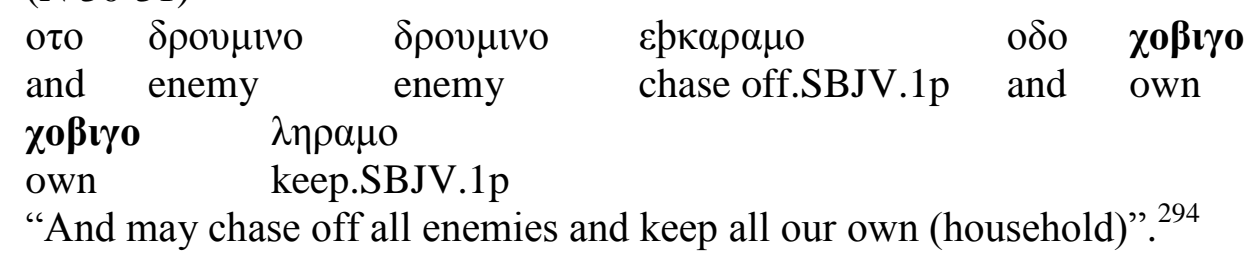

\subsubsection{Summary}

According to the given examples and information, we can conclude that there are four words in Bactrian which function as the reflexive pronoun or reflexive adjective. The most common reflexive pronoun is $\chi 0 \alpha \delta o$. It is used very often in the extant material. The form $\chi 0 \beta 0$ is a reflexive possessive adjective and also occurs very often in the texts. Sometimes it plays the role of a possessive adjective. The word $\chi 0 \beta 1 \gamma o$, like $\chi 0 \beta o$, functions as a reflexive adjective, but it is not attested very often in the extant material. Both $\chi_{0} \beta$ r $\gamma_{0}$ and $\chi_{0} \beta o$ may occur in the role of a noun. The word $\chi 0 \beta 0 \sigma \alpha \rho o$ occurs only twice as a reflexive pronoun in the extant texts. There is no distinction in the case, number, or person of reflexive pronouns or of reflexive adjectives in Bactrian.

\subsection{Indefinite Pronouns}

The following indefinite pronouns or adjectives usually refer to one or more unspecified beings, objects or places, though they can sometimes function as other words, depending on context. There is only one form for indefinite pronouns. A case, gender, or number distinction is not attested.

\subsubsection{With animates}

(i) кІбо, кцко(?)

The first group of indefinite pronouns are used for animate referents. Кıбo means "someone, anyone, any person"; with $\alpha v \delta \alpha \rho o$, it means "someone else, anyone else, other people", and with a negative, it means "no-one, not... anyone". ${ }^{295}$ Кıко "anyone" 296 is used only in Y9:

\footnotetext{
${ }^{293}$ Sims-Williams 2007a: 11.

${ }^{294}$ Sims-Williams 2000a: 79.

295 Sims-Williams 2007a: 224.

${ }^{296}$ Sims-Williams 2007a: 223.
} 
(Y 9-10)

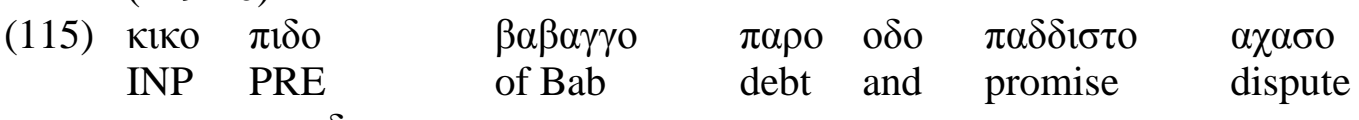
$\mu \alpha \gamma o \alpha \chi \alpha \sigma \alpha \delta o$

PROH.dispute.SBJV.3s

"no-one may dispute ... on account of a debt and promise or dispute of Bab's"297

According to Sims-Williams, кıко here may have another interpretation: "If not merely a mistake for кıбo perhaps from reduplicated *kah kah, cf. AV. kaýhe kaýhe "of which"”,. ${ }^{298}$

The pronoun $\kappa 1 \sigma o$ can occur with an adjective such as oløo "every, all", and thus convey the meaning of "everyone":

(Q 33)

(116) $\varphi \alpha \rho о$ оเбо кıбо

PRE every INP

"for everyone" 299

Kıбo may occur with a plural verb as the example (120) or with a singular verb as in the following example. In both of these constructions, it expresses the role of subject:

(jh 7-8)

\begin{tabular}{|c|c|c|}
\hline & $\begin{array}{l}\text { кıбо } \\
\text { INP }\end{array}$ & $\begin{array}{l}\alpha \gamma \alpha \delta o \\
\text { come.PST } 3 \mathrm{~s}\end{array}$ \\
\hline
\end{tabular}

"now someone has come thither" 300

$\kappa \iota \sigma 0$ may also express the role of object. As mentioned before, there is no case distinction in the form of indefinite pronouns. These pronouns usually refer to animate entities. Therefore, in either role, whether subject or object, the same form, i.e., кıбo, is used:

(xl 13)

(118) oto

кІбо $\quad \mu \alpha v i \rho \zeta o$

and INP PROH.permit.IMPV.2s

"and you should not permit anyone"301

\section{(ii) $\alpha v \delta \alpha \rho о$ кıбо}

In the following example, $\kappa \iota \sigma o$ is used together with another indefinite pronoun, $\alpha v \delta \alpha \rho o$ "other". The occurrence of an indefinite pronoun with another indefinite pronoun is common in the extant Bactrian material:

(F 10-11)

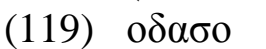

and-PRE

$\alpha v \delta \alpha \rho o$

КІбо

"and from anyone else"302

INP

(ce 4-5)

(120)

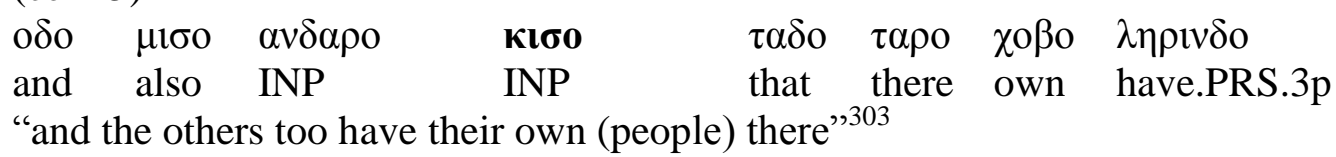

\footnotetext{
${ }^{297}$ Cf. Sims-Williams 2000a: 145.

${ }^{298}$ Sims-Williams 2007a: 223.

${ }^{299}$ Sims-Williams 2000a: 91.

${ }^{300}$ Sims-Williams 2007a: 137.

${ }^{301}$ Sims-Williams 2007a: 157.

${ }^{302}$ Sims-Williams 2000a: 45.
} 


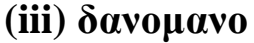

$\delta \alpha v o \mu \alpha v_{0}$ "such and such" is an indefinite adjective which is used only in X22. Here this word modifies a singular noun with animate referents, "person":

(X 22-23)

\begin{tabular}{|c|c|c|c|c|c|}
\hline (121) & $\begin{array}{l}\kappa i \delta o \\
\text { so that }\end{array}$ & 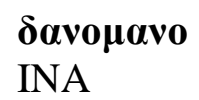 & $\begin{array}{l}\mu \alpha \rho \delta o \\
\text { person }\end{array}$ & 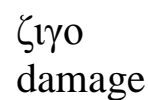 & $\begin{array}{l}\beta \eta \lambda \alpha \delta \delta \imath \gamma \imath \delta \delta o \\
\text { unlawful-be PRS } 3 p\end{array}$ \\
\hline
\end{tabular}

\subsubsection{With inanimates}

\section{(i) $\sigma \alpha \gamma \iota \sigma 0, \sigma \alpha \gamma \gamma \iota \sigma 0, \sigma \iota \gamma \iota \sigma 0^{305}$}

The words $\sigma \alpha \gamma 1 \sigma 0, \sigma \alpha \gamma \gamma 1 \sigma 0, \sigma \imath \gamma \imath \sigma o$ are indefinite pronouns and adjectives, conveying the meaning of "something, anything, some, any", with negation as "nothing, not...any", and with $\alpha \sigma 1 \delta \mathrm{o}$, as "whatever". ${ }^{306}$ These words are typically used to refer to inanimate beings.

$\sigma \alpha \gamma 1 \sigma o$ may function as a pronoun:

$$
\text { (eb 10-11) }
$$

(122) $\tau \alpha \delta o-\mu o$

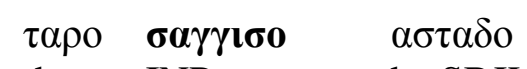

then-I.CP there INP be.SBJV.3s

"so I should have anything there",307

It can also function as an adjective. In this case, it usually occurs before the noun that it modifies:

(J 21-22)

(123) $\boldsymbol{\sigma \alpha \gamma \boldsymbol { \alpha } \boldsymbol { 0 }}$

INA claim and argument NEG.be.PRS.3s

"(we) do not have any claim and argument"308

In the following example, it is used as an adjective preceding a noun, after another adjective, i.e., $\alpha v \delta \alpha \rho o$ "another":

(L 10-11)

(124) $\tau \alpha \delta o-\mu \eta v o$

then-we.CP PRE house

$\alpha v \delta \alpha \rho o$

other

$v 1 \sigma \tau o \alpha \sigma \tau \alpha \delta o$

NEG.be.PST.3s

"And we had no other assets (left) in the house."

(ii) $\sigma \iota \sigma 0$

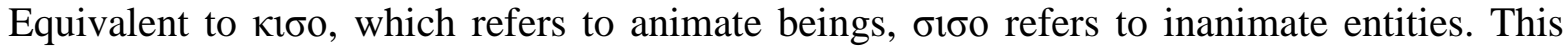
indefinite pronoun is only used twice in the Bactrian materials, and only in the document $\mathrm{X}$ with

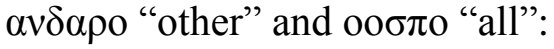

\footnotetext{
${ }^{303}$ Sims-Williams 2007a: 77.

${ }^{304}$ Sims-Williams 2000a: 141.

305 There are different forms of one word.

${ }^{306}$ Sims-Williams 2007a: 261.

${ }^{307}$ Sims-Williams 2007a: 111.

${ }^{308}$ Sims-Williams 2000a: 59.

${ }^{309}$ Sims-Williams 2000a: 65.
} 


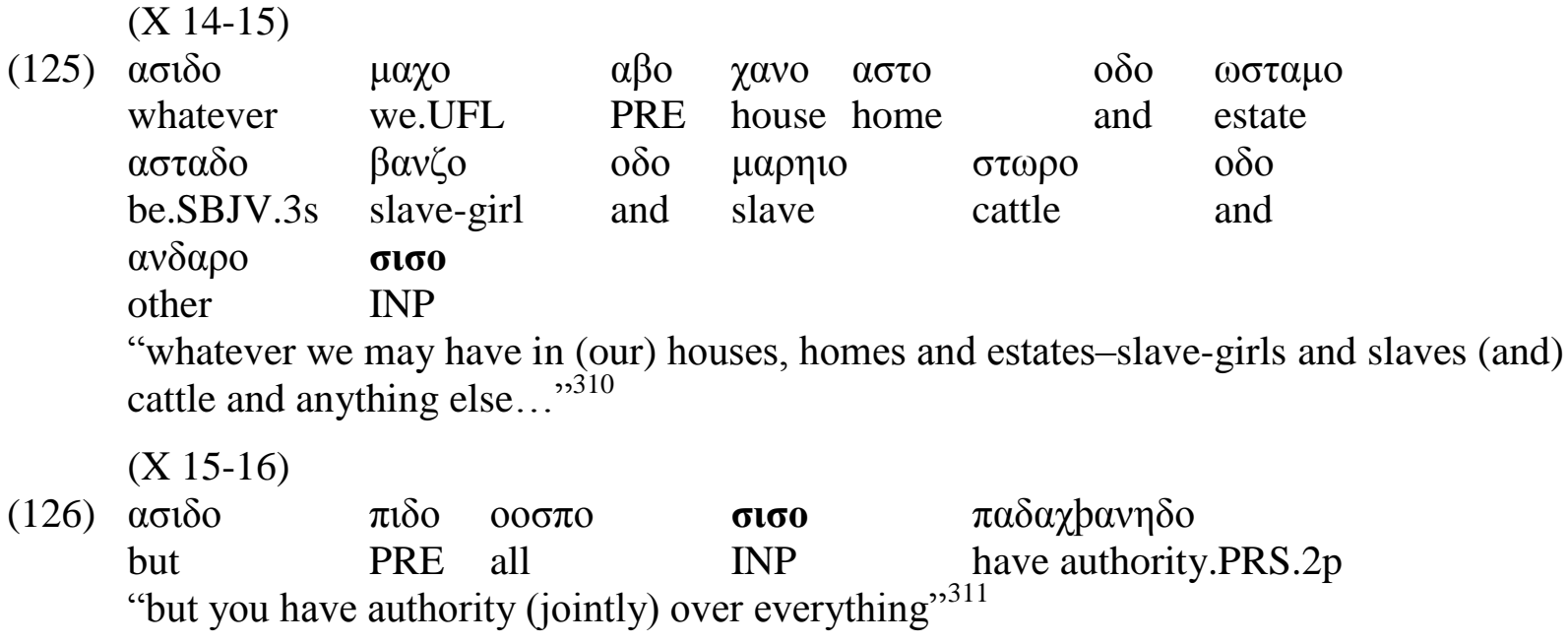

\section{(iii) $\kappa \alpha \delta \alpha \mu \mathrm{o}$}

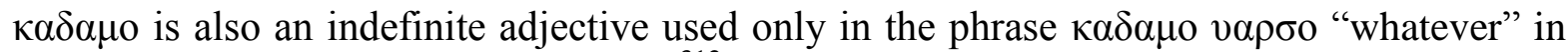
the document $\mathrm{N}$. It has inanimate reference: ${ }^{312}$

$$
\text { (N 21-22) }
$$

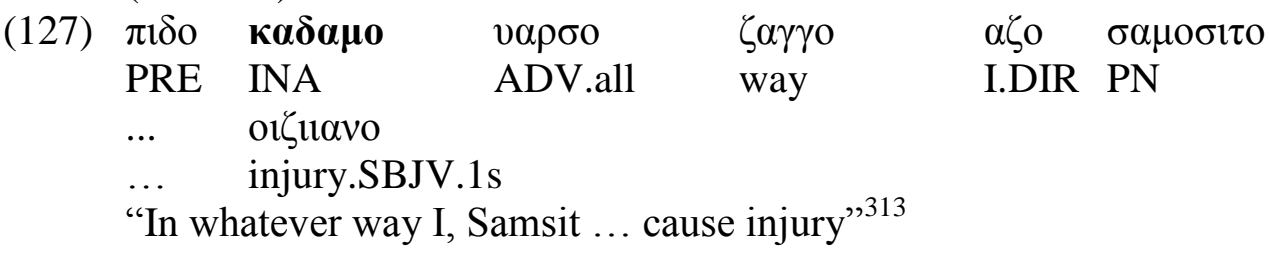

Like the word kadām in Middle Persian, which is only used to refer to inanimate entities, it is probable that $\kappa \alpha \delta \alpha \mu \mathrm{o}$ in Bactrian may also only be used with such inanimate reference.

\subsubsection{With both animates and inanimates}

${\operatorname{\alpha v} \delta \boldsymbol{\alpha} \rho \boldsymbol{o}^{314}}^{314}$

$\alpha \nu \delta \alpha \rho o$ "other" is an example of an indefinite pronoun which frequently refers to animate beings. There are also a few examples of it with reference to inanimate beings. As an adjective, it usually appears before a noun, nominal phrase, or such words as $\sigma \alpha \gamma 1 \sigma 0$ "thing", v $\alpha \rho \sigma o ~ \kappa i \sigma o$ "someone", or кıбо vарбо "someone". It always agrees with its noun in number. There is no distinction between the oblique and direct case of $\alpha v \delta \alpha \rho o$, as the next examples show:

(A 18)

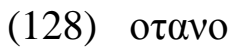
and-PAR

$\mu \alpha \pi \alpha \delta$ o $\alpha$ p $\alpha v \eta 10$

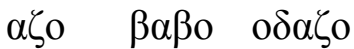

$\pi 1 \delta$ око

PROH.have the right.OPT.1s

PN

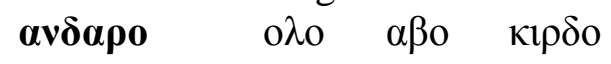

INA

wife PRE

I.DIR PN and-I.DIR.

"And I, Bab and I, Piduk shall not have the right to make another wife."

\footnotetext{
${ }^{310}$ Sims-Williams 2000a: 139.

${ }^{311}$ Sims-Williams 2000a: 139.

${ }^{312}$ Sims-Williams 2007a: 220.

${ }^{313}$ Cf. Sims-Williams 2000a: 77.

${ }^{314}$ According to Sims-Williams $\alpha v \delta \alpha \rho o$ is a pronominal adjective cf. SIMS-WILLIAMS 2007a: 191.

${ }^{315}$ Sims-Williams 2000a: 33.
} 
$(\operatorname{cg} 7-8)$

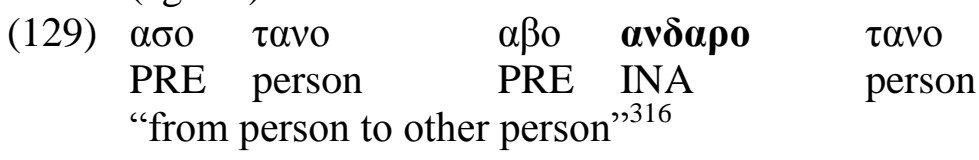

This word can also occur with a plural verb, as in the following example:

(X 30-31)

\begin{tabular}{|c|c|c|c|c|}
\hline $\begin{array}{l}\text { o } \delta \alpha \sigma o \\
\text { and-PRE }\end{array}$ & $\begin{array}{l}\text { l } \\
\text { ART(?) }\end{array}$ & $\begin{array}{ll}\alpha \beta \eta ı ⿻ & \boldsymbol{\alpha v \boldsymbol { \delta } \alpha \rho o} \\
\text { away } & \text { INA }\end{array}$ & $\begin{array}{l}\pi \omega \sigma \tau \imath \gamma o \\
\text { contract }\end{array}$ & $\begin{array}{l}\kappa \alpha \beta о \gamma \gamma о \\
\text { old }\end{array}$ \\
\hline$v \omega \gamma o \quad \alpha$ & $\tau \alpha \rho \mu \alpha v o$ & $\beta o o t v \delta \alpha \delta o$ & & \\
\hline & It authority & be.SBJV.3p & & \\
\hline
\end{tabular}

The plural form of this pronominal adjective is attested in the extant texts. In the following example, it agrees with its noun, $\sigma \tau \eta \beta \gamma \gamma \alpha v o \alpha \zeta \alpha \beta o \rho \gamma \alpha v_{0}$ "freemen of Steb", which is plural:

(A 7)

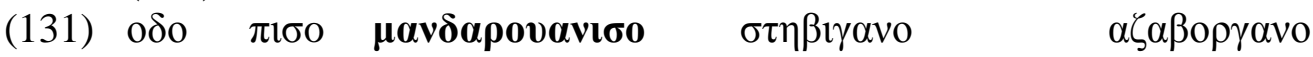

and PRE ART-INA.PL-ADV of the Steb.PL freemen.PL

"and in the presence of the other freemen of Steb",318

It may function as an indefinite pronoun, as shown in the following example:

(ef 15-16)

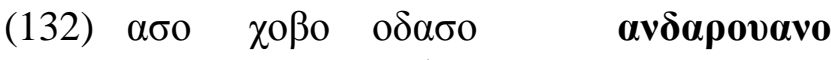

PRE RP and-PRE INP.PL

"from their own and from (that of) the others" 319

Adverbs may be prefixed or suffixed to $\alpha v \delta \alpha \rho o$, as seen in $\alpha v \delta \alpha \rho 1 \sigma o$ "also other" ( $\alpha v \delta \alpha \rho o+$

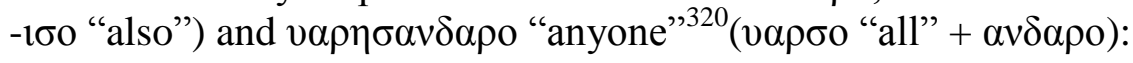

(cp 7-8)

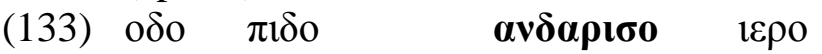

and PRE INA.ADV matter

"and concerning the other matters" 321

(xe 22-23)

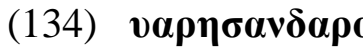

ADV-INP INP ART-formerly come.SBJV.3s

"whoever else may come first",322

\subsubsection{Summary}

There are two groups of indefinite pronouns in Bactrian. The first group refers to animate beings, e.g., К1бо "someone, anyone", $\delta \alpha v o \mu \alpha v_{0}$ "such and such", while the second group refers to inanimate entities, e.g., $\sigma \alpha \gamma 1 \sigma 0$ "something", $\sigma 1 \sigma 0$ "something", $\kappa \alpha \delta \alpha \mu \mathrm{o}$ "which". The form $\alpha v \delta \alpha \rho o$ "other" is used very often to refer to animate beings, and, in a few cases, to inanimate

\footnotetext{
${ }^{316}$ Sims-Williams 2007a: 81.

${ }^{317}$ Sims-Williams 2000a: 143.

${ }^{318}$ Cf. Sims-Williams 2000a: 33.

${ }^{319}$ Sims-Williams 2007a: 119.

${ }^{320}$ Sims-Williams 2007a: 272.

${ }^{321}$ Sims-Williams 2007a: 95.

${ }^{322}$ Sims-Williams 2007a: 147.
} 
entities. It must be added that $\delta \alpha v o \mu \alpha v o$ and $\kappa \alpha \delta \alpha \mu$ ore used only once in the extant material, and their function is not very clear. There is no distinction between oblique and direct case of pronominal adjectives, but the plural form of $\alpha v \delta \alpha \rho o$, i.e., $\alpha v \delta \alpha \rho o v \alpha v o$, is attested in the extant texts. In this case, the plural form of this indefinite pronoun agrees with its antecedent. It has

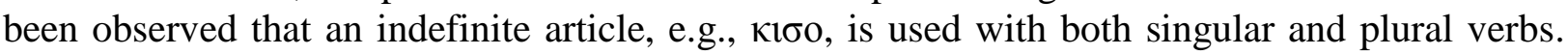
As an indefinite adjective, it usually occurs before the noun that it modifies. As an indefinite pronoun, it appears in various positions.

\subsection{Possessive Pronouns}

The suffix - $\boldsymbol{\alpha} \gamma \gamma \boldsymbol{0}$ combines with the personal pronouns and forms an adjective, which usually functions as a possessive pronoun. This group of possessive pronouns is used much more often with animate beings:

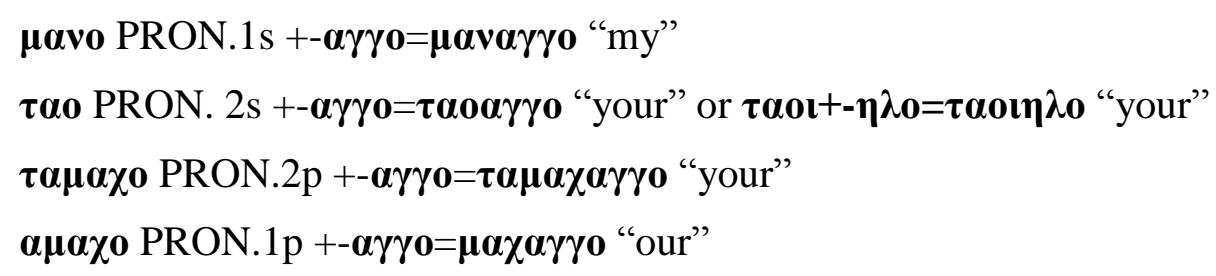

In the role of a possessive adjective it usually appears before a noun:

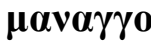

(135) $\mu 1 \sigma 1 \delta o$

(jf 3-4)

$\begin{array}{lllllll}\mu 1 \sigma 1 \delta \text { o } & 1 & \text { op } \beta \imath \gamma \gamma o & 1 & \boldsymbol{\mu \alpha v \alpha \gamma \gamma o} & \beta \alpha \gamma o & \mu \alpha \rho o \\ \text { moreover } & \text { ART } & ? & \text { ART } & \text { my } & \text { share } & \text { hither }\end{array}$

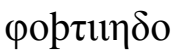

send.IMPV. $2 p$

"moreover, you (PL.) should send hither my share of..."323

In the following examples, possessive pronouns are used with nouns referring to animate beings:

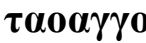

(M 6)

(136) $о \delta \alpha \lambda \alpha \beta o$

or-PRE

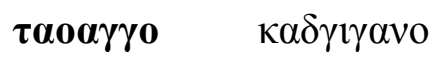

$\alpha \chi \alpha \sigma \alpha \delta o$

"or should dispute with the members of your household" 324

$\tau \alpha \mu \alpha \chi \alpha \gamma \gamma \mathrm{o}$

(Q 13)

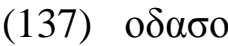

and-PRE

"and from your brothers",

$\begin{array}{ll}\tau \alpha \mu \alpha \chi \alpha \gamma \gamma о & \beta \rho \alpha \delta \text { o } \\ \text { your.PL } & \text { brother }\end{array}$

$\mu \alpha \chi \alpha \gamma \gamma 0$

(Q 11-12)

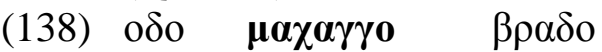

and our brother

"and our brothers",326

${ }^{323}$ Sims-Williams 2007a: 133.

${ }^{324}$ Sims-Williams 2000a: 73.

${ }^{325}$ Sims-Williams 2000a: 89. 
They can also be used with nouns referring to inanimates, as in the following examples:

(U $\left.27^{\prime}\right)$

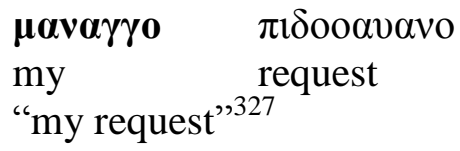

(Y 9)

(140)

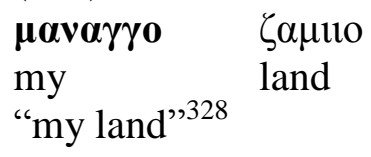

The possession can also be expressed by an oblique pronoun, which can be enclitic or in independent form. In this case, the pronoun may refer to both animates and inanimates, but it is more often used with nouns with inanimate referents:

\section{With inanimates}

In the following example, an enclitic pronoun is used with a noun with an inanimate referent:

(ba 4)

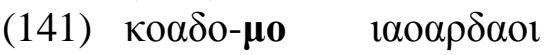

that-I.CP corn

"that my corn..." 329

In the following example, an independent pronoun is also used with a noun with an inanimate referent:

(dd 5-6)

(142) $1-\mu a v o$

ART-I.OBL

"my property",330

$\chi \circ \beta 0$

property

With animates

In the following example, an independent oblique pronoun is used with a noun with an animate referent:

(ba 16)

(143)

\begin{tabular}{|c|c|c|}
\hline & $\begin{array}{l}\tau \alpha \mathrm{ol} \\
\text { you.OBL }\end{array}$ & 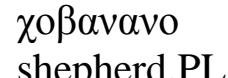 \\
\hline
\end{tabular}

\subsubsection{Summary}

There are two different ways to indicate possession in Bactrian: first, by the use of the possessive pronouns, and second, by the use of personal pronouns in the oblique case. The oblique pronoun can be an enclitic or an independent form. The possessive pronoun is used much more often with animates, while the oblique pronoun is used more with inanimates. In

\footnotetext{
${ }^{326}$ Sims-Williams 2000a: 89.

${ }^{327}$ Sims-Williams 2000a: 113.

${ }^{328}$ Sims-Williams 2000a: 145.

${ }^{329}$ Sims-Williams 2007a: 53.

${ }^{330}$ Sims-Williams 2007a: 105.

${ }^{331}$ Sims-Williams 2007a: 53.
} 
both of these groups, the pronoun occurs before the noun and functions as a possessive adjective.

\subsection{Relative pronouns}

\subsubsection{Main relative pronouns}

Two relative pronouns are often distinguished for their use in standing for an antecedent which is human and for an antecedent which is non-human.. The first relative pronoun occurs in the following autographic forms:

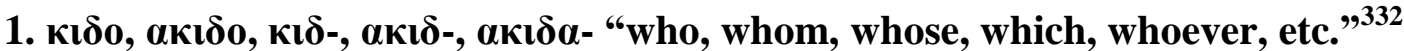

This relative pronoun is usually reserved for human antecedents:

$$
\left(\mathrm{O} 4^{\prime}-5^{\prime}\right)
$$

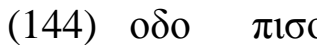
and PRE

$$
\mu \alpha v \delta \alpha \rho o v \alpha v i \sigma o
$$
other
$\alpha \zeta \alpha \delta o \beta o \rho \gamma \alpha v o$
freemen

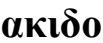

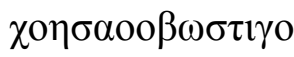
$\tau \alpha \beta \delta$ o
contract of undertaking seal.PST.3s
"and also in the presence of the other freemen who have sealed (this) contract of undertaking,"333

This relative pronoun is not inflected, but it can express various grammatical roles, for example, the role of subject, object, and possessive. In the following example, it expresses the role of subject:

(J 22-24)

(145) $\alpha \zeta$

\section{I.DIR PN}

$\mu \alpha \sigma \kappa o$

hereupon

oıб $\alpha \rho \delta$ o

argue

oinuo o $\delta 0$

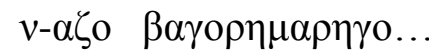

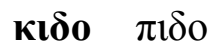

and nor-I PN

$v \alpha \beta \imath \chi \tau \imath \gamma o$

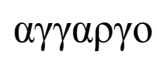

pp.written property

$\alpha \beta \zeta 11-\alpha \mu \mathrm{o}$

"I, Wyem, nor I, Bag-re-mareg ... who might continue to claim or argue (over) anything in respect of the property described herein" 334

It can also express the role of object, such as in the following example:

(O $\left.3^{\prime}\right)$

(146) $\pi 1 \sigma 0$

PRE god PN god.PL

$\alpha \beta o \quad \sigma \tau \omega \varphi \quad \sigma \pi \imath \sigma-\imath \delta \delta o$

PRE PN worship-PRS.3p

"in the presence of the god Wakhsh, the king of gods, whom they worship in Stof" 335

In the following example, it occurs in the role of a possessive:

\footnotetext{
${ }^{332}$ Sims-Williams 2007a: 222.

${ }^{333}$ Sims-Williams 2000a: 81.

${ }^{334}$ Sims-Williams 2000a: 59.

${ }^{335}$ Sims-Williams 2000a: 81.
} 


$$
\left(\mathrm{O} 5^{\prime}-6^{\prime}\right)
$$

(147) $\mu 1 \sigma 1 \delta$ o ...

$$
\begin{array}{lll}
\alpha \sigma \tau \omega \varphi \sigma \iota \gamma o & \alpha \kappa i \delta o-\mu o & \kappa \alpha \delta \alpha \gamma o \\
\text { inhabitant of Astof } & \text { whose-ART } & \text { house }
\end{array}
$$

$1 \omega \gamma \alpha v o \quad \rho \alpha \zeta-1 v \delta o$

PN call-PRS.3p

"now, I, Yobig, inhabitant of Astof, whose house they call Yogan"336

It may rarely denote a non-human antecedent:

(W 7-8)

(148) $\tau \alpha \delta o-\mu o$

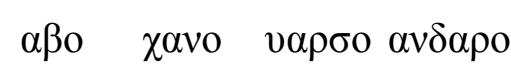

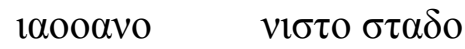

then-I.CP

PRE house at all other

$\boldsymbol{\alpha \kappa \iota \boldsymbol { \delta }} \gamma \alpha \zeta \iota \tau о$

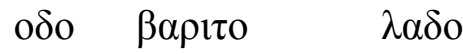

means

which poll-tax

and harvest-tax give.INF

NEG.be. PST.3s

"And I had no other means in (my) house which could have been given (as) poll-tax and harvest-tax",337

Another example is given here:

(T 6)

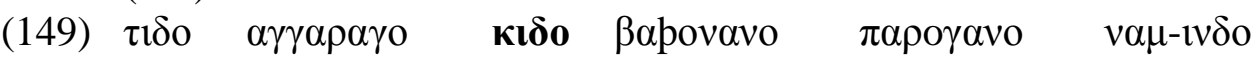

that property which PN PN name-PRS.3p

"that property which they name Bashunan Pargan"338

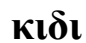

The form $\kappa \imath \delta \imath$ is used four times in the Rabatak inscription. In two instances, it refers to a singular and direct noun:

(Rabatak 1-3)

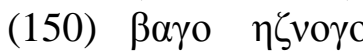

god worthy of worship

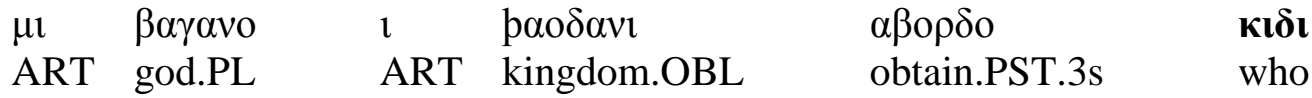

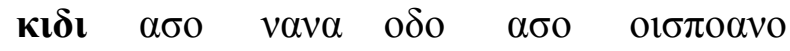

who PRE Nana and PRE all

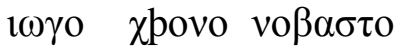

one year inaugurate.PST?.3s

"the god worthy of worship, who has obtained the kingship from Nana and from all the gods, who has inaugurated the year one",339

In the following example, it refers to a plural and an oblique noun:

(Rabatak 8-9)

(151) $\varphi \alpha \rho-\varepsilon \mu \rho \alpha v o$ $\beta \alpha \gamma \alpha v o \quad \mathbf{\kappa} \mathbf{\delta} \mathbf{\imath}$

$\mu \alpha \rho о \quad \kappa 1 \rho \delta 1$

PRE-DEM.PL.OBL god.PL.OBL who.PL here make. PRS. 3s

$\alpha v \delta \mu \alpha v 1 \quad$ оф $\alpha \rho \rho о \quad$ о $\mu \mu \alpha$

presence glorious Umma

"for these gods, who have come hither into the presence of the glorious Umma",340

It can also refer to a plural and direct noun, as in the following example:

\footnotetext{
336 Sims-Williams 2000a: 81.

${ }^{337}$ Sims-Williams 2000a: 127.

338 Sims-Williams 2000a: 99.

${ }^{339}$ Sims-Williams 2004 (2008): 55.

${ }^{340}$ Sims-Williams 2004 (2008): 56.
} 
(Rabatak 17)

(152)

$\begin{array}{llll}\varepsilon 1 \mu 1 \delta \beta \alpha^{341} & \beta \alpha \gamma \varepsilon & \mathbf{k} \boldsymbol{\delta} \mathbf{\imath} \mu \alpha \rho \text { vi } \beta \imath \chi \tau \imath \gamma \varepsilon v \delta \imath \\ \text { DEM } & \text { god.PL.DIR who here write.PF.3p } \\ \text { “(may) these gods who are written here..., } 342\end{array}$

\section{2. $\alpha \sigma \iota \delta 0, \sigma เ \delta 0, \alpha \sigma เ \delta \alpha-, \alpha \sigma ı \delta-, \sigma ı \delta$ - "what, whatever, which, who"}

This relative pronoun is used to refer to inanimate objects, but it rarely occurs with reference to persons. ${ }^{343}$

In the following example, it refers to an inanimate object and plays an accusative role:

(xn 6-7)

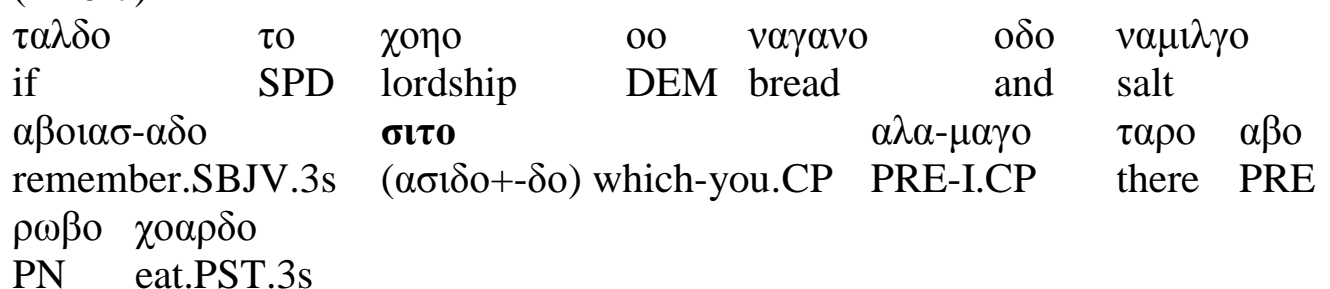

"then, if your lordship should remember that bread and salt which you ate with me there in Rob",344

In the following example, it refers to an inanimate object and plays a nominative role:

(L 12)

(154) $\varepsilon 10$

$\begin{array}{llll}\alpha \gamma \gamma \alpha \rho \gamma o & \boldsymbol{\alpha} \boldsymbol{\sigma} \boldsymbol{\delta} \mathbf{0} & \sigma \alpha \gamma \alpha \delta \alpha \gamma o & \rho 1 \zeta \delta \text { o } \\ \text { property } & \text { which } & \text { PN } & \text { call.PST.3s }\end{array}$

"this property which is called Sagadag" 345

In the following example, it is used to refer to a person:

(T 6-7)

(155) o oo- $\mu \mathrm{o}$

$$
\lambda \alpha \delta \delta-\eta \imath
$$

$\mu 1 \sigma o \quad \mu \alpha \sigma \kappa o v \delta o \quad$ i

and-I.CP give-PST.OPT.3s also person one woman

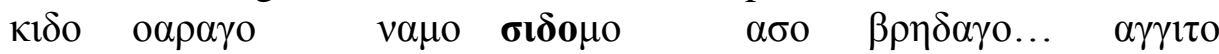

whose PN name who-I.CP PRE PN receive.PST.3s

"and also there was given by me, a person, a woman whose name (is) Warag who was received by me from the bredag" 346

In the following example, the reference occurs after the relative pronoun, which is very rare:

$(\mathrm{G} 2-4)$

(156) $\mu 1 \sigma 1 \delta \mathrm{o}$

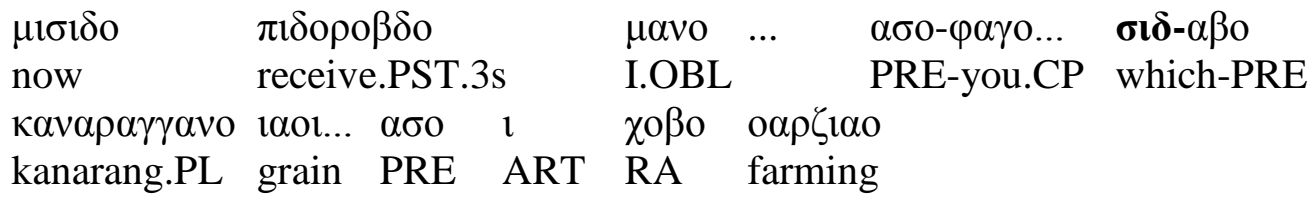

"Now, I ... received from you the grain ... which was assessed (to be given) to the

\footnotetext{
${ }^{341}$ According to Sims-Williams, $\varepsilon \mu \iota t+-\delta-+-\beta \alpha(?) . \varepsilon \mu 1:$ DEM, $-\delta-:$ Particle marking the first word of a clause, $-\beta \alpha(?)$ : Particle giving hortative value to the present indicative? see Sims-Williams and Cribb 1996: 91.

${ }^{342}$ Sims-Williams 2004 (2008): 57.

${ }^{343}$ Sims-Williams 2007a: 194 adds that it is a nominative and accusative relative pronoun.

${ }^{344}$ Sims-Williams 2007a: 159.

${ }^{345}$ Sims-Williams 2000a: 65.

${ }^{346}$ Sims-Williams 2000a: 99.
} 
kanarangs from the farming of (their) own (land)",347

\subsubsection{Special case}

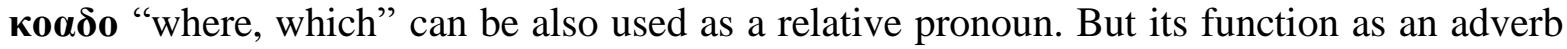
or a conjunction is much more common in Bactrian. It may be used "with preposition $\alpha \sigma o$ "whence, whereby, from which", also used as oblique form of $\alpha \sigma i \delta o$ ("in respect of which", etc.) and of $\kappa 1 \delta o$ (with $\varphi \alpha \rho o$ "to whomsoever, to (anyone) who")". ${ }^{348}$ But it is used very rarely in the extant Bactrian documents. There seems to be no difference between the meanings and functions of $\kappa \circ \alpha \delta \mathrm{o}$ and $\kappa \imath \delta \mathrm{o}$.

In the following example, $\kappa o \alpha \delta o$ is used with the preposition $\alpha \sigma 0$ :

(J 11-12)

\begin{tabular}{|c|c|c|c|c|c|}
\hline $\begin{array}{l}\mu \alpha \sigma \kappa о \\
\text { hereupon }\end{array}$ & 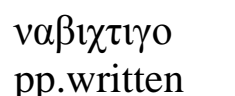 & $\begin{array}{l}\alpha \gamma \gamma \alpha \rho \gamma o \\
\text { property }\end{array}$ & $\begin{array}{l}\text { laor } \\
\text { grain }\end{array}$ & $\begin{array}{l}\pi \alpha \rho \alpha \gamma \alpha v o \\
\text { sowing }\end{array}$ & $\begin{array}{l}\lambda \mathrm{o} \chi \sigma \mathrm{o} \quad \zeta^{\prime} \ldots \\
\text { lukhs } 7\end{array}$ \\
\hline$\alpha \sigma 0 \quad$ ко $\alpha \delta о$ & $\varepsilon \mu \mathrm{O}$ & $\pi \alpha \delta o v \alpha \mu \mathrm{o} v \delta \delta i \gamma i v \delta \mathrm{o}$ & & & \\
\hline PRE RTP & DEM & boundary.PL & & & \\
\hline
\end{tabular}

In the following example, it refers to a person and is used with the preposition $\varphi \alpha \rho o$ "to":

(ci 10)

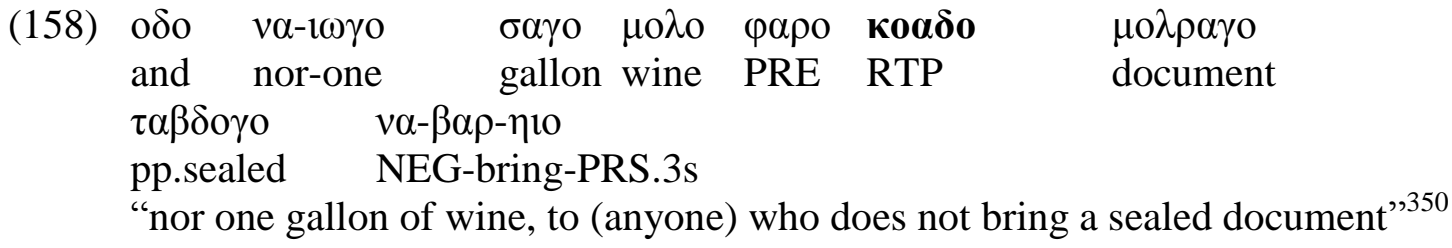

\subsubsection{Summary}

There are two main relative pronouns in Bactrian, $\kappa 1 \delta o$ and $\sigma 1 \delta 0$. $\kappa 1 \delta o$ is often used with human antecedents. This relative pronoun may express the role of a subject, an object, or a possessive. It may also denote a non-human antecedent. The form $\kappa 1 \delta 1$ is used only in the Rabatak inscription. It may refer to a singular and direct noun, a plural and oblique noun, or a plural and direct noun.

$\alpha \sigma \downarrow \delta o$ is primarily used to refer to inanimate objects, but it can also occur with reference to persons, though this is rare.

$\kappa o \alpha \delta$ o often functions as an adverb or a conjunction, but it may also used as a relative pronoun. In this case, it usually appears with a preposition.

The following table shows the most common forms of relative pronouns and their functions in Bactrian:

\footnotetext{
${ }^{347}$ Sims-Williams 2000a: 49.

${ }^{348}$ Sims-Williams 2007a: 224.

${ }^{349}$ Sims-Williams 2000a: 57.

${ }^{350}$ Sims-Williams 2007a: 85.
} 
Table 25. Relative pronouns

\begin{tabular}{|c|c|c|}
\hline & Human & Nonhuman \\
\hline Subject & $\kappa \iota \delta о$ & 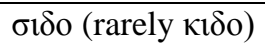 \\
\hline Object & $\kappa \iota \delta o$ & $\sigma i \delta o$ \\
\hline After preposition & 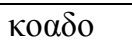 & 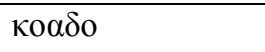 \\
\hline Possessive & $\kappa \iota \delta о$ & $\sigma \iota \delta o$ \\
\hline
\end{tabular}




\section{Chapter Five: Prepositions AND POStPositions}

\subsection{The functions of prepositions and postpositions}

\subsection{1 $\alpha \beta 0, \alpha \beta \alpha-, \alpha \beta-$ "to, for, in, etc."}

This preposition plays an important role in Bactrian and has the following functions:

$-\alpha \beta$ o can be used as a preposition of location, with the meaning "in":

(Surkh Kotal 6)

(159)

$\begin{array}{llll}\alpha \tau \alpha v o & \boldsymbol{\alpha \beta o} & \mu \alpha & \lambda_{1} \zeta \mathrm{o} \\ \text { also-PAR } & \text { PRE } & \text { ART } & \text { fortress } \\ \text { "also in the fortress" } 351 & \end{array}$

Another example:

(J 1-2)

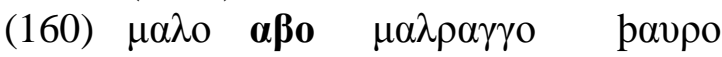

here PRE (of) PN city

"here in the city of Malr" 352

-It can be used as a temporal preposition. In this case, it means "until":

(W 18-19)

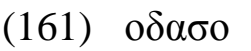
and-PRE

$$
\mu \omega \sigma o \quad \boldsymbol{\alpha \beta 0}
$$

now PRE

$1 \alpha 0\rceil \delta \alpha v 0$

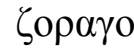

"and from now until eternity",353

eternal

time

$-\alpha \beta$ o occasionally governs a past infinitive:

(A 18)

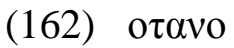
and-PAR

$\mu \alpha \pi \alpha \delta o \alpha p \chi \alpha v \eta 10$

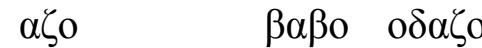

$\pi \mathrm{\imath}$ око

PROH.have the right.OPT.1s

I.DIR

PN and-I.DIR

PN $\alpha v \delta \alpha \rho o$

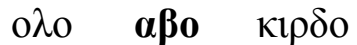

INA

wife PRE do.PST.INF

"And I, Bab and I, Piduk shall not have the right to make another wife." 354

-This preposition plays an important role in marking the object. ${ }^{355}$

In the role of an object marker, it can be used both in ergative and non-ergative constructions.

In an ergative construction:

In the following example $\alpha \beta$ o marks the direct object, which is both human and definite.

\footnotetext{
${ }^{351}$ Cf. Lazard, Grenet and de Lamberterie 1984: 226.

352 Sims-Williams 2000a: 55.

${ }^{353}$ Sims-Williams 2000a: 131.

${ }^{354}$ Sims-Williams 2000a: 33.

${ }^{355}$ For differential object marking in Bactrian, see Sims-Williams 2011: 23-38.
} 
(cp 19-21)

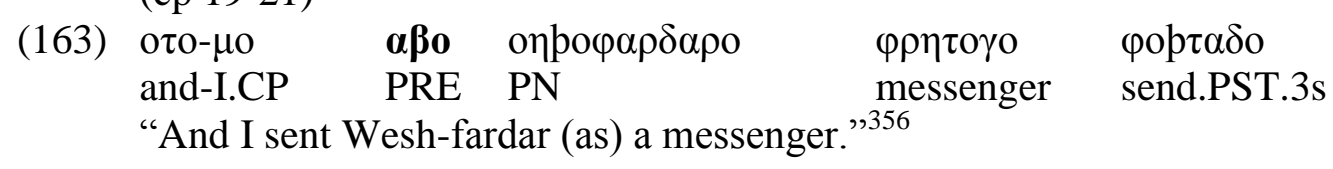

In a non-ergative construction:

In the following examples it also marks objects, which are both human and definite:

(bc 15-17)

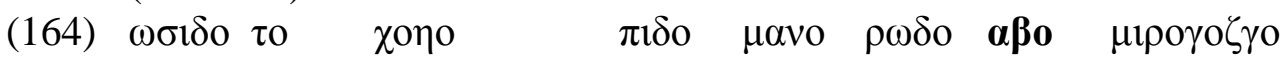

now SPD lordship PRE I.OBL sake PRE PN

$\pi \alpha \rho \circ \beta \alpha \lambda \mathrm{o}$

look after.IMPV.2s

"Now, your lordship for my sake should look after Mihr-guzg"357

(cp 13-14)

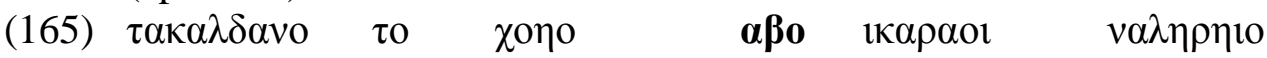

then-if-PAR SPD lordship PRE ART-staff NEG.have.PRS.OPT.2s?

"so if your lordship should not have the staff". 358

It seems that the use of the preposition $\alpha \beta$ o as an object marker is not obligatory in Bactrian and it can be omitted in special cases. In the next example, the direct object is attached to a conjunction without $\alpha \beta$ :

(bc 14-15)

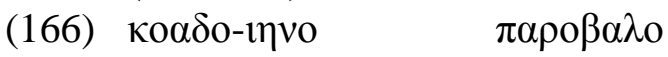

that-they.OBL ,359 look after.IMPV.2s

"Look after them.,"359

At first view, it seems that $\alpha \beta$ o may be omitted when the object is a pronoun. But the other examples counter this theory. In the following examples, the preposition $\alpha \beta 0$ marks the direct objects, which are pronouns:

(167) $\mathrm{o} \delta \alpha \lambda \delta \mathrm{o}$

and-if

$$
\begin{array}{ll}
\boldsymbol{\alpha \beta o} & \tau \omega \mu \alpha \chi 0 \\
\text { PRE } & \text { you.OBL }
\end{array}
$$

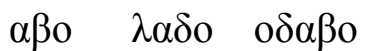

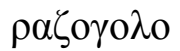

oin $\lambda \alpha \mu \mathrm{o}$

PRE court and-PRE

royal tribunal

take.SBJV.PRS.1p

"if we should take you to court and to the royal tribunal" 360

In the following example, this preposition marks the definite and human direct object, which is the second person demonstrative $\tau o$ + noun:

(bb 4)

(168) $\kappa \alpha \lambda \delta \alpha v o$

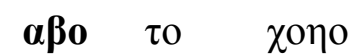

$\chi 0 \alpha \delta o$

when-PAR PRE SPD lordship RP

"when I myself might see your lordship healthy"361

$\lambda \rho \circ \gamma$

opvavo

\footnotetext{
"when I myself might see your lordship healthy"
}

\footnotetext{
${ }^{356}$ Sims-Williams 2007a: 95.

${ }^{357}$ Sims-Williams 2007a: 57.

${ }^{358}$ Sims-Williams 2007a: 95.

${ }^{359}$ Sims-Williams 2007a: 57.

${ }^{360}$ Cf. Sims-Williams 2000a: 59.

${ }^{361}$ Sims-Williams 2007a: 55.
} 
In light of the above examples, we can conclude that there are two different possibilities when the object is a pronoun. In the first case, a full pronoun may occur with $\alpha \beta o$ as an object marker (examples 166, 167). In the second case, an enclitic pronoun without $\alpha \beta 0$ may be used (example 165). The first case is more common in the extant material.

\section{A special case}

The preposition $\alpha \beta o$ also marks a non-personal indirect object. In the following example, $\varphi \rho \mu_{\alpha \nu 0}$ "order" is a direct object and $\sigma \alpha \gamma_{0}(\mathrm{PN})$ is an indirect object. In this context, we would have expected papo, which usually marks a personal indirect object, but instead, we find the preposition $\alpha \beta$ o (compare with the example 162):

(bb 10-11)

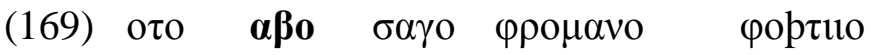

and PRE PN order send.IMPV.2s

"And you should send an order to Sag." 362

$\alpha \beta$ o as object marker or directive?

In some cases, it is not very clear whether $\alpha \beta 0$ is an object marker or a directive. In the following example, it is used with an inanimate. Here the question arises whether this noun is a direct object:

(C 20-21)

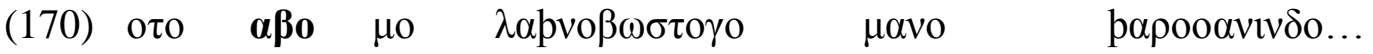

and PRE DEM deed of gift I.OBL PN

$\mu$ $\mu \lambda \rho о \quad \tau \alpha \beta \delta o$

seal impress.PST.3s

"and I, Sharwanind sealed this deed of gift"363

The verb $\tau \alpha \beta \delta$ o "impress" is a transitive verb. When we accept that $\mu$ o $\lambda \rho o$ "seal" is a direct object, then we can interpret $\mu$ o $\lambda \alpha p v o \beta \omega \sigma \tau o \gamma_{0}$ "this deed of gift" as an indirect object, and $\alpha \beta 0$ can be used with an indirect object which is not human.

In the following example, the verb $\tau \alpha \beta \delta$ o is used without $\mu$ o $\lambda \rho o$ "seal" and a direct object, i.e., $\chi 0 \eta \sigma \alpha 00 \beta \omega \sigma \tau \imath \gamma o$ "contract of undertaking", occurs with it:

$\left(\mathrm{O} 4^{\prime}-5^{\prime}\right)$

(171) odo $\pi 1 \sigma 0$

and PRE

$\mu \alpha v \delta \alpha \rho o v \alpha v i \sigma o$

other

$\chi 0 \eta \sigma \alpha 0 o \beta \omega \sigma \tau \imath \gamma о$

contract of undertaking

$\tau \boldsymbol{\alpha \beta \delta о}$

seal.Pst.3s

"and also in the presence of the other freemen who have sealed (this) contract of undertaking,"364

In New Persian, there is a parallel construction to the Bactrian verb $\mu$ o $\lambda \rho o \tau \alpha \beta \delta$, i.e., New Persian mohr zadan "seal". This verb is usually used with a direct object. In this case, it functions as a transitive compound verb and requires a direct object. In Bactrian, it is not absolutely clear whether $\mu$ o $\rho$ o $\tau \alpha \beta \delta$ o "seal" functions like mohr zadan "seal" in New Persian. When it functions as a compound verb, it requires a direct object, and therefore in example

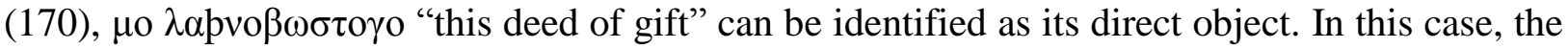
preposition $\alpha \beta$ o marks a non-human direct object.

\footnotetext{
${ }^{362}$ Sims-Williams 2007a: 55.

${ }^{363}$ Sims-Williams 2000a: 41.

${ }^{364}$ Sims-Williams 2000a: 81.
} 

$\alpha \beta$.

The only possible alternative to the above interpretation would be a directive function of

-In one case, $\alpha \beta$ o may also be used as a postposition: ${ }^{365}$ (jc 6-7)

(172) $\kappa \alpha \lambda \delta \delta \alpha \beta o$

$(\kappa \alpha \lambda \delta \mathrm{o}+-\delta \mathrm{o} ?+\alpha \beta \mathrm{\beta})$ if-you.CP-POST ART-penalty?

$\pi \mathrm{o} \rho \delta \delta \mathrm{i} \gamma \alpha 10$

( $\pi$ o $\delta$ o $\left.\gamma_{0}+-\alpha 10\right)$ owing- be.OPT?.3s

"if the penalty may have been owing to you",366

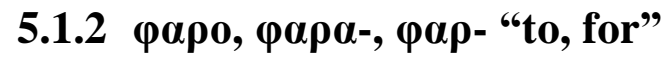

1. This preposition is used only with animates in the meaning of "to, for": (dd 5-6)

(173) $\tau \alpha \sigma 1 \delta \alpha \sigma 0$ whatever-PRE

$\alpha \zeta \gamma \alpha \mu \mathrm{o} \quad \kappa i \rho \alpha \delta o$ allocation make.SBJV.3s

"Whatever allocation of hay he may make for them out of my property",367

2. It is occasionally used with an indirect object. For example:

(bg 13-14)

(174) фаро $\chi 0 \alpha \delta \eta о o \alpha v i v \delta o \quad \lambda \alpha \eta 10$

PRE PN give.OPT.1s or $3 \mathrm{~s}$

"I (?) should give (it) to Khwadew-wanind"368

In the following example, $\varphi \alpha \rho o$ is used with the indirect object $\lambda \alpha \delta o \beta \alpha \rho o$ "judge", which is human, and $\alpha \beta$ o with the inanimate indirect object $\gamma \alpha \zeta$ vo "treasury":

(Q 29-30)

(175) $\tau \alpha \delta$ o $\tau \alpha o o \alpha v o$

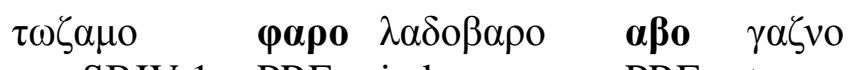
then fine pay.SBJV.1p PRE judge PRE treasury "Then we shall pay a fine to the judge to the treasury.",369

There is an example which can be discussed relating to the use of $\varphi \alpha \rho o$. As mentioned above, this preposition occurs only with indirect objects. There is only one example in which it is not clear whether it marks an indirect or direct object:

(co 8-9)

$\alpha \sigma 1 \delta 0$

$\alpha \delta o \rho l \gamma o^{370}$

"but (if) you can discipline Adurig..."371

$\begin{array}{ll}\text { pulo } & \kappa i p \delta o \\ \text { can.INJ.2s } & \text { do.INF }\end{array}$

\footnotetext{
${ }^{365}$ Sims-Williams 2007a: 185.

${ }^{366}$ Sims-Williams 2007a: 129.

${ }^{367}$ Sims-Williams 2007a: 105.

${ }^{368}$ Sims-Williams 2007a: 65.

${ }^{369}$ Sims-Williams 2000a: 91.

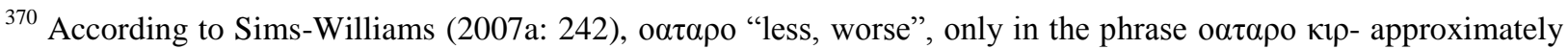
"to discipline".

${ }^{371}$ Sims-Williams 2007a: 93.
} 
о $\alpha \tau \alpha \rho$ кıр- is a complex verb and occurs only once in the Bactrian material. We do not know exactly whether $\alpha \delta$ o

\subsection{3 $\alpha \sigma 0$ "from, (out) of, by, against, concerning, according to, in respect of, as a result of, than, etc."}

This preposition has the following functions:

1. It can be used with the agent in a passive clause with the meaning of "by": (ch 20-21)

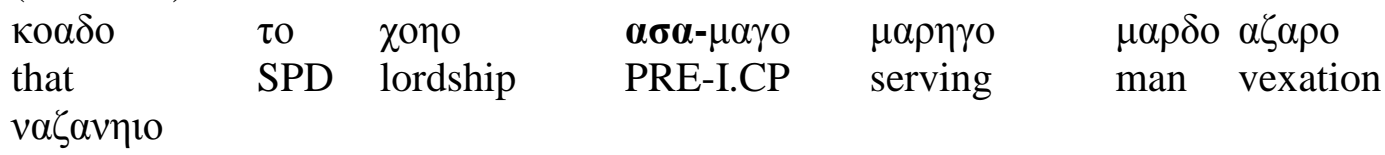

NEG.know.OPT.3 or $2 \mathrm{~s}$

"That your lordship should not feel aggrieved by me, (your) serving man.,"372

2. In the following example, it is used with the meaning "for":

(K 12)

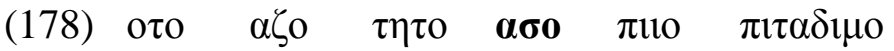

and I.DIR PN PRE PN guarantee.PST.1s

"And I Tet, have guaranteed for Piy.,"373

3. It is can also be used to specify direction or location:

(C9)

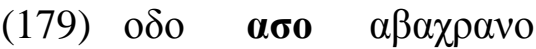

and PRE north

"and to north",374

4. It sometimes forms temporal phrases:

(A 14)

(180) $\boldsymbol{\alpha \sigma \sigma} \mu \alpha \beta \rho \imath \sigma o(\mu o+\alpha \beta \alpha \rho 0+-1 \sigma o)$

PRE ART-future-also

"also in the future" 375

It is occasionally used with the preposition $\alpha \beta$ o to indicate temporal distance:

(J 20)

(181) $\boldsymbol{\alpha \sigma o} \mu \omega \sigma o \quad \alpha \beta o \quad 1 \alpha o \eta \delta \alpha v o$

PRE now PRE eternity

"from now to eternity",376

Another example follows:

(U 14)

(182) $\quad \boldsymbol{\alpha \sigma o} \quad \sigma \alpha \rho \delta o \quad \alpha \beta o \quad \sigma \alpha \rho \delta$ o

PRE year PRE year

"from year to year" 377

\footnotetext{
${ }^{372}$ Sims-Williams 2007a: 83.

${ }^{373}$ Sims-Williams 2000a: 63.

${ }^{374}$ Sims-Williams 2000a: 39.

375 Sims-Williams 2000a: 33.

376 Sims-Williams 2000a: 59.

${ }^{377}$ Sims-Williams 2000a: 109.
} 
$\alpha \sigma 0$ with the preposition $\alpha \beta 0$ can also indicate local distance:

(V 19)

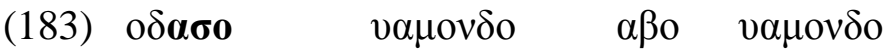

and-PRE boundary PRE boundary

"from boundary to boundary",378

$\alpha \sigma o$ with the preposition $\alpha \beta 0$ can also indicate personal distance:

(cg 7-8)

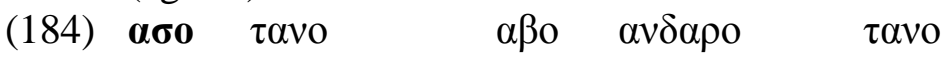

PRE person PRE INA person

"from (one) person to another person.,"379

5. It may indicate the source or origin:

(A 25-26)

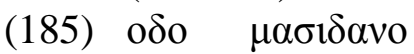

and PROH.PAR-REL.PRON-PAR PRE PN

"nor (to) whatever (child) may be born from Ralik.",380

6. It frequently indicates the parts of a whole:

(K 13-14)

(186) $\tau \alpha \delta \alpha \zeta \mathrm{o} \quad \tau \eta \tau$ o $\boldsymbol{\alpha \sigma o} \quad \chi 0 \beta о \quad \tau \omega \zeta \alpha v o$

then-I.DIR PN PRE own pay.SBJV.1s

"Then I, Tet shall pay from (my) own (property)."

7. It can also show geographical origin:

(S 5)

(187)

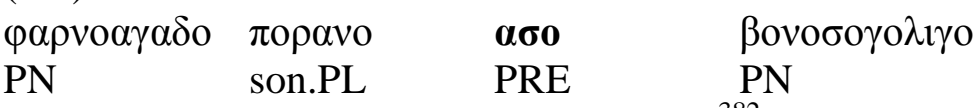

"the sons of Farn-agad from Bonchuqlïgh"382

\subsection{4 $\pi \mathrm{l} \delta 0, \pi \mathrm{l} \delta-, \pi \mathrm{l} \delta \delta$ - "in, on, by, with,..."}

1. This preposition can be used to specify a location, for example, in the expression $\pi$ ioo $\mu \lambda \lambda \alpha \gamma \gamma \mathrm{O}$ "in the midst, amongst". 383

2. It may be used in time expressions such as: $\pi 1 \delta$ o $\alpha$ $\mu \alpha v o$ "for one month".

3. It may be used with the meaning "in respect of":

(ba 11)

(188) $\pi$ ז $\delta 0$

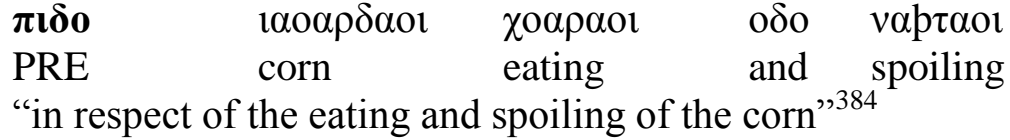

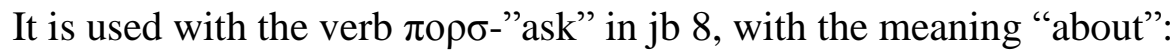

\footnotetext{
${ }^{378}$ Sims-Williams 2000a: 119.

${ }^{379}$ Sims-Williams 2007a: 81.

${ }^{380}$ Sims-Williams 2000a: 35.

${ }^{381}$ Sims-Williams 2000a: 63.

382 Sims-Williams 2000a: 95.

${ }^{383}$ Sims-Williams 2007a: 232.

${ }^{384}$ Sims-Williams 2007a: 53.
} 
(jb 7-8)

(189) $\mu 1 \sigma เ \delta \mathrm{o}<\mu \mathrm{o}>$

Moreover-I.CP

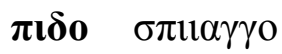

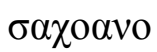

$\pi \mathrm{\circ} \rho \alpha \delta \mathrm{o}$

"Moreover, I asked about the matter of Spiy."385

ask.PST.3s

4. It may be used with the meaning "because":

(cm 9-10)

(190) $\tau \alpha \delta o-\mu о$

$\pi \mathbf{\pi} \boldsymbol{\delta} \quad \tau \alpha \mu \alpha \chi 0$

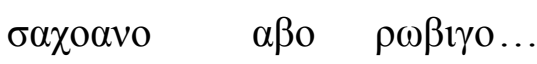

$\beta \alpha \sigma \tau \imath \delta \delta$

then-I.OBL PRE you.OBL

statement PRE men of Rob

bind.PST.3p

"Because of your statement, I bound the men of Rob." 386

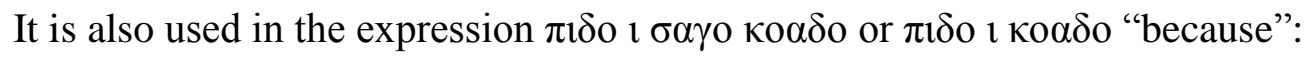

(ba 8-9)

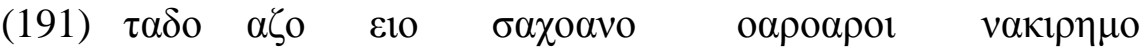

then I.DIR DEM statement belief NEG.do.PRS.1s

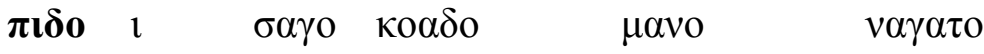

PRE ART shade? that I.OBL hear.PST.3s

"I do not believe this statement, because I have heard..." 387

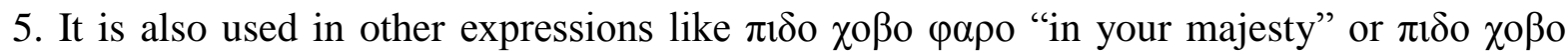

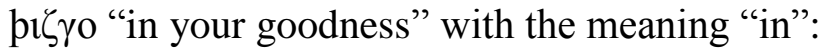

(cc 12-14)

(192) $\tau \alpha \delta o-\mu о$

then-I.CP PRE SPD majesty ${ }_{, 388}$ dog good send.IMPV.2s

"so in your majesty send me a good dog",388

6. Sometimes, it qualifies a substantive descriptively and has the meaning of "with":

(ci 11-12)

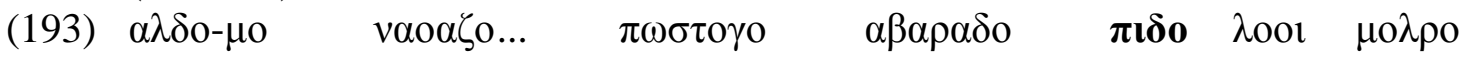
if-I.CP PN document bring.PRS.3s PRE two seal "If Nawaz brings me a document with two seals",389

7. In the following example, it is used with the meaning "as":

(je 5-6)

(194) $\sigma ı \delta \sigma \sigma o . .$.

which-PRE

"which were taken away... as tax." 390

$\zeta 1 \delta 0 \quad \pi \mathbf{l} \delta 0 \quad \tau \omega \gamma o$

take away.PST.3s PRE tax

8. It is also frequently used in adverbial phrases, as $\pi \imath \delta o \mu \alpha \beta \alpha \rho o$ "in the future". 391

\footnotetext{
${ }^{385}$ Sims-Williams 2007a: 127.

${ }^{386}$ Cf. Sims-Williams 2007a: 91.

${ }^{387}$ Sims-Williams 2007a: 53.

388 Sims-Williams 2007a: 73.

${ }^{389}$ Sims-Williams 2000a: 85.

${ }^{390}$ Cf. Sims-Williams 2007a: 131.

${ }^{391}$ This expression is a parallel to $\alpha \sigma o \mu \alpha \beta \rho 1 \sigma o$ "in the future".
} 
(za 1-2)

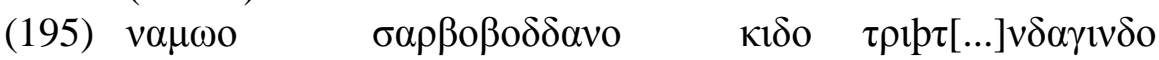

homage all the buddhas.PL who ?-be.PRS.3p

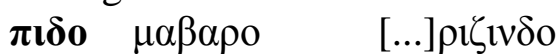

PRE ART-future ?-call.PRS.3p

"Homage to all buddhas who are ...(and) will ... in the future",392

9. It may express a relationship between two numerals, such as $1 \omega \gamma \mathrm{o} \pi \mathrm{\imath} \delta \mathrm{o} \lambda \mathrm{oo}$ "two to one".

(K 10-11)

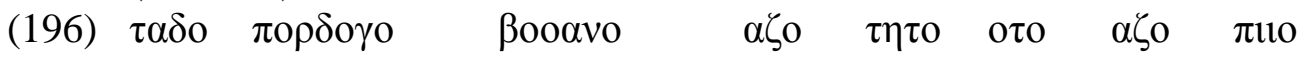

then owing be.SBJV.1s I.DIR PN and I.DIR PN

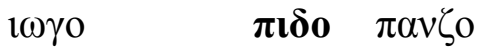

one PRE five

"then, I, Tet, and I, Piy shall be owing (at the rate of) five to one"393

This preposition can be directly added to other nouns or adjectives and it can form adverbs, e.g., $\pi 1 \delta o \lambda \alpha \delta i \gamma o, \pi \imath \delta o \lambda \alpha \delta \delta \gamma_{0}(\pi 1 \delta o+\lambda \alpha \delta o+$ suffix $-1 \gamma o)$ "legally, formally" or $\pi 1 \delta o v \omega \gamma \alpha \rho o$ $\left(\pi 1 \delta o^{+*} v \omega \gamma \alpha \rho 0\right.$ "new") "again".

It may be added to the demonstrative pronoun such as oo, e10 and forms $\pi 1 \delta$ oo and $\pi 1 \delta \delta 110$ :

(je 7-8)

(197) $\pi \mathrm{i} \delta$ oo

PRE-DEM RTP-he.CP

podo

pay out.INF

$\sigma \alpha \chi \sigma \iota \delta 0$

$1 \quad \chi \alpha \rho o \quad \alpha \beta o \quad \mu o \lambda_{0}$

ART donkey PRE wine

"Because his donkey is assessed to be paid out (in return) for wine.",394

\subsection{5 $\pi l \sigma 0, \pi l \sigma \alpha-, \pi l \sigma o \alpha-$ "to, in the presence of"}

It usually indicates a location. It is used very often with the meaning of "in the presence of". In this case, a nominal phrase or personal name usually occurs after $\pi \imath \sigma 0$ :

(A 5)

(198) $\pi \mathbf{\imath} \sigma 0$

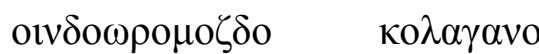

PRE

PN PN

"in the presence of Wind-ormuzd Kulagan"395

(A 7)

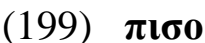

PRE

$\mu \alpha v \delta \alpha \rho 0 v \alpha v i \sigma o$

$\sigma \tau \eta \beta 1 \gamma \alpha v_{0}$

$\alpha \zeta \alpha \beta$ op $\alpha$ vo

"in the presence of the other freemen of Steb",396

In the following example, it seems that $\pi \imath \sigma o$ plays the role of an object marker, which marks an indirect and animate object. According to the extant material, in such a situation, we expect the occurrence of $\varphi \alpha \rho o$ (see ex. 174). It must be added that this is the only example with this function of $\pi 1 \sigma 0$. As this document is an a relatively old one, it is difficult to show the development of a preposition to object marker. In this case, $\pi 1 \sigma 0$ may again play the role of a preposition:

\footnotetext{
392 Sims-Williams 2007a: 175.

${ }^{393}$ Sims-Williams 2000a: 63.

${ }^{394}$ Sims-Williams 2007a: 131.

395 Sims-Williams 2000a: 33.

${ }^{396}$ Sims-Williams 2000a: 33.
} 
(cd 11-12)

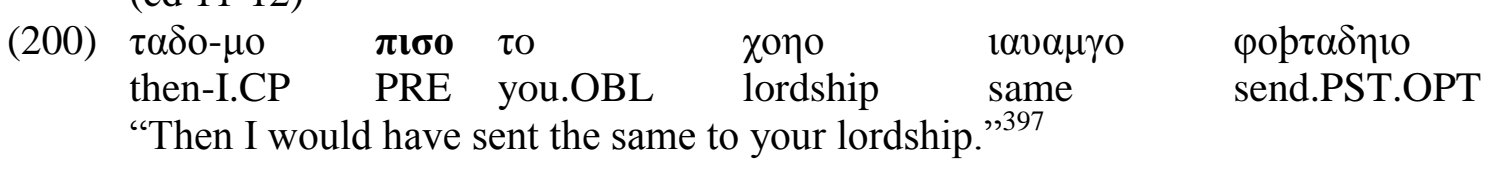

\subsection{6 $\alpha \lambda_{0}$}

This preposition is used very often with the meaning of "with, together with":

(bc 10)

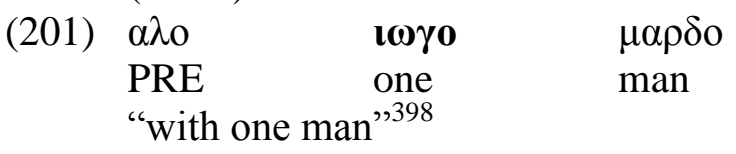

This preposition can be prefixed to other nouns to form an adjective, e.g., $\alpha \lambda o \gamma \alpha \mu \mathrm{o}$

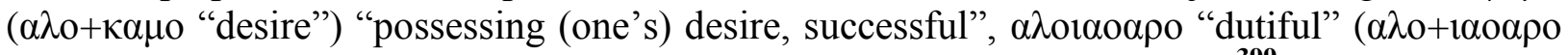
"conditions"), $\alpha \lambda \sigma \sigma \iota \chi \tau 0 \gamma_{0}(\alpha \lambda \mathrm{o}+* \sigma \chi \chi \tau \gamma \mathrm{\gamma o}$ "inclination")"inclined, desirous". 399

\subsection{7 v $\alpha \alpha \alpha \delta o, ~ v o \beta \alpha v \delta o$}

This preposition means "beside, with" and is rarely used as a postposition.

As a preposition:

(A 9-10)

\begin{tabular}{|c|c|c|c|c|c|}
\hline$\kappa \iota \delta 0$ & $\omega \sigma 0$ & vo $\beta \alpha v \delta o$ & vivঠоко & 1 & $\omega \chi \mathrm{po} \beta \alpha \delta$ o $\alpha \alpha v_{0}$ \\
\hline who & now & PRE & PN & ART & $\mathrm{PN}$ \\
\hline $\begin{array}{l}\alpha \zeta \alpha \delta o \\
\text { free }\end{array}$ & $\begin{array}{l}\alpha \sigma \pi \alpha c \\
\text { servic }\end{array}$ & & $\begin{array}{l}\eta \zeta \alpha \mu \mathrm{o} \\
\text { RS.1p }\end{array}$ & & \\
\hline
\end{tabular}

As a postposition it is used only in two letters. In the following example, it occurs after a full pronoun:

(xk 4-5)

(203) $\omega \sigma 1 \delta o$

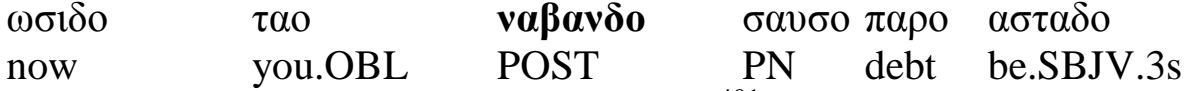

"Now (if) Sahs's debt should be with you"401

In the next example, it occurs after an enclitic personal pronoun:

(dd 4-5)

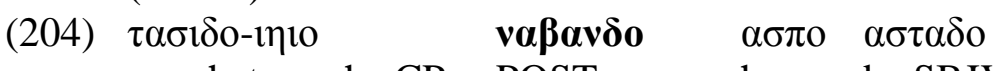

so-whatever-he.CP POST horse be.SBJV.3s

"so whatever horses there may be with him" 402

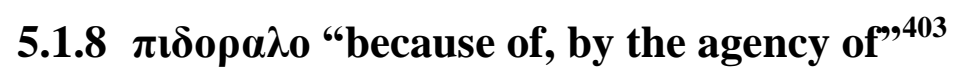

This postposition is only used in ba, after a nominal phrase:

\footnotetext{
${ }^{397}$ Sims-Williams 2007a: 75.

${ }^{398}$ Sims-Williams 2007a: 57.

${ }^{399}$ Sims-Williams 2007a: 190.

${ }^{400}$ Sims Williams 2000a: 33.

${ }^{401}$ Sims-Williams 2007a: 155.

${ }^{402}$ Sims-Williams 2007a: 105.

${ }^{403}$ Sims-Williams 2007a: 255.
} 
(ba 5-6)

(205) $\tau \alpha \delta \alpha v o$

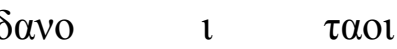

then-PAR ART you.OBL

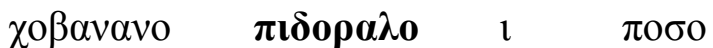

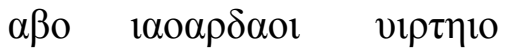

PRE corn let.PST.OPT.

"Because of your shepherds, sheep were let into the corn."

\subsubsection{Prepositions as preverbs}

So far as we can tell from the material available, two prepositions are used as preverbs. The preposition $\pi 1 \delta o$ "in, on, by, with,..." occurs often as a preverb, as illustrated in Table 26:

Table 26. Verbs with the preverb $\pi i \delta o$ "in, on, by, with,..."

\begin{tabular}{|c|c|}
\hline$\pi ı \delta 0 \alpha \zeta \mathrm{\imath -}$ & referring to some hostile act ${ }^{405}$ \\
\hline$\pi 1 \delta о \kappa \alpha \rho \lambda-$ & "to withhold, prevent, retain, detain, arrest" \\
\hline 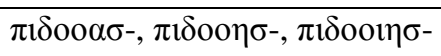 & "to declare" $" 407$ \\
\hline$\pi 1 \delta 00 \alpha v-$ & "to request" \\
\hline$\pi \mathrm{\imath} \delta \circ \rho \circ \beta-, \pi \mathrm{\imath} \delta \mathrm{o} \rho \beta-(?)$ & "to receive, to accept" \\
\hline 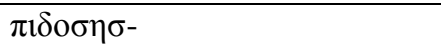 & "to fix, determine, agree" \\
\hline
\end{tabular}

The other preposition used as a preverb is $\alpha \beta$, e.g., $\alpha \beta$ or $\alpha \sigma-$ "remember" $"$.

\subsection{Summary}

In this chapter, we first investigated the semantic functions of prepositions and postpositions. Thereafter we showed the special functions of certain prepositions.

Among the prepositions in Bactrian, some play a special and important role, such as $\alpha \beta 0$ "to", $\varphi \alpha \rho o$ "for", and $\alpha \sigma o$ "from". The preposition $\alpha \beta o$ is used occasionally to mark a direct object that is both definite and human, and also to mark an indirect object, which can also be inanimate. This preposition also occurs with infinitives. The preposition $\varphi \alpha \rho o$ marks an animate indirect object. In one instance, it appears that the preposition $\pi 1 \delta$ o plays the role of $\varphi \alpha \rho o$, which is not expected. The form $\alpha \sigma 0$ is rarely used in passive constructions with the agent, with the meaning of "by". Some of prepositions like $\alpha \lambda_{0}, \pi \mathrm{l} \delta \mathrm{o}$ can be prefixed to other substantives and form a compound, namely, an adjective or adverb. $\pi i \delta$ o is used very commonly as a preverb. The preposition $\alpha \beta 0$ can also be used as a preverb.

\footnotetext{
${ }^{404}$ Sims-Williams 2007a: 53.

405 Sims-Williams 2007a: 254

${ }^{406}$ Sims-Williams 2007a: 255.

${ }^{407}$ Cf. Sims-Williams 2007a: 255.

${ }^{408}$ Cf. Sims-Williams 2007a: 255.

${ }^{409}$ Sims-Williams 2007a: 256.

${ }^{410}$ Sims-Williams 2007a: 256.

${ }^{411}$ Sims-Williams 2007a: 186.
} 


\section{Chapter SiX: AdVerbS}

\subsection{Formation of adverbs by suffixes}

Some suffixes help us to distinguish adverbs from other word classes in Bactrian. Some adverbs are formed from nouns and adjectives by adding a suffix. We should not forget that many adverbs do not have any adverbial suffix and are not indicated morphologically at all. The following forms are suffixes that may form adverbs:

1. $-\eta \lambda \mathrm{o},-1 \lambda \mathrm{o}$

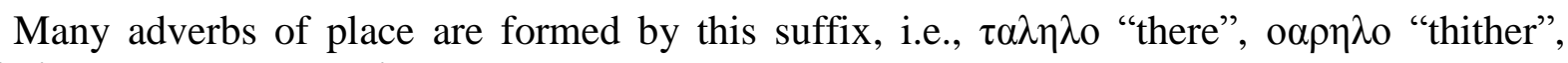
$\mu \alpha \lambda \eta \lambda_{0}$ "here", $\mu 1 \rho о \sigma \alpha \nu \eta \lambda_{0}$ "eastwards".

2. - $\gamma \omega \gamma \gamma \mathrm{o},-\gamma о \gamma \gamma \mathrm{o},-о \gamma \gamma \mathrm{o}$

A word with this suffix can be an adjective. In many cases, it means "like...", for example,

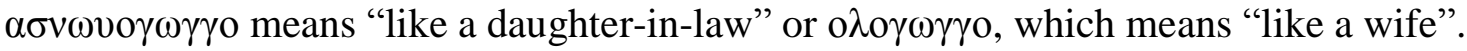

3. $-\delta \alpha \rho o,-\tau \alpha \rho o,-\alpha \tau \alpha \rho o$

Some words formed by the comparative suffix may be adverbs, i.e., o1 $\zeta \gamma \gamma \gamma$ $\delta \alpha \rho o$, "otherwise", $\alpha \nu \delta \alpha \rho \circ \zeta \alpha \gamma \gamma о \delta \alpha \rho \circ$ "otherwise", $\alpha \sigma \kappa \alpha \delta \alpha \rho$ "more", $\alpha \pi \imath \sigma o \delta \alpha \rho o$ "previously".

4. $-\delta o,-1 \delta o$

Some words formed by the suffix - $\delta$ o may be adverbs, e.g., $\tau \alpha \lambda \imath \delta$ o "in this matter" or $\omega \sigma 1 \delta o$ "now". In both of these cases, the suffix $-\delta$ o is added to another adverb, but it has not changed the meaning of the original adverbs.

5. $-1 \gamma 0,-\eta \gamma 0,-110,-10,-100$

This suffix may form adjectives or adverbs, e.g., $\varphi \rho o \mu \alpha v i \gamma_{0}$ "at the command (of)", $\pi \imath \delta \mathrm{o} \lambda \alpha \delta \gamma_{0}$ "legally".

6. $-1 \sigma 0,-\sigma 0$

It is an enclitic adverb with the meaning of "also, too". This adverb can be suffixed to other

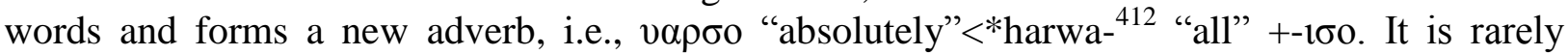
attested in the extant material.

\subsection{Types of adverbs}

There are three kinds of adverbs in Bactrian:

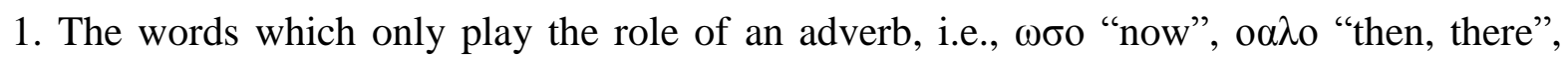
$\tau \alpha \lambda_{0}$ "there".

2. The adverbs which are also used as preverbs and prepositions, i.e., $\alpha \beta \eta \gamma o, \alpha \beta \eta 10$. As an adverb, it means "away, out"; as a preverb, it is used with some verbs such as $\beta \alpha \rho$ - "bear" in the meaning of "to take away", and $\lambda \alpha v$ - "give" in the meaning of "to give away".

${ }^{412}$ The Bactrian form of this word is not attested in the extant material. 
(X 15)

(206) $\mu \alpha \rho \eta 10$

slave

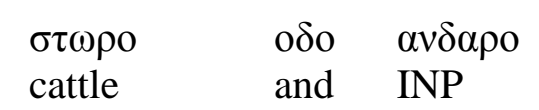

$\sigma ı \sigma o \quad \alpha \kappa \iota \delta \delta \eta v o$

$\alpha \sigma o$

$\tau \alpha \mu \alpha \chi 0$

INP who-they.OBL

PRE

you.OBL

\section{$\boldsymbol{\alpha \beta \eta}$}

preverb

$\beta \alpha \rho \alpha \mu$

bear.SBJV.1p

"cattle and anything else-that we should take them away from you" "413

(A 28)

(207) odo

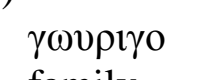

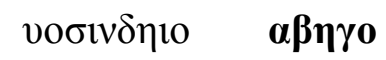

$\alpha \beta o \quad \lambda \alpha \delta o$

and family

agree.OPT.3s preverb

"and the family may agree to give (her) away"

PRE give.INF

In the following example, this adverb appears once after the preposition $\alpha \sigma o$ "from" and once it is attached to $\pi \alpha \rho \mu \alpha v_{0}$ "authority":

$$
\text { (X 30-31) }
$$

(208) o $\delta \alpha \sigma o \quad 1$

and-PRE ART(?)

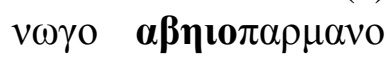

$\boldsymbol{\alpha \beta \eta \iota 0} \alpha v \delta \alpha \rho о$

$\pi \omega \sigma \tau \imath \gamma o$

contract

$\kappa \alpha \beta о \gamma \gamma о$

odo

away INA

old

and

new without authority

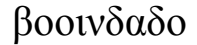

"and apart from this (?) (one), other contracts, old or new, may be without authority" 415

3. Some words are nouns or adjectives, but they can also be used as adverbs, i.e., $\alpha \sigma \pi$ oplyo "complete" which is used as adverb with the meaning of "completely" or $\chi \alpha \beta$ "night" $\rho \omega \sigma o$ "day" which are joined together and form an adverb with the meaning of "(by) night and (by) day".

In the following example, $\sigma \pi$ opıro is used as an adjective before a noun:

(U 7)

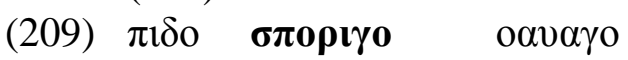

PRE complete price
"in complete price" 416 .

In the following example, it plays the role of an adverb:

(G 5-7)

(210) $\mu 1 \sigma เ \delta o$

$\begin{array}{ll}\mu \text { now } & \mu \alpha v o \quad \mu \mathrm{o} \zeta \delta \\ \text { I.OBL PN }\end{array}$

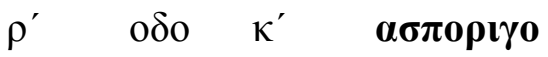

$\pi 1 \delta$ о $о \beta \delta о \quad 1 \alpha 01 \quad \alpha \gamma \rho \eta \alpha \mathrm{ol}$

100 and 20 completely

receive.PST.3s grain peck

"Now, I Muzd received one hundred and twenty pecks of grain completely."417

\subsection{Deictic adverbs}

In many languages, deixis can be expressed by some elements as demonstratives, adverbs and particles. In my 2009a article ${ }^{418}$ on demonstratives, I emphasized the distinction between various demonstratives and showed that there is no clear contrast between proximate and remote deixis. In this section, I will focus on the adverbs which may show local deixis in Bactrian. In

\footnotetext{
${ }^{413}$ Sims-Williams 2000a: 139.

${ }^{414}$ Sims-Williams 2000a: 35.

${ }^{415}$ Cf. Sims-Williams 2000a: 143.

${ }^{416}$ Cf. Sims-Williams 2000a: 107.

${ }^{417}$ Cf. Sims-Williams 2000a: 49.

${ }^{418}$ See Gholami 2009a: 19-26.
} 
some languages as Sogdian, there are different adverbs with the meaning of "here", which show proximate deixis, and "there", which show remote deixis. These adverbs are developed from three demonstrative stems, i.e., -m-, -t- and -w-. The adverbs from the stem -m- are translated as "here" and the adverbs from the stem - $\mathrm{t}$ - and - $\mathrm{w}$ - as "there". According to Wendtland, these adverbs can be classified according to their semantic attributes expressed by suffixes. She distinguishes two groups of adverbs. Adverbs of the first group indicate a definite explicit point or the localization of a single person or object by the speaker. When it is a matter of the localization by a third person or an item that is located at a remote distance from the speaker, an adverb of the second group is used. Furthermore, the adverbs of the second group may show whether the speaker shares in an action or is aware of it. ${ }^{419}$ In this section, I first introduce the different adverbs in Bactrian which indicate local deixis. Then I examine whether there is a clear contrast between these adverbs, as in Sogdian.

In Bactrian, there are two main groups of adverbs which indicate local deixis. Each group contains three adverbs. The first group marks proximate deixis, whereas the second group marks remote deixis.

Both $\mu \alpha \rho \rho$ "here" and $\mu \alpha \lambda_{0}$ "here" are used 42 times in the documents in BD I and II. The form $\mu \alpha \lambda \eta \lambda \mathrm{o}$ "here" is only used three times in these documents. The remote deixis $\tau \alpha \rho \mathrm{o}$ "there" is used 39 times and $\tau \alpha \lambda_{0} 7$ times in BD I and II. The form $\tau \alpha \lambda \eta \lambda_{0}$ are attested only once in BD I and II. The form oa $\lambda_{0}$ is the most common remote deixis adverb found in the mentioned material. The following table shows the place adverbs and their frequency in the texts in BD I and II:

Table 27. Place adverbs

\begin{tabular}{|l|l|l|l|l|l|}
\hline $\begin{array}{l}\text { proximate } \\
\text { deixis }\end{array}$ & $\begin{array}{l}\text { frequency } \\
\text { in BD I, II }\end{array}$ & remote deixis & $\begin{array}{l}\text { frequency } \\
\text { in BD I, II }\end{array}$ & remote deixis & $\begin{array}{l}\text { frequency } \\
\text { in BD I, II }\end{array}$ \\
\hline$\mu \alpha \rho 0$ & 42 & $\tau \alpha \rho 0$ & 39 & $0 \alpha \lambda_{0}$ & 46 \\
\hline$\mu \alpha \lambda_{0}$ & 42 & $\tau \alpha \lambda_{0}$ & 7 & $0 \alpha \rho o$ & 8 \\
\hline$\mu \alpha \lambda \eta \lambda \mathrm{o}$ & 3 & $\tau \alpha \lambda \eta \lambda_{0}$ & 1 & - & - \\
\hline
\end{tabular}

\subsubsection{Proximate deixic adverbs}

\section{$\mu \alpha \rho 0$}

This adverb usually occurs in one of the following cases:

1. When someone or something is located at a proximate distance from the speaker or writer of the letter:

(cd 3-4)

(211) $\mu 1 \sigma \iota \delta o$

$$
\begin{array}{llllll}
\alpha \gamma \alpha \delta o & \mu \alpha \rho 0 & \alpha \sigma o & \tau o & \chi 0 \eta о & \pi \omega \sigma \tau o \gamma o
\end{array}
$$

moreover arrive.PST.3s here PRE SPD lordship letter

"Moreover a letter has come hither from your lordship." 420

Sometimes there is an emphasis on the speaker or writer of the letter or document. In this case, aside from "here", some expressions as "into my presence" or "to me" are mentioned:

(eb 14-15)

(212) $\tau \alpha \delta o-\mu o$



then-I.CP here send.OPT or INJ.2s

"Then you should send (them) hither to me.",421

\footnotetext{
${ }^{419}$ Wendtland 2006: 244, 257.

${ }^{420}$ Sims-Williams 2007a: 75.
} 
(ba 13)

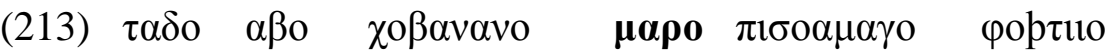

then PRE shepherd.PL here PRE-I.CP send.IMP.2s

"Then send the shepherds hither into my presence.",422

The name of a place may be mentioned, to which someone or something has come or should be sent:

(cl 5-6)

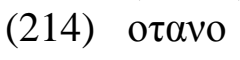

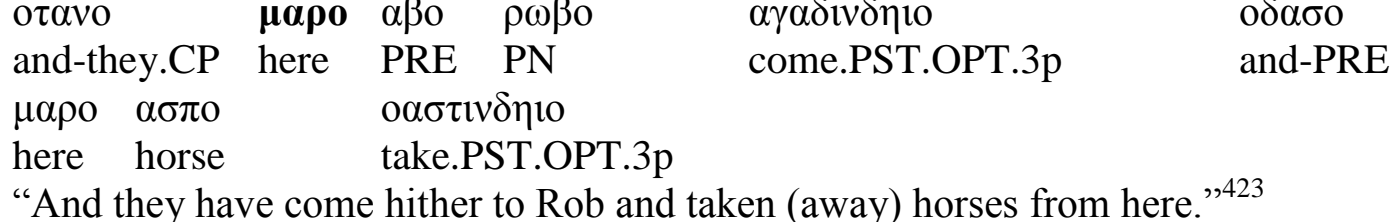

2. When something happens or exists in the place of speaker or writer of the letter: (ji 9-10)

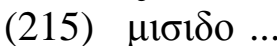
moreover here live.PRS.1s PRE your majesty

"Moreover, I live here through your majesty." 424

(jb 10)

(216) $\tau \alpha \delta \alpha \sigma 0$ then-PRE here go.PST.3p

"Then they have gone from here." 425

$\mu \alpha \lambda \mathbf{0}$

This word is used as much as $\mu \alpha \rho o$ in the texts in BD I and II. $\mu \alpha \lambda$ o has the same function as наро:

1. When someone or something is located at a proximate distance from the speaker or writer of the letter:

$$
\text { (ba 6-7) }
$$

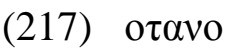

and-PAR

o $\alpha \beta \mathrm{O}$

and-PRE

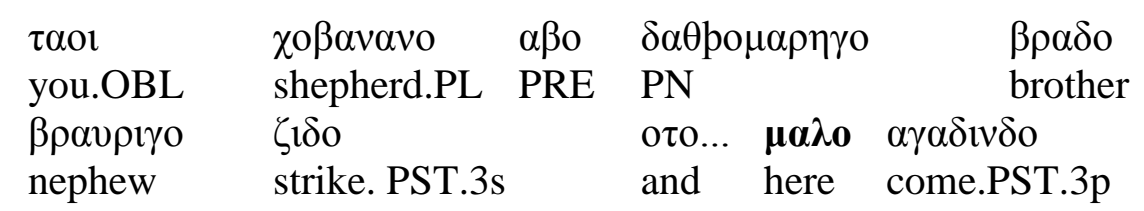

"and your shepherds struck Dathsh-mareg's brother and nephew and they came here" 426 letter:

In the following example, there is an emphasis on the presence of the speaker or writer of the (bd 7-8)

(218) $\omega \sigma 1 \delta o$

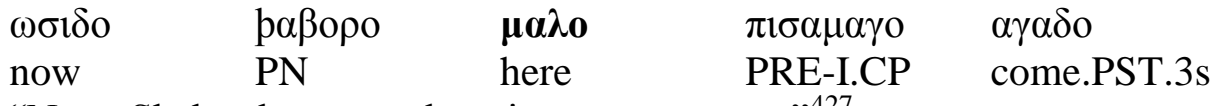

"Now, Shabur has come here into my presence" $" 427$

\footnotetext{
${ }^{421}$ Cf. Sims-Williams 2007a: 111.

${ }^{422}$ Sims-Williams 2007a: 53.

${ }^{423}$ Sims-Williams 2007a: 89.

${ }^{424}$ Sims-Williams 2007a: 139.

${ }^{425}$ Cf. Sims-Williams 2007a: 127.

${ }^{426}$ Sims-Williams 2007a: 53.

${ }^{427}$ Sims-Williams 2007a: 59.
} 
In the following example, there is an emphasis on the name of a mentioned place:

(A 1-2)

(219) $\kappa \alpha \lambda \delta o$

when

\begin{tabular}{|c|c|c|}
\hline 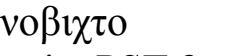 & $\mu \mathrm{o}$ & о $\lambda \circ \beta \omega \sigma \tau о \gamma о$ \\
\hline $\begin{array}{l}\text { write.PST.3s } \\
\text { b } \alpha \rho \alpha \quad \alpha \beta ı 0\end{array}$ & $\begin{array}{l}\text { DEM } \\
\alpha v \delta \alpha \gamma\end{array}$ & \\
\hline in-DEI & & borough \\
\hline
\end{tabular}

$\mu \alpha \lambda \mathbf{\alpha} \quad \alpha \beta o \quad \mu o$

$\rho \omega \beta \alpha \gamma \gamma \mathrm{O}$

of Rob

city in-DEM borough

"When this marriage contract was written here in the city of Rob, in the borough..." "428

2. When something happens or something or someone exists in the place of the speaker or the writer of the letter:

(cn 6-7)

(220) $\kappa о \alpha \delta o-\mu о$

that-I.CP here horse NEG.be.PST.3s

"That I did not have (any) horses here." 429

\section{$\mu \alpha \lambda \eta \lambda \mathbf{0}$}

This adverb is used only three times in similar phrases, in which the name of place is mentioned:

$$
\text { (L 11-12) }
$$

(221) $\alpha \sigma 1 \delta o-\mu \eta v o$

but-we.CP

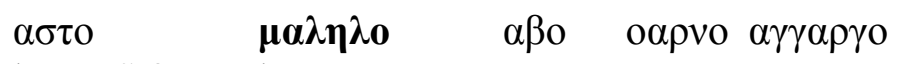

$\pi \alpha \rho \circ \alpha \beta \imath \gamma о$

be.PRS.3s here PRE PN property

disposable

"But we have a disposable property here in Warnu." 430

\subsubsection{Remote deixis adverbs}

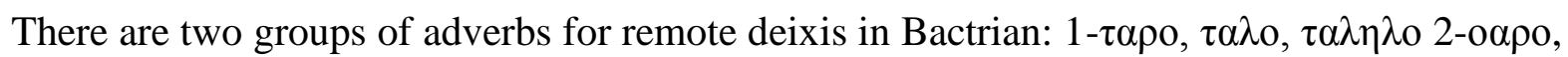

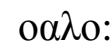

$\tau \alpha \rho 0$

This adverb is used very often in the Bactrian letters and occurs in the following cases:

1. When something or someone has been sent or come to the location of the reader of the letter:

(jh 7-8)

(222)
$\omega \sigma 0 \ldots \kappa \iota \sigma 0$
$\alpha \gamma \alpha \delta \mathrm{o}$
$\tau \alpha \rho \circ$
now INP
come.PST.3s there

"now someone has come thither (to you)",431

In the following example, there is an emphasis on the presence of the reader of the letter:

(ba 10)

(223) o $\delta \alpha \beta \mathrm{o}$

and-PRE

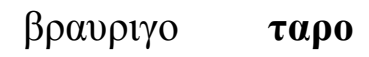

$\pi \imath \sigma o \alpha \varphi \alpha \gamma о \quad \varphi о p \tau \alpha \delta о$

PRE-you.CP send.PST.3

"And I have sent Dathsh-mareg's brother and nephew thither into your presence."432

\footnotetext{
${ }^{428}$ Cf. Sims-Williams 2000a: 33 and Sims-Williams 2007a: 35.

${ }^{429}$ Sims-Williams 2007a: 93.

${ }^{430}$ Sims-Williams 2000a: 65.

${ }^{431}$ Cf. Sims-Williams 2007a: 137.

${ }^{432}$ Cf. Sims-Williams 2007a: 53.
} 
2. When something happens or exists in the same location as place of the reader of the letter: (cf 4-5)

(224) $\omega \sigma 1 \delta$ o $\tau 0$ now SPD lordship know.IMP.2s that $\alpha \sigma \tau \mathrm{O}$ be.PRS.3s

"now, your lordship should know, that I have slaves there (with you)"433

(xc 5-6)

(225) $\alpha \sigma 1 \delta o$

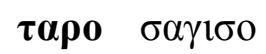
whatever there INP "whatever news you hear there"434

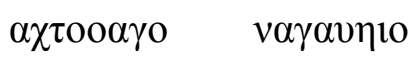
news hear.OPT or PRS.2s

$\tau \alpha \lambda \mathbf{0}$

This adverb is used in all the situations that $\tau \alpha \rho o$ occurs:

$(\mathrm{xb} 7-8)$

$\begin{array}{lllll}\kappa o \alpha \delta o & 1 \alpha 0 \alpha \rho \delta \text { o } & \tau \alpha \lambda \alpha \beta o & \alpha \sigma \pi \alpha \nu \delta \alpha 10 & \alpha \beta \alpha \rho \alpha \delta o \\ \text { that } & \text { grain } & \text { there-PRE } & \text { PN } & \text { bring.SBJV.3s }\end{array}$

"So that he may bring the grain there to (you in) Aspanday." 435

$\mu \alpha v o \quad \tau \alpha \rho 0 \quad \mu \alpha \rho \eta \gamma o$

I.DIR there slave (bd 5-6)

(227) $\kappa \alpha \lambda \delta$ o $\quad \alpha \zeta_{0} \quad \tau \alpha \lambda$ o $\alpha \rho \mu \alpha \sigma \tau \eta \mu о$

when I.DIR there stay.PST.1s

"When I was staying there (with you)."

\section{$\tau \alpha \lambda \eta \lambda \mathbf{0}$}

This adverb occurs only once in the extant Bactrian material:

(T 4-6)

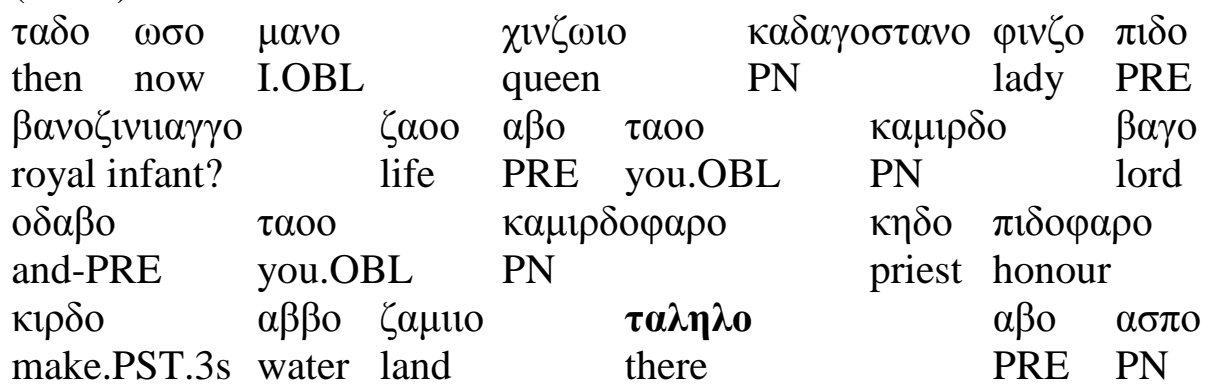

"So now by me, the queen, the lady of Kadagstan, for the life of the royal infant, to you, the lord Kamird, and to you, Kamird-far the priest, the irrigated land there in Asp ... has been made a honour" 437

The Sogdian form of this adverb, i.e., $t \delta \delta^{\prime} y \delta$, is used without the cooperation or acknowledgement of the speaker, and when a second or third person is present in the place. In this case, the first person is usually in the place of addressee. ${ }^{438}$ In the above example, it seems that the speaker is not in the mentioned place, but the second person exists there. In this case, the

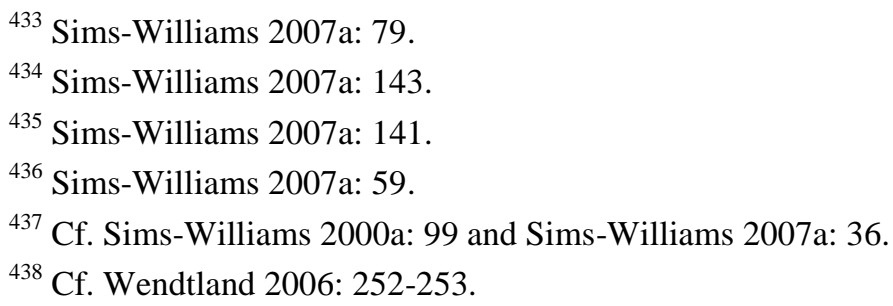


adverb $\tau \alpha \lambda \eta \lambda \mathrm{o}$ "there" is used after $\alpha \beta \beta$ o $\zeta \alpha \mu 110$ "irrigated land", which indicates remote deixis. According to the above information and example, it appears that this adverb has the same function in Bactrian as it does in Sogdian.

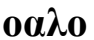

o $\alpha \lambda \mathrm{o}$ is used very often with the meaning of "then", and rarely with the meaning of "there". It seems that this adverb developed from a local adverb to a temporal adverb. In the following examples, this word is used with the meaning of "then":

(bh 2-3)

(229) otavo

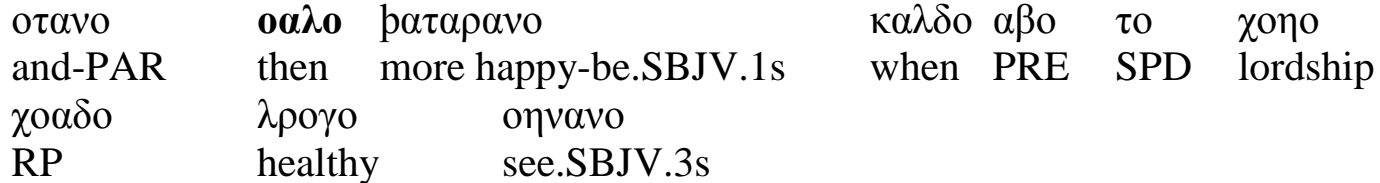

"And then I would be more happy when I myself might see your lordship healthy." 439

In the following examples, it is used as an local adverb and shows remote deixis. It has the same function as $\tau \alpha \lambda_{0}$ "there":

( $\mathrm{J} 3-4)$

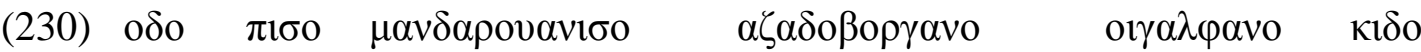

and PRE other.PL-ADV freemen.PL witness.PL who

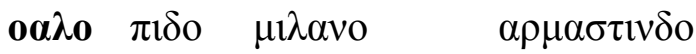

there PRE amongst be present.PST.3p

"and in the presence of the other freemen (and) witnesses, who were present there amongst (them)",440

oxpo

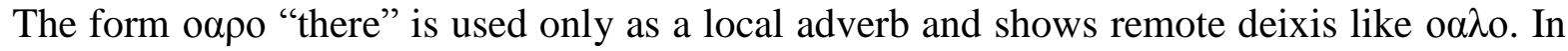
the next set of examples given here, this adverb introduces an indefinite place:

(C 12-13)

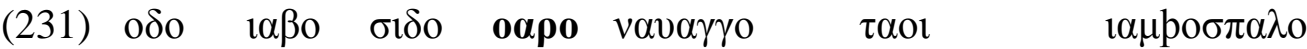

and water which thereto adjacent you.OBL PN

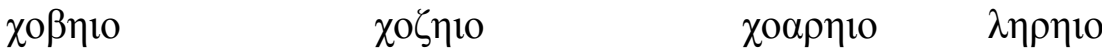

good-be.OPT.3s well-be.OPT.3s have.OPT.2s hold.OPT.2s

"And the water which (is) adjacent thereto may belong properly and belong well to you, Yamsh-spal, you may have (and) hold (it).",441

(C 11-12)

(232) $\pi 1 \sigma 1 \delta o$

\begin{tabular}{|c|c|c|c|c|c|c|}
\hline 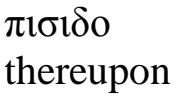 & 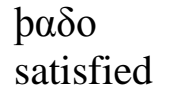 & $\begin{array}{l}\text { vov } \alpha \sigma i v \delta \\
\text { content-b }\end{array}$ & S.1s & $\begin{array}{l}1 \theta \alpha 0 \\
\text { so }\end{array}$ & $\begin{array}{l}\alpha \tau \alpha v o \\
\text { that-PAR }\end{array}$ & $\begin{array}{l}\mu \alpha \pi о \rho \sigma o \\
\text { afterwards }\end{array}$ \\
\hline 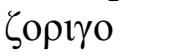 & $\mu \alpha \sigma \kappa о$ & $v \alpha \beta \imath \chi \tau о \gamma c$ & $\zeta \alpha \mu \imath \gamma_{0}$ & & o $\delta o \quad 1 \alpha \beta o$ & $\sigma 1 \delta o$ \\
\hline me & hereupon & write.pp & land & & and water & which \\
\hline & 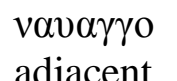 & $\tau \alpha \mathrm{ol}$ & $\begin{array}{l}1 \alpha \mu \text { po } \sigma \\
\text { PN }\end{array}$ & $\sigma \pi \alpha \lambda \mathrm{o}$ & 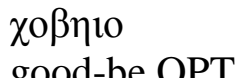 & \\
\hline
\end{tabular}

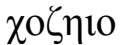

well-be.OPT.3s

"Thereupon I am satisfied and content, so that in the future the land described herein and the water which (is) adjacent thereto may belong properly and belong well to you,

\footnotetext{
${ }^{439}$ Sims-Williams 2007a: 67.

${ }^{440}$ Sims-Williams 2007a: 55.

${ }^{441}$ Sims-Williams 2000a: 41.
} 
Yamsh-spal"

(cp 31-33)

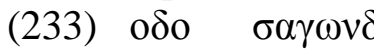

and as much as $\quad$ SPD lordship $\quad$ PRE ART-staff there

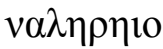

NEG.have.PRS.2s

"and in as much as your lordship does not have the staff there"

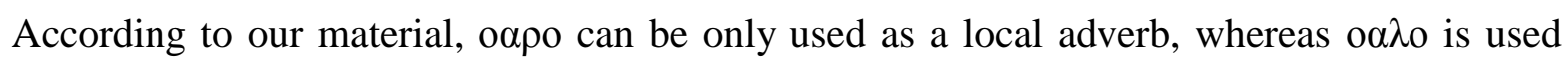
much more as a temporal adverb, and rarely as a local adverb.

\subsection{Syntactical positions of adverbs}

\section{Enclitic adverb -ıбo, - $\sigma 0$}

One of the characteristics of adverbs is their ability to move in a sentence. The enclitic adverb, $-1 \sigma 0$ or $-\sigma o$, can be attached to different kinds of words and shows the emphasis on these words. In the following example, the enclitic adverb is suffixed to a personal pronoun:

(bf 11-12)

(234) $\tau \alpha \delta o \quad \alpha \zeta-\iota \sigma 0$

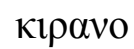

then I.DIR-ADV

act.SBJV.1s

"then I shall act too" $" 443$

It can be suffixed to an article, as the following example shows:

(X 2-3)

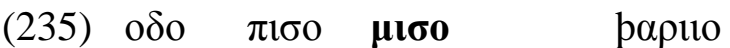

and PRE ART-ADV citizens

"and also in the presence of the citizens",444

In the following example, $-1 \sigma 0$ is suffixed to a noun:

(bb 9-10)

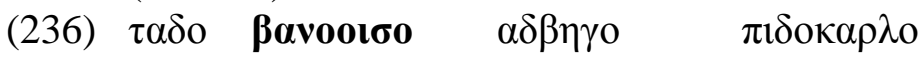

then queen-ADV disrespect prevent.IMP.2s

"then you should also prevent disrespect (towards) the queen" 445

This word can be suffixed to another adverb:

(A 33)

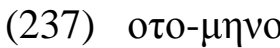

and-I.CP

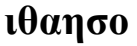

ADV-ADV

$\chi 0 \alpha v \delta o$

odo

olo $\alpha \rho \circ$

vaoooopo

$\alpha \beta$ ov $\eta 10$

be.OPT.3s

"and so too our claim and argument shall be invalid"446

In the following example, $-1 \sigma 0$ is attached to a plural indefinite pronoun:

\footnotetext{
${ }^{442}$ Cf. Sims-Williams 2007a: 97.

${ }^{443}$ Cf. Sims-Williams 2007a: 63.

${ }^{444}$ Sims-Williams 2000a: 137.

${ }^{445}$ Sims-Williams 2007a: 55.

${ }^{446}$ Sims-Williams 2000a: 35.
} 
(A 7)

(238) odo

$\pi ı \sigma o \quad \boldsymbol{\mu \alpha v \delta \alpha \rho o v \alpha v ı \sigma o} \quad \sigma \tau \eta \beta \iota \gamma \alpha v o$

and PRE ART-other.PL-ADV

of the Steb.PL

$\alpha \zeta \alpha \beta o \rho \gamma \alpha v o$

freemen.PL

"and in the presence of the other freemen of Steb"

\section{Independent forms}

Like enclitic adverbs, independent forms may occur in different positions in a sentence. It appears that there is no rule for the position of independent adverbs in Bactrian. It is only in the case of local adverbs that they occur before the prepositional phrases and the name of places:

(A 1-2)

(239) $\kappa \alpha \lambda \delta o$

when

$$
\text { voßıน }
$$

но $\quad$ o $\lambda \mathrm{o} \beta \omega \sigma \tau \mathrm{o} \gamma \mathrm{o}$

$\rho \omega \beta \alpha \gamma \gamma o$

write.PST.3s DEM marriage contract

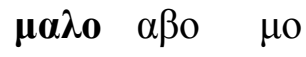

of Rob

papo $\alpha \beta 110 \alpha v \delta \alpha \gamma o$

"when this marriage contract was written here in the city of Rob, in the borough"448

It can also occur before the predicate:

(bd 7-8)

(240) $\omega \sigma 1 \delta o$

now

paßopo

PN

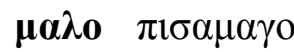

$\alpha \gamma \alpha \delta o$

"Now, Shabur has come here into my presence." 449 come.PST.3s

In the case of the sequence of adverbs, it seems that a local adverb occurs after a time adverb:

(bh 6-7)

(241) oto

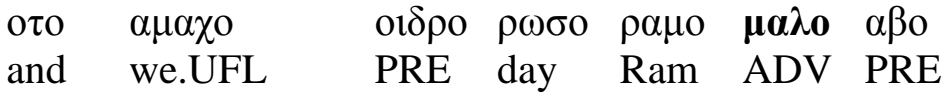

$\alpha \mu \alpha \gamma \gamma \alpha v o \quad \alpha \rho \mu \alpha v \alpha \mu o$

Amangan stay.PRS.1p

"And we will stay here at Amangan until the day Ram."

In the following example, the adverb appears directly after the verb:

(ed 4-5)

(242) $\mu 1 \sigma 1 \delta o$

"moreover, Shabur-ormuzd came here"

An independent adverb may occur directly after a conjunction as the first element in a subordinate clause, as illustrated in the following example:

\footnotetext{
447 Sims-Williams 2000a: 33.

${ }^{448}$ Cf. Sims-Williams 2000a: 33 and Sims-Williams 2007a: 35.

${ }^{449}$ Sims-Williams 2007a: 59.

${ }^{450}$ Sims-Williams 2007a: 67.

${ }^{451}$ Sims-Williams 2007a: 115.
} 
(ca 8-9)

(243)

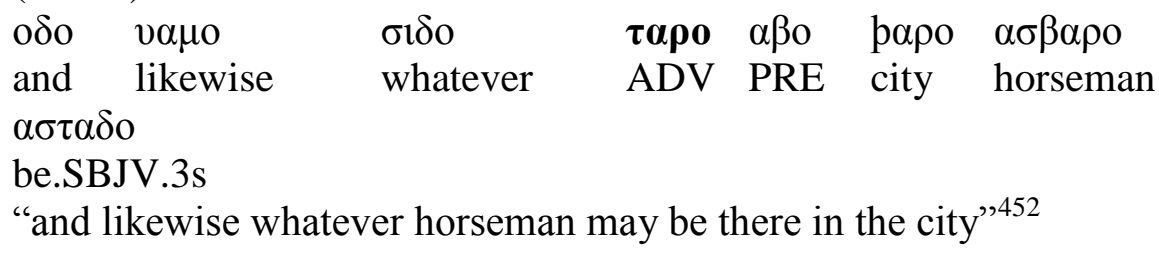

In the following example, an independent adverb appears between a pronoun and noun, which is not common. This pronoun, which is oblique, usually functions as a possessive pronoun:

(ce 3-4)

(244) $\omega \sigma 1 \delta o$ to

now SPD lordship

$\pi \imath 1 \sigma \tau о \beta \alpha \rho \alpha \gamma o \quad \alpha \sigma \tau o$

surety

be.PRS.3s PN

\begin{tabular}{|c|c|c|}
\hline$\zeta \alpha v o$ & $\kappa о 0 \alpha \delta \mathrm{o}$ & $\mu \alpha v o \quad \tau \alpha \rho o$ \\
\hline $\begin{array}{l}\text { know.IMPV.2s } \\
\alpha p \varphi \alpha \rho \delta \alpha \rho o\end{array}$ & that & I.OBL ADV \\
\hline
\end{tabular}

"Now, your lordship should know that Ash-fardar is my surety there."453

The adverbs of time, $\omega \sigma 0, \mu 1 \sigma 1 \delta o,{ }^{454} \omega \sigma 1 \delta o$ "now", occasionally occur at the beginning of a clause. For example:

(A 10)

\begin{tabular}{|c|c|}
\hline $\begin{array}{l}\boldsymbol{\mu} \boldsymbol{\iota} \boldsymbol{\sigma} \boldsymbol{\delta} \boldsymbol{0} \\
\text { now }\end{array}$ & 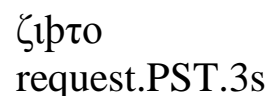 \\
\hline "now, I & ted" \\
\hline
\end{tabular}

If the clause begins with a conjunction, the adverb of time usually appears after it:

(A 9-10)

(246) $\kappa 1 \delta 0 \quad \omega \sigma 0$

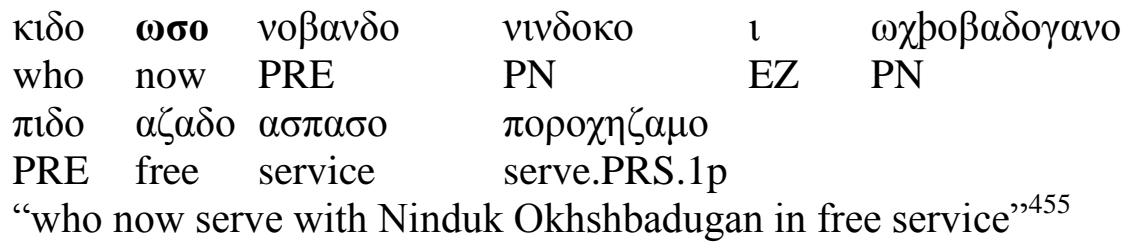

In the following example, an independent pronoun occurs after a conjunction and the adverb $\omega \sigma 0$ appears after it:

(U 6)

(247) $\tau \alpha \delta$

then we.UFL now give.PST.3s

Manner adverbs as $\chi 0 \beta 0$ "well” and $\chi 0 \zeta_{0}^{457}$ "good" usually occur before the verb:

\footnotetext{
${ }^{452}$ Cf. Sims-Williams 2007a: 69.

${ }^{453}$ Sims-Williams 2007a: 77.

${ }^{454} \mu 1 \sigma 1 \delta$ o may also be used as a conjunction.

${ }^{455}$ Sims-Williams 2000a: 33.

${ }^{456}$ Cf. Sims-Williams 2000a: 107.

${ }^{457}$ It may also be used as an adjective.
} 
$\left(\mathrm{P} 13^{\prime}-14^{\prime}\right)$

(248) $\tau \alpha \delta o \quad \omega \sigma o$

$\alpha \beta о \mu \alpha \sigma \kappa о$

then now

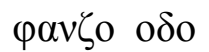

herein

$v \alpha \beta \imath \chi \tau \imath \gamma_{0}$

$\beta \alpha \lambda \alpha \kappa о$

$\tau \alpha 00$

PN and

$\tau \alpha 00$

written.pp

boy

you.OBL

Boinio

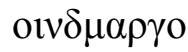

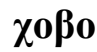

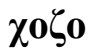

PN

properly

good

be.OPT.3s

"So, now may the boy written herein belong properly and well to you Fanz and to you Wind-marg" 458

Many adverbs are used with prepositions in different contexts, i.e., $\alpha \beta 0 \mu \alpha \sigma \kappa o$ or $\alpha \beta 01$

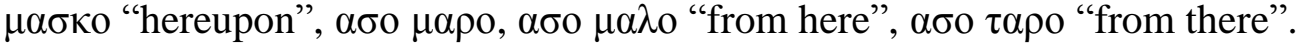

Some adverbs may be repeated and form a new adverb with a new meaning, i.e., -1бo "also",

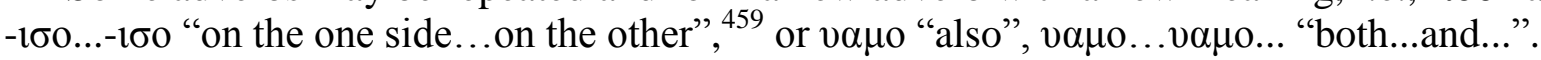

There are some independent adverbs in Bactrian which can be prefixed to other words. For example, $\mu \alpha \lambda_{0}$ "here" can be prefixed to the preposition $\alpha \beta$ o "to, in", as in the following example:

(L 1-2)

(249) $\kappa \alpha \lambda \delta o$

when

$v \alpha \beta \imath \tau \tau \quad \mu$ нор $\alpha \gamma_{0}$

$\mu \alpha \chi 1 \rho \sigma o \beta \omega \sigma \tau \imath \gamma о$

$\mu \alpha \lambda \alpha \beta o$

write.PST.3s sealed document

ART-purchase contract

ADV-PRE

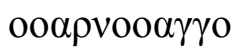

papo

"when (this) sealed document, this purchase contract, was written here in the city of Warnu" 460

In the following example, o $\alpha \lambda_{0}$ "then, there" is prefixed to the pronoun $\alpha \zeta_{\mathrm{o}}$ "I":

(W 25-27)

(250) $\tau \alpha \delta 0$

then

$\boldsymbol{\alpha} \alpha \lambda \alpha \zeta o$

ADV-I.DIR

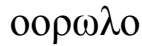

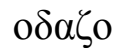

and-I.DIR

vı $\lambda \iota \tau о \beta \eta \rho о . .$.

$\pi \imath \tau \iota \alpha \mu \mathrm{o}$

guarantee.PRS.1p

"then I, Wurol, and I, Hilitber ... guarantee thus",461

Another example is seen in that the adverb $1 \theta \alpha o$ can be prefixed to a conjunction as $\imath \theta \alpha v \alpha \tau \alpha v o$ (ADV-COJ-PAR) "so that", to a preposition, e.g., $\imath \theta \alpha \sigma o$ "so from", to a verb, e.g., $\imath \theta \alpha \chi 0 \alpha v \imath \delta \delta \eta 10$ (ADV-state.OPT.1p), or to an enclitic pronoun, e.g., $\imath \theta \alpha o \delta \eta \imath$ (ADV-you.2s).

\subsection{Summary}

There are three groups of adverbs in Bactrian. First, there is the group of some words which only play the role of adverbs. Second, there are adverbs which can also be used as preverbs or prepositions. Third, there is the group of nouns and adjectives which are used as adverbs.

We also focused on the proximate deixis adverbs in Bactrian, i.e., $\mu \alpha \rho o, \mu \alpha \lambda o, \mu \alpha \lambda \eta \lambda o$

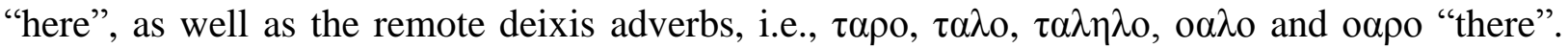
The adverbs $\mu \alpha \lambda \eta \lambda \mathrm{o}$ and $\tau \alpha \lambda \eta \lambda \mathrm{o}$ are rarely used in the extant material. There is no clear

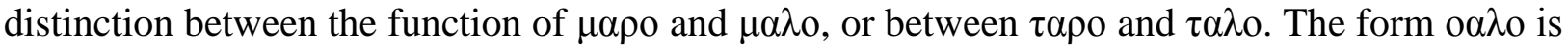

\footnotetext{
${ }^{458}$ Cf. Sims-Williams 2000a: 85.

${ }^{459}$ Sims-Williams 2007a: 218.

${ }^{460}$ Sims-Williams 2000a: 65.

${ }^{461}$ Cf. Sims-Williams 2000a: 133.
} 
used much more as a temporal adverb with the meaning "then", whereas oopo is only used as a local adverb. In some languages like Sogdian, we can find some distinctions between different adverbs of remote deixis or proximate deixis, but it seems that in Bactrian, such distinctions are not found.

Adverbs occur in different syntactic positions. For example, the enclitic adverb $-1 \sigma 0,-\sigma 0$ "thus" can be suffixed to personal pronouns, indefinite pronouns, nouns, and articles. We cannot find an exact position for independent adverbs in Bactrian. Some of these adverbs can be prefixed to other words as pronouns, prepositions, other adverbs, conjunctions, and verbs. 


\section{Chapter Seven: Conjunctions}

Subordinate clauses may be introduced by different types of conjunctions. In Bactrian, there are three types of conjunctions: coordinating, correlative and subordinating.

\subsection{Coordinating conjunctions}

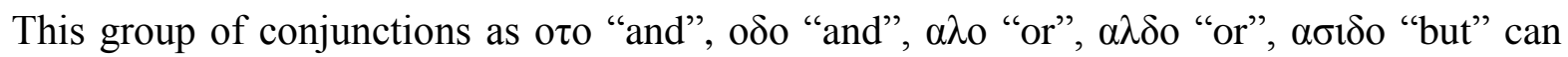
link similar elements, which can be single items or a group of words. The following list shows the coordinating conjunctions in Bactrian.

Some of these conjunctions can also be used as subordinating conjunctions. For example, $\boldsymbol{\alpha} \boldsymbol{\lambda} \boldsymbol{o}$ and $\boldsymbol{\alpha} \boldsymbol{\lambda} \boldsymbol{\delta} \boldsymbol{o}$ with the meaning of "if" can be a subordinating conjunction.

An explanation follows of the environments and the functions of these conjunctions.

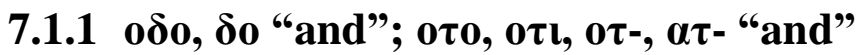

Both of these conjunctions can be used as free forms or they can be prefixed to other words such as nouns, adjectives, other conjunctions, prepositions, enclitic pronouns, and enclitic and demonstrative pronouns. But in the Bactrian texts, the conjunctions are not attached to articles.

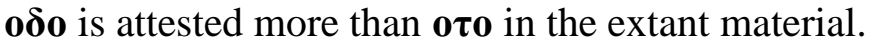

обо, $\boldsymbol{\delta 0}$

A coordinating conjunction can be prefixed to a noun:

(jf 8-9)

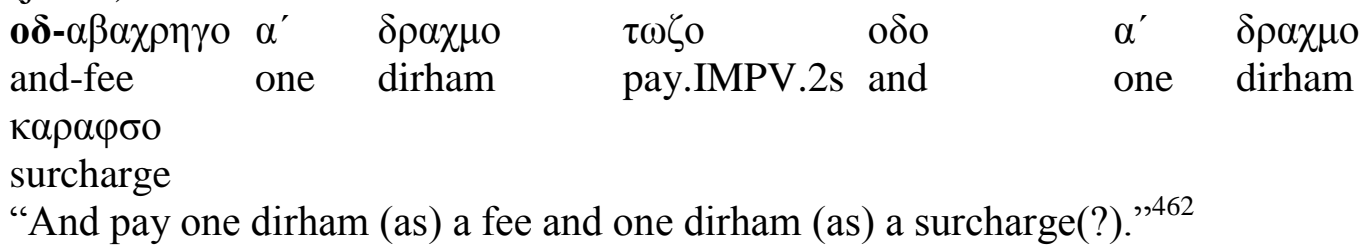

A coordinating conjunction can be prefixed to an adjective:

$\left(\mathrm{X} 18^{\prime}\right)$

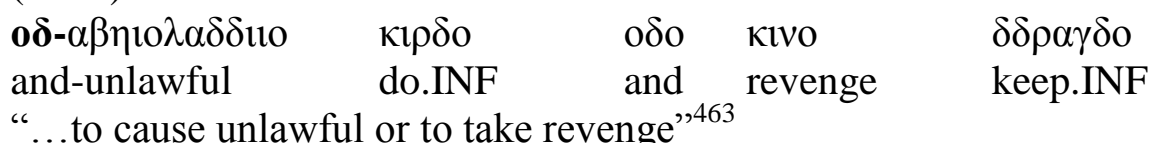

"...to cause unlawful or to take revenge"463

In the following example, the coordinating conjunction is prefixed to another conjunction:

(cl 8)

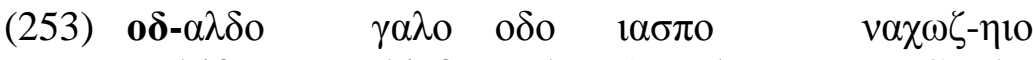

and-if thief and ART-horse NEG.ask.OPT.2s

"and if you do not search out the thieves and the horses" 464

A conjunction can be prefixed to a preposition:

\footnotetext{
${ }^{462}$ Cf. Sims-Williams 2007a: 133.

${ }^{463}$ Cf. Sims-Williams 2000a: 139.

${ }^{464}$ Sims-Williams 2000a: 89.
} 
(eb 1-2)

(254) $\mathbf{0 \delta}$ - $\alpha \beta \mathrm{O}$ and-PRE "and to Gurambad Khwadewan greetings"465

$\lambda \rho o \delta$ o greeting

A conjunction can be prefixed to an enclitic pronoun (T 6)

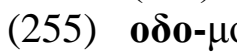
and-I.CP give.PST. "and also I gave a certain person, a woman" 466

A conjunction can be prefixed to a demonstrative pronoun:

(X 31)

(256) $\mathbf{0} \delta \delta$

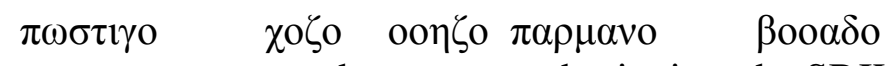
and-DEM contract good potent authoritative be.SBJV.3s "And may this contract be (considered) good (and) potent (and) authoritative.",467

It can also be prefixed to a hypothetical particle -avo:

(S 22)

(257) od- $\alpha v_{0}$ and-PAR

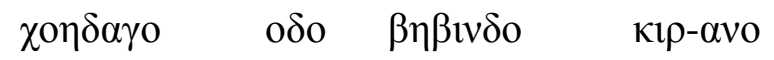
"and I would cause (the property to be) released and detached from all"468

\section{The function of $0 \delta 0$}

Harmatta writes in his article "The Great Bactrian Inscription":

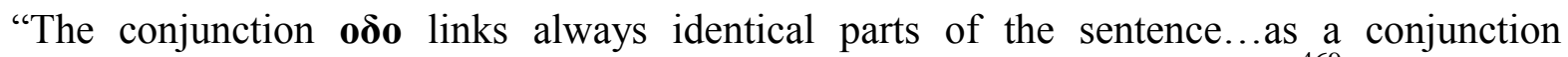
introducing a sentence it can be used only together with another conjunction", ${ }^{69}$ as shown in example (258):

(Surkh Kotal 7)

(258) обо $\kappa \alpha \lambda \delta \alpha v o$

and when-PAR PRE ? ? ART-matter

ßoonio

be.PRS.OPT.3s

"and when it would be a matter of...",470

In the above example, it is used together with $\kappa \alpha \lambda \delta$ o which is also a conjunction.

He adds:

"Since alone it never introduces a sentence, it is never linked with an enclitic pronoun". ${ }^{471}$

This conjunction is used only three times in the Surkh Kotal inscription. In the following example, it links two parts of a number:

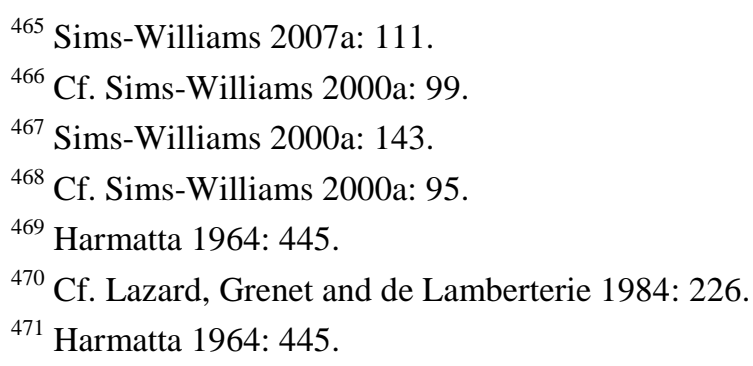


(Surkh Kotal 5)

(259) $1 \omega \gamma 0$ odo vipбo

"thirty one" 472 and thirty

What is written by Harmatta about odo is limited to the Surkh Kotal inscription. From the new Bactrian material, we can gain some new information about the function of odo.

The conjunction odo usually coordinates two nominal phrases, though it rarely links two clauses. In the following example, the first occurrence of odo introduces the sentence, the second and third odo coordinates two nouns, whereas the fourth coordinates two clauses.

(jf 6-9)

(260) od- $\alpha \sigma 0$

and-PRE

$1 \quad \chi \alpha \rho o$

saddle(?)

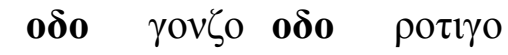

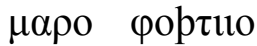

$\boldsymbol{o \delta} \alpha \beta \alpha \chi \rho \eta \gamma о \quad \alpha^{\prime}$

and bag and rope

hither send.IMPV.2s

and-fee

one

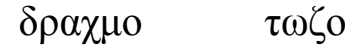

"And (apart) from this, send hither a donkey-saddle and a bag and a rope(?) and pay one dirham as (as) a fee."

\section{The function of $0 \tau 0$}

According to Harmatta:

"... the conjunction oto never links parts of the sentence, it always serves for the introduction of sentences, it stands always alone in the beginning of the sentence and it is frequently connected with forms of enclitic personal pronouns." 474

This conjunction is used five times in the Surkh Kotal inscription. In three of these instances, it stands alone, as shown in the following example:

(Surkh Kotal 4)

(261)

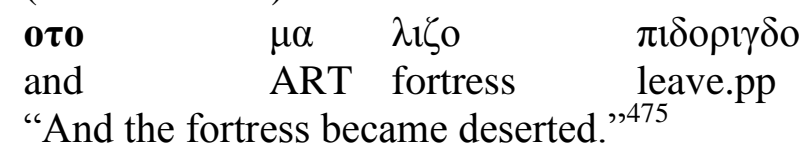

In one instance, the particle - $\alpha v o$ is added to this conjunction:

(Surkh Kotal 7)

$\begin{array}{llll}\text { o } \tau-\alpha v_{0} & \mu \alpha \quad \lambda i{ }_{0} & \mu \alpha \pi 1 \delta o \rho \imath \chi \sigma \eta 10 \\ \text { and-PAR } & \text { ART fortress } & \text { PROH.leave.PRS.OPT.PASS.3s } \\ \text { "And fortress } & \text { should not become deserted"476 }\end{array}$

And in another instance, an enclitic pronoun is attached to this conjunction:

(Surkh Kotal 8)

\begin{tabular}{|c|c|c|c|c|}
\hline 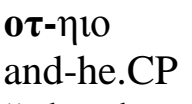 & $\begin{array}{l}\alpha \sigma \alpha \sigma \kappa о \\
\text { PRE-top }\end{array}$ & $\begin{array}{l}\mu \mathrm{O} \\
\text { ART }\end{array}$ & $\begin{array}{l}\sigma \alpha \delta o \\
\text { well }\end{array}$ & $\begin{array}{l}\alpha \chi p \tau \rho \imath \gamma о \\
?\end{array}$ \\
\hline
\end{tabular}

\footnotetext{
${ }^{472}$ Cf. Lazard, Grenet and de Lamberterie 1984: 226.

${ }^{473}$ Sims-Williams 2007a: 133.

${ }^{474}$ Harmatta 1964: 445.

${ }^{475}$ Cf. Lazard, Grenet and de Lamberterie 1984: 226.

${ }^{476}$ Cf. Lazard, Grenet and de Lamberterie 1984: 226.

${ }^{477}$ Cf. Lazard, Grenet and de Lamberterie 1984: 226.
} 
In all these examples, the conjunction is used to coordinate two clauses. From the extant Bactrian texts, we can conclude that the conjunction oto is usually used to coordinate two clauses, whereas the conjunction odo coordinates two nominal phrases and rarely two clauses.

\section{$\alpha \lambda_{0}$ "or"}

$\alpha \lambda \mathrm{o}$ is used very often in the role of a conjunction. In the following example, it coordinates two pronouns and nouns which express the subject of the clause:

(A 19-20)

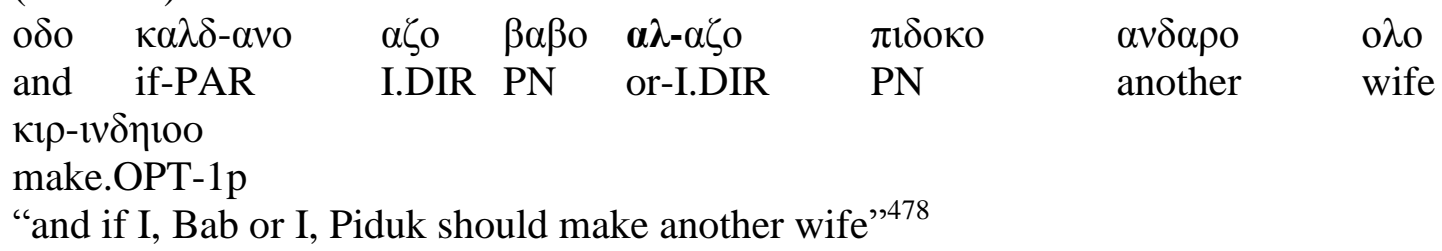

In the following example, it coordinates two nouns which express the object of a clause:

(A 30)

(265) $\alpha \lambda \delta-\alpha v o$

or-PAR

раро $\rho \alpha \lambda i \kappa o$

$1 \alpha о \alpha \rho \gamma o$

$\boldsymbol{\alpha \lambda \boldsymbol { 0 }} \tau \alpha \rho \alpha \zeta_{0}$

$\lambda \alpha v-1 v \delta \eta 10$

"or if (we) should assign duties or tasks to Ralik"479

give.OPT-1p

In the following example, the second $\alpha \lambda$ o coordinates two clauses:

(A 19-20)

(266)

\begin{tabular}{|c|c|c|c|c|c|}
\hline$\kappa \alpha \lambda \delta-\alpha \nu 0$ & $\alpha \zeta o$ & $\beta \alpha \beta o$ & $\alpha \lambda-\alpha \zeta_{0}$ & $\pi 1 \delta$ око & $\alpha v \delta \alpha \rho o$ \\
\hline if-PAR & I.DIR & $\mathrm{PN}$ & or-I.DIR & $\mathrm{PN}$ & another \\
\hline$\rho-\imath \delta \delta \eta 10$ & $\alpha \lambda \mathbf{0}$ & $\alpha \zeta \alpha \delta o$ & $\pi \iota \delta о \rho \omega \varphi \sigma о$ & $\lambda \eta \rho-\imath v \delta \eta ı$ & \\
\hline ake.OPT-1p & & free & concubine & have.OPT-1p & \\
\hline
\end{tabular}

$\alpha \lambda \delta 0$ "or"

There is no visible semantic and syntactic distinction in the function of $\alpha \lambda \mathrm{o}$ and $\alpha \lambda \delta \mathrm{o}:{ }^{481}$

In the following example, it coordinates two clauses:

(A 29-30)

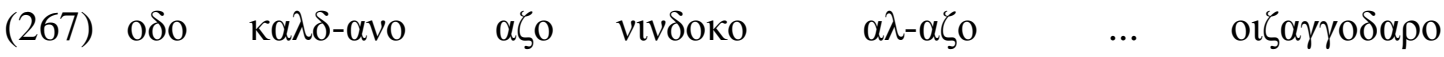

and if-PAR I.DIR PN or-I.DIR otherwise

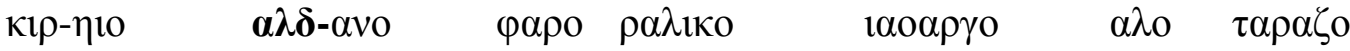

do.OPT-1s or-PAR PRE PN duty or task

$\lambda \alpha v i v \delta-\eta 10$

give.OPT-1p

"if (we) should assign duties or tasks to Ralik"482

In the following example, another conjunction, i.e., odo "and", is attached to $\alpha \lambda \delta$ o and coordinates two clauses:

\footnotetext{
${ }^{478}$ Cf. Sims-Williams 2000a: 33-35.

${ }^{479}$ Sims-Williams 2000a: 35.

${ }^{480}$ Cf. Sims-Williams 2000a: 33-35.

${ }^{481}$ Here I mean $\alpha \lambda \delta o$ as a coordinating conjunction. It can be also used with the meaning "if" in subordinate clauses.

${ }^{482}$ Cf. Sims-Williams 2000a: 35.
} 
(A 30-31)

(268) $\alpha \lambda \delta-\alpha v o$

or-PAR

$$
\text { фаро } \rho \alpha \lambda \imath \kappa о
$$

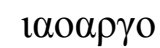

$\alpha \lambda_{\mathrm{o}} \quad \tau \alpha \rho \alpha \zeta_{0}$

$\lambda \alpha v-1 v \delta \eta 10$

$\boldsymbol{o \delta}-\boldsymbol{\alpha} \lambda \boldsymbol{\delta} \boldsymbol{\imath} \quad \imath \theta \alpha \chi 0 \alpha v-1 v \delta \eta 10$

duty

or task give.OPT-1p

and-or claim.OPT-1p

"and if I, Ninduk and I ... should do otherwise, or (if we) should assign duties or tasks to Ralik or (if we) should claim"

It can also coordinate two nouns, as shown in the following example:

(F 14)

$\begin{array}{lllll}\alpha \nu \delta \alpha \rho o & \mu \text { o } \lambda \rho \gamma_{0} & \mathbf{0 \delta}-\boldsymbol{\alpha} \lambda \boldsymbol{\delta} \mathbf{0} & \pi \omega \sigma \tau \alpha \gamma o & \pi \alpha \rho \beta \beta \alpha \rho \alpha \delta \text { o } \\ \text { another } & \text { sealed document } & \text { and-or } & \text { contract } & \text { produce.SBJV.3s } \\ \text { "(and) might } & \text { produce another sealed document or contract"484 }\end{array}$

\section{$\alpha \sigma \iota \delta, \sigma ı \delta 0, \alpha \sigma ı \delta \alpha-, \alpha \sigma ı \delta-, \sigma ı \delta$ - "but, on the other hand"}

It is often used as a relative pronoun, but it can also play the role of a conjunction. The general meaning of $\boldsymbol{\alpha \sigma \boldsymbol { \sigma } \delta \mathbf { o }}$ as a conjunction is "but, on the other hand". According to SimsWilliams, it marks a contrast between what precedes and what follows. ${ }^{485}$

As a conjunction, it coordinates only two clauses, such as in the following example:

(ba 2-3)

\begin{tabular}{|c|c|c|c|}
\hline $\begin{array}{l}\tau \alpha \delta o \\
\text { then }\end{array}$ & $\begin{array}{l}\text { p } \alpha \delta-\eta \mu \mathrm{o} \\
\text { happy-be.PRS.1s }\end{array}$ & $\begin{array}{l}\boldsymbol{\alpha} \boldsymbol{\sigma} \boldsymbol{\iota} \delta-\alpha v 0 \\
\text { but-PAR }\end{array}$ & $\begin{array}{ll}\text { o } \alpha \lambda \mathrm{o} & \text { p } \alpha \tau \alpha \rho-\alpha \nu o \\
\text { then } & \text { more hanny-be SBJV } 1 \mathrm{~s}\end{array}$ \\
\hline
\end{tabular}

\subsubsection{Rarely attested coordinating conjunctions}

\section{$\alpha \tau \mathbf{0}$}

$\alpha \tau$ "that, so that" is rarely used in the extant Bactrian texts. It coordinates two clauses, as shown in the following example:

(C 11-13)

(271)

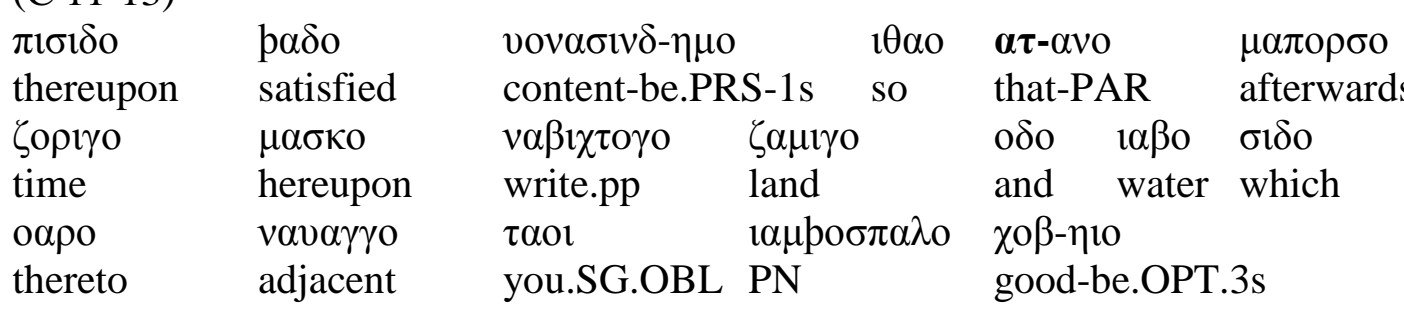

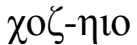

well-be.OPT.3s

"Thereupon I am satisfied and content, so that in the future the land described herein and the water which (is) adjacent thereto may belong properly and belong well to you, Yamsh-spal.",487

In the following example, $\alpha \tau \mathrm{c}(\alpha \tau)$ is attached to an adverb, and a particle is attached to $\alpha \tau \mathrm{o}$ $(\alpha \tau)$ :

\footnotetext{
${ }^{483}$ Cf. Sims-Williams 2000a: 35 .

${ }^{484}$ Cf. Sims-Williams 2000a: 47.

${ }^{485}$ Sims-Williams 2007a: 195.

${ }^{486}$ Sims-Williams 2007a: 53.

${ }^{487}$ Sims-Williams 2000a: 41.
} 
(A 12-13)

(272) $\quad \imath \theta \alpha v-\alpha \tau-\alpha v o$

so-that-PAR

vo $\beta \iota \tau \tau \imath \sigma o \quad \zeta ı 0$

write.pp.f wife

"so that I, Bag-farn, may treat the woman described herein...",488

\section{фарбо "but"}

The function of this conjunction is not clear. It is used only once in the extant Bactrian material:

(Y 23-24)

(273) o $\delta$

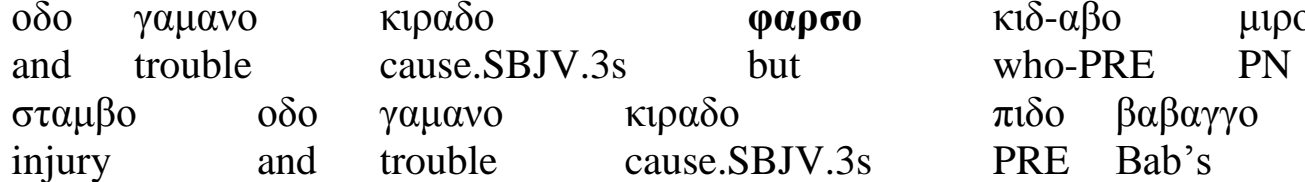

$\alpha \chi \alpha \sigma o$

dispute

“... and may do trouble, but whoever may commit injury and violence toward Mir on account of a dispute of Bab's"

In the above example, it links two clauses.

\section{$\alpha \varphi \alpha \rho \sigma เ \delta о ~ " e x c e p t "$}

Like $\varphi \propto \rho \sigma o$, this conjunction is rarely attested in Bactrian texts. It is used only in two documents (In: ea 11 and ef 18-19). In the following example, it links a sentence to a nominal phrase $^{490}$ :

(ea 10-11)

(274) v vрбо кıбо

no one right and

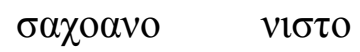

business

NEG.be.PRS.3s

$\alpha \varphi \alpha \rho \sigma เ \delta 0$

paßopo $\quad \chi 0 \alpha \delta$ o

except

$\mathrm{PN} \quad \mathrm{RP}$

"no-one has (any) right or (other) business ... except Shabur himself"

In the following example, it appears that $\alpha \varphi \alpha \rho \sigma 1 \delta o$ links two clauses:

(275) $\tau \alpha \delta o \quad \pi \mathrm{l} \delta \mathrm{o}$

then PRE

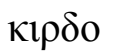

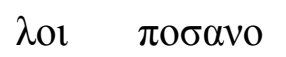

фаро $\omega \rho о \mu о \zeta \delta o$

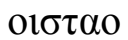

two sheep PRE PN promise

do.PST.3s

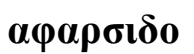

$\chi \alpha[$ ]o $\gamma-1 v \delta o$

"so, regarding the two sheep, a promise was made to Ormuzd, but...were..."492

$\alpha \sigma 0$

The form $\alpha \sigma o$ is a preposition with the meaning "from". It is also classified by SimsWilliams as a conjunction.

\footnotetext{
${ }^{488}$ Sims-Williams 2000a: 33.

${ }^{489}$ Cf. Sims-Williams 2000a: 145 and Sims-Williams 2007a: 37.

${ }^{490}$ In these examples, it is possible that it plays the role of a preposition, rather than that of a conjunction.

${ }^{491}$ Cf. Sims-Williams 2007a: 109.

${ }^{492}$ Cf. Sims-Williams 2007a: 119.
} 
According to Sims-Williams, it is used as a conjunction only in two documents, cd, ci. In both cases, it is used with another conjunction. The use of a preposition with a conjunction is very common in other Iranian languages. For example, in Sogdian, the preposition c- "from" is used occasionally with other conjunctions. Here, in Bactrian, the question is whether $\alpha \sigma 0$ is a preposition or a conjunction. In the following example, it is shown to be used with another conjunction, and it joins two sentences:

(ci 11-12)

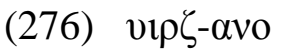

let SBJV-1s

$\boldsymbol{\alpha \sigma o} \quad \alpha \lambda \delta о \mu о \quad v \alpha о \alpha \zeta o$

but(?) if-I.CP

$\mathrm{PN}$

$\alpha \sigma 0 \quad \chi 0 \eta \circ 1$

$\pi \omega \sigma \tau$ бо $\quad \alpha \beta \alpha \rho \alpha \delta$ o

document bring.SBJV.3s

"let alone a (piece of) land! But if Nawaz brings me a document from the lord..."493

Another example is presented here:

(cd 8-13)

(277)

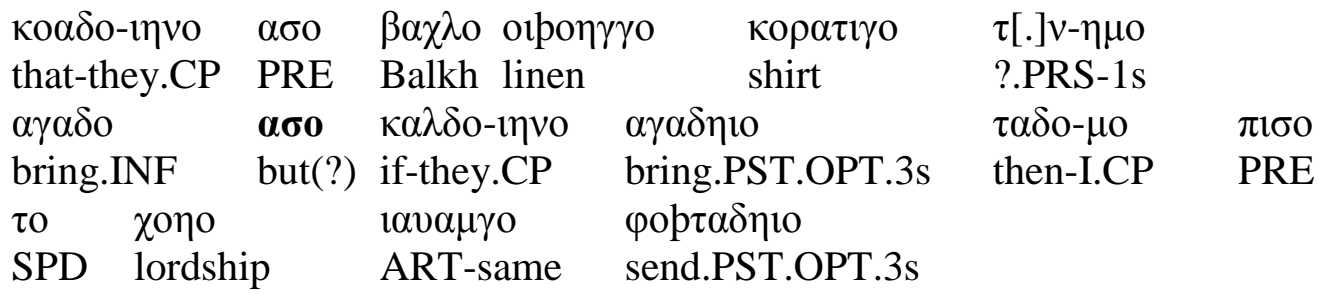

"I am [urging?] them to bring linen shirts from Balkh. If they had in fact brought (them), I would have sent the same to your lordship" 494

In both of these examples, $\alpha \sigma o$ is used with other conjunctions, i.e., $\alpha \lambda \delta o, \kappa \alpha \lambda \delta o$ "if", and it links two sentences. According to the above examples, it has a function which may be compared with the preposition c- in Sogdian and plays the role of a preposition rather than a conjunction. Because of the limited number of examples, it is not easy to make an exact judgment.

\section{$\mu \iota \sigma \iota \delta 0$ "moreover"}

In many constructions, it is used in the meaning of "moreover" and introduces a new topic or sentence:

(jf 12-15)

(278)

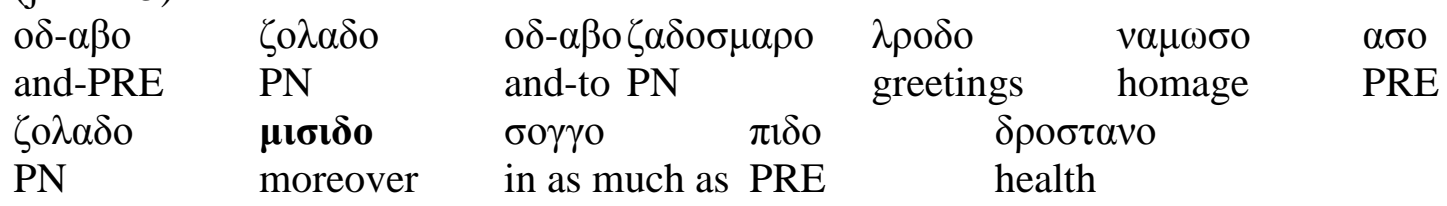

$\alpha \rho \mu \alpha v-\eta \delta o$

remain.PRS or OPT-2p

"and to Zhulad and to Zhad-smar greetings (and) homage from Zhulad. Moreover, in as much as you (pl.) remain in (good) health"495

Another example is given here:

(bg 3-5)

(279)

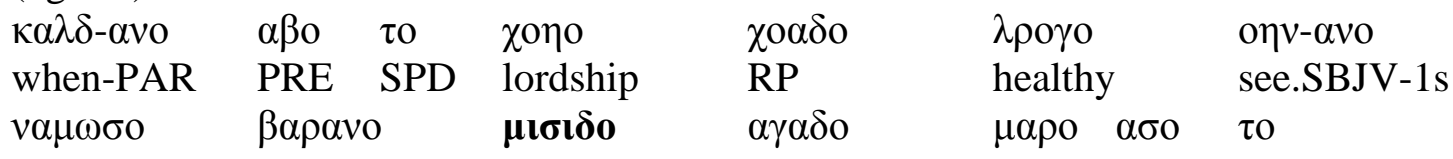

\footnotetext{
${ }^{493}$ Cf. Sims-Williams 2007a: 85.

${ }^{494}$ Sims-Williams 2007a: 75.

${ }^{495}$ Sims-Williams 2007a: 133.
} 


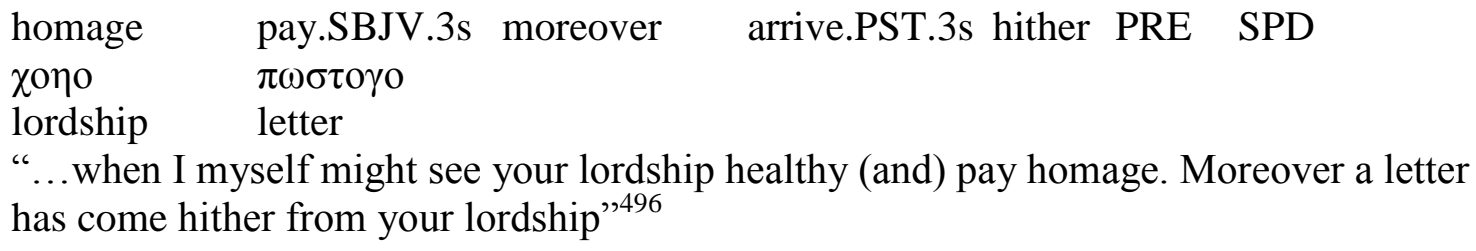

\subsubsection{Summary}

The following table shows the coordinating conjunctions in the extant Bactrian texts and their functions:

Table 28. Coordinating conjunctions

\begin{tabular}{|c|c|}
\hline$\alpha \tau \mathrm{o}$ "that" & Sentence + Sentence \\
\hline 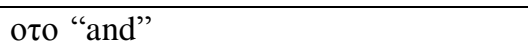 & Sentence + Sentence \\
\hline odo "and" & $\begin{array}{l}\text { Nominal phrase + Nominal phrase } \\
\text { Sentence + Sentence (rarely) }\end{array}$ \\
\hline$\alpha \lambda_{0}$ "or" & $\begin{array}{l}\text { Nominal phrase + Nominal phrase } \\
\text { Sentence + Sentence }\end{array}$ \\
\hline$\alpha \lambda \delta o$ "or" & $\begin{array}{l}\text { Nominal phrase + Nominal phrase } \\
\text { Sentence + Sentence }\end{array}$ \\
\hline$\alpha \sigma t \delta o$ "but" & Sentence + Sentence \\
\hline $\begin{array}{l}\alpha \varphi \alpha \rho \sigma t \delta o \text { "but, except" } \\
\text { (only in two documents) }\end{array}$ & $\begin{array}{l}\text { Sentence + Nominal phrase } \\
\text { Sentence + Sentence }\end{array}$ \\
\hline & Sentence + Sentence \\
\hline$\mu 1 \sigma \iota \delta o$ "moreover" & Sentence + Sentence \\
\hline
\end{tabular}

\subsection{Correlative conjunctions}

These conjunctions are always used in pairs, and they link similar elements. Here are the correlative conjunctions found in the extant Bactrian texts:

$\alpha \lambda$ o... $\alpha \lambda_{0}$ "either...or", "both...and"

$\alpha \lambda$ o...o o o "either...or", "both....and"498

$\alpha \lambda \mathrm{o} \ldots$..o $\alpha \lambda_{\mathrm{o}}$ "either...or"

$\alpha \lambda$ o...o $\tau_{0}$ "both....and"

$\delta \alpha \lambda \delta$ o...o $\delta \alpha \lambda \mathrm{o}$ "either...or" 499

$\delta \alpha \lambda \delta$ o...o $\delta \alpha \lambda \delta$ o "either...or"

$\alpha \lambda \delta$ o... $\alpha \lambda \mathrm{o} / \alpha \lambda \delta \mathrm{o}$ "whether...or", "both....and", 501 or $\alpha \lambda \delta$ o...o $\delta \alpha \lambda \delta$ o "whether...or"

In the following example, the correlative conjunction $\alpha \lambda_{0} \ldots \alpha \lambda_{0}$ joins two adjectives:

\footnotetext{
${ }^{496}$ Sims-Williams 2007a: 65.

${ }^{497}$ Sims-Williams 2007a: 190.

${ }^{498}$ Sims-Williams 2007a: 190.

${ }^{499}$ Sims-Williams 2007a: 190.

${ }^{500}$ Sims-Williams 2007a: 189.

${ }^{501}$ Sims-Williams 2007a: 189.
} 
(W 15)

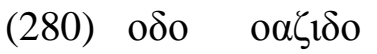

and employ.PRS.3s

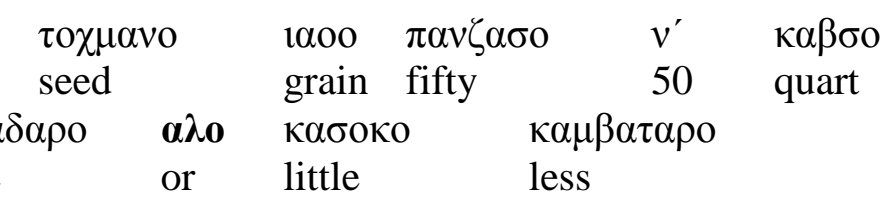

either little more or little les

"and (one) employs fifty quarts of grain (as) seed, either a little more or a little less"

It can also join two nominal phrases:

(C 14-15)

(281)

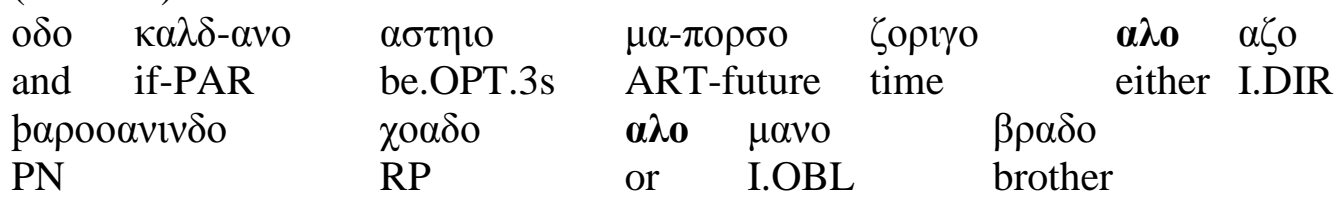

"and if in the future there should be (anyone)-whether I, Shar-wanind myself, or my brothers"

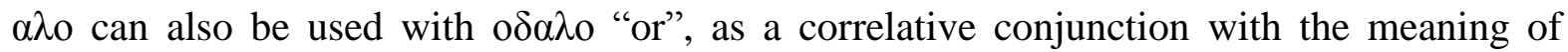
"either...or". In the following example, $\alpha \lambda_{0} \ldots . .0 \delta \alpha \lambda$ o joins two adjectives:

(282) $\alpha \sigma \tau 0$

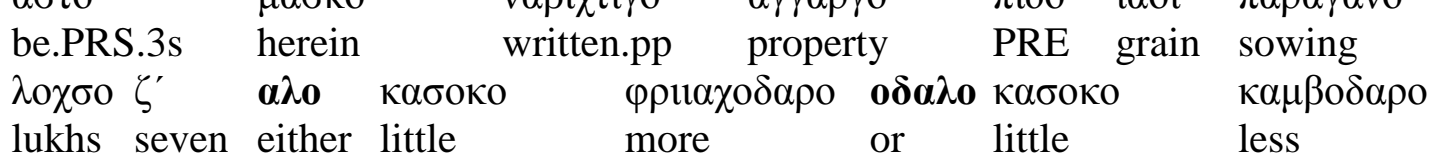

"(This) is the property described herein, (of a size requiring) seven lukhs-either a little more or a little less-for sowing with grain."

It seems that there is no semantic or functional difference between $\alpha \lambda_{0} \ldots o \delta \alpha \lambda_{0}$ and $\alpha \lambda_{0} \ldots$ $\alpha \lambda$ o. In examples (406 and 404), both are used in a similar context with the meaning of "either...or".

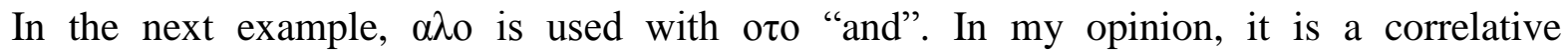
conjunction. It is shown here to link two clauses:

(al 6-7)

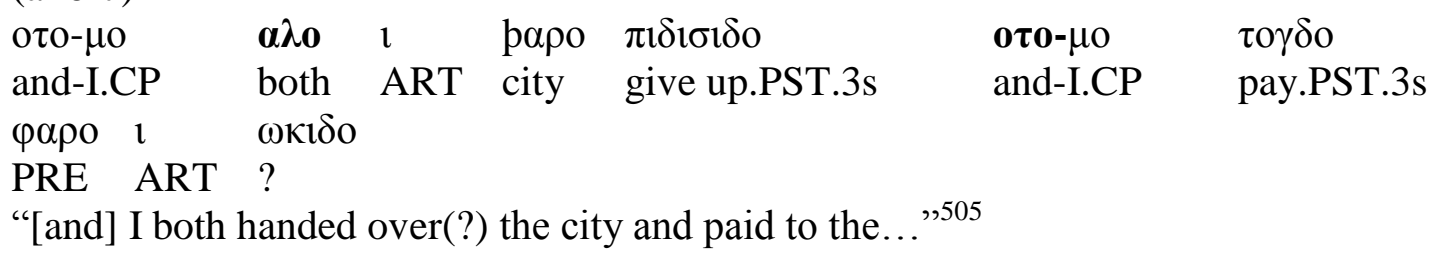

In the following example, $\delta \alpha \lambda \delta$ o...o $\delta \alpha \lambda$ o "either...or" is used to link two nominal phrases:

(xp 12-13)

(284) $\tau \alpha \lambda \delta$ o $\tau$ o

to $\chi 0 \eta$

if SPD lordship

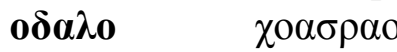

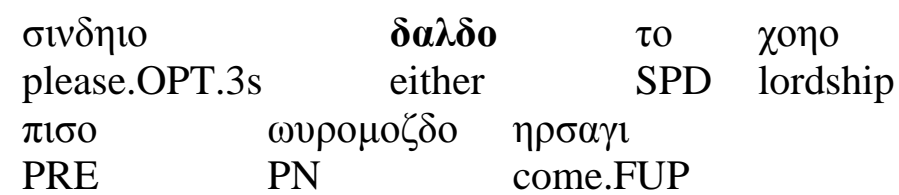

or PN PRE PN

"If it please your lordship, either your lordship or Khwasraw should come into the

\footnotetext{
${ }^{502}$ Cf. Sims-Williams 2000a: 129.

${ }^{503}$ Cf. Sims-Williams 2000a: 41.

${ }^{504}$ Sims-Williams 2000a: 57.

${ }^{505}$ Cf. Sims-Williams 2000a: 163.
} 
presence of Ohrmuzd"506

In the following example, $\alpha \lambda \delta o \ldots$... $\delta \alpha \lambda \delta$ o "whether...or" links two nominal phrases: (F 11)

(285) o $0 \quad \kappa 1 \delta-\alpha v 0$ and whoever-PAR

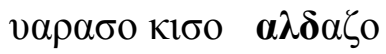
anyone whether-I.DIR $\alpha \sigma \tau \alpha \delta$ o $\quad \pi \alpha \rho \sigma o \mu \alpha-\beta \alpha \rho o \quad \zeta \alpha \mu \alpha v o$ $\beta \rho \alpha \delta o$ brother "and whoever there may be in the future -anyone at all, whether I, Asbid, myself, or my brothers",507

\subsubsection{Summary}

According to the above examples, we can conclude that no difference in meaning can be given for $\alpha \lambda_{0} \ldots \alpha \lambda \mathrm{o}, \alpha \lambda_{0} \ldots o \delta \alpha \lambda \mathrm{o}, \delta \alpha \lambda \delta \mathrm{o} \ldots o \delta \alpha \lambda \mathrm{o}, \delta \alpha \lambda \delta \mathrm{o} \ldots$..o $\delta \alpha \lambda \delta \mathrm{o}$; all them mean "either...or". $\alpha \lambda_{0} . . .0 \tau$ o can be also used in the meaning of "both... and". $\alpha \lambda o \ldots$... $\tau_{0}$ means also "both....and". These correlative conjunctions very often link nominal phrases, while they rarely link two sentences.

Table 29 shows the correlative conjunctions and their functions in the extant Bactrian texts:

\section{Table 29. Correlative conjunctions}

\begin{tabular}{|c|c|}
\hline Correlative conjunctions & Function in the extant Bactrian texts \\
\hline 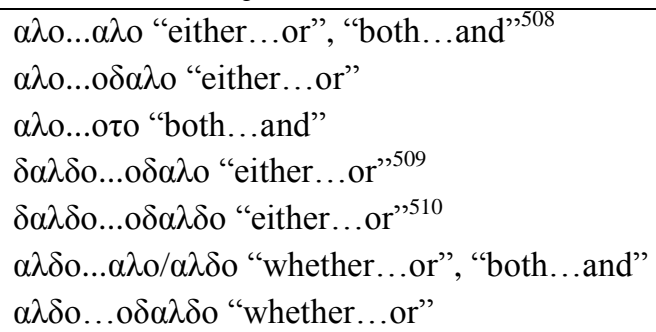 & $\begin{array}{l}\text { Nominal phrases+Nominal phrases } \\
\text { Sentence+Sentence }\end{array}$ \\
\hline
\end{tabular}

\subsection{Subordinating conjunctions}

Subordinating conjunctions are the largest group of conjunctions in Bactrian. They join subordinate clauses to main clauses. Most of them are used both as adverbs and conjunctions. According to their functions, they can be classified as temporal, causal, effective, and conditional.

\subsubsection{Time}

\section{$\sigma \alpha \zeta \alpha \mu \alpha v \delta o$ "as soon as"}

It is used in two documents as an independent form and in two other documents suffixed to the conjunction $\tau \alpha$ "and". It is illustrated in the following example:

\footnotetext{
${ }^{506}$ Cf. Sims-Williams 2007a: 163.

${ }^{507}$ Sims-Williams 2000a: 45.

${ }^{508}$ Sims-Williams 2007a: 190.

${ }^{509}$ Sims-Williams 2007a: 190.

${ }^{510}$ Sims-Williams 2007a: 189.
} 
(ca 6-7)

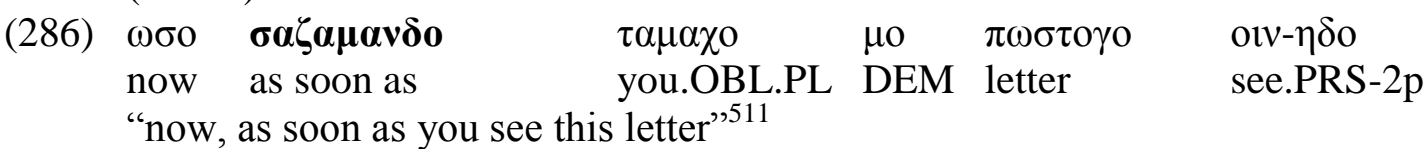

In the following example, it is attached to the conjunction $\tau \alpha$ :

(cp 19-20)

(287)

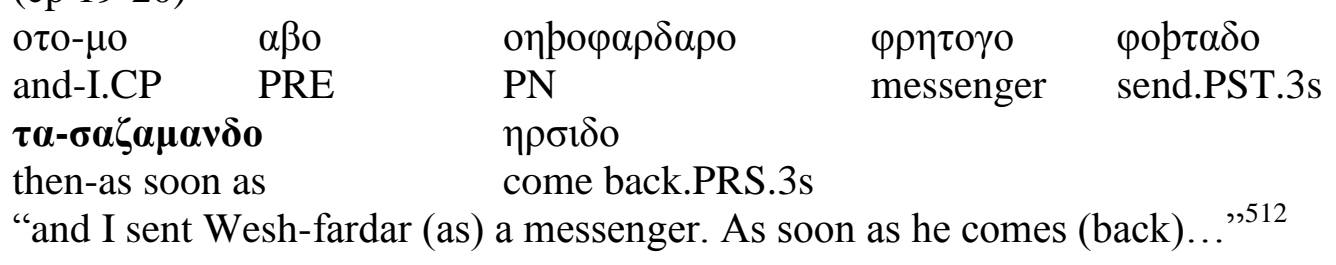

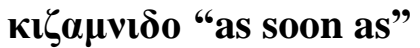

This subordinating conjunction is only used once in cf 13 with the meaning of "as soon as". It is suffixed to the conjunction $\tau \alpha$ and an enclitic pronoun, i.e., -iๆvo, is suffixed to it:
(cf 11-13)

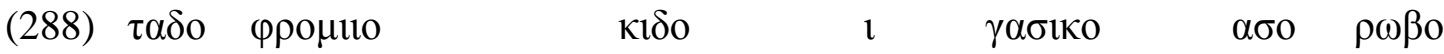
then order.IMPV.2s someone ART concubine PRE PN

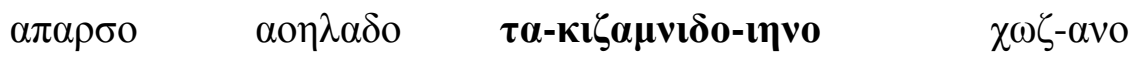
back fetch.INF and-as soon as-they.CP.p ask.SBJV-1s
"then order (someone) to fetch the concubine back from Rob, and as soon as I ask for them,"513

\section{$\sigma \alpha \zeta \alpha \mu \alpha v o$ "as soon as"}

It is used three times in the extant Bactrian documents. In the following example, it occurs at the beginning of the clause with the meaning of "as soon as", together with another conjunction, i.e., $\mu 1 \sigma 1 \delta$ :

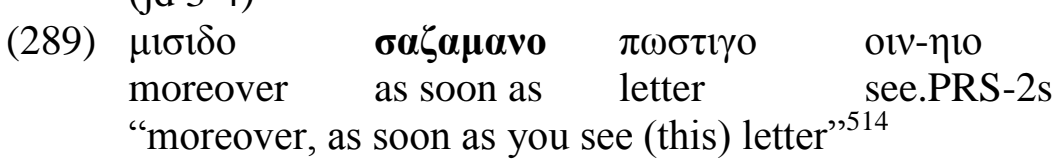

\section{$\pi \alpha \rho \sigma 0$ "back, afterwards"}

The form $\pi \alpha \rho \sigma o$ may be used as an adverb and it can function in both a prepositional and postpositional role. As a conjunction, it is used at the beginning of a subordinate clause with the meaning of "after":

(N 26-27)

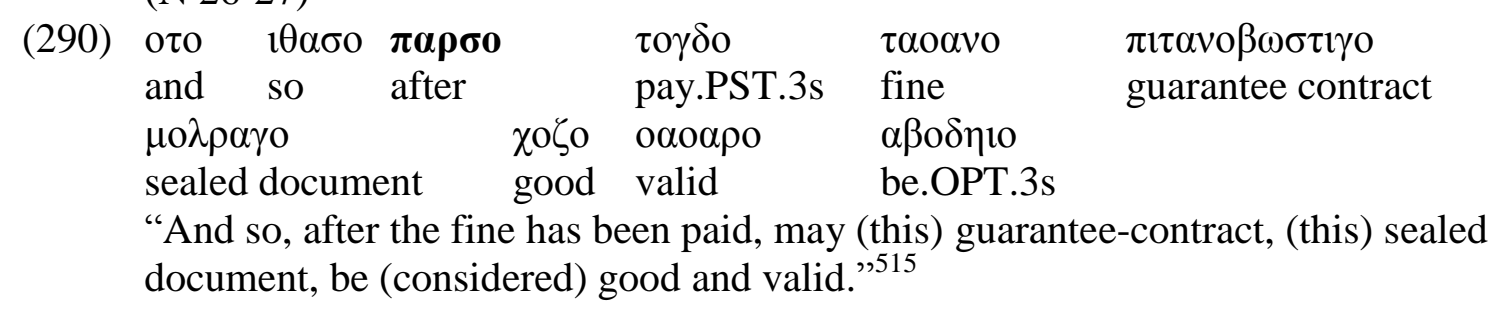

\footnotetext{
${ }^{511}$ Sims-Williams 2007a: 69.

512 Sims-Williams 2007a: 95.

${ }^{513}$ Sims-Williams 2007a: 79.

${ }^{514}$ Sims-Williams 2007a: 131.

${ }^{515}$ Sims-Williams 2000a: 77.
} 
(A 20-21)

(295) $\tau \boldsymbol{\alpha} \delta \alpha v o$ then-PAR

\begin{tabular}{|c|c|c|c|c|}
\hline $\begin{array}{l}\lambda \alpha v-\imath v \delta \eta 10 \\
\text { give.OPT-1p }\end{array}$ & $\begin{array}{l}\tau \alpha o \alpha v o \\
\text { fine }\end{array}$ & $\begin{array}{l}\alpha \beta o \\
\text { PRE }\end{array}$ & $\begin{array}{l}\text { pao } \gamma \alpha v o \\
\text { royal }\end{array}$ & $\begin{array}{l}\gamma \alpha \zeta \text { vo } \\
\text { treasury }\end{array}$ \\
\hline$\kappa^{\prime} \quad \delta i v \alpha \rho o$ & & & & \\
\hline
\end{tabular}
stuck gold 20 dinar "Then (we) shall give a fine to the royal treasury of twenty dinars of struck gold."

The verb can also occur at the end of the clause beginning with this conjunction:

(A 28-29)

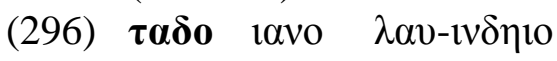

then wish give.OPT-3p

"Then they may give her.",523

Different kinds of words like prepositions (e.g., $\alpha \beta$ " "to"), personal pronouns (e.g., $-\eta 10$ "it,

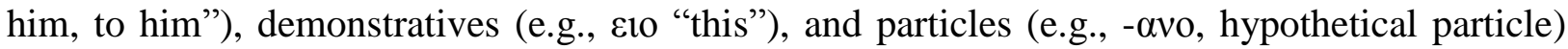
are suffixed to this conjunction in the extant material.

It can be used in a conditional sentence relating to $\boldsymbol{\kappa} \boldsymbol{\alpha} \lambda \boldsymbol{\delta} \boldsymbol{0}$ :

(Q 19)

(297) $\kappa \alpha \lambda \delta o$

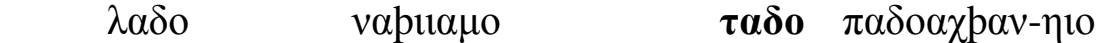

if give.INF NEG.SBJV.1p then have a right.PRS.2s

"if we cannot give (it to you), then you have the right...",524

\section{$\sigma \alpha \gamma \omega v \delta o, \sigma \alpha \gamma o v \delta o$ "as, like, that"}

This conjunction is attested very often in Bactrian texts. Other words like prepositions or pronouns are very often suffixed to this word, but only once is the conjunction itself suffixed:

$$
\text { (A 14-15) }
$$

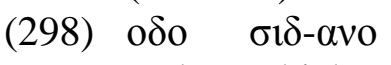

and which-PAR

$\mathbf{\imath} \boldsymbol{\theta} \alpha-\sigma \alpha \gamma \omega v \delta 0 \alpha \sigma v \omega v o$

$\alpha \sigma o \quad \mu-\alpha \beta \rho-1 \sigma o$

$\alpha \lambda \varphi \alpha v \zeta-\alpha \mu \eta 10$

thus-as daughter in law

PRE ART-future-also

$\pi \mathrm{o} \rho \delta \mathrm{o}$

acquire.OPT-1p

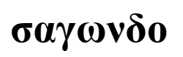

$\alpha \beta o \quad \mu o \quad \lambda \alpha \mu$

ought PRE

$\lambda \rho \imath \gamma \delta$ o

treat.PST.INF

as PRE ART land established custom

"And also which we may acquire in the future, as (one) ought to treat a daughter-in- law, as (is) the established custom in the land." 525

It very often coordinates two clauses, as illustrated in the following examples:

(eh 5-6)

(299) $\tau \alpha \delta o-\mu o$

then-I.CP

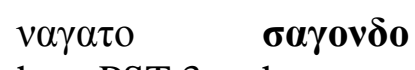

$v \alpha \beta \imath \tau \tau-\eta \mu o \quad \pi i \delta o \quad \mu \alpha{ }_{0}$

$\lambda \rho o \gamma o \sigma \tau \alpha v o$

hear.PST.3s how

write.PST.1s PRE I.OBL

health

"So I have heard how you have written to me concerning my health.",526

In above example, it is used with the meaning "how".

Another example is given here:

\footnotetext{
${ }^{522}$ Sims-Williams 2000a: 35.

${ }^{523}$ Cf. Sims-Williams 2000a: 35 and Sims-Williams 2007a: 35.

${ }^{524}$ Cf. Sims-Williams 2000a: 91.

${ }^{525}$ Sims-Williams 2000a: 33.

${ }^{526}$ Cf. Sims-Williams 2007a: 123.
} 
(N 31)

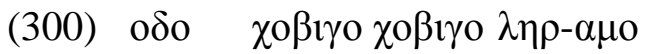

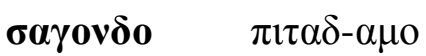
and all our own keep.SBJV.1p as guarantee.PST.1p "And may we keep all our own (household) as we have guaranteed." 527

In the following example, it coordinates a clause and a nominal phrase and is used with the meaning "than":

(ec 9-11)

(301) $\tau \alpha \delta-\eta v o$ $\alpha \sigma \kappa \alpha \delta \alpha \rho o \quad \pi \alpha \rho \circ \beta \alpha \lambda-\alpha \nu o$ then-they.CP more o $\delta-\alpha \lambda-\imath$ vo $\quad$ v $\alpha \varphi \mathrm{op} \tau-110(?)$ to take care of.SBJV.1s than $1-\chi 0 \beta 0$ and-if NEG.send.OPT?.2s "then I would take care of them more than my own; and if you should not send them",528

In the following example, it coordinates two prepositional phrases:

(cd 11-14)

(302) $\tau \alpha \delta o-\mu о$

then-I.CP

$\pi 1 \sigma 0 \quad \tau 0 \quad \chi 0 \eta о$

PRE SPD lordship

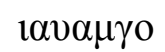

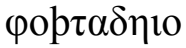

$\boldsymbol{\sigma \alpha \gamma \omega v \delta o}$ $\pi 1 \sigma 0 \quad \chi 011 \alpha \chi 0$ $\beta \rho \alpha \delta$ o

as PRE elder brother

"I would have sent the same to your lordship as to an elder brother."

$\kappa \iota \delta 0, \alpha \kappa \iota \delta 0, \kappa \iota \delta-, \alpha \kappa \iota \delta-, \alpha \kappa ı \delta \alpha-$ "that"

It is occasionally used as a relative pronoun, but it can also play the role of a conjunction with the meaning "that" in late texts and introduce a subordinate clause or direct $\operatorname{speech}^{530}$ :

(X 5-6)

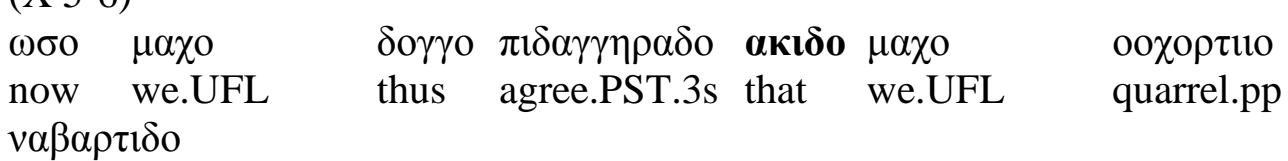

NEG.be necessary.PRS.3s

"Now it has been thus agreed by us, that it is not necessary for us to quarrel.",531

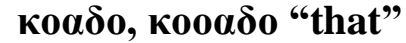

$\kappa o \alpha \delta$ o plays different roles. As a conjunction, it means "that, so that". It can also be used as a relative pronoun or adverb. In the following examples, it coordinates two clauses. (ba 9)
(304) $\mu \alpha v o \quad v \alpha \gamma \alpha \tau o$

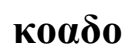
too $\quad \mu \alpha \rho \delta o \lambda \alpha \delta i \gamma-\eta 10$
I.OBL hear.PST.3s that
"I have heard that you are a just man." 532
man just-be.PRS.2s

This conjunction can also be used to introduce direct speech, as in the following example:

\footnotetext{
${ }^{527}$ Cf. Sims-Williams 2000a: 79.

${ }^{528}$ Sims-Williams 2007a: 113.

${ }^{529}$ Sims-Williams 2007a: 75.

${ }^{530}$ Cf. Sims-Williams 2007a: 222.

${ }^{531}$ Sims-Williams 2000a: 137.

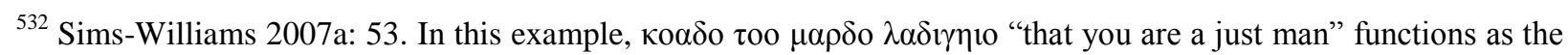

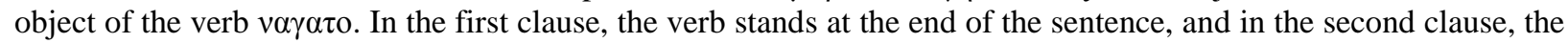
enclitic form of the verb "to be" is attached to an adjective, which is very common.
} 
(cc 9-11)

(305) $\tau \alpha \delta o \quad \tau 1$

then SPD lordship promise.PST.2s that dog give.PRS.1s
"Then your lordship promised: "I (shall) give (you) a dog.",533

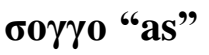

This word is classified as an adverb by Sims-Williams. It can also be used as a conjunction coordinating two clauses:

(U 10-11)

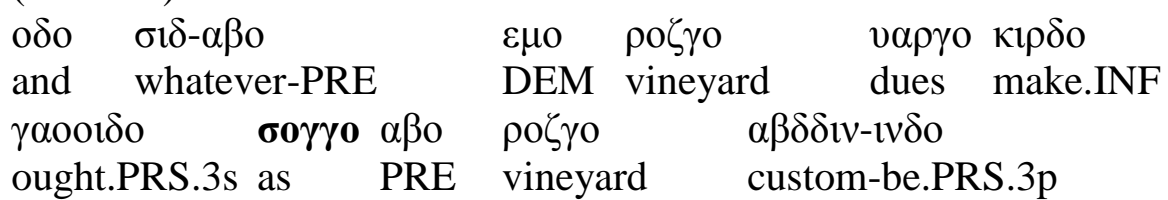

"And whatever (payment of) dues ought to be made for this vineyard, as it is the custom for a vineyard." 534

\subsubsection{Condition}

\section{$\kappa \alpha \lambda \delta 0$ "when, if"}

The form $\kappa \alpha \lambda \delta$ o "if" is one of the most common conjunctions in Bactrian. It is used alone or attached to other words, such as prepositions, pronouns, conjunctions and particles. It can be suffixed to other words such as in $\tau \alpha \kappa \alpha \lambda \delta$ o ( $\tau \alpha$ COJ "then"- $\kappa \alpha \lambda \delta$ o "if, when") or prefixed, as in $\kappa \alpha \lambda \delta \alpha \sigma o$ ( $\kappa \alpha \lambda \delta$ o "if, when"- $\alpha \sigma o$ PRE "from"). It can also be in the middle of an expression e.g. $\tau \alpha \kappa \alpha \lambda \delta \alpha \sigma o$ ( $\tau \alpha$ COJ "then"- $\kappa \alpha \lambda \delta$ o "if, when"- $\alpha \sigma o$ PRE "from"). It frequently introduces a subordinate clause.

In connection with the particle $-\alpha v o,{ }^{535}$ it has the meaning of "if", and it very often forms a conditional sentence:

$$
\text { (A 19-21) }
$$

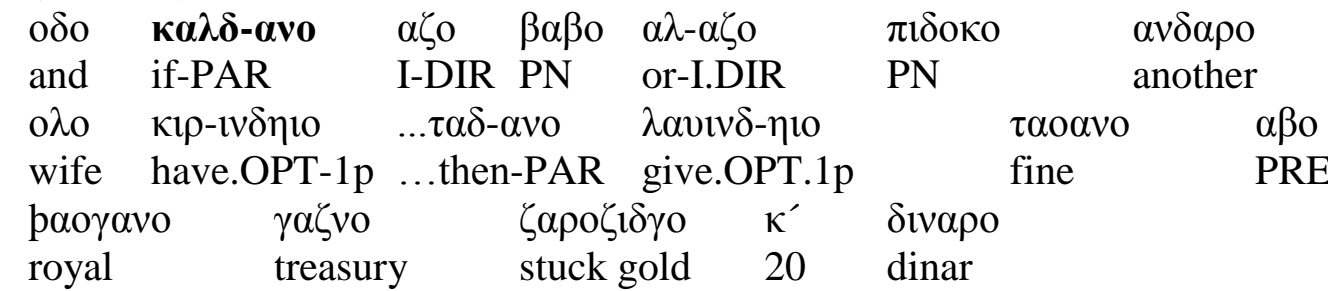

"And if, I, Bab or I, Piduk should make another wife..., then we shall give a fine to the royal treasury of twenty dinars of struck gold."

In a construction beginning with $\kappa \alpha \lambda \delta$, the verb usually occurs at the end:

(bh 2-3)

\begin{tabular}{|c|c|c|c|c|c|}
\hline$o \tau-\alpha \nu 0$ & $o \alpha \lambda o$ & p $\alpha \tau \alpha \rho-\alpha \nu o$ & $\kappa \alpha \lambda \delta о \alpha \beta o$ & $\tau 0$ & ұопо \\
\hline $\begin{array}{l}\text { and-PAR } \\
\chi_{0} \alpha \delta o\end{array}$ & $\begin{array}{l}\text { then } \\
\lambda \rho \circ \gamma_{0}\end{array}$ & $\begin{array}{c}\text { more happy-be.SBJV.1s } \\
\text { onvavo }\end{array}$ & when PRE & SPD & lordship \\
\hline $\mathrm{RP}$ & healthy & see.SBJV.3s & & & \\
\hline
\end{tabular}

\footnotetext{
${ }^{533}$ Sims-Williams 2007a: 73.

${ }^{534}$ Cf. Sims-Williams 2000a: 109 and Sims-Williams 2007a: 36.

${ }^{535}$ For the function of - $\alpha v 0$, see Sims-Williams 2007a: 48.

${ }^{536}$ Cf. Sims-Williams 2000a: 33-35.

${ }^{537}$ Sims-Williams 2007a: 67.
} 
Rarely, a verb can follow $\kappa \alpha \lambda \delta$ :

(A 1-2)

(309) $\kappa \boldsymbol{\alpha} \lambda \boldsymbol{\delta}$

when

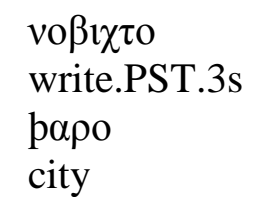

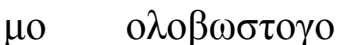

$\mu \alpha \lambda_{0} \quad \alpha \beta o \quad \mu o$

$\rho \omega \beta \alpha \gamma \gamma \mathrm{O}$

city

DEM

marriage contract

here PRE ART

of Rob

$\alpha \beta 110$

$\alpha v \delta \alpha \gamma o$

PRE-DEM borough

"when this marriage contract was written here in the city of Rob, in the borough..."538

\section{$\alpha \lambda \delta 0$ with the meaning of "if"}

As mentioned before, this conjunction is used very often as a coordinating conjunction. It occurs also in conditional sentences with the meaning of "if" and plays the role of a subordinating conjunction:

(ba 16-17)

(310) $\tau \alpha \delta o-1 \eta \nu o$

then-they.CP punishment

$\tau \alpha \mathrm{Ol}$

your.SG

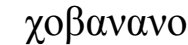

$\kappa \iota-\alpha v 0$

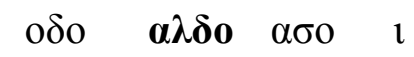

make.SBJV.1s

and if PRE ART

shepherd

$\beta 1 \zeta \delta \alpha v_{0}$

$\kappa 1 \rho \delta \delta$ o

evil

make.PST.SBJV.3s then I.DIR

$\alpha \beta \alpha-\varphi \alpha \gamma o$

$v \alpha \beta \imath \tau \tau o$

$\varphi \rho о \mu t 1-\alpha \nu o$

PRE-you.CP write.INF order.SBJV-1s

"and then I shall punish them; and if evil should have been committed by your shepherds, then I shall order (a letter) to be written to you",539

\subsubsection{Summary}

Most of the subordinate conjunctions are adverbs also used as conjunctions. The following table shows the subordinate conjunctions and their functions in the extant Bactrian texts:

Table 30. Subordinating conjunctions

\begin{tabular}{|c|c|c|}
\hline Time & Cause/Effect & Condition \\
\hline 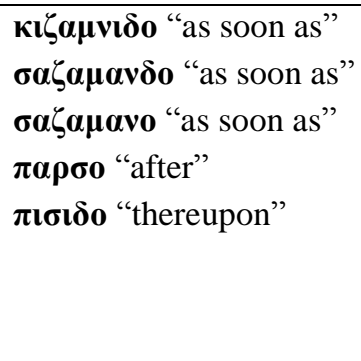 & 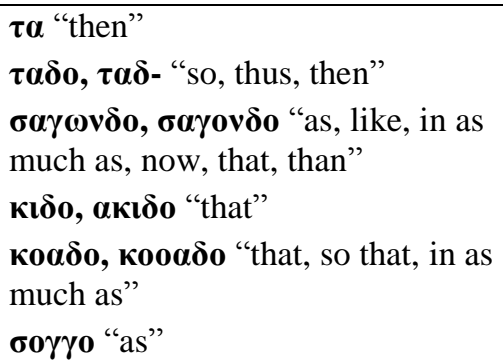 & $\begin{array}{l}\boldsymbol{\kappa} \boldsymbol{\alpha} \boldsymbol{\lambda} \boldsymbol{\delta} \boldsymbol{o} \text { "when, if" } \\
\boldsymbol{\alpha} \boldsymbol{\lambda} \boldsymbol{\delta} \boldsymbol{o} \text { with the meaning of "if" }\end{array}$ \\
\hline
\end{tabular}

\footnotetext{
${ }^{538}$ Cf. Sims-Williams 2000a: 33 and Sims-Williams 2007a: 35.

${ }^{539}$ Sims-Williams 2007a: 53.
} 


\section{Chapter Eight: The Verb}

\subsection{Position}

The verb occurs in variant positions in the clause. It may have an initial or a final position, but most frequently it occurs in the final position. In the following example, the verb occurs at the end of the clause:

(ci 6)
(311) $\tau \alpha \delta o-1 \eta 10$
фаранауо
$\lambda \alpha v-\eta \iota$
then-it.CP
PRE-I.CP
"And you should give it to me."
give.OPT.2s

In the following example, the verb occurs at the beginning of the sentence:

(Document 1, 1-4)

\begin{tabular}{|c|c|c|c|c|}
\hline $\begin{array}{l}\boldsymbol{\pi} \mathbf{\iota} \boldsymbol{\delta} \boldsymbol{\rho} \boldsymbol{\beta} \boldsymbol{\delta} \boldsymbol{o} \\
\text { receive.PST.3s }\end{array}$ & $\begin{array}{l}\mu \alpha v o \\
\text { I.OBL }\end{array}$ & $\begin{array}{l}\alpha \sigma \pi \alpha \lambda \mathrm{o} \beta 1 \delta o \\
\mathrm{PN}\end{array}$ & $\begin{array}{l}\alpha \sigma \alpha-\varphi \alpha \gamma o \\
\text { PRE-you.CP }\end{array}$ & $\begin{array}{l}\zeta o o \alpha v i v \delta o \\
\text { PN }\end{array}$ \\
\hline $\begin{array}{l}\alpha \mu \beta \alpha \rho \circ \beta 1 \rho \sigma \alpha \rho \lambda о \gamma o \\
\text { store keeper }\end{array}$ & $\begin{array}{l}\sigma 1 \delta-\alpha \sigma o \\
\text { what-PRE }\end{array}$ & $\begin{array}{ll}l & v \alpha \mu \alpha \gamma c \\
\text { ART } & \text { list }\end{array}$ & $\begin{array}{l}\text { vißıбıьo } \\
\text { write.PRS }\end{array}$ & S. 3s \\
\hline
\end{tabular}

"I, Aspal-bid have received from you, Zuwanind the store keeper, what is written in this list." 541

It may also occur directly after the subject, as in the following example:

(cq11-12)

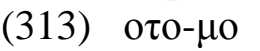

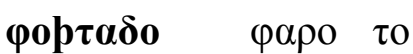

ұопо

Sivapo

$\alpha^{\prime}$ and-I.CP send.PST.3s PRE SPD

"And I have sent one dinar for your lordship." 542 lordship dinar

one

\subsubsection{Two verbs in a construction}

In the following section, variants of word order are shown, when more than one verb occurs in a construction:

\section{Verb (inflected) + INF without $\alpha \beta$ o}

In the following example, the infinitive occurs after the inflected verb, without the preposition $\alpha \beta$ o usually governing the past stems:

(Rabatak 11-12)

$\begin{array}{llll}\text { o } \tau-\eta 1 \alpha & \boldsymbol{\varphi \rho о \mu} \boldsymbol{\alpha} \boldsymbol{\delta} \mathbf{o} & \ldots & \kappa i \rho \delta \iota \\ \text { and-he.CP } & \text { order.PST.3s } & \ldots & \text { make.PST.INF } \\ \text { "and he gave orders to make..." } & \end{array}$

\section{Verb (inflected) + INF with $\alpha \beta 0$}

In the following example, the preposition $\alpha \beta$ governs the past infinitive:

\footnotetext{
${ }^{540}$ Sims-Williams 2007a: 85.

${ }^{541}$ Sims-Williams 2000b: 5.

${ }^{542}$ Sims-Williams 2007a: 97.

${ }^{543}$ Sims-Williams 2004 (2008): 56.
} 
(A 24-25)

(315) o $\tau-\alpha v o$ and-PAR PROH.have right.OPT.1p PRE assign.PST.INF "and (we) shall not have the right ...to assign" "544

\section{INF without $\alpha \beta 0+$ Verb (inflected)}

In the following example, two infinitives which are not coordinated by a conjunction occur before the inflected verb:

(C 17)

\begin{tabular}{|c|c|c|}
\hline $\begin{array}{l}\chi 0 \alpha v \delta o \\
\text { claim.PST.INF }\end{array}$ & 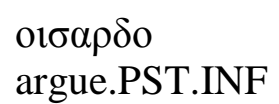 & $\begin{array}{l}\boldsymbol{\alpha \beta} \zeta \text { ıाрı } \\
\text { continue.OPT.3s }\end{array}$ \\
\hline
\end{tabular}

"(who) might continue to claim or argue",545

\section{INF without $\alpha \beta 0+$ Verb "to be" (inflected and suffixed)}

In the following example, an infinitive is used with the verb "to be":

(bc 7-8)

(317) $\tau \alpha \delta o-\mu o$

then-I.CP

$$
\tau \alpha \lambda \mathrm{o} \quad \alpha \beta \mathrm{o}
$$

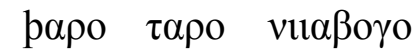

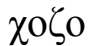

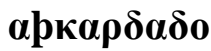

thus PRE

city

thither fitting

good

follow.PST.INF-be.SBJV.3s

"So it would be very fitting for me to follow (him) thither to the city.",546

In the following example, the infinitive is attached to a substantive, and the verb "to be" is attached to the infinitive:

(ck 7)

\section{$\pi 0 \rho \delta 0-\gamma \iota \delta \delta-\alpha v o$}

proper-do.INF-be.SBJV.1s

"I am obliged to do",547

\section{Verbs used with the infinitive:}

According to Sims-Williams, "the infinitive is identical with the past stem." verbs or constructions, an infinitive without $\alpha \beta$ o is occasionally used.

The verb pu- "can, to be able" is treated like a modal verb, and an infinitive is used with it:

(319) $\kappa \alpha \lambda \delta o$

$\lambda \alpha \delta 0$

if give.PST.INF NEG.can.SBJV.1p

"if we cannot give" 549

The verb $\pi \alpha \delta \alpha \chi b \alpha v$ - "to have a right, have authority" may be used with an infinitive without $\alpha \beta o$ :

\footnotetext{
${ }^{544}$ Sims-Williams 2000a: 35.

545 Sims-Williams 2000a: 41.

${ }^{546}$ Sims-Williams 2007a: 57.

${ }^{547}$ Sims-Williams 2007a: 89.

${ }^{548}$ Sims-Williams 2007a: 45.

${ }^{549}$ Sims-Williams 2000a: 235.
} 
(Q 19-20)

(320) $\tau \alpha \delta o$

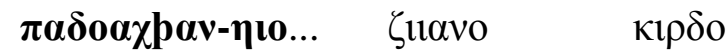

then have a right.PRS.2s penalty make.INF

"then, you have the right to fix such a penalty of...,

$-\pi$ o $\delta$ o "ought to" + copula is occasionally used with an infinitive without $\alpha \beta 0$ :

(xn 7-8)

(321) $\tau \alpha \sigma 1 \delta \mathrm{o}$

whatever

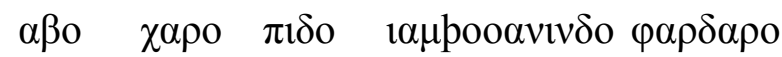

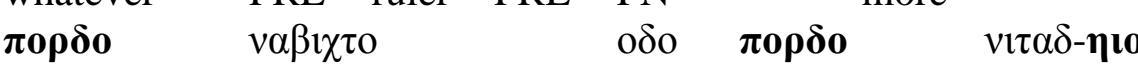

ought to write.PST.INF and ought to send.INF-be.PRS.2s

"Whatever more you ought to write and ought to send to the ruler concerning Yamshwanind." 551

The verb $\varphi \rho \circ \mu$ tl- "to order" is occasionally used with an infinitive with $\alpha \beta 0$ :

(xk 11)

(322)

\begin{tabular}{|c|c|c|c|}
\hline & 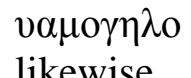 & 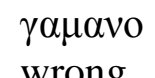 & 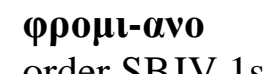 \\
\hline
\end{tabular}

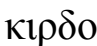

do.PST.INF

"And I likewise should give orders to do wrong (to you).,"552

The verb $\rho \mu$ - "to order" is also used with an infinitive without $\alpha \beta$ o:

$\left(\mathrm{P} 16^{\prime}\right)$

(323) $v \alpha \rho \sigma o$

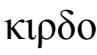

do.PST.INF

whatever

"whatever it may suit to do",553

\section{$\boldsymbol{\alpha \rho \iota \mu \alpha \delta o ~}$}

suit.SBJV.3s

The verb $\alpha \beta \zeta$ ul- "to continue" occasionally occurs with an infinitive without $\alpha \beta 0$ :

(bd 7)

(324)

$\begin{array}{ll}\boldsymbol{\alpha} \boldsymbol{\beta} \zeta \boldsymbol{\alpha} \boldsymbol{\delta} \text { - } \eta \mathbf{1 0} & \chi 1 \rho \delta \text { o } \\ \text { continue.PST.2s } & \text { do.INF } \\ \text { "you continued to buy"554 }\end{array}$

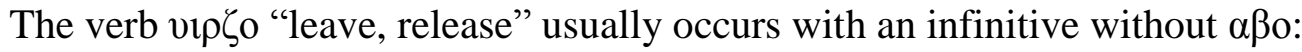

(jh 10-11)

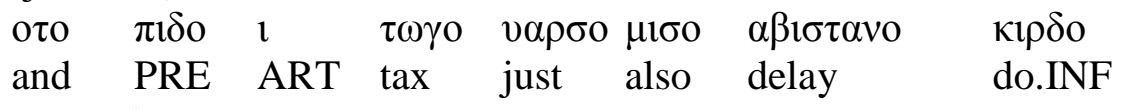

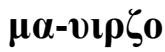

PROH.leave.IMPV.2s

"And with regard to the tax do not allow any further delay to be made." 555

The verb кц- "want" can also govern a following infinitive without $\alpha \beta 0$ :

\footnotetext{
${ }^{550}$ Sims-Williams 2000a: 91.

${ }^{551}$ Sims-Williams 2007a: 159.

${ }^{552}$ Sims-Williams 2007a: 155.

${ }^{553}$ Sims-Williams 2000a: 85.

${ }^{554}$ Sims-Williams 2007a: 59.

${ }^{555}$ Sims-Williams 2007a: 137.
} 
(jh 9)

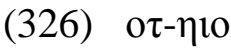

and-he.CP sheep want.SBJV.3p give.INF

"and (if) they should want sheep to be given to him" "556

The verb $\sigma \alpha \chi \sigma-$ "to be assessed" usually occurs with an infinitive without $\alpha \beta 0$ :

(je 7-8)

(327) $\pi$ เ $\delta$ oo

PRE-DEM RTP-he CP

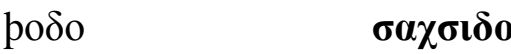

pay out.PST.INF to be assessed.PRS.3s

"Because his donkey is assessed to be paid out (in return) for wine." 558

\section{-Verb and past participle}

In Bactrian, a few verbs such as $\beta \alpha \rho \tau$ - "to be necessary (?)" and $\gamma \alpha 00$ "to be necessary, ought" govern a preceding past participle instead of an infinitive:

$$
\text { (xj 4-6) }
$$

(328) $\tau \alpha \delta o \quad \omega \sigma o \quad \delta \alpha \gamma o \gamma \gamma o$

then now in such a way

$\begin{array}{lll}\kappa \iota \rho о & \kappa o \alpha \delta o & \kappa \alpha \rho \gamma \alpha \rho о \\ \text { do.IMPV.2s } & \text { that } & \text { worker }\end{array}$

$\omega \zeta \alpha \delta \gamma_{0} \quad \boldsymbol{v \alpha} \boldsymbol{\beta} \boldsymbol{\alpha} \boldsymbol{\alpha} \boldsymbol{\alpha} \boldsymbol{\alpha} \boldsymbol{0}$

liable.pp NEG.to be necessary. SBJV.3s

"So now you (sg.) should act in such a way that it should not be necessary for the workers to be (held) liable."

Another example is given here:

(U 10)

(329) $\sigma 1 \delta \alpha \beta 0$

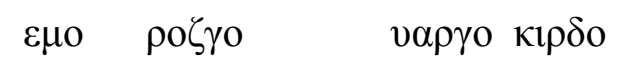

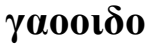

whatever DEM vineyard rent do.pp ought.PRS.3s

"whatever (payment of) rent ought to be made for this vineyard"560

\subsubsection{Enclitic forms of the verb "to be"}

The enclitic forms of the verb "to be" can be attached to a substantive, an adjective, adverb, infinitive, and negative particle.

In the following example, the enclitic form of the verb "to be" is attached to an adjective:

(A 24)

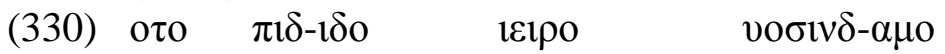

and PRE-DEM matter in agreement-be.PRS.1p

"and in this matter we are in agreement" 561

It may also be attached to a substantive:

\footnotetext{
${ }^{556}$ Sims-Williams 2007a: 137.

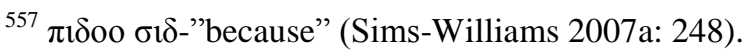

${ }^{558}$ Sims-Williams 2007a: 131.

${ }^{559}$ Sims-Williams 2007a: 153.

${ }^{560}$ Sims-Williams 2000a: 109.

${ }^{561}$ Sims-Williams 2000a: 35.
} 
(J 17)

(331) $\varphi \rho о \gamma \alpha о-\alpha \mu о$

profit-.be.PRS.1p

"we are profited"

In the following example, it is attached to an adverb:

(C 13)

(332) $\tau \alpha 01$

$1 \alpha \mu$ роб $\pi \alpha \lambda_{0} \quad \chi о \beta \eta 10$

you.OBL PN properly-be.OPT.3s

"may belong properly to you, Yamsh-spal""563

It can also be attached to an infinitive:

(bc 7-8)

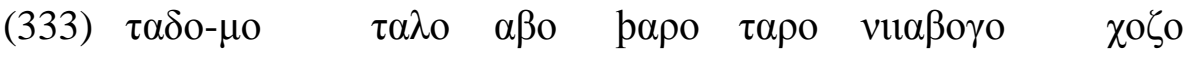

then-I.CP thus PRE city thither fitting good

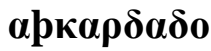

follow.PST.INF-be.SBJV.3s

"So it would be very fitting for me to follow (him) thither to the city." 564

In the following example, it is attached to the negative particle $v \alpha-$ :

\begin{tabular}{|c|c|c|c|c|}
\hline 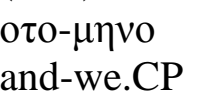 & $\begin{array}{l}\text { oqvayo } \\
\text { price }\end{array}$ & 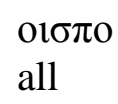 & $\begin{array}{l}\alpha \sigma \pi \text { opıүo } \\
\text { complete }\end{array}$ & 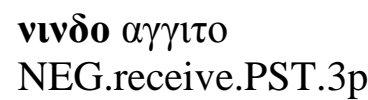 \\
\hline
\end{tabular}

It seems that enclitic form of the verb "to be" occurs always as the last enclitic in constructions with more than two elements (see examples 320-325).

\subsection{Agreement with subject}

In non-ergative constructions, the verb agrees with the subject in number and person. When the subject is more than one substantive or pronoun which are coordinated by a conjunction, the verb tends to occur in the singular:

$$
\text { (A 17-18) }
$$

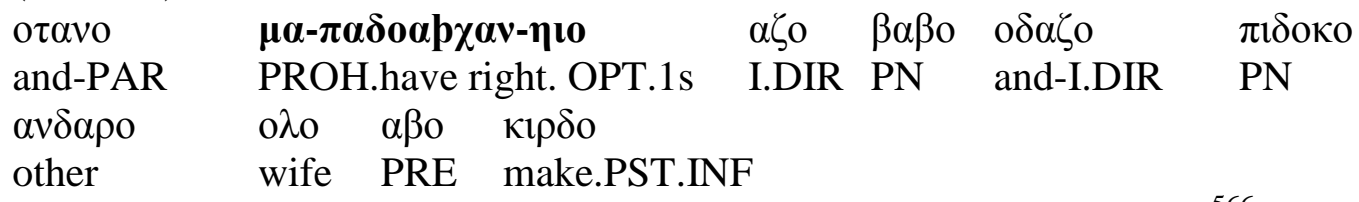

"and I, Bab, and I, Piduk, shall not have the right to make another wife",566

The verb usually tends to be singular with $\delta \rho \alpha \chi \mu o+$ Number. In the following ergative construction, the verb which agrees with the object is singular:

\footnotetext{
562 Sims-Williams 2000a: 57.

${ }^{563}$ Sims-Williams 2000a: 41.

${ }^{564}$ Sims-Williams 2007a: 57.

565 Sims-Williams 2000a: 59, 61.

${ }^{566}$ Sims-Williams 2000a: 33.
} 
(al 14-15)

(336) $\tau \alpha \delta o-\mu o$ then-I.CP $\tau \boldsymbol{\gamma} \gamma \boldsymbol{\delta} \boldsymbol{0}$ $\delta \rho \alpha \chi \mu o$

$\beta^{\prime}$

"Then, I [again] paid two dirhams." 567

two

But in the following example, the verb tends to occur in the plural with $\delta \rho \alpha \chi \mu o+$ Number:

(M 3-4)

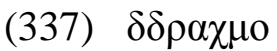

dirham

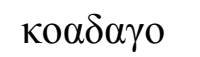

$\gamma^{\prime} \ldots$

$\alpha \sigma 1 \delta-\alpha \sigma 0$

$\mu \omega 1 \alpha v o$

three which-PRE PN

$\pi \alpha \rho \circ$

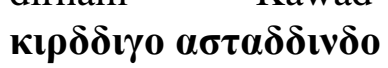

do.PLUP.3p

"the three dirhams of (king) Kawad which had been loaned by Moyan"568

With few singular words, the verb is used in the plural. According to Sims-Williams, "the noun may perhaps be regarded as pl.Tantum." 569 With oavaro "price", the verb usually occurs in the plural:

(L 21)

\begin{tabular}{|c|c|c|c|}
\hline 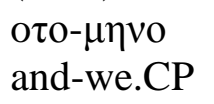 & $\begin{array}{l}\boldsymbol{\alpha} \gamma \gamma \mathbf{\iota} \tau-\mathbf{\imath v \delta o} \\
\text { receive.PST.3p }\end{array}$ & 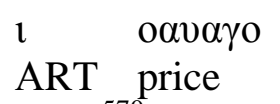 & 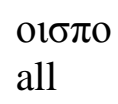 \\
\hline
\end{tabular}

But in two cases it is treated as singular:

(F14-15)

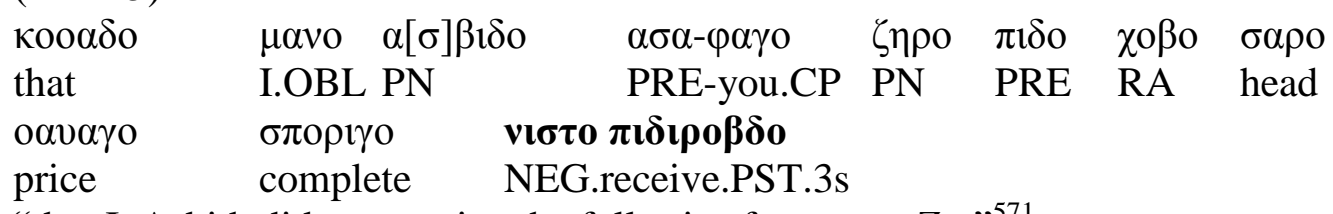

"that I, Asbid, did not receive the full price from you, Zer",571

Another example is given here:

(U 7)

(340) odo

\begin{tabular}{|c|c|c|c|}
\hline $\begin{array}{l}\mu \alpha \chi 0 \\
\text { we.UFL }\end{array}$ & 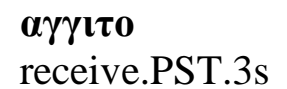 & $\begin{array}{l}\text { odvayo } \\
\text { price }\end{array}$ & $\begin{array}{l}\alpha \sigma o-\varphi \alpha \gamma o \\
\text { PRE-you.CP }\end{array}$ \\
\hline
\end{tabular}

With $\tau \alpha o o \alpha v_{0}$ "fine", the verb occurs in the plural:

(jh 11)

(341)
$\kappa о \alpha \delta-\alpha \beta o$

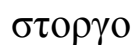
$\tau \alpha 0 o \alpha v 0$

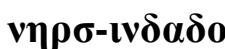
so that-PRE much
"so that the fine may not come to much",573
NEG.come.SBJV.3p

With $\alpha \zeta \delta$ o "information", the verb may be in the singular or in the plural. In the following sentence, the first verb is in the singular, whereas the second verb is in the plural. Both constructions are ergative, and $\alpha \zeta \delta$ o is the object.

\footnotetext{
${ }^{567}$ Sims-Williams 2000a: 163.

${ }^{568}$ Sims-Williams 2000a: 73.

${ }^{569}$ Sims-Williams 2007a: 48.

${ }^{570}$ Sims-Williams 2000a: 66.

${ }^{571}$ Sims-Williams 2000a: 47.

${ }^{572}$ Sims-Williams 2000a: 107.

${ }^{573}$ Sims-Williams 2007a: 137.
} 
(cp 23-25)

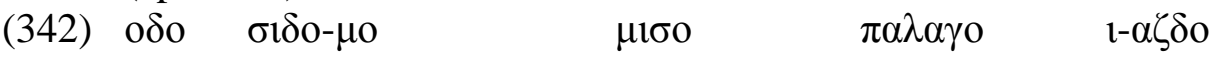 and whatever-I.CP further PN ART-information

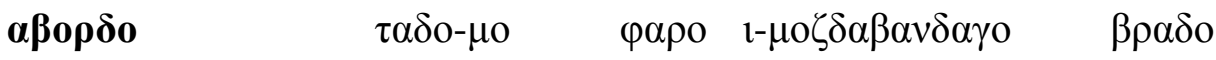 obtain.PST.3s then-I.CP PRE ART-PN brother
$\boldsymbol{\lambda} \boldsymbol{\alpha} \boldsymbol{\delta}-\mathbf{t v} \boldsymbol{\delta} \mathbf{0}$
give.PST.3p
"and whatever further information (about) Palag I obtained, I gave to Muzda-bandag's brother"

It is not easy to determine the exact function of this word, because it is only used in three documents. In one instance, as in the above example, and two other instances, with the verb кip"do", it has the meaning of "make notice, inform".

In the following example, the verb occurs in the plural with $\chi 0 \beta \alpha o \alpha v \delta o$ "owner":

(V 26)

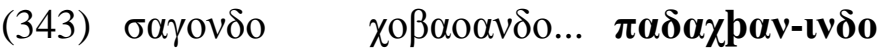
just as owner have authority.PRS.3p "just as owners have authority"575

With the word $\alpha \gamma \gamma \alpha \rho \gamma o$ "property", the verb may occur in the plural. But this happens very rarely:

(V 14)

\begin{tabular}{|c|c|c|}
\hline $\begin{array}{l}\alpha \gamma \gamma \alpha \rho \alpha \gamma o \\
\text { property }\end{array}$ & $\begin{array}{l}\alpha \sigma 1 \delta \text { o } \chi 0 \delta \delta \eta \circ o \\
\text { which lord }\end{array}$ & $\begin{array}{ll}\beta \alpha \rho \alpha \delta \delta ı \kappa \alpha v o & \rho \omega \beta о \chi \alpha \rho о \\
\text { of Baradikan } & \text { the khar of Rob }\end{array}$ \\
\hline
\end{tabular}

With indefinite pronouns the verb maybe used in the plural or singular. In the following example, the verb occurs in the plural:

(V 27)

(345) $\alpha \kappa \imath \delta o$

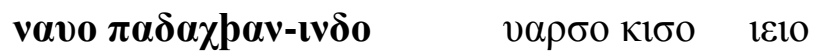

so that NEG.have authority.PRS.3p any one DEM

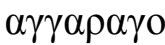

property

"so that no-one has authority",577

In the following example, the indefinite pronoun $\kappa \iota \sigma o$ is used with a singular verb:

(jc 3-6)

(346) $\mu 1 \sigma 1 \delta o$ moreover

$$
\alpha \beta O \quad 1
$$

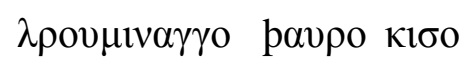

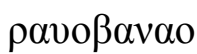

$\lambda \eta \rho \eta 10$

PRE ART enemy

city no-one

highway

robbery

have.OPT.3s

"Moreover, no-one would commit highway robbery in the city of the enemy."578

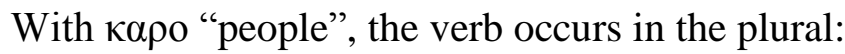

\footnotetext{
${ }^{574}$ Sims-Williams 2007a: 95.

${ }^{575}$ Sims-Williams 2000a: 121.

${ }^{576}$ Sims-Williams 2000a: 117.

577 Sims-Williams 2000a: 121.

${ }^{578}$ Sims-Williams 2007a: 129.
} 
(X 22)

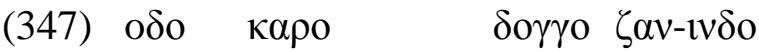

and people thus bear witness.PRS.3p

"and the people bear witness thus...,"579

With $\alpha \sigma \tau \omega \rho \delta$ o "cattle", the verb tends to occur in the plural:

(cq 7)

(348) $\tau \alpha \delta o-\mu$

$\alpha \sigma \tau \omega \rho \delta$ o $\quad \tau \alpha \rho o \quad \varphi \circ \tau \tau \delta \delta-\imath \delta \delta$ o

then-I.CP cattle thither send.PST.3p

"So I have sent the cattle (?) thither (to you).,

\subsection{Summary}

The position of the verb is flexible in Bactrian. It may occur in the beginning, middle, or at the end of the clause, but it most frequently occurs in final position. With some special verbs, an infinitive occasionally occurs. When there are two verbs in a construction, we observe one of the following variants:

Table 31. Constructions with two verbs

\begin{tabular}{|l|}
\hline 1- Verb (inflected) + INF without $\alpha \beta \mathrm{o}$ \\
\hline 2- Verb (inflected) + INF with $\alpha \beta \mathrm{o}$ \\
\hline 3- INF without $\alpha \beta \mathrm{o}+$ Verb (inflected) \\
\hline 4- INF without $\alpha \beta \mathrm{o}+$ Verb "to be" (inflected) \\
\hline
\end{tabular}

The enclitic form of the verb "to be" can be attached to different classes of words like substantives, adjectives, infinitives, adverbs, and negative particles. It occurs always as the last enclitic.

In non-ergative constructions, the verb usually agrees with its subject in number and person. With pluralia tantum and some special words, the verb exhibits no agreement. With indefinite pronouns, the verb may occur both in the singular and plural.

\subsection{Passive and ergative constructions}

Many linguists believe that either passive or ergative can be observed in a language. For example, according to Dixon:

Passive in a syntactically accusative language and antipassive in a syntactically ergative language will coincide. This effectively assumes that all languages have either an S/O or an S/A pivot, and that passive occurs only if there is an S/A pivot and antipassive only if there is an $\mathrm{S} / \mathrm{O}$ pivot. ${ }^{581}$

But there are some Iranian languages, such as Northern Kurdish, in which both constructions exist. The question arises here whether Bactrian possesses ergative, passive, or both. In my $2009 \mathrm{~b}$ article on "Ergativity in Bactrian", ${ }^{582}$ I discussed different ergative constructions. Here, in this chapter, I try to show whether passive can be found in Bactrian. First, I will look at the different opinions about the origin of ergativity and the relationship between Old Persian and Middle Persian in the case of passive and ergative constructions.

\footnotetext{
${ }^{579}$ Sims-Williams 2000a: 141.

${ }^{580}$ Sims-Williams 2007a: 97.

${ }^{581}$ Dixon 1994: 233.

${ }^{582}$ See Gholami 2009b: 132-141.
} 
Many scholars believe that the ergative construction in Iranian languages arises from a passive construction and the underlying structures in the ergative languages are passive. The following more recent statement of these views stems from Comrie:

Diachronically, however, there is good evidence that some instances of morphological ergativity do arise from passive constructions, through loss of the corresponding actives. The best evidence comes from the development of ergativity in the Indo-Iranian languages (Pirejko 1968), especially in the Indic languages; these languages typically are ergative only in the past tense form or, more restrictedly still, in the perfective past forms. ${ }^{583}$

He also writes:

... passive tends to be more frequent with the perfect aspect (in particular the perfect of result) than with other verbal forms (Comrie 1976a: 84-86); in the development of the ergative in Indo-Iranian, the ergative is first found only in the perfect, and the later wider range of ergativity follows from the extension of these forms to oust all other past perfective forms... ${ }^{584}$

To clarify this topic, we compare a Middle Iranian language which has ergativity, for example, Middle Persian, with an Old Iranian language, for example, Old Persian. In the following, some examples of both languages are given:

\section{Old Persian}

(a) (tya) manā kartam

(what) I.GEN done.pp.NOM.NE

"(what) was done by me"

(c)

$\begin{array}{lll}\text { (tya) } & \text { adam } & \text { akunavam } \\ \text { (what) I.NOM } & \text { do.IMPF.1s } \\ \text { "(what) I did" } & & \end{array}$

Middle Persian

(b) man kird

I.OBL do.PST.3s

"I did"

(d) az kunam

I.DIR do.PRS.1s

"I do."

In sentence (a), a genitive personal pronoun with a perfect participle is used. This construction appears to be a passive. In sentence (b), the verb (which is in the third person singular) agrees with the object, i.e., "it", and not with the agent "I". On the other hand, the oblique form of man of the first person singular pronoun continues the old genitive, i.e., mana whereas the direct case form $a z$ "I" in sentence (d) continues the old nominative. According to Bynon, "the middle Persian construction had become ergative, since morphologically it resembled a passive while distributionally it belonged within the paradigm of the active verb." 585

While the accusative construction of the present tenses derives from the accusative construction of Old Iranian, the ergative construction of the past tenses must be derived from the Old Iranian perfect participle in -ta-. Cardona (1970) believes that Old Persian used three passive constructions:

\section{1. $R$-ta+N-GEN (for the perfect)}

In this construction, $\mathrm{R}$ designates a verb root, R-ta a participial form, and N-GEN a genitive form of a nominal expressing the agent of the action. Consider the following example:

\footnotetext{
${ }^{583}$ Comrie 1978: 370-371.

${ }^{584}$ Comrie 1978: 373.

${ }^{585}$ Bynon 1980: 154.
} 
(DB I, 26-28)

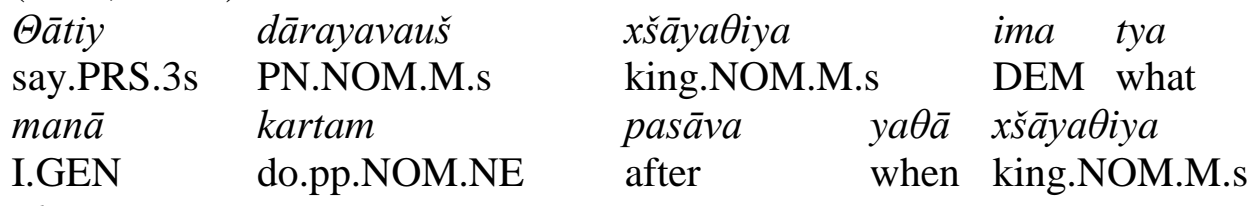

abavam

become.PST.1s

"Says king Darius: this is what I have done [according to Kent "what (was) done by me"] since I became king."

\section{2. haca $+N-A B L+R-y a($ for the present-imperfect)}

In this second construction, R-ya is a passive verb stem, and the combination of haca "from" and a nominal in the ablative case is used:

(DB I, 19-20)

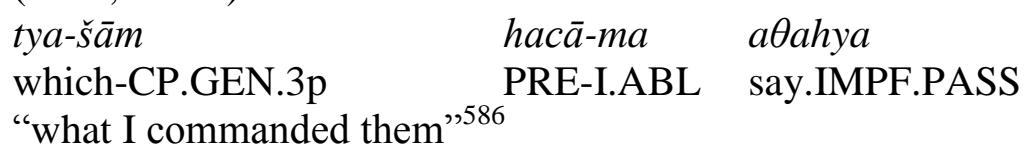

\section{3. $N-G E N+R-y a($ for the present-imperfect)}

In the third construction, N-GEN denotes the agent:

(DB V, 15-16)

(351)

$\begin{array}{llll}u t \bar{a}-\check{s} \bar{a} m & \text { Auramazdā naiy } & \text { ayadiya } \\ \text { and-CP.GEN.3p } & \text { Ahuramazda.NOM.M } & \text { NEG } & \text { worship.IMPF.PASS } \\ \text { "and by them Ahuramazda was not worshipped"587 } & \end{array}$

Kent (1953) notes that "there are two passive groups in Old Persian, those with the passive suffix -ya, which are always in passive in meaning and, those which are composed of the past participle with or without the verb "to be", which is usually omitted" ${ }^{588}$ At first we will focus on the first passive group.

There are three different interpretations of the mana krțam construction: 1 . the possessive interpretation, which was contested by Benveniste (1952) and Anderson (1977) 2. the passive interpretation put forward by others, Cardona (1970), Skjærvø (1985) and Statha-Halikas (1979) and 3. neither a passive nor a possessive, advocated by Haig (2008). Haig points out that the manā krtam construction is based on a passive, but this type of participial construction is not a passive of the same order as the synthetic passives and interprets the constructions such as in the following example as an intransitive sentence with an adjectival predicate.

(XPa 13-14)

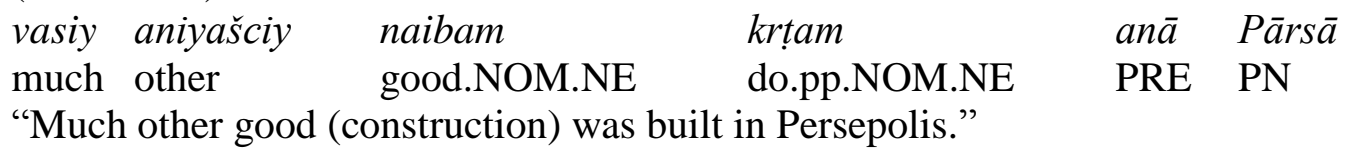

Haig also notes that the construction was not exclusively used to express possession, but it was one of the readings available, along with benefactive, experiencer, possessor, recipient and indirect object. ${ }^{589} \mathrm{He}$ adds:

\footnotetext{
${ }^{586}$ Cardona 1970: 2.

${ }^{587}$ Kent 1953: 134.

${ }^{588}$ Kent 1953: 88.

${ }^{589}$ Haig 2008: 86.
} 
the Middle Iranian 'ergative construction' does not demonstrably differ syntactically from the Old Persian m. k. construction. The differences are located primarily in the massively increased frequency of the construction, which by Middle Iranian had advanced to the sole means of expressing past transitive propositions. ${ }^{590}$

\subsubsection{Passive in Bactrian}

In comparison with other Middle Iranian languages like Middle Persian and Parthian, there are only a few examples that we can introduce as passive constructions in Bactrian. For example in Parthian and Middle Persian the past passive is formed by $\mathrm{pp}+(\mathrm{a}) \mathrm{h}-$ and present passive by

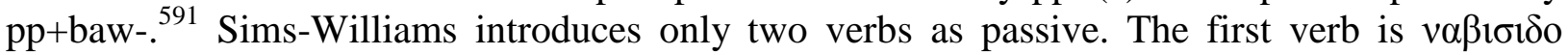
(write.PRS.PASS.3s) which is mentioned with a question mark:

(J 30-31)

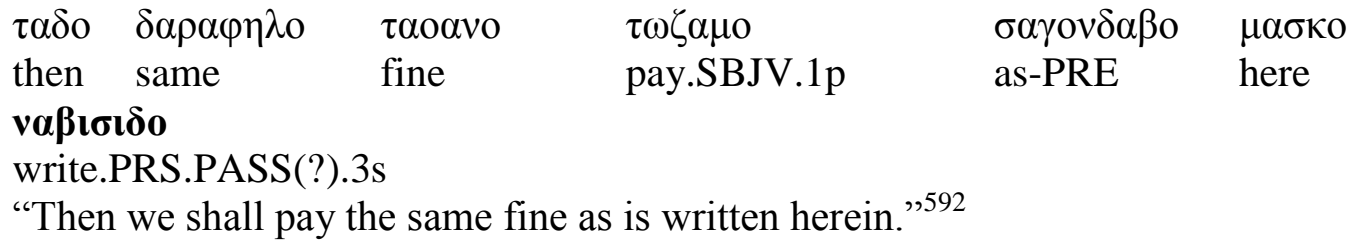

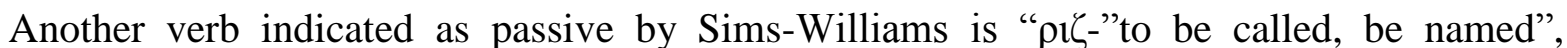
passive to $\rho \alpha \zeta-" .593$ The third person and present form of this verb is used in different texts. In this case the present stem is changed, whereas in the case of $v \alpha \beta 1 \sigma 1 \delta o$, the present stem is changeless:

\section{(A 2)}

$$
\begin{aligned}
& \alpha \beta o \quad \text { но } \quad \rho \omega \beta \alpha v \gamma \gamma_{0} \\
& \text { PRE ART of(the city) Rob }
\end{aligned}
$$

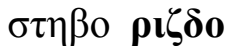

$$
\begin{aligned}
& \text { papo } \quad \text { } \beta \text { 11o } \quad \alpha v \delta \alpha \gamma o \quad \sigma, \delta o \\
& \text { Steb call.PASS.3s } \\
& \text { "in the city of Rob, in the borough which is called Steb" }
\end{aligned}
$$

It must be added that many constructions in which a past verb or a past participle as adjective with the verb "to be" are used have a passive meaning. The verb "to be" can be omitted in some cases and therefore we have only a past participle as adjective but with the meaning of passive:

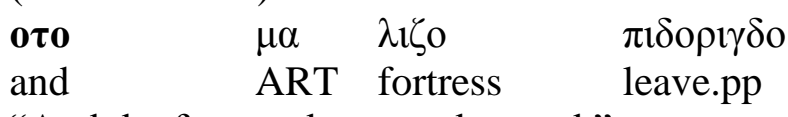

"And the fortress became deserted."

In the following example the past and third person of this verb is used. But it functions as a passive verb:

\footnotetext{
${ }^{590}$ Haig 2008: 87.

${ }^{591}$ Sundermann 1989a: 128-129.

592 Sims-Williams 2000a: 61.

${ }^{593}$ See Sims-Williams 2007a: 260.

${ }^{594}$ Cf. Sims-Williams 2000a: 33 and Sims-Williams 2007a: 35.
} 
(M 2-5)

\begin{tabular}{|c|c|c|c|c|c|c|}
\hline $\begin{array}{l}\pi \circ \zeta \zeta o \\
\text { debt }\end{array}$ & $\begin{array}{l}\alpha \beta o \rho \alpha \delta \alpha v o \\
\text { repayment }\end{array}$ & $\begin{array}{l}\delta \delta \rho \alpha \chi \mu o \\
\text { dirham }\end{array}$ & $\begin{array}{l}\kappa о \alpha \delta \alpha \gamma o \\
\text { PN }\end{array}$ & $\begin{array}{l}\gamma^{\prime} \\
\text { three }\end{array}$ & $\begin{array}{l}\alpha \sigma \pi \text { о } ү \gamma о \\
\text { complete }\end{array}$ & $\begin{array}{l}\alpha \sigma 1 \delta \boldsymbol{\alpha} \sigma \mathbf{0} \\
\text { which-PRE }\end{array}$ \\
\hline & $\pi \alpha \rho o$ & & $\gamma 0 \alpha \sigma \tau \alpha \delta \delta$ & & & \\
\hline
\end{tabular}

"(as) repayment of a debt, the three dirhams of (king) Kawad, which had been loaned by Moyan,"599

There are also other constructions which could be interpreted as passive. In these constructions, it seems that $\beta$ oo- "become" plays the role of an auxiliary verb and indicates a passive construction. In this case, it is used with a past participle:

(eb 16-17)

(361) odo кıро

and IMP.2s

$\kappa о 0 \alpha \delta o$

$\mu \alpha \rho o$

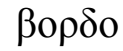

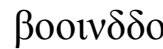

"and you should act (in such a way) that they be brought hither"600

(dc 4-5)

(362) $\tau \alpha \delta \mathrm{o} \kappa \iota \eta \delta о$

so IMP.2sp

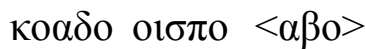

$\lambda \alpha \delta$ ок $\alpha$ vo

PN pp. brought

$\beta$ oow $\delta \alpha \delta o$

SBJV.3p

"so you should act (in such a way) that they are all taken to Ladkan"601

(dc 5-6)

(363)

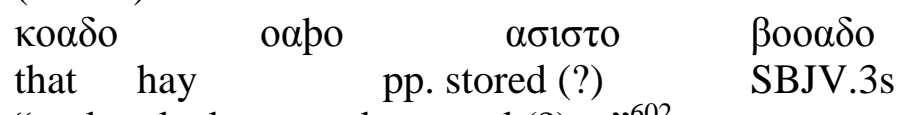

“...that the hay may be stored (?)..."602

\subsection{Summary}

In Bactrian, there are both passive and ergative constructions. We can therefore conclude that Bactrian is a language which has a mixture of passive and ergative.

There are three kinds of constructions in Bactrian which could be interpreted as passive. Because of the limited texts, it is not possible to formulate an exact statement. Two verbs, namely, $v \alpha \beta 1 \sigma i \delta o$ and $\rho 1 \zeta \delta o$, have a passive formation, which are comparable to Old Iranian verbs with the passive suffix -ya. But it is not really clear whether constructions with these verbs are passive or not. In Bactrian, we can also find some constructions in which the past participle is used, though these have a passive meaning. In other constructions, the verb is past but the agent is not expressed. In this case, the verb occurs in the third person singular. As the agent is a core element in ergative constructions, it would be better to classify these constructions as passive. In both present and past constructions, we have examples of the use of the preposition $\alpha \sigma o$ "with", which is used with an agent. These constructions could also be interpreted as passive. In Middle Persian, the present passive is expressed by the construction pp+baw-. ${ }^{603}$ In Bactrian, we find the same construction in three examples. Finally, regarding the last point, we can conclude that in the case of passive constructions, Bactrian shares similarities with Western

\footnotetext{
${ }^{599}$ Sims-Williams 2000a: 72.

${ }^{600}$ Sims-Williams 2007a: 111.

${ }^{601}$ Sims-Williams 2007a: 103.

${ }^{602}$ Sims-Williams 2007a: 103.

${ }^{603}$ Sundermann 1989a: 128-129.
} 
Middle Iranian languages. The same characteristic can be also observed in the case of ergativity. ${ }^{604}$

\subsection{Auxiliary verbs}

The verbs $\beta$ o- "to be, to become", $\alpha \sigma \tau$ o "to be", pr "can, must", can be used as or auxiliary verb in Bactrian. The verbs "to have" ( $\lambda \eta \rho$ - in Bactrian) however, can only function as full verbs in Bactrian, while in other languages, it can function as both full and auxiliary verbs.

An auxiliary verb can be commonly used in forming passive, progressive, or perfect constructions, or it may function as a modal.

In Bactrian the verb $\alpha \sigma \tau$ o "to be" as an auxiliary verb has the following functions:

\section{Forming the forms from the past stems}

The enclitic form of the verb "to be" is added occasionally to the past stems to form different verbal past forms, as in the following tenses: ${ }^{605}$

\section{Perfect}

The perfect is formed with past participle $+-\gamma_{0}+$ verb "to be". In the following example, the third person, plural, present indicative form of the verb "to be" $-1 v \delta o$, is added to a past participle, i.e., $v \alpha \beta \imath \tau \tau \imath \gamma o$ :

(364) $\pi \mathrm{\imath} \delta \mathrm{o}$

$\pi \alpha \delta o v \alpha \mu o v \delta \delta \imath \gamma \alpha v o \quad v \alpha \beta \imath \chi \tau \imath \gamma-\mathbf{l v \delta o}$

PRE boundary write.PF.3p

"has been stated with reference to the boundary" 606

\section{Pluperfect}

The full form of the verb "to be" can also be used with a past participle. In the following

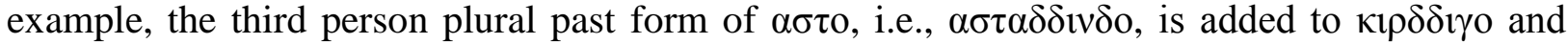
forms a pluperfect:

(M 4-5)

(365) $\alpha \sigma 1 \delta-\alpha \sigma o$ which-PRE PN loan.PLUP.3p

"which had been loaned by Moyan"

\section{Past Subjunctive}

The negative form of $-\alpha \delta$ o is used to indicate the negative form of a past subjunctive verb, as shown in the following example:

(be 17)

(366) $\tau \alpha \lambda \mathrm{o} \quad v \alpha \delta o . \alpha \gamma \alpha \delta \mathrm{o}$

here NEG.PST.SBJV.3s

"[if...] should not have come here" 608

\footnotetext{
${ }^{604}$ See Gholami 2009b: 49.

${ }^{605}$ Examples of perfect verbs are very rare in Bactrian. Sims-Williams classifies only the above verbs as perfect and pluperfect.

${ }^{606}$ Sims-Williams 2000a: 59.

${ }^{607}$ Sims-Williams 2000a: 73.

${ }^{608}$ Sims-Williams 2007a: 61.
} 


\section{Negation}

The auxiliary verb "to be" is used very commonly to form the negative form of verbs. The following negative forms of the verb "to be" are used in the extant material:

Table 32. NEG Auxiliary

\begin{tabular}{|l|l|l|}
\hline NEG. Auxiliary & Positive form/Tense & Function \\
\hline$v 1 \sigma \tau o$ & $-1 \sigma \tau \mathrm{o} /$ PRS.IND.3s & $3 s . P S T . I N D$ \\
\hline$v \imath v \delta o$ & $-1 v \delta \mathrm{o} /$ PRS.IND.3p & $3 p . P S T . I N D$ \\
\hline$v \alpha \delta o$ & $-\alpha \delta \mathrm{o} /$ PRS.SBJV.3s & 3 s.PST.SBJV \\
\hline
\end{tabular}

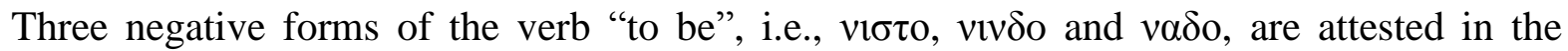
extant material. The negative particle $v \alpha$ - is added directly to the enclitic forms of the verb "to

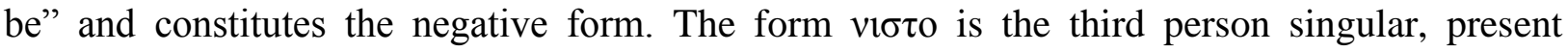
indicative, while the form $v \mathrm{v} \delta \delta$ is the third person plural, present indicative and $v \alpha \delta o$ is the third person, present subjunctive. It must be added that only in these tenses does the negative form of the verb "to be" occur. In other cases, only negative particles are used. ${ }^{609}$

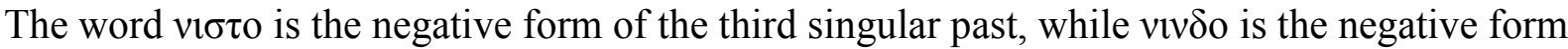
of third plural past and $v \alpha \delta o$ is the negative form of third singular past subjunctive.

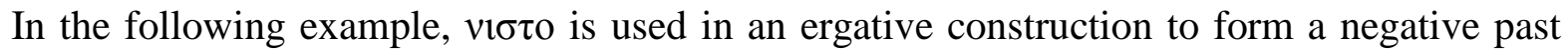
verb. In this case, the verb "to be" occurs in the present indicative form with a past main verb:

(cp 29)

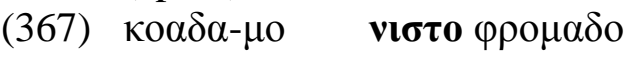

that-I.CP NEG.order.PST.3s

"that I did not order" 610

The negative form of the verb "to be" as an auxiliary may also occur with an intransitive verb, as in the following example:

(U 9)

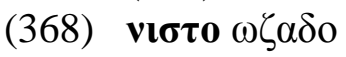

NEG.to be a liability.PST.3s

"was no liability" 611

In the following example, vivסo occurs with a past verb:

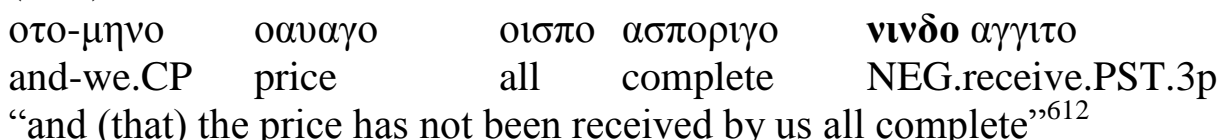

In the following example, $v \alpha \delta o$ is used with the verb $\alpha \gamma \alpha \delta o$, which is past and subjunctive:

(be 17)

(370) $\mathbf{v \alpha \delta o} \alpha \gamma \alpha \delta o$

NEG.come.PST.SBJV.3s

"should not have come here" 613

\footnotetext{
${ }^{609}$ For negation and prohibition in Bactrian, see Sims-Williams 2007a: 47.

${ }^{610}$ Sims-Williams 2007a: 29.

${ }^{611}$ Sims-Williams 2000a: 109.

612 Sims-Williams 2000a: 59, 61.

${ }^{613}$ Sims-Williams 2007a: 61.
} 


\section{Forming passive}

The verbs $\beta$ - "to be, to become" is used three times in our corpora to indicate a passive construction. (see the examples 359-363)

\subsubsection{The syntactic position of the auxiliary verb}

From the above examples we can understand that an enclitic form of the auxiliary verb is suffixed to a main verb (example (364)), and we see that the full form of auxiliary occurs after that (example (365)). But in the case of negation, the negative form of auxiliary occurs before the main verb (examples (369), (370)).

In the case of negative auxiliaries, the negative particle is attached directly to the enclitic forms of the auxiliary verbs. In the extant material, only the third singular present and subjunctive and third plural present tense of auxiliary verb "to be" are used. The other forms of the auxiliary verb "to be" are not found in the present texts.

\subsubsection{Summary}

The enclitic or full form of the verb $\alpha \sigma \tau$ o "to be" may be used as an auxiliary verb in Bactrian. It may occur in past forms as perfect and pluperfect.

Some verbal forms are negated by negative forms of the verb "to be". Only three negative forms of the verb "to be" are attested in the extant material. As an enclitic form, it is attached to main verbs and as a full form it occurs usually after main verbs. The negative form of the verb "to be" always occurs before the main verb. The verb $\beta$ o- "to be, to become" is used with a past participle to indicate a passive mood. It occurs in all examples after past participle. 


\section{CHAPTER NiNE: WORD ORDER}

In this chapter, we focus on different varieties of word order in Bactrian and try to find a basic or a typical word order. First, we concentrate on word order in intransitive clauses and then on word order in transitive clauses and double oblique constructions.

\subsection{Intransitive verbs}

There are different varieties of word order in sentences with intransitive present tense verbs: S-V and V-S. They are shown here:

\section{S-V}

In the example here, the verb "to be" follows the subject:

(W 8-9)

\begin{tabular}{|c|c|c|c|}
\hline $\begin{array}{ll}\alpha \sigma 1 \delta \text { o } & \mu \alpha \chi 0 \\
\text { which } & \text { we.UFL }\end{array}$ & $\begin{array}{l}\boldsymbol{\alpha} \sigma \tau \mathbf{0} \\
\text { be.PRS.3s }\end{array}$ & $\begin{array}{ll}\alpha \beta \beta o & \text { odo } \\
\text { water } & \text { and }\end{array}$ & $\begin{array}{l}\zeta \alpha \mu 1 \gamma o \alpha \gamma \gamma \alpha \rho \alpha \gamma o \\
\text { land property }\end{array}$ \\
\hline
\end{tabular}

V-S

In the next example, the verb occurs before the subject:

$(\operatorname{cd} 3-4)$

(372) $\mu 1 \sigma 1 \delta o$ moreover arrive.PST.3s here PRE SPD lordship letter "Moreover a letter has come hither from your lordship." 615

In this example, the verb occurs after the conjunction $\mu 1 \sigma 1 \delta o$, and the subject is at the end of the sentence.

\subsection{Transitive verbs}

\section{O-S-V}

In the following example, the verb occurs in final position:

(eg 4-5)

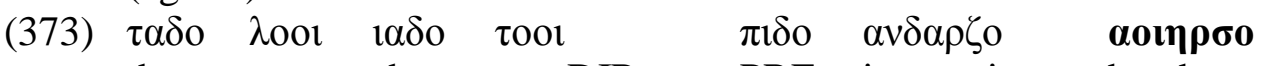
then two share you.DIR PRE instruction hand over. IMPV.2s "You should hand over two shares according to instructions."

\section{O-V}

In this case, the subject is omitted and the verbal ending indicates the number and person of the subject:

\section{(T 11)}

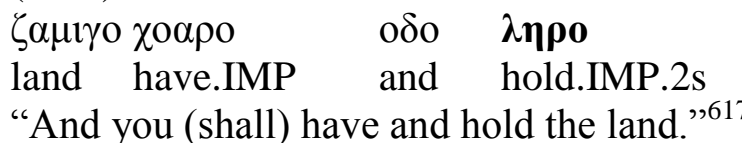

\footnotetext{
${ }^{614}$ Sims-Williams 2000a: 127.

${ }^{615}$ Sims-Williams 2007a: 75.

${ }^{616}$ Sims-Williams 2007a: 121.

${ }^{617}$ Sims-Williams 2000a: 101.
} 
Another example follows:

(375) $\chi 1 \rho \sigma 0$ purchase purchasable have.OPT.2p and hold.OPT.2p

"You may have and hold a purchase which may be purchased."

In the above examples, the sentences begin with an object and end with a verb.

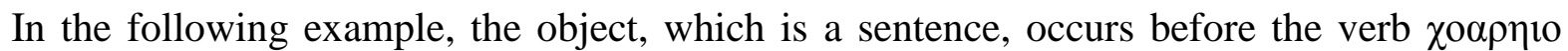
"have" and $\lambda \eta \rho \eta 10$ "hold":

(C 12-13)

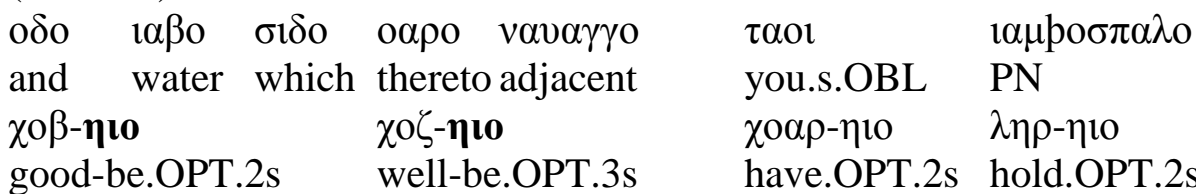

"And the water which (is) adjacent thereto may belong properly and belong well to you, Yamsh-spal, you may have (and) hold (it)."

\section{V-S-O}

In the following example, the sentence begins with a verb:

(Document No.1, 1-4)

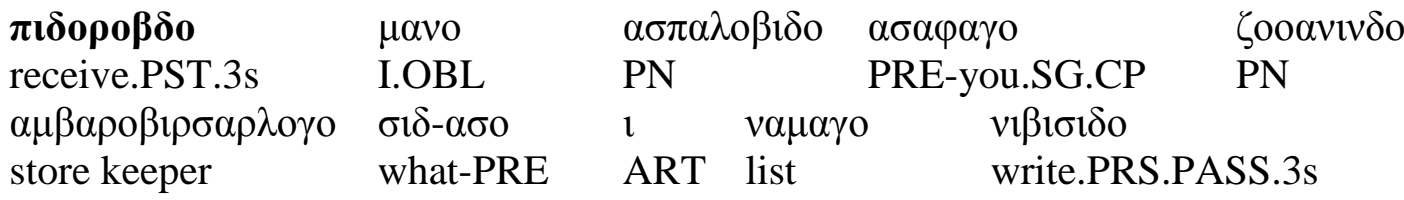

"I, Aspal-bid, have received from you, Zuwanind the store keeper, what is written in this list." $" 620$

In the above example, the subject, i.e., $\mu \alpha v o \alpha \sigma \pi \alpha \lambda o \beta 1 \delta o$ "I, Aspal-bid", follows the verb and the object, i.e., $\sigma 1 \delta \alpha \sigma o l v \alpha \mu \alpha \gamma o v i \beta 1 \sigma 1 \delta o$ "what is written in this list", which is a relative sentence, occurs in the final position.

\section{S-V-O}

In the following examples, the subject is an enclitic pronoun suffixed to a conjunction and a verb follows it. The object occurs at the end of sentence. Here a prepositional phrase appears before the object:

$$
\text { (cq11-12) }
$$

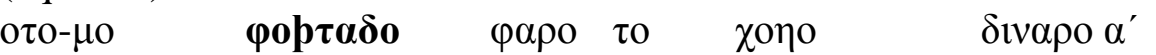
and-I.CP send.PST.3s PRE SPD lordship dinar one "And I have sent one dinar for your lordship."

Another example:

(xо 11)

\begin{tabular}{|c|c|}
\hline $\begin{array}{l}\sigma \imath \delta o-\mu o \\
\text { which-I.CP }\end{array}$ & $\begin{array}{l}\boldsymbol{\lambda} \boldsymbol{\alpha} \boldsymbol{\delta} \mathbf{0} \\
\text { give.PST 3s }\end{array}$ \\
\hline
\end{tabular}

\footnotetext{
${ }^{618}$ Sims-Williams 2000a: 69.

${ }^{619}$ Sims-Williams 2000a: 40.

${ }^{620}$ Sims-Williams 2000b: 5 .

${ }^{621}$ Sims-Williams 2007a: 97.
} 


\section{S-O-V}

This type of word order is not very common in Bactrian.

\begin{tabular}{|c|c|c|c|}
\hline$\mu 1 \sigma \iota \delta o \imath \eta v o$ & $\alpha \sigma o$ & 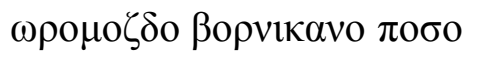 & $\zeta \mathbf{l} \delta-\mathrm{tv} \delta 0$ \\
\hline moreover-they.CP & PRE & $\begin{array}{ll}\text { PN } & \text { sheep }\end{array}$ & took.PST-3p \\
\hline$\pi \alpha \rho \alpha \sigma \alpha \rho \lambda \circ$ & & & \\
\hline vo last year & & & \\
\hline
\end{tabular}

This construction is very unusual, because the verb occurs between a noun and its number,

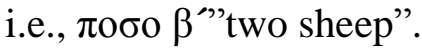

\subsection{Double object constructions}

Now let us point out some specific features of double object constructions in Bactrian. In languages with four cases, like German, the direct object occurs in accusative case and the indirect object in dative case. In another group of languages, which includes English, an indirect object "may appear either as the object of a preposition or as one of two noun phrase objects of the verb, the other being the direct object". ${ }^{624}$ First, we try to discover the kind of double objects in Bactrian and then we move on to discuss the character of these constructions.

There are different categories of double oblique constructions in the extant Bactrian material. In the first group, the direct object occurs before the indirect object. The different varieties are summarized here:
(Ia)
DIR.O
CP
INDIR.O
V
$S$ (indicated by verbal ending)

In the following example, both the direct object which is an enclitic pronoun and the indirect object which is marked by a preposition are in oblique case. We can therefore conclude that this construction has a double oblique system:

(ci 6)

(381) $\tau \alpha \delta o-\eta \eta 10 \quad \varphi \alpha \rho \mu \mu \alpha \gamma o \quad \lambda \alpha v-\eta 10$

then-it.CP PRE-I.CP give.OPT-2s

"And you should give it to me.",625

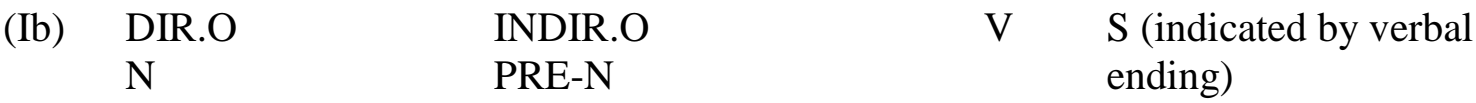

In the same group, the direct object may be a noun and the indirect object another noun which is marked by a preposition:

$(\mathrm{xb} 7-8)$

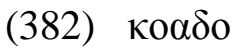

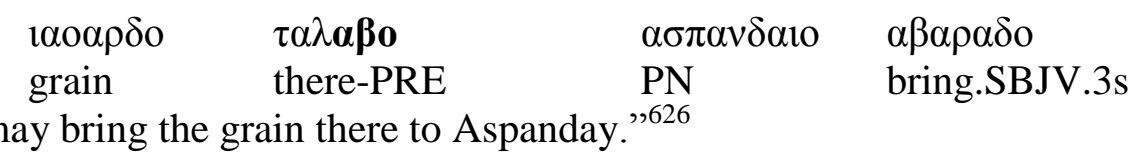

(Ic) DIR.O INDIR.O indicated by verbal ending (in an ergative construction) $\mathrm{N}$

\footnotetext{
${ }^{622}$ Cf. Sims-Williams 2007a: 161.

${ }^{623}$ Sims-Williams 2007a: 119.

${ }^{624}$ Emonds and Whitney 2006: 74.

${ }^{625}$ Sims-Williams 2007a: 85.

${ }^{626}$ Sims-Williams 2007a: 141.
} 
In the next case, there is no independent indirect object; rather, it is indicated by the verbal ending:

(Ii 6-7)

(383) $\eta \beta о \delta \alpha \lambda \alpha \gamma \gamma о \quad \tau \omega \gamma \gamma о$

Hephthalite tax gold and sheep charge.PST-1s

"[And they] have charged me gold and sheep for the Hephthalite tax." 627

$\begin{array}{llll}\text { (Id) } & \mathrm{S} & \text { DIR.O } & \text { V-INDIR.O } \\ & \mathrm{PN} & \mathrm{N} & \text { V-CP }\end{array}$

The indirect object in the form of an enclitic pronoun can be suffixed to the verb:

(Y 6-7)

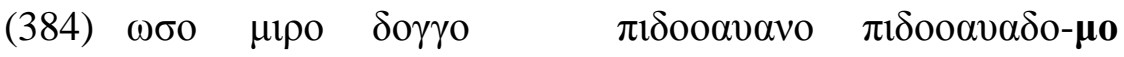

now PN thus request request.PST.3s-I.OBL

"Now Mir has thus made a request to me",628

(Ie) DIR.O $\quad \mathrm{V} \quad \mathrm{S}$ (indicated by verbal ending) INDIR.O

$\mathrm{N} \quad$ PRE+N

In (Ie), the direct object occurs before the indirect object, but the verb stands between them: (Q 29-30)

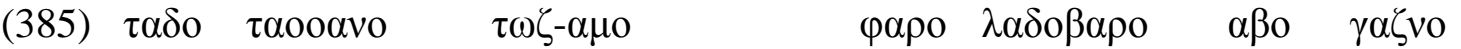

then fine pay.SBJV-1p PRE judge PRE treasury

"Then we shall pay a fine to the judge, to the treasury"629

In the second group, the indirect object occurs before the direct object:

$\begin{array}{llll}\text { (IIa) INDIR.O } & \text { DIR.O } & \text { V } & \text { S (indicated by verbal ending) } \\ \text { PRE-N } & \mathrm{N} & & \end{array}$

In this case, both the direct and indirect object are nouns, and the indirect object is marked by a preposition:

(bb 10-11)

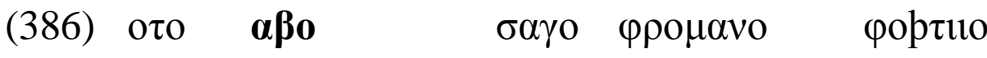

and PRE PN order send.IMPV.2s

"And you should send an order to Sag"630

$\begin{array}{llll}\text { (IIb) INDIR.O } & \text { DIR.O } & \mathrm{V} & \mathrm{S} \text { (indicated by verbal ending) }\end{array}$

$\mathrm{CP} \quad \mathrm{N}$

In (IIb) the indirect object is an enclitic pronoun, and the direct object is a noun:

(ci 13-14)

(387) $\alpha \sigma 1 \delta o-\imath \eta 10$

then-he.CP immediately land give.SBJV-1s

"Then I will give him the land immediately"631

$\begin{array}{llll}\text { (IIc) INDIR.O } & \text { DIR.O } & \mathrm{V} & \text { S (indicated by verbal ending) } \\ \text { PRON.OBL } & \mathrm{N} & & \end{array}$

${ }^{627}$ Sims-Williams 2000a: 53.

${ }^{628}$ Sims-Williams 2000a: 145.

${ }^{629}$ Sims-Williams 2000a: 91.

${ }^{630}$ Sims-Williams 2007a: 55.

${ }^{631}$ Cf. Sims-Williams 2007a: 85. 
In the following example, the indirect object is a full pronoun in the oblique case, and the direct object is a noun in the direct case:

(cf 8-9)

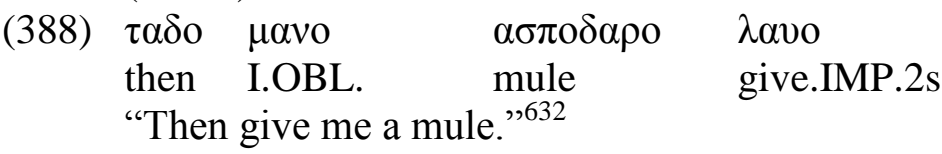

$\begin{array}{llll}\text { (IId) } & \mathrm{S} \quad \mathrm{V} & \text { INDIR.O } & \text { DIR.O } \\ & \text { PRON } & \text { PRE-CP } & \mathrm{N}\end{array}$

In (IId), the indirect object occurs before the direct object, but the verb stands before the indirect object. The indirect object is an enclitic pronoun, which is marked by a preposition. The direct object is a noun:

(U 6-7)

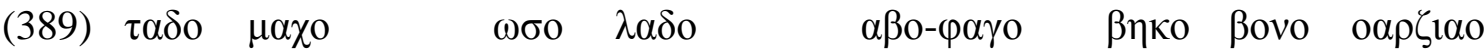
then we.UFL now give.PST.3s PRE-you.CP PN land farming "So now we gave the farming of the state to you, Bek.",633

(IIe) $\mathrm{S}$

PRON

\begin{abstract}
IND.O
\end{abstract}
PRE-PN

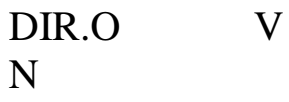

In the following example, the sentence begins with the subject, and an indirect object follows it. The direct object is used after the indirect object, i.e., $p \alpha \beta$ $\alpha о \pi \eta p o \lambda \alpha \delta \alpha v o$, and the verb occurs in final position:

$$
\text { (ea 4-5) }
$$

\begin{tabular}{|c|c|c|c|}
\hline$\mu \alpha v o$ & $\varphi \alpha \rho о$ & раßоро $\pi \eta р о \lambda \alpha \delta \alpha \nu o$ & $\mu \alpha \rho \sigma \kappa о \vee \delta о$ \\
\hline I.OBL & PRE & PN & staff \\
\hline$\pi \imath \delta о \rho \alpha \sigma \tau о$ & oঠo & $\pi 1 \delta \mathrm{o} \chi 0 \alpha v_{0}$ & \\
\hline ground & and & give.Ps & T.3s \\
\hline
\end{tabular}

\subsection{Summary}

Because of the lack of material, we cannot make an in-depth investigation of the word order in Bactrian. In the extant Bactrian material, there is no strict word order. In some languages, there are some differences between the word order in main clauses and subordinate clauses. It seems that the same word order can be observed in both main and subordinate clauses. We can find different varieties of word order like O-S-V, V-S-O, S-V-O and S-O-V in Bactrian texts, but $\mathrm{S}-\mathrm{O}-\mathrm{V}$ is the most frequent.

The position of the direct and indirect object is interchangeable in double oblique constructions. The following table presents the different varieties of double object constructions in Bactrian. If the subject is indicated by the verbal ending, subject is not mentioned:

\footnotetext{
${ }^{632}$ Sims-Williams 2007a: 79.

${ }^{633}$ Cf. Sims-Williams 2000a: 107.

${ }^{634}$ Sims-Williams 2007a: 109.
} 
Table 33. Double object constructions

\begin{tabular}{|l|l|l|l|l|}
\hline \multirow{4}{*}{ I } & $\mathrm{a}$ & DIR.O: CP & INDIR.O:PRE-CP & V \\
\cline { 2 - 5 } & $\mathrm{b}$ & DIR.O: N & INDIR.O:PRE+N & V \\
\cline { 2 - 5 } & $\mathrm{c}$ & DIR.O: N & & $\begin{array}{l}\text { V, INDIR.O: Verbal } \\
\text { ending }\end{array}$ \\
\cline { 2 - 6 } & $\mathrm{d}$ & $\mathrm{S}$ DIR.O: N & & V- INDIR.O: CP \\
\cline { 2 - 6 } & $\mathrm{e}$ & DIR.O: N & V & INDIR.O: PRE+N \\
\hline \multirow{4}{*}{ II } & $\mathrm{a}$ & INDIR.O: PRE+N & DIR.O: N & V \\
\cline { 2 - 6 } & $\mathrm{b}$ & INDIR.O: CP & DIR.O: N & V \\
\cline { 2 - 6 } & $\mathrm{c}$ & INDIR.O:PRON.OBL & DIR.O: N & V \\
\cline { 2 - 6 } & $\mathrm{d}$ & $\mathrm{S}$ & INDIR.O: PRE-CP & DIR.O: N \\
\cline { 2 - 5 } & $\mathrm{e}$ & $\mathrm{S}$ INDIR.O: PN & DIR.O: N & V \\
\hline
\end{tabular}




\section{Chapter Ten: Compounds}

In this chapter, I introduce the different types of compounds in Bactrian. In this regard, some points must be noted: first of all, the grammatical characteristics of the elements in the compound, and second, the syntactical connection of the members of compounds to each other and their meaning relationship in a sentence.

Compounds were researched by Brugmann in Indo-European languages ${ }^{635}$ and by Wackernagel in Old Indian. ${ }^{636}$ They introduced the types of the first and second elements of compounds, and they pointed out the different characteristics of components, such as case, gender, as well as special and rare stems, etc. In Bactrian, we do not find all these types and features.

\subsection{Bactrian compounds according to the grammatical feautures of elements}

Bactrian compounds consist almost exclusively of two elements. There are few examples of tripartite compounds. In Bactrian:

1. When the first element is a noun, the second element can be one of the following:

\section{a. Noun}

This group is the most common type

Examples:

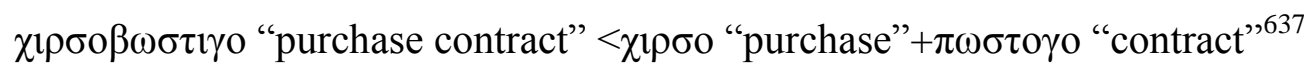

$\beta \alpha \gamma о \pi$ оро "son of the gods" $<*$ baga-pu $\theta \mathrm{ra}^{638}$

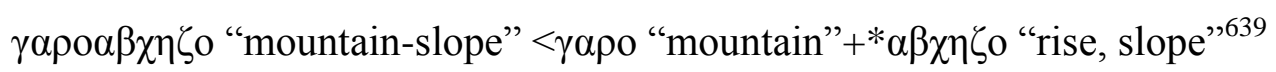

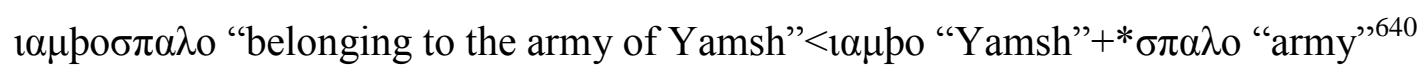

кораvopao "Kushan-shah" < кораvo "Kushan"+pao "king"641

$\alpha \beta \beta$ $\delta \alpha \chi \mu \mathrm{o}$ "watercourse, stream" $<\alpha \beta \beta \mathrm{o}$ "water" $+\tau \alpha \chi \mu \mathrm{o}$ "stream" 642

\section{b. Adjective}

\section{Examples:}

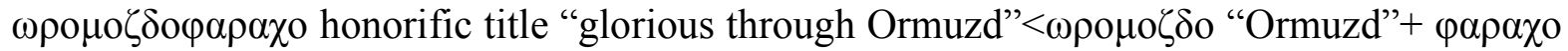
"glorious"643

$\alpha p \varphi \alpha \rho \delta \alpha \rho o$ "best (through) Fire" or "best (gift) of Fire" $<\alpha p-$ perhaps the name of a god "Fire"+ $\alpha \alpha \rho \delta \alpha \rho$ " more, better"644

\footnotetext{
${ }^{635}$ Brugmann 1906: 52-120.

${ }^{636}$ Wackernagel 1957: 24-329.

${ }^{637}$ Cf. Sims-Williams 2007a: 199.

${ }^{638}$ Cf. Sims-Williams and Cribb 1996: 91.

${ }^{639}$ Cf. Sims-Williams 2007a: 207.

${ }^{640}$ Cf. Sims-Williams 2010: 68-69.

${ }^{641}$ Cf. Sims-Williams 2007a: 225.

${ }^{642}$ Cf. Sims-Williams 2007a: 183.

${ }^{643}$ Cf. Sims-Williams 2007a: 282.
} 
$\sigma w 0 \rho \zeta \alpha \delta$ o "noble in respect of (her) lineage" <*Či $\theta$ r-āzātā-645

c. Suffix

There are different types of suffixes in Bactrian relating to the compound:

1. The first group may form verbal governing compounds i.e.,:- $\beta \alpha \rho \rho,-\beta \alpha \rho \gamma o,-\beta \alpha \rho \alpha \gamma o$; $\lambda \alpha \rho \circ,-\lambda \alpha \rho \gamma о(?),-\lambda \eta \rho о,-\lambda \eta \rho \gamma о,-\lambda \eta \rho \alpha \gamma о$

Examples:

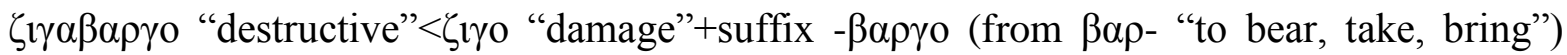
forming nomina agentis from nouns646

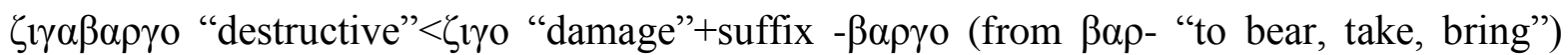
forming nomina agentis from nouns647

$\lambda \alpha \delta$ o $\beta \alpha \rho o$ "judge" $<\lambda \alpha \delta$ o "law" 648+suffix - $\beta \alpha \rho o$ forming nomina agentis from nouns "bearing"649

$\lambda 1 \sigma \tau$ oß $\alpha \rho o$ "manuscript" $<\lambda 1 \sigma \tau o$ "hand" $650+$ suffix $-\beta \alpha \rho o$ forming nomina agentis from nouns "bearing" 651

$\sigma \iota \rho, \lambda \alpha \rho$ "record-keeper" $<*$ * $\rho о$ "evidence" $652+$ suffix $-\lambda \alpha \rho$ forming nomina agentis from nouns653 (from $\lambda \eta \rho$ - "to have")

$\delta \delta \rho \alpha \gamma \gamma о \lambda \eta \rho о$ "official" $<*$ dranga- "office" $654+$ suffix $-\lambda \eta \rho 0$ forming nomina agentis from nouns655 (from $\lambda \eta \rho$ - "to have")

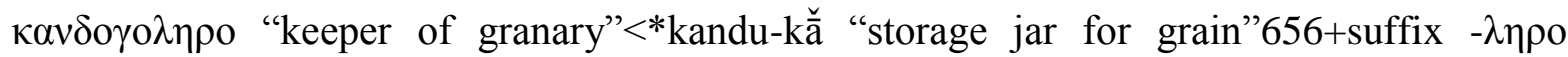
forming nomina agentis from nouns657 (from $\lambda \eta \rho$ - "to have")

$\lambda \iota \sigma \tau 0 \lambda \eta \rho \gamma_{0}$ "(person) in authority" $<\lambda \iota \sigma \tau 0$ "hand"658+ suffix $-\lambda \eta \rho \gamma o$ forming nomina agentis from nouns "keeping" 659

2. The second group are quasi-suffixes:

$-\gamma \alpha \rho \circ,-\gamma \alpha \rho \gamma o,-\lambda \alpha v_{0}$ “containing", $-\beta 1 \delta o$ forming titles and personal names, originally "chief, lord" $660,-\sigma \tau \alpha v o$ forming nouns, chiefly referring to places 661

\footnotetext{
${ }^{644}$ Cf. Sims-Williams 2010: 38.

${ }^{645}$ Cf. Sims-Williams 2010: 130.

${ }^{646}$ Cf. Sims-Williams 2007a: 212.

${ }^{647}$ Cf. Sims-Williams 2007a: 212.

${ }^{648}$ Cf. Sims-Williams 2007a: 225.

${ }^{649}$ Cf. Sims-Williams 2007a: 202.

${ }^{650}$ Cf. Sims-Williams 2007a: 227.

${ }^{651}$ Cf. Sims-Williams 2007a: 202.

${ }^{652}$ Cf. Sims-Williams 2007a: 264.

${ }^{653}$ Cf. Sims-Williams 2007a: 226.

${ }^{654}$ Cf. Sims-Williams 2007a: 208.

${ }^{655}$ Cf. Sims-Williams 2007a: 226.

${ }^{656}$ Cf. Sims-Williams 2007a: 221.

${ }^{657}$ Cf. Sims-Williams 2007a: 226.

${ }^{658}$ Cf. Sims-Williams 2007a: 227.

${ }^{659}$ Cf. Sims-Williams 2007a: 226.

${ }^{660} \mathrm{Cf}$. Sims-Williams 2007a: 203.

${ }^{661}$ Cf. Sims-Williams 2007a: 265.
} 


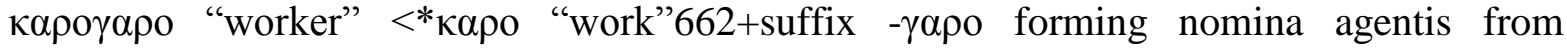
nouns663

$\alpha \beta \beta$ o $\alpha \alpha v_{0}$ "reservoir" $<\alpha \beta \beta o$ "water"+suffix- $-\lambda \alpha v o$, MP āb-dān664

$\lambda \alpha \beta 1 \rho о \beta 1 \delta$ o "chief scribe" $<\lambda \alpha \beta 1 \rho o$ "scribe"+suffix $-\beta 1 \delta$ o665

$\sigma \pi \alpha \lambda \mathrm{o} \beta 1 \delta$ o "army-commander"<*spāda-“army"666+ suffix - $\beta 1 \delta o 667$ (MP spāhbed)668

$\lambda \rho \gamma_{0} \sigma \tau \alpha v_{0}$ "(state of) health, well-being" $669<\lambda \rho \gamma_{0}$ "healthy"+ suffix $-\sigma \tau \alpha v_{0}$

These suffixes are not used in the Bactrian period as separate words and for this reason, I prefer to not classify this group as compound. But from the point of view of historical grammar, these suffixes were separate words at an earlier stage, and at that time, they could also be used to form compounds.

3. The third group of suffixes are ambiguous quasi-suffixes: $-* \gamma \varphi \delta \mathrm{o}^{670} ;-\delta \alpha v 0$ forming abstract nouns from nouns and adjectives ${ }^{671}$ These forms appear to be Middle Persian:

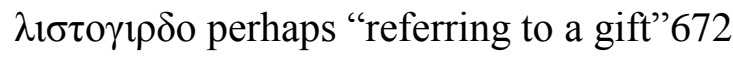

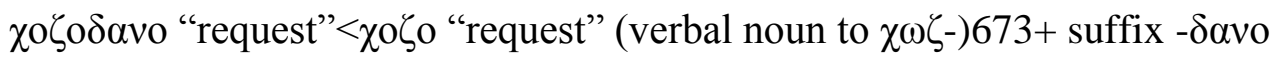

d. Adverb

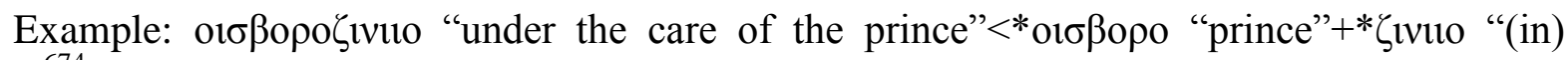
trust" ${ }^{\prime 674}$

e. pp or past stem

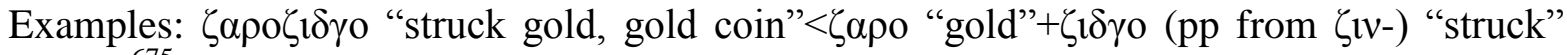
$(<* \text { jataka- })^{675}$

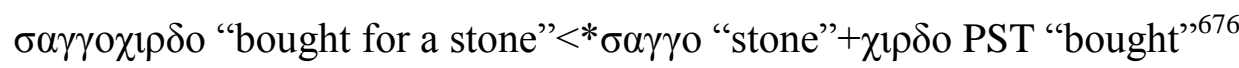

2. When the first element is an adjective, the second element can be:

a. Noun

This type is common in the extant materials.

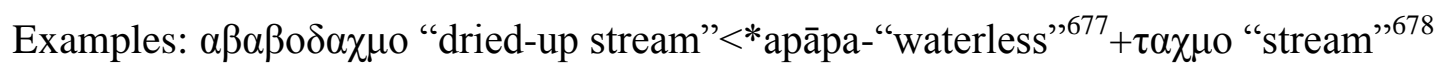

${ }^{662}$ Cf. Sims-Williams 2007a: 221.

${ }^{663}$ Cf. Sims-Williams 2007a: 206.

${ }^{664}$ Cf. Sims-Williams 2007a: 182.

${ }^{665}$ Cf. Sims-Williams 2007a: 225.

${ }^{666}$ Cf. Sims-Williams 2007a: 265.

${ }^{667}$ Cf. Sims-Williams 2007a: 203.

${ }^{668}$ Cf. Sims-Williams 2007a: 265.

${ }^{669}$ Cf. Sims-Williams 2007a: 228.

${ }^{670}$ This suffix is used also in two other Middle Persian PN i.e. $1 \propto \zeta \delta o \gamma \iota \rho \delta o$ and $1 \varepsilon 1 \zeta \delta o \gamma\llcorner\rho \delta o$.

${ }^{671}$ Cf. Sims-Williams 2007a: 208.

${ }^{672}$ Cf. Sims-Williams 2007a: 228.

${ }^{673}$ Cf. Sims-Williams 2007a: 280.

${ }^{674}$ Cf. Sims-Williams 2010: 109.

${ }^{675}$ Cf. Sims-Williams 2007a: 212.

${ }^{676}$ Cf. Sims-Williams 2010: 122.

${ }^{677}$ Cf. Sims-Williams 2007a: 181.

${ }^{678}$ Cf. Sims-Williams 2007a: 269. 


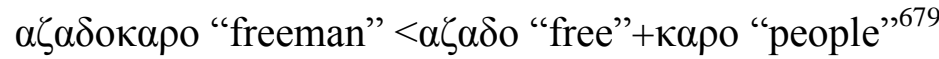

$\alpha \gamma \gamma \alpha \delta 0 \sigma \pi \alpha \lambda_{0}$ "belonging to the army of Fortunate (God)" $<*$ han-gata- "fortunate, rich"+ *spāda- "army" 680

The adjective can be comparative or supperlative, as in the following:

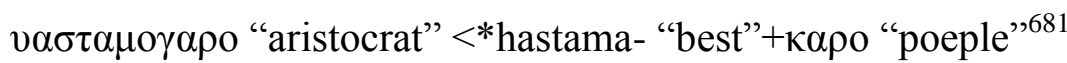

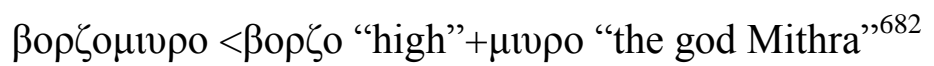

b. Adjective

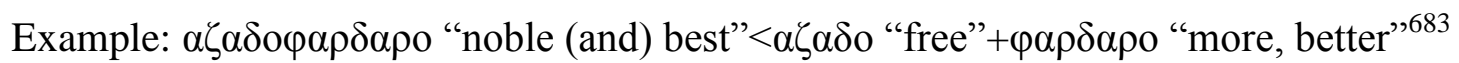

c. pp or past stem

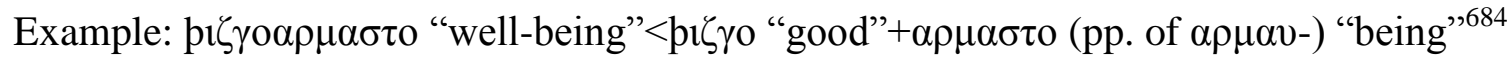

3. When the first element is a number, the second element can be a noun:

Example: $\sigma \alpha \delta \alpha 1 \omega \lambda \mathrm{o}$ "having a hundred warriors" $<*$ Satā-yauda- ${ }^{685}$

4. When the first element is a prefix, the second element can be a noun:

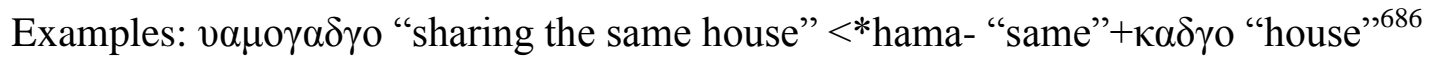

$\alpha \beta \eta \beta \imath \delta \delta$ " "detached", lit. "without bond" $<\alpha \beta \eta$ - "without" $+\beta \alpha v \delta o^{\text {"bond" }} 687$

$\chi о \alpha \kappa \alpha \mu$ o "acting willingly, acting freely in accordance with one's own wishes" $<\chi 0 \alpha$ "own, self"+*kāma- "wish, will”, ${ }^{8}$

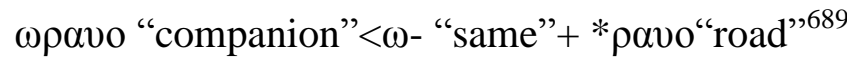

5. When the first element is a preposition, the second element can be:

a. Noun

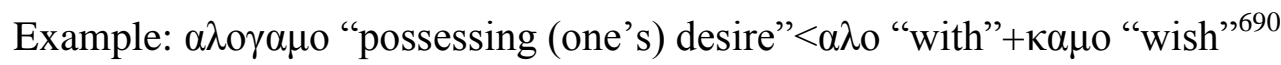

$\pi \alpha \delta \alpha \rho \lambda$ o 0 "opposite party"<*pati "against"+*arda "side" 691

b. Adjective

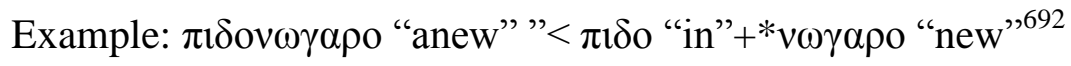

c. Adverb

${ }^{679}$ Cf. Sims-Williams 2007a: 188.

${ }^{680}$ Cf. Sims-Williams 2010: 30.

${ }^{681}$ Cf. Sims-Williams 2007a: 272.

${ }^{682}$ Cf. Sims-Williams 2010: 51.

${ }^{683}$ Cf. Sims-Williams 2010: 32.

${ }^{684}$ Cf. Sims-Williams 2007a: 284.

${ }^{685}$ Cf. Sims-Williams 2010: 122.

${ }^{686}$ Cf. Sims-Williams 2007a: 272.

${ }^{687}$ Cf. Sims-Williams 2007a: 183.

${ }^{688}$ Cf. Sims-Williams 2007a: 278.

${ }^{689}$ Cf. Sims-Williams 2007a: 282.

${ }^{690}$ Cf. Sims-Williams 2007a: 190.

${ }^{691}$ Cf. Sims-Williams 2007a: 250.

${ }^{692}$ Cf. Sims-Williams 2007a: 255 
Examples: $\alpha \beta \alpha \chi \rho \alpha v o$ "north" $<\alpha \beta$ o "to"+* $\alpha \chi \rho \alpha v o$ "north"693

$\alpha \beta \alpha v \delta \alpha \rho o$ "within, inside" $<\alpha \beta$ o "to" $+\alpha v \delta \alpha \rho o$ "inside",694

6. When the first element is a pp or past stem, the second part can be a noun:

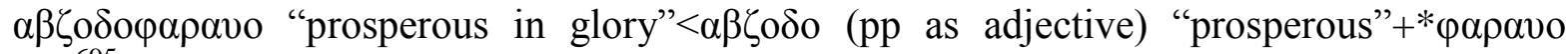
"glory",695

$\lambda \alpha \delta$ o $\alpha \gamma \alpha \lambda \gamma_{0}$ "by whom wishes are granted" $<\lambda \alpha \delta$ o "to give, to grant" ${ }^{696}+\alpha \gamma \alpha \lambda \gamma_{0}$ "wish" 697

$\lambda \alpha \delta$ o $\mu$ o $\delta$ o "by whom the reward is given" $<\lambda \alpha \delta$ o "given" $+* \mu o \zeta \delta o ~ " r e w a r d " 698$

\subsection{Classification of the two element compounds according to the syntactical connection of members to each other and their meaning relationship in a sentence}

\subsubsection{Exocentric}

In this construction, the subject does not occur in the compound, but rather outside of it.

Example: longlegs. It does not mean "long leg", but rather "a person who has long-legs". 699

\subsubsection{Bahuvrihi (possessive compound)}

Compounds with $*_{v 0{ }^{-}}{ }^{700}$ and $* v \alpha \mu-{ }^{701}$ as the first component belong to possessive compounds.

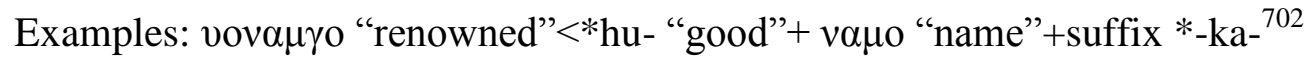

voלıvo "well-armed" $<* H u-z a i n a-{ }^{703}$,

v $\alpha \mu \gamma \alpha \alpha \delta \gamma_{0}$ noun or adjective "sharing the same house" $<*$ hama- "same" $+\kappa \alpha \delta \gamma_{0}$ "house"704

Compounds with - $\varphi \alpha \rho o$ as the second element belongs to this group, too:

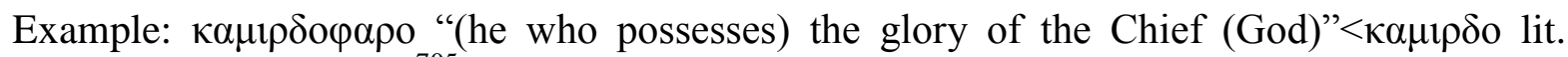
"head, chief"+

Other examples:

$1 \alpha \tau 0 \alpha \sigma \pi 0$ "by whom horses are sacrificed" $<*$ Yašta- "sacrificed"+*aspa- "horse"706

$\pi о \rho \lambda \alpha \gamma \gamma о \zeta$ เvo "he who wears the skin of a leopard" $<*$ prdankV- "leopard/panther"+*izaina"(garment) made of leather"707

${ }^{693}$ Cf. Sims-Williams 2007a: 181-182.

${ }^{694}$ Cf. Sims-Williams 2007a: 181.

${ }^{695}$ Cf. Sims-Williams 2007a: 182.

${ }^{696}$ Cf. Sims-Williams 2007a: 225.

${ }^{697}$ Cf. Sims-Williams 2007a: 187.

${ }^{698}$ Cf. Sims-Williams 2010: 82.

${ }^{699}$ Cf. Brugmann 1906: 72, Fleischer 1982: 106, Lewandowski 1994: 289 and Bußmann 1983: 133.

${ }^{700}$ su- in OI. cf. Wackernagel 1957: 81.

${ }^{701}$ sam- in OI. cf. Wackernagel 1957: 75.

${ }^{702}$ Cf. Sims-Williams 2007a: 273.

${ }^{703}$ Cf. Sims-Williams 2010: 140.

${ }^{704}$ Cf. Sims-Williams 2007a: 272.

${ }^{705}$ Cf. Sims-Williams 2010: 75.

${ }^{706}$ Cf. Sims-Williams 2010: 70. 


\subsubsection{Verbal governing}

$\alpha$. The second element can be a suffix derived from a verb:

All compounds with suffixes $-\beta \alpha \rho o,-\beta \alpha \rho \gamma o,-\beta \alpha \rho \alpha \gamma o ;-\lambda \alpha \rho o,-\lambda \alpha \rho \gamma_{0}(?),-\lambda \eta \rho о,-\lambda \eta \rho \gamma o$,

$-\lambda \eta \rho \alpha \gamma o$ as the second element belong to this group. (For examples see this chapter I.c.1.)

$\beta$. The second element may have a verbal stem:

* $1 \omega \lambda \alpha \beta o$ "protecting warriors"<*Yauda-pā- ${ }^{708}$

$\sigma \alpha \delta \alpha \iota \omega \lambda_{0}$ "having a hundred warriors" $<*$ Satā-yauda- ${ }^{709}$

i

$\delta$. The second element can be a verb. In this case, the first element is a substantive. In the following, the most common complex verbs are listed:

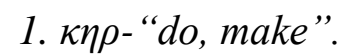

This verb is attested very often in the compounds.

Examples:

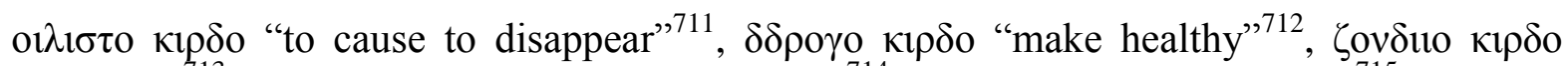

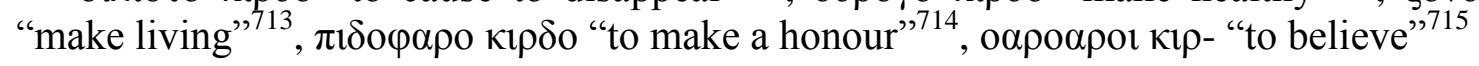

2. $\beta \alpha \rho$ - "bring"

Example: $\pi \alpha \rho \circ \beta \alpha \rho$ "to bring forward” (verbal prefix+verb)

3. $\lambda \alpha v-$ "give".

$\kappa \eta \rho-$ is used very often to make a verbal compounds:

Example: $\alpha \pi \alpha \rho \sigma o \lambda \alpha v$ - "to give back",716

4. $\omega \sigma \tau \alpha \delta o$ "to put"

Example: $v \alpha \beta \alpha \gamma o \omega \sigma \tau \alpha \delta o$ "to place (as a) pawn"717

5. $\eta \rho \sigma-$ "come, arrive"

Example: $\alpha \beta 0 \pi \alpha \zeta o \eta \rho \sigma-$ "to fall on one's face, come to grief",718

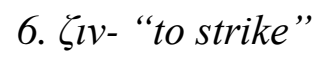

Example: $\pi \alpha \rho \alpha \sigma o \zeta$ เv- "to take away" ( $\pi \alpha \rho \alpha \sigma o: a w a y){ }^{719}$

${ }^{707}$ Cf. Sims-Williams 2010: 117.

${ }^{708}$ Cf. Sims-Williams 2010: 72.

${ }^{709}$ Cf. Sims-Williams 2010: 122.

${ }^{710}$ Cf. Sims-Williams 2010: 9.

${ }^{711}$ Cf. Sims-Williams 2007a: 246.

${ }^{712}$ Cf. T5, Sims-Williams 2000a: 99.

${ }^{713}$ Cf. T5, Sims-Williams 2000a: 99.

${ }^{714}$ Cf. T 5, Sims-Williams 2000a: 99.

${ }^{715}$ Cf. Sims-Williams 2007a: 242.

${ }^{716}$ Cf. Sims-Williams 2007a: 253.

${ }^{717}$ Cf. Sims-Williams 2007a: 236.

${ }^{718}$ Cf. Sims-Williams 2007a: 250.

${ }^{719}$ Cf. Sims-Williams 2007a: 251. 
$\gamma$. The first element may have a verbal stem:

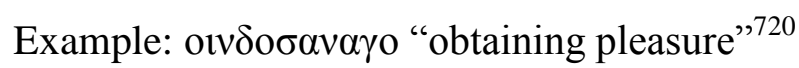

\subsubsection{Prepositional governing}

Examples: $\alpha \beta \alpha \chi \rho \alpha v_{0}$ "north". $<\alpha \beta$ " to"+* $\alpha \chi \rho \alpha v_{0}$ "north"721

$\alpha \lambda$ o $\alpha \mu \mu \mathrm{o}$ "possessing (one's) desire" $<\alpha \lambda \mathrm{o}$ "with" $+\kappa \alpha \mu \mathrm{o}$ "wish",722

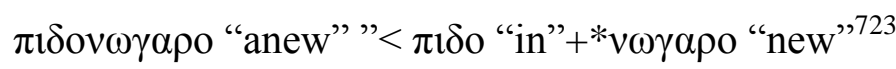

\subsubsection{Derivative (Ableitung) ${ }^{724}$}

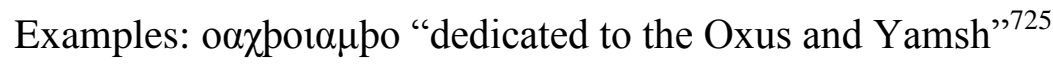

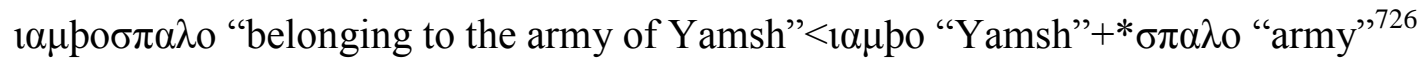

$\alpha \gamma \gamma \alpha \delta$ o $\pi \alpha \lambda_{0}$ "belonging to the army of Fortunate (God)" $<*$ han-gata- "fortunate, rich"+ *spāda- "army",727

$\lambda \alpha \delta$ o $\alpha \gamma \alpha \lambda \gamma_{0}$ "by whom wishes are granted" $<\lambda \alpha \delta \mathrm{o}$ "to give, to grant" ${ }^{728}+\alpha \gamma \alpha \lambda \gamma_{0}$ "wish"729

$\lambda \alpha \delta$ o $\mu$ o $\delta$ o "by whom the reward is given" $<\lambda \alpha \delta$ o "given" $+* \mu o \zeta \delta o ~ " r e w a r d " 730$

$\chi о \alpha \kappa \alpha \mu$ o "acting willingly, acting freely in accordance with one's own wishes" $<\chi_{0} \alpha$ "own, self"+*kāma- "wish, will"”731

\subsubsection{Endocentric}

In this construction, the subject occurs in the compound and the base word (determinate) can be used instead of the compound, ${ }^{732}$ e.g., a verbal compound lat. prōferō ${ }^{733}$ "to carry or move from one place to another,"734

There are different kinds of endocentric compounds in Bactrian:

\subsubsection{Determinative compound}

This is the most common compound in Bactrian, as in other Iranian languages.

In this group, one element is defined more closely (in details) by the other element, generally the second one by the first, and regularly so by the old stem compound.

${ }^{720}$ Cf. Sims-Williams 2010: 9.

${ }^{721}$ Cf. Sims-Williams 2007a: 181-182.

${ }^{722}$ Cf. Sims-Williams 2007a: 190.

${ }^{723}$ Cf. Sims-Williams 2007a: 255.

${ }^{724}$ For the examples of this compound in Rgveda, see Korn 1998: 183-188. Risch does not offer an extra category for derivative compound and classify it as a sub group. Cf. Risch 1981: 115.

${ }^{725}$ Cf. Sims-Williams 2010: 104.

${ }^{726}$ Cf. Sims-Williams 2010: 68-69.

${ }^{727}$ Cf. Sims-Williams 2010: 30.

${ }^{728}$ Cf. Sims-Williams 2007a: 225.

${ }^{729}$ Cf. Sims-Williams 2007a: 187.

${ }^{730}$ Cf. Sims-Williams 2010: 82.

${ }^{731}$ Cf. Sims-Williams 2007a: 278.

${ }^{732}$ Cf. Brugmann 1906: 71-72, Lewandowski 1994: 259.

${ }^{733}$ In Brugmann 1906, prōfero.

${ }^{734}$ Glare 1976: 1474. 


\section{Attributive definiteness}

$\alpha$. Adjective (number)+ substantive or substantive + adjective

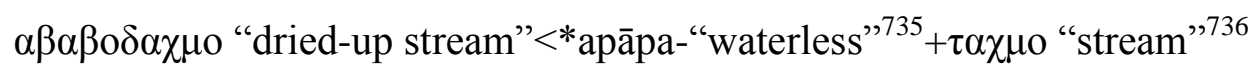

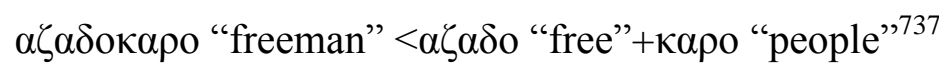

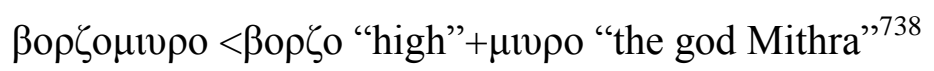

ק. Substantive + Substantive

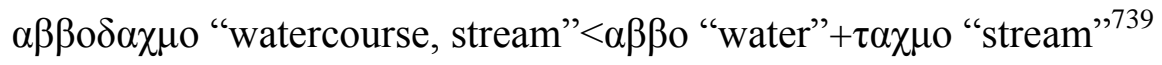

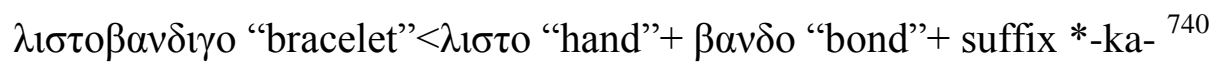

$\beta \alpha \gamma$ жлооро "son of the gods" $<*$ baga-pu $\theta \mathrm{ra}^{741}$

$\beta \alpha \gamma o 0 \alpha \rho \alpha \zeta_{0}$ "bore of (the) God" $<\beta \alpha \gamma \mathrm{o}$ "god"+*o $\alpha \rho \alpha \zeta_{0}$ "bore"742

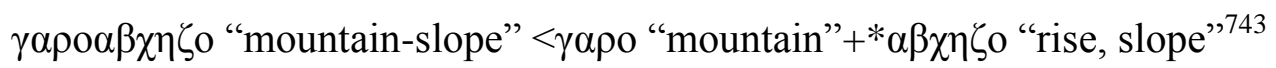

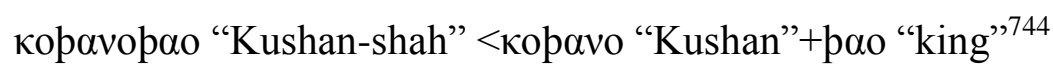

\section{Adverbal definiteness}

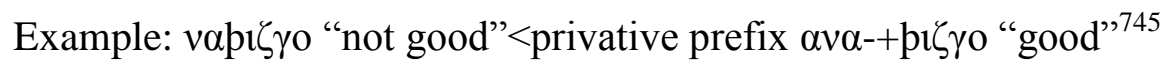

As in other Iranian languages, the modifier and head in a compound can be reversed. There are a few examples of this inversion in Bactrian:

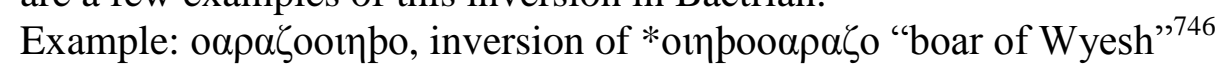

\subsubsection{Copulative (Dvandva)}

In this group, both items have the same syntactical relationship in the sentence, and it appears that the items can be connected by "and".

Example: $\alpha \zeta \alpha \delta$ o $\alpha \rho \rho \delta \rho \rho$ " "noble (and) best" $<\alpha \zeta \alpha \delta$ o "free"+ $+\varphi \alpha \rho \delta \alpha \rho o$ "more, better"

It is not clear whether the compound has a meaning (e.g., noble (and) best) or whether it is merely a mechanical combination of components taken from two other names. ${ }^{747}$

\subsection{Tripartite compounds}

Tripartite compounds are very rare in Bactrian:

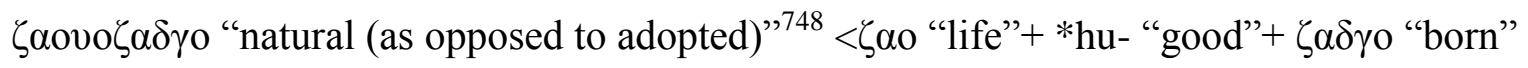

${ }^{735}$ Cf. Sims-Williams 2007a: 181.

${ }^{736}$ Cf. Sims-Williams 2007a: 269.

${ }^{737}$ Cf. Sims-Williams 2007a: 188.

${ }^{738}$ Cf. Sims-Williams 2010: 51.

${ }^{739}$ Cf. Sims-Williams 2007a: 183.

${ }^{740}$ Cf. Sims-Williams 2007a: 227.

${ }^{741}$ Cf. Sims-Williams and Cribb 1996: 91.

${ }^{742}$ Cf. Sims-Williams 2010: 41.

${ }^{743}$ Cf. Sims-Williams 2007a: 207.

${ }^{744}$ Cf. Sims-Williams 2007a: 225.

${ }^{745}$ Cf. Sims-Williams 2007a: 239.

${ }^{746}$ Cf. Sims-Williams 2010: 101.

${ }^{747}$ Cf. Sims-Williams 2010: 32.

${ }^{748}$ Cf. Sims-Williams 2007a: 211. 
$\lambda \alpha p v o \pi \alpha \lambda \alpha$ pvo $\beta \omega \sigma \tau \imath \gamma_{0}$ "contract for the exchange of gifts" $<\lambda \alpha p v v^{\prime}$ "gift" $+\pi \alpha \lambda \alpha p v o$ "gift in exchange" $+\pi \omega \sigma \tau$ o $\gamma_{0}$ "contract"749

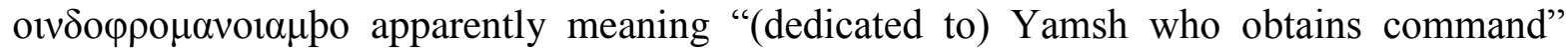
Probably a mechanical juxtaposition of the short name 1 apo "Yamsh" with a governing

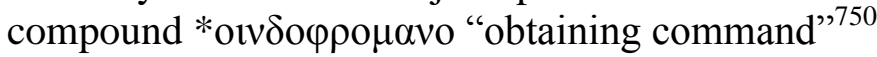

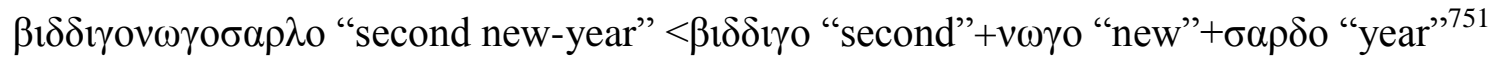

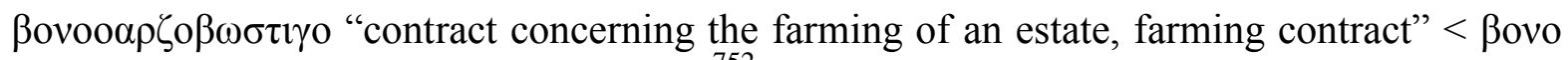

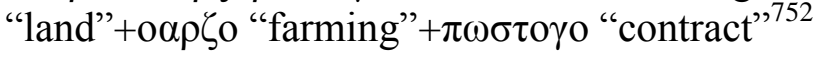

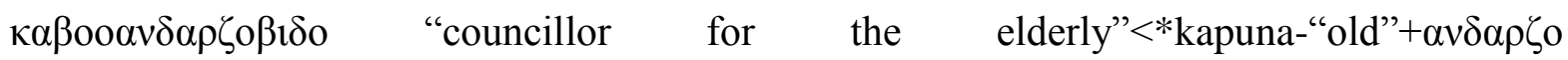
"instruction"+suffix

$-\beta 1 \delta o^{753}$ forming titles and personal names, originally "lord, chief",754

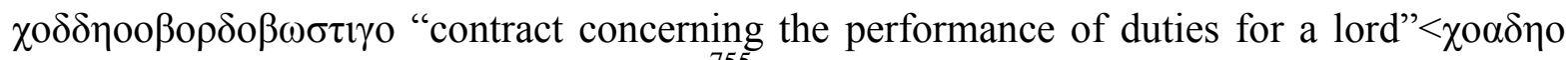
"lord" $+\pi \mathrm{o} \rho \delta \mathrm{o}$ "proper" $+\pi \omega \sigma \tau \mathrm{o}$ o "contract"

We can find the following construction in the examples of tripartite compounds:

Substantive+Substantive+Substantive

Substantive+ prefix+substantiv

Adjective+Adjective+Substantive

Adjective+Substantive+Suffix

It seems that the first construction is the most common type in Bactrian.

\subsection{Seam vowel}

In some languages, e.g., German, the relationship between the elements of a compound may be marked with a case suffix or another morpheme. ${ }^{756}$ In the extant Bactrian material, the first part of compounds very often contains an o ending. The vowel - $\eta$ - Pth.-y- (in dstygyrd) is used

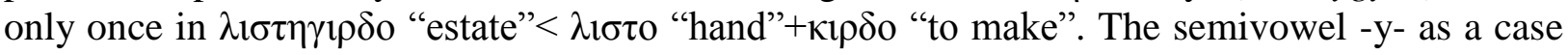
ending for genitive-dative is used in Manichean. It may also occur between two stems forming a compound with either the -aka- suffix, or trace of OIr. -i- stems, or it belongs to compounds borrowed from other Iranian languages. ${ }^{757}$ According to Sims-Williams, this vowel is probably a locative ending and perhaps a vowel ending, and therefore the etymological meaning of *dastay $(\bar{a})-k r t a-$ being "(person or thing) put into (someone's) hands" ${ }^{758} \mathrm{He}$ also classified internal $-\eta$ - in $\alpha \zeta \delta \eta \beta \delta$ o "with the cognizance of" $<\alpha \zeta \delta$ o "notice" $+\pi \imath \delta$ o "in" as an oblique case ending. ${ }^{759}$

There are three major compounding strategies in the extant Bactrian materials, classified according to the final endings of the members of a compound:

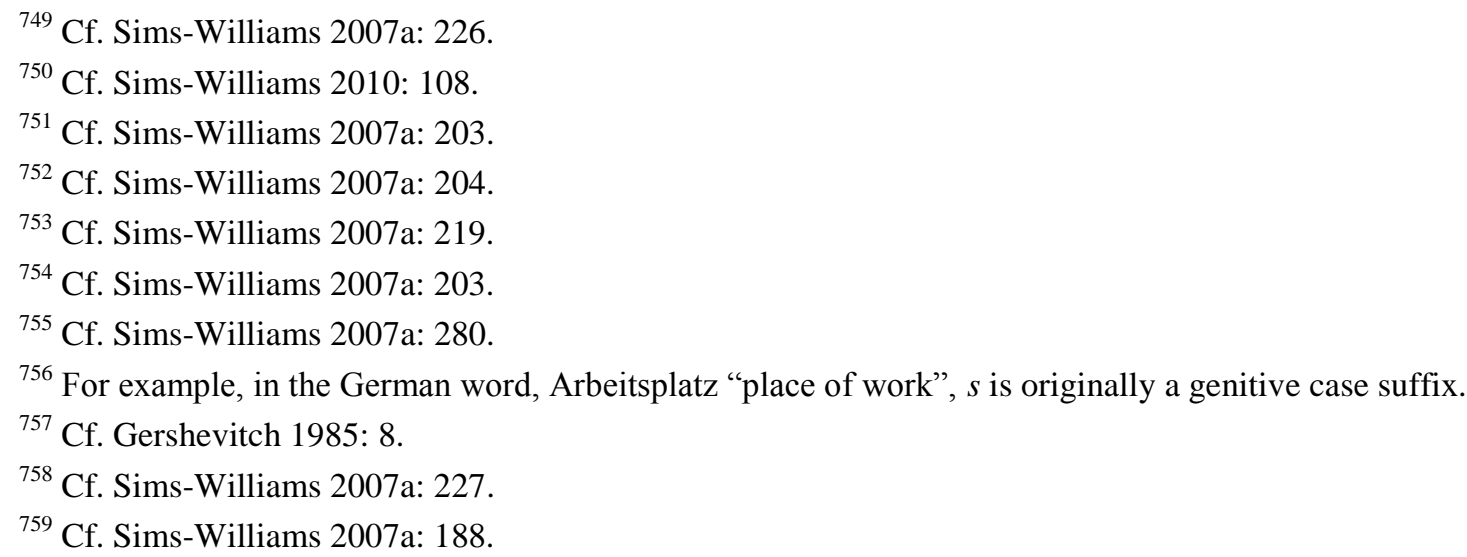




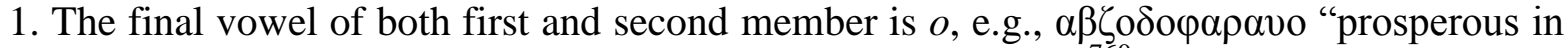
glory" $<\alpha \beta \zeta$ o $\delta$ o (pp as adjective) "prosperous"+* $\varphi \alpha \rho \alpha v o$ "glory"," This type is the most common form in Bactrian compounds.

2. The final vowel of the first element is omitted, whereas the final element of the second element is $o$. When the second member of a compound begins with a vowel the final $o$ of the first member is often omitted e.g., * $\beta \alpha \gamma \alpha \sigma \pi \mathrm{o}<\beta \alpha \gamma 0+\alpha \sigma \pi \mathrm{o}$ "god+horse" (rather than a compound meaning, e.g., "horse of (the) God"). ${ }^{761}$ There is an exception of this rule in the extant Bactrian materials: $\lambda \alpha \delta o \alpha \gamma \alpha \lambda \gamma_{0}$ "by whom wishes are granted" $<\lambda \alpha \delta o$ "to give, to grant" $762+\alpha \gamma \alpha \lambda \gamma o$

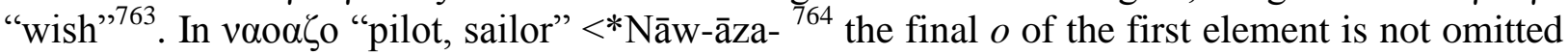
because of $a$ before the final $o$.

3. The final vowel of the first element is $a$ not $o$. In the Bactrian documents, the majority of words ends with $o$, but there are few examples of the other endings e.g., $i$ or $a{ }^{765}$

In $\chi о \alpha \kappa \alpha \mu \mathrm{o}$ "acting willingly, acting freely in accordance with one's own wishes" $<\chi 0 \alpha$ "own, self"+*kāma- "wish, will" "766, the first element is a prefix ends in $a$. In $\pi \alpha \rho \sigma \alpha p \alpha \rho \alpha \beta o$ "Persian satrap" "767 $\pi \alpha \rho \sigma \alpha$ seems to be an abstract form of $\pi \alpha \rho \sigma \alpha \gamma \gamma 0$ "Persian"768.

In $\zeta$ l $\alpha \beta \alpha \rho \gamma_{0}$ "destructive" $<\zeta$ lyo "damage"+suffix - $\beta \alpha \rho \gamma_{0}$ (from $\beta \alpha \rho-$ "to bear, take, bring")

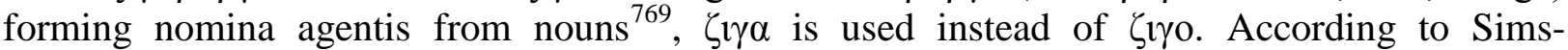

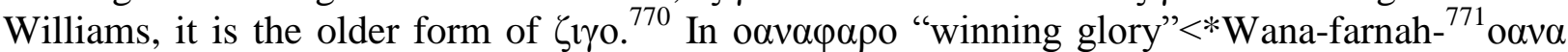
seems to be an old form of oavo (?).In $\sigma \alpha \delta \alpha 1 \omega \lambda \mathrm{o}$ "having a hundred warriors" $<*$ Satā-yauda- ${ }^{772}$ $\sigma \alpha \delta \alpha$ is used instead of $\sigma \alpha \delta$.

In $\alpha p \varphi \alpha \rho \delta \alpha \rho o$ "best (through) Fire" or "best (gift) of Fire"< $<$ p- perhaps the name of a god "Fire"+ $\varphi \alpha \rho \delta \alpha \rho o$ "more, better" 773 ap has no vowel ending.

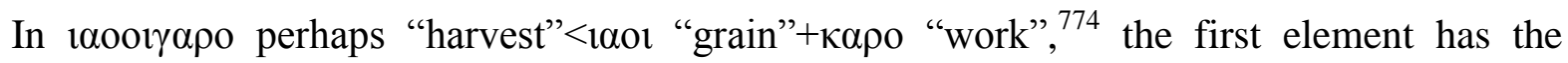
ending $i$, which is preserved without any change.

We can summarize the mentioned compounding types as the following:

1. o-o

2. $\varnothing-\mathrm{o}$

3. a-o (the oldest form)

$o$ and a: word endings

-: boundary between two components

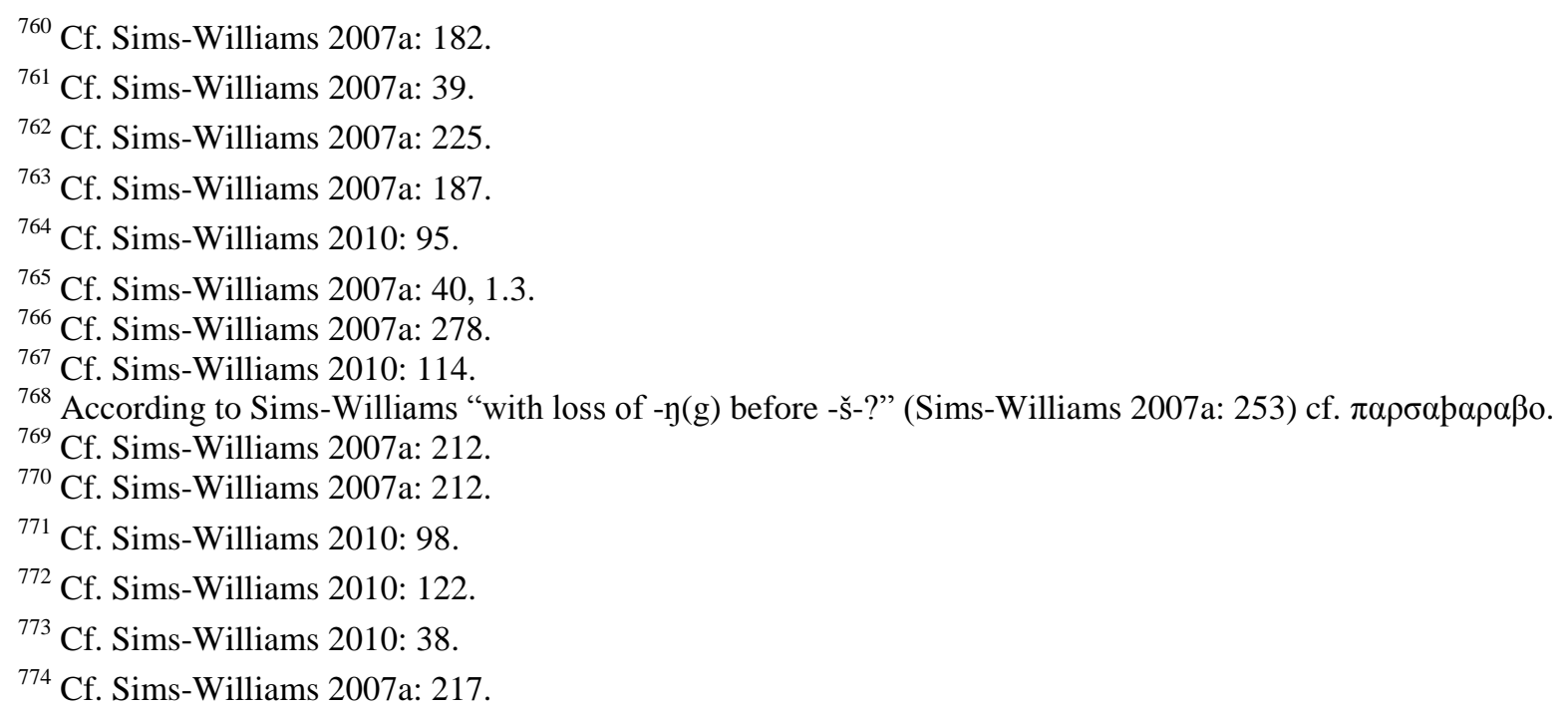


$\varnothing$ : without ending (ending is omitted)

\subsection{Summary}

As in other Middle Iranian languages, the most common compounds are demonstrative ones, which have a substantive as both first and second element. The following table shows the different types of compounds according to the grammatical character of the members:

Table 34. Grammatical characteristics of compound elements in Bactrian

\begin{tabular}{|l|l|}
\hline first element & second element \\
\hline noun & noun \\
\cline { 2 - 2 } & adjective \\
\cline { 2 - 2 } & suffix \\
\cline { 2 - 2 } & adverb \\
\cline { 2 - 2 } & pp or past stem \\
\hline adjective & noun \\
\cline { 2 - 2 } & adjective \\
\cline { 2 - 2 } & pp or past stem \\
\hline number & noun \\
\hline prefix & noun \\
\hline preposition & noun \\
\cline { 2 - 2 } & adjective \\
\cline { 2 - 2 } & adverb \\
\hline pp or past stem & noun \\
\hline
\end{tabular}

Tripartite compounds are rare in our extant material. In this case it seems that the Substantive+Substantive+Substantive construction and determinative is the most common type. There is no seam vowel in Bactrian compounds, but the ending o of the first element could be preserved or ommitted. We find few examples of compounds in which the first element has the ending $a$. This $a$ is not changed to $o$ and is preserved. 


\section{REFERENCES}

Anderson, Stephan 1977: “On Mechanisms by which Languages Become Ergative.” In: Charles Li (ed.): Mechanisms of Syntactic Change. Texas, pp. 317-363

Baltin, Mark and Collins, Chris 2001: The Handbook of Contemporary Syntactic Theory. Massachusetts, Oxford: Blackwell Publishers

Bartholomae, Christian 1904: Altiranisches Wörterbuch. Strassburg: Verlag von Karl J. Trübner

Bellew, Henry Walter 1867: A Dictionary of the Pukkhto or Pukshto Language. Lahore: Rai Saheb M. Gulab Singh and Sons

Benveniste, Emile 1952/1966: "La construction passive du parfait transitif.” In: Emile Benveniste (ed.): Problèmes de linguistique générale. Paris: Gallimard, pp. 176-186

— 1961: “Inscriptions des Bactriane.” In: Journal Asiatique 286, 2, pp. 113-152

Bivar, A. D. H. 1968: Kushan and Kushano-Sasanian Seals and Kushano-Sasanian Coins: Sasanian Seals in the British Museum. Corpus Inscriptionum Iranicarum, Part III Pahlavi Inscriptions VI, Seals and Coins

- 1963: "The Kanishka Dating from Surkh Kotal.” In: Bulletin of the School of Oriental and African Studies 26, pp. 498-502

Bopearachchi, Osmund 1991: Monnaies Gréco-Bactriennes et Indo-Grecques. Paris: Bibliothèque Nationale

Brown, Keith and Miller, Jim 1996: Concise Encyclopedia of Syntactic Theories. New York: Pergamon

Browning, Robert 1983: Medieval and Modern Greek. Cambridge: Cambridge University Press

Brugmann, Karl and Delbrück, Berthold 1906: Grundriss der Vergleichenden Grammatik der Indogermanischen Sprachen . Bd 2: Lehre von den Wortformen und ihrem Gebrauch. Strassburg / Berlin / Leipzig : Karl J. Trübner / Walter de Gruyter \& Co

Brunner, Christopher J. 1977: A Syntax of Western Middle Iranian. Delmar, New York: Caravan Books

Bußmann, Hadumod 1983: Lexikon der Sprachwissenschaft. Stuttgart: Alfred Kröner

Cardona, George 1970: “The Indo-Iranian Construction mana (mama) kṛtam.” In: Language 46, pp. 1-12

Davary, G. Djelani 1982: Baktrisch, Ein Wörterbuch auf Grund der Inschriften, Handschriften, Münzen und Siegelsteine. Heidelberg: Julius Groos Verlag

Davary, G. Djelani and Humbach, Helmut 1976: Baktrische Inschrift IDN 1 von Dasht-e Nāwūr (Afghanistan). Mainz: Akademie der Wissenschaften und der Literatur

Delfitto, Denis 2006: “Adverb Classes and Adverb Placement.” In: Martin Everaert, Henk Van Riemsdijk (eds.): The Blackwell Companion to Syntax I. Malden, Mass. et al.: Blackwell Publishing, pp. 83-120

Diessel, Holger 1999: Form, Function and Grammaticalization. Amsterdam [u.a.]: Benjamins

Dixon, R.M.W. 1994: Ergativity. Cambridge Studies in Linguistics 69: Cambridge University Press

Durkin-Meisterernst, Desmond 2004: Dictionary of Manichaen Middle Persian and Parthian. Dictionary of Manichaen texts III. Texts from Asia and China edited by Sims-Williams part 1. Turnhout: Brepolis

Emonds, Joseph 2006: “Adjectival Passives. The Construction in the Iron Mask.” In: Martin Everaert, Henk Van Riemsdijk (eds.): The Blackwell Companion to Syntax I. Malden, Mass. et al.: Blackwell Publishing, pp. $16-60$

Falk, Harry 2004: “The Kaniška Era in Gupta Records.” In: Silk Road Art and Archaeology X, pp. 167-176

— 2001: "The Yuga of Sphujiddhvaja and the Era of the Kušāns.” In: Silk Road Art and Archaeology VII, pp. 121136

Fallahi, Mohammad 1991: Contrastive Linguistics and Analysis of Errors. Vol.1: The Grammatical Structure of English and Persian. Tehran: Iran University Press

Fleischer, Wolfgang 1982: Wortbildung der deutschen Gegenwartssprache. Tübingen: Niemeyer 
Fussman, G. 1998: “L’inscription de Rabatak.” In: Journal Asiatique 286, 2, pp. 571-651

Georges, Karl Ernst 1951: Ausfürliches Lateinisch-Deutsches Handwörterbuch II. 9. Auflage. Nachdruck der achten verbesserten und Vermehrten Auflage von Heinrich Georges. Basel: Benno Schwabe und Co.

Gershevitch, Ilya 1985: "Sogdian Compounds" In : Nicholas Sims-Williams (ed.): Philologia Iranica. Wiesbaden: Reichert, pp. 6-18

— 1983: "Bactrian Literature." In: Ehsan Yarshater (ed.): The Cambridge History of Iran 3(2). Cambridge: Cambridge university, pp. 1250-1258

— 1979: "Nokonzok's Well.” In: Afghan Studies 2, pp. 55-73

Glare, P. G. W. 1968: Oxford Latin Dictionary. Oxford: Clarendon Press

- 1976: Oxford Latin Dictionary Fascicle V. Oxford: Clarendon Press

Gholami, Saloumeh 2011: "Definite articles in Bactrian.” In: Korn/ Haig/ Karimi/ Samvelian (eds.): Topics in Iranian Linguistics. Beiträge zur Iranistik, Band 34, pp. 11-22

— 2009a: "Demonstratives and Determiners in Bactrian." In: From Daēnā to Dîn: Religion, Kultur und Sprache in der iranischen Welt:Festschrift für Philip Kreyenbroek zum 60. Geburtstag. Wiesbaden: Harrassowitz, pp. 19-26

— 2009b: "Ergativity in Bactrian.” In: Studia Iranica Upsaliensia, pp. 132-141

Göbl, Robert 1967: “Dokumente zur Geschichte der iranischen Hunnen in Baktrien und Indien.” Vol.3. Wiesbaden: Harrassowitz

- 1964: System und Chronologie der Münzprägung des Kušānreiches. Wien: Verlag der Österreichischen Akademie der Wissenschaften

Grenet, F. 1989: "Bactria II. In the Avesta and in Zoroastrian Tradition.” In: Ehsan Yarshater (ed.): Encyclopaedia Iranica III. London and New York: Routledge and Kegan Paul, pp. 343-344

Harmatta, J. 1986: “The Bactrian Inscription of Ayrtam.” In: Studia Grammatica Iranica. Festschrift für Helmut. München: R. Kitzinger , pp. 131-146

— 1965: "Minor Bactrian Inscriptions.” In: Acta Antiqua Hung XIII, pp. 151-205

— 1964: “The Great Bactrian Inscription.” In: Acta Antiqua Academiae Scientiarum Hungaricae 12, pp. 373-471

Haig, Geoffrey L.J. 2008: Alignment Change in Iranian Languages: A Construction Grammar Approach. Berlin, New York: Mouton de Gruyter

Hawkins, J.A. 1978: Definiteness and Indefiniteness: A study in reference and grammaticality prediction. London: Croom Helm

Henning, W. B. 1965: “Surkh-Kotal and Kanișka.” In: Zeitschrift der Deutschen Morgenländischen Gesellschaft 115 , pp. $75-87$

— 1962: “A Bactrian Seal-Inscription.” In: Bulletin of the School of Oriental and African Studies XXV, 2, p. 335

- 1960: “The Bactrian Inscription.” In: Bulletin of the School of Oriental and African Studies XXIII, 1, pp. 47-55

- 1956: "Surkh Kotal, Notes and Communications." In: Bulletin of the School of Oriental and African Studies XVIII, 2, pp. 366-367

Heston, Wilma Louise 1976: Selected Problems in Fifth to Tenth-Century Iranian Syntax: University of Pennsylvania, $\mathrm{Ph}$. D thesis

Himmelmann, Nikolaus P. 1997: Deiktikon, Artikel, Nominalphrase: Zur Emergenz syntaktischer Struktur. Tübingen: Niemeyer

Huang, Lillian M. and Zeitoun, Elizabeth. "Ordering of Pronouns in Formosan Languages.” In:

http://www.sil.org/asia/philippines/ical/abstracts/Huang\%20Lillian_Zeitoun_Formosan\%20pronouns.pdf

Humbach, Helmut 2003: “The Great Surkh Kotal Inscription.” In: Carlo G. Cereti, Mauro Maggi, Elio Provasi (eds.): Religious Themes and Texts of Pre-Islamic Iran and Central Asia. Wiesbaden: Reichert, pp.157-166

— 1971: "Die Baktrische Ära der Tochi-Inschriften.” In: Wilhelm Eilers (Hrsg.): Festgabe deutscher Iranisten zur 2500 Jahrfeier Irans. Stuttgart: Hochwacht, pp. 74-79

— 1970: “Kara Tepe- Tochi- Surkh Kotal.” In: Münchner Studien zur Sprachwissenschaft 28, pp. 43-50 
— 1969: "Bactrian Seals.” In: Münchner Studien zur Sprachwissenschaft 25, pp. 65-74

- 1967a: Baktrische Sprachdenkmäler II. Wiesbaden: Harrassowitz

- 1967b: “Zu den Legenden der hunnischen Münzen, Siegel und Kontermarken.” In: Münchner Studien zur Sprachwissenschaft 22, pp. 39-56

— 1966: Baktrische Sprachdenkmäler I. Wiesbaden: Harrassowitz

— 1963a: “Nokonzoko und Surkh-Kotal.” In: Wiener Zeitschrift für die Kunde Süd- und Ostasiens VII, pp. 13-19

- 1962a: "Die neugefundenen Versionen der Kaniška-Inschrift von Surkh-Kotal." In: Wiener Zeitschrift für die Kunde Süd- und Ostasiens VI, pp. 40-43

— 1962b: "Ein Baktrischer Titel bei Curtius Rufus." In: Wiener Zeitschrift für die Kunde Süd- und Ostasiens VI, pp. 44-46

— 1960: Die Kaniška-Inschrift von Surkh-Kotal. Wiesbaden: Harrassowitz

Hübschmann, Heinrich 1897: Armenische Grammatik. I. Teil: Armenische Etymology. Leipzig: Breitkopf und Härtel

Justi, Ferdinand 1976: Der Bundehesh. Hildesheim, New York: Georg Olms

Kahnemuyipour, Arsalan. "Persian Ezafe Construction: Case, Agreement or something else." In: http://www.iranianlinguistics.org/papers/IranConference_2006.pdf

Kent, Roland G. 1953: Old Persian: Grammar, text, lexicon. New Haven, Connecticut: American oriental society

Klenk, Ursula 2003: Generative Syntax. Tübingen: Narr

Korn, Agnes 2011: "Demonstratives and the Copula in Iranian.” In: Korn/ Haig/ Karimi/ Samvelian (eds.): Topics in Iranian Linguistics. Beiträge zur Iranistik, Band 34, pp. 53-70

— 2008: "Marking of Arguments in Balochi Ergative and Mixed Constructions." In: Simin Karimi, Vida Samiian, Donald Stilo (eds.): Proceedings of the First International Conference on Iranian Linguistics. Festschrift for Mohammad Bateni. Newcastle: Cambridge Scholars Press, pp. 249-276

- 2005: Towards a historical grammar of Balochi: Studies in Balochi Historical phonology and vocabulary. Wiesbaden: Reichert

- 1998: Metrik und metrische Techniken im Rgveda. Graz: Leykam

Lazard, G; Grenet, F; De Lamberterie, Ch. 1984: “Notes bactriennes.” In: Studia Iranica 13, pp. 199-232

Lee, Jonathan, and Nicholas Sims-Williams 2003: “The Antiquities and Inscription of Tang-i Safedak.” In: Silk Road Art and Archaeology 9, pp. 159-184

Leriche. P. 1989: "Bactria.” In: Ehsan Yarshater (ed.): Encyclopaedia Iranica III. London and New York: Routledge and Kegan Paul pp. 339-343

Levy, Reuben 1951: The Persian Language. London: Hutchinson's University Library

Lewandowski, Theodor. Linguistisches Wörterbuch 1. Heidelberg, Wiesbaden: Quelle and Meyer

Li, Charles and Thompson, Sandra 1977: “A mechanism for the development of copula morphemes.” In: Charles Li (ed.): Mechanisms of Syntactic Change. Austin: University of Texas, pp. 419-444

Mace, John 2005: Persian Grammar. London and New York: Routledge Curzon

MacKenzie, D. N. 1981: Kurdish Dialect Studies-I. London Oriental Series, 9. London: School of Oriental and African Studies, University of London

Maricq, M. André 1958: “La grande inscription de Kaniška et l'étéo-tokharien, l'ancienne de la Bactriane.” In: Journal Asiatique CCXLVI 4, pp. 345-440

Mayrhofer, Manfred 1996: Etymologisches Wörterbuch des Altindoarischen II. Band. Heidelberg: Universitätsverlag C. Winter

— 1992: Etymologisches Wörterbuch des Altindoarischen I. Band. Heidelberg: Universitätsverlag C. Winter

Megerdoomian, Karine: "Finite-State Morphological Analysis of Persian.” In:

http://wing.comp.nus.edu.sg/acl/W/W04/W04-1607.pdf 
Morgenstierne, Georg 2003: A New Etymological Vocabulary of Pashto. Beiträge zur Iranistik 23. Wiesbaden: Reichert

Pakzad, Fazlollah 2005: Bundahišn. Zoroastrische Kosmogonie und Kosmologie. Band I Kritische Edition. Ancient Iranian Studies Series 2. Tehran: Centre for the Great Islamic Encyclopaedia

Payne, John 1996: "Ergative Construction.” In: Ehsan Yarshater (ed.): Encyclopaedia Iranica VIII. Costa Mesa, California: Mazda Publishers, pp. 555-558

— 1989: “Pamir Languages.” In: R. Schmitt (ed.): Compendium Linguarum Iranicarum. Wiesbaden: Reichert, pp. 417-444

— 1980: “The Decay of Ergativity in the Pamir Languages.” In: Lingua 51, pp. 147-186

Ramers, Karl Heinz 2007: Einführung in die Syntax. Paderborn: Wilhelm Fink

Risch, Ernst 1981: Kleine Schriften. Berlin, New York: Walter de Gruyter

Selig, Maria 1992: Die Entwicklung der Nominaldeterminanten im Spätlatein: Romanischer Sprachwandel und lateinische Schriftlichkeit. Tübingen: Narr

Sims-Williams, Nicholas 2011a: "Differental Object Marking in Bactrian.” In: Korn/ Haig/ Karimi/ Samvelian (eds.): Topics in Iranian Linguistics. Beiträge zur Iranistik, Band 34, pp. 23-38

— 2011b: "Remarks on the phonology of the Manichaean Bactrian fragment (M 1224)." In: Лексика, этимология, языковые контакты, кюбилею доктора филологических наук, лрофессора Джой Иосифовны Эдельман. Мосkва, pp. 244-251

- 2010: Bactrian Personal Names [Iranische Onomastik herausgegeben von Bert G. Fragner und Velizar Sadovski Nr. 7: Iranisches Personennamenbuch herausgegeben von Rüdiger Schmitt, Heiner Eichner, Bert G. Fragner und Velizar Sadovski: Band II Mitteliranische Personennamen: Faszikel 7: Bactrian Personal Names]. Wien: Verlag der Österreichischen Akademie der Wissenschaft

- 2009: "The Bactrian fragment in Manichaean script (M 1224)." In: Literarische Stoffe und ihre Gestaltung in mitteliranischer Zeit. Kolloquium anlässlich des 70. Geburtstags von Prof. Dr. W. Sundermann (Beiträge zur Iranistik 31, ed. D. Durkhin-Meisterernst et al.). Wiesbaden: Reichert, pp. 245-268

— 2004 (2008): “The Bactrian Inscription of Rabatak: A New Reading.” In: Bulletin of the Asia Institute 18, pp. 53-68

- 2007a: Bactrian Documents from Northern Afghanistan II: Letters and Buddhist Texts, Studies in the Khalili Collection III, Corpus Inscriptionum Iranicarum II, 4: The Nour Foundation in Association with Azimuth Editions and Oxford University Press

— 2007b: “A Bactrian Quarrel.” In: Bulletin of the Asia Institute 17, pp. 9-15

- 2006: "Bactrian Letters from the Sasanian and Hephthalite Periods." In: Antonio Panaino and Andrea Piras (eds.): Proceedings of the $5^{\text {th }}$ Conference of the Societas Iranologica Europara held in Ravenna, 6-11 October 2003 I, Ancient and Middle Studies. Milano: Mimesis, pp. 701-713

- 2005: "Bactrian Legal Documents from $7^{\text {th }}$-and $8^{\text {th }}$ - Century Guzgan." In: Bulletin of the Asia Institute 15, 2001[2005], pp. 9-29

- 2002a: "Ancient Afghanistan and its Invaders: Linguistic Evidence from the Bactrian Documents and Inscriptions.” In: N. Sims-Williams (ed.): Indo-Iranian Languages and Peoples: Oxford University Press, pp. $225-242$

— 2002b: "New Documents in Ancient Bactrian Reveal Afghanistan's Past." In: IIAS Newsletter,\#27, March 2002, pp. 12-13

- 2000a: Bactrian Documents I: Legal and Economic Documents, Studies in the Khalili Collection III, Corpus Inscriptionum Iranicarum II, 4: The Nour Foundation in Association with Azimuth Editions and Oxford University Press

— 2000b: "Four Bactrian Economic Documents." In: Bulletin of the Asia Institute 11, 1997[2000], pp. 3-15

— 1998a: “A Bactrian Deed of Manumission.” In: Silk Road Art and Archaeology 5, 1997/8, pp. 191-211

— 1998b: “The Bactrian Calendar.” In: Bulletin of the Asia Institute 10, 1996[1998], pp. 149-165

- 1997a: "New Findings in Ancient Afghanistan.” In: http://www.gengo.l.u-tokyo.ac.jp/ hkum/bactrian.html

— 1997b: "Four Bactrian Economic Documents." In: Bulletin of the Asia Institute 11, pp. 3-15 
— 1996: "Nouveaux documents sur l'histoire de la langue de la Bactriane." In: Comptes Rendus de l'Académie des Inscriptions et Belles-Lettres, pp. 634-654

— 1993 [1994]: "Bactrian Ownership Inscriptions.” In: Bulletin of the Asia Institute 7, pp. 173-179

— 1989a: "Bactrian.” In: R. Schmitt (ed.): Compendium Linguarum Iranicarum, Wiesbaden: Reichert, pp. 230-235

— 1989b: "Eastern Middle Iranian.” In: R. Schmitt (ed.): Compendium Linguarum Iranicarum. Wiesbaden: Reichert, pp. 165-172

- 1989c: "Bactrian Language." In: Ehsan Yarshater (ed.), Encyclopaedia Iranica III. London and New York: Routledge and Kegan Paul, pp. 344-349

— 1985: "A Note on Bactrian Phonology." In: Bulletin of the School of Oriental and African Studies 48, pp. 111116

— 1973: “A Note on Bactrian Syntax.” In: Wolfgang P. Schmid (ed.), Indogermanische Forschungen 78. Berlin: Walter de Gruyter, pp. 95-99

Sims-Williams, N., Cribb, J. 1996: "A New Bactrian Inscription of Kanishka the Great, Part 1: The Rabatak Inscription, Text and Commentary." In: Silk Road Art and Archeology IV, pp. 75-96 and pp. 128-137

Sims-Williams, Nicholas and Tucker, Elizabeth 2005: “Avestan huuōišta- and its cognates.” In: Günter Schweiger (ed.), Indogermanica, Festschrift Gert Klingenschmitt. Taimering: Schweiger VWT, pp. 587-604

Skjærvø, Prods Oktor 1985: "Remarks on the Old Persian Verbal System." In: Münchner Studien zur Sprachwissenschaft 45, pp. 211-227

Staviskij, B. Ja. 1986: La Bactriane Sous les Kushans. Paris: Librairie Jean Maisonneuve

Sundermann, Werner 1989a: "Partisch.” In: R. Schmitt (ed.): Compendium Linguarum Iranicarum. Wiesbaden: Reichert, pp. 114-137

— 1989b: "Mittelpersisch." In: R. Schmitt (ed.): Compendium Linguarum Iranicarum. Wiesbaden: Reichert, pp. $138-164$

- 1973: Mittelpersische und partische kosmogonische und Parabeltexte der Manichäer. Schriften zur Geschichte und Kultur des Alten Orients 8. Berliner Turfantexte IV. Berlin: Akademie-Verlag

Tarn, W. W. 1951: The Greeks in Bactria and India. Cambridge: The Syndics of the Cambridge University Press

Tremblay, Xavier 2003: "La résurrection du bactrien: à propos des Bactrian documents." In: Indo-Iranian Journal 46, pp. 119-133

Valois, Daniel 2006: “Adjectives: Order within DP and Attributive APs.” In: Martin Everaert, Henk Van Riemsdijk (eds): The Blackwell Companion to Syntax I. Oxford: Blackwell Publishing, pp. 61-82

Wackernagel, Jakob 1957: Altindische Grammatik Band II,1: Einleitung zur Wortlehre Nominalkomposition. Göttingen: Vandenhoeck und Ruprecht

Wendtland, Antje 2009: "The position of the Pamir languages within East Iranian.” In: Orientalia Suecana Vol. LVIII, pp. 172-188

— 2008: "On Ergativity in the Pamir languages." In: Simin Karimi, Vida Samiian, Donald Stilo (eds.): Proceedings of the First International Conference on Iranian Linguistics. Festschrift for Mohammad Bateni. Newcastle: Cambridge Scholars Press, pp.419-434

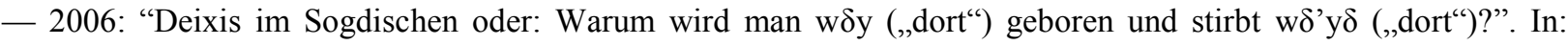
Heiner Eichner, Bert G. Fragner, Velizar Sadovski, Rüdiger Schmitt (Hrg.): Iranistik in Europa- Gestern, Heute, Morgen. Wien: Der Österreichischen Akademie der Wissenschaften, pp. 241-259

- 2004: "Zur Artikelentstehung in den iranischen Sprachen." In: Omid Tabibzadeh (Hrg.): Iranistik 3.Jahrgang, Heft 1, 1fd. Nr.5, pp. 17-39

West, E. W. 1978: Glossary and index of the Pahlavi texts of the book of Arda Viraf, the tail of Goshti-i Fryano, the hadokht Nask, and to some extracts from the Din-kard and Nirangistan. Osnabrück: Biblio Verlag

Widmer, Paul 2007 “zur Bedeutung von indoiranisch *nāuiiia-." In: Indo-Iran J 50, pp. 215-228

Yoshida, Yutaka 2003: "Review of BD 1." In: Bulletin of the Asia Institute 14, pp. 154-159

\section{Internet sources}


http://titus.uni-frankfurt.de/indexd.htm

http://www.accessmylibrary.com/coms2/summary_0286-8302598_ITM

http://www.canoo.net/services/OnlineGrammar/Satz/Satzgliedbau/Pronomen.html

http://www.odlt.org/

http://www.sil.org/linguistics/GlossaryOfLinguisticTerms/WhatIsAnaphora.htm

http://www.utexas.edu/courses/slavling/grapp/papers/glip2.pdf

http://schoyencollection.com/greekdocscr.html 
Hiermit versichere ich an Eides statt, dass ich die eingereichte Dissertation ,Selected Features of Bactrian Grammar" selbständig und ohne unerlaubte Hilfe verfasst habe. Anderer als der von mir angegebenen Hilfsmittel und Schriften habe ich mich nicht bedient. Alle wörtlich oder sinngemäß den Schriften anderer Autorinnen oder Autoren entnommenen Stellen habe ich kenntlich gemacht. Die Abhandlung ist noch nicht veröffentlicht worden und noch nicht Gegenstand eines Promotionsverfahrens gewesen.

Saloumeh Gholami 